\title{
Implementation of a distributed sediment model in different data availability scenarios
}

GIANBATTISTA BUSSI 



\section{Universitat Politècnica de València}

Departamento de Ingeniería Hidráulica y Medio Ambiente Programa de doctorado de Ingeniería Hidráulica y Medioambiental

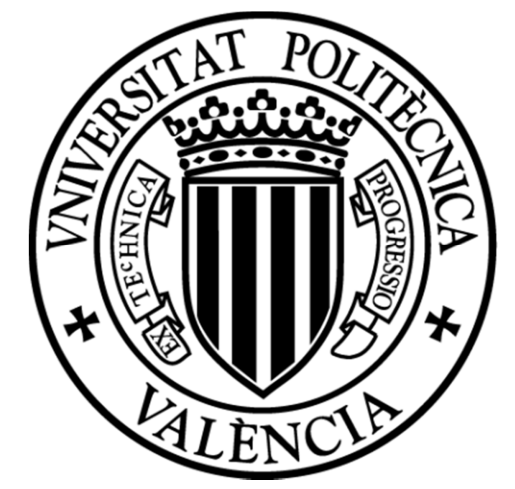

PhD thesis:

Implementation of a distributed sediment model in different data availability scenarios

Author:

Gianbattista Bussi

Director:

Félix Francés

Valencia, February 2014 
Collection doctoral thesis

(C) Gianbattista Bussi

(c) 2014, of the present edition: Editorial Universitat Politècnica de València Telf.: 963877012 / www.lalibreria.upv.es

ISBN: 978-84-9048-215-5 (CD version)

Any unauthorized copying, distribution, marketing, editing, and in general any other exploitation, for whatever reason, of this piece of work or any part thereof, is strictly prohibited without the authors' expressed and written permission. 


\section{Abstract}

Soil erosion by water can cause agricultural soil losses, desertification, water pollution, reservoir sedimentation, local excess of erosion (such as bridge scour) or deposition, etc. For this reason, the assessment of soil erosion and sediment transport is a key component of integrated catchment management. One of the most useful and up-to-date tools available to catchment managers for soil erosion and sediment transport assessment is distributed modelling. During the last few decades, many sedimentological distributed models were developed and applied for a wide range of climates and basins. Their main advantage is that they allow spatial interpolation or extrapolation of their results. Nevertheless, their use is still limited by some constraints. One of the most relevant limitations to the use of such models is the lack of recorded sediment transport data to be used for model calibration and validation. It is widely recognised that both sediment discharge series and soil erosion measurements are only available in a few and small- to medium-size experimental catchments. The aim of this dissertation is to investigate the possibility of using reservoir sedimentation data as a source of proxy information for sedimentological model calibration and validation. In order to carry out this task, a distributed sedimentological model called TETIS was tested in set of catchments with different sediment data availability. First of all, the TETIS model, developed over the last years by the research group of hydrological and environmental modelling of the Technical University of Valencia, is described, especially focusing on the new features developed within this dissertation (sedimentological sub-model automatic calibration algorithm, small pond sediment retention module, etc.). Then, the model is applied to three catchments with different sediment data availability. The first case-study is the Goodwin Creek catchment (Mississippi, US), an experimental catchment with high sediment transport data availability. The model performance is evaluated, and some considerations are made on the estimation of the sediment volume deposited into the drainage network at the beginning of a rainstorm. The second case-study is the Rambla del Poyo catchment (Valencia, Spain), a medium size semi-arid catchment draining to a coastal lagoon with severe sedimentation problems. The TETIS sedimentological sub-model is calibrated and validated using checkdam sedimentation volumes as an estimator of the total sediment transport. A detailed description of the alluvial stratigraphy infilling a check dam that drains a $12.9 \mathrm{~km}^{2}$ subcatchment was used as indirect information of sediment yield data. A further application was also developed in this catchment in order to investigate the possibility of calibrating and validating both the hydrological and the sediment sub-models by using reservoir sedimentation volumes and employing neither water nor sediment discharge direct records. The third case-study is the Ésera River catchment (Huesca, Spain), a 1,500 km² Pyrenean catchment drained by a large reservoir. The depositional history of the reservoir was reconstructed and used for sediment sub-model implementation. The model results were compared with gauged suspended sediment data in order to verify model robustness. The results of this dissertation indicate that TETIS model is a robust tool which provides a reliable reconstruction of the catchment sediment cycle. Its implementation is subject to data availability, both for parameter estimation and for model calibration and validation. Nevertheless, this dissertation proved that sediment records can be replaced by reservoir 
sedimentation volumes with satisfactory results, taking into account reservoir trap efficiency and sediment dry bulk density. Two modelling approaches were proposed for sediment model implementation, depending on the data availability. These methodologies proved to be consistent and provided a correct estimation of the sediment transport. Nevertheless, further research is needed to address model limitations and to reduce model results uncertainty. 


\section{Resumen}

La erosión de suelo puede causar importantes pérdidas suelo agrícola, desertificación, contaminación del agua, sedimentación de los embalses, exceso de erosión (como socavación de puentes) o deposición local, etc. Por esta razón, la evaluación de la erosión del suelo y el transporte de sedimentos es una componente clave de la gestión integrada de las cuencas. Una de las herramientas más útiles y novedosas a disposición de los administradores de cuenca es la modelación distribuida de la erosión del suelo y del transporte de sedimentos. A lo largo de las últimas décadas, se han desarrollado y aplicado muchos modelos sedimentológicos distribuidos para una amplia gama de climas y cuencas. Su principal ventaja es que permiten la interpolación o extrapolación espacial de sus resultados. Sin embargo, su uso está todavía limitado por algunos inconvenientes. Una de las limitaciones más importantes a la utilización de estos modelos es la falta de datos medidos de transporte de sedimentos para la calibración y validación de modelos. Es ampliamente reconocido que tanto las series de caudal sólido como las mediciones de erosión del suelo están disponibles sólo en unas pocas cuencas experimentales, habitualmente de tamaño pequeño o mediano. El objetivo de esta tesis doctoral es investigar la posibilidad de utilizar los datos de sedimentación en los embalses como una fuente de información indirecta para la calibración y validación de un modelo sedimentológico. Para llevar a cabo esta tarea, un modelo sedimentológico distribuido llamado TETIS ha sido utilizado en un conjunto de cuencas con diferente disponibilidad de datos de sedimentos. En primer lugar, el modelo TETIS, desarrollado en los últimos años por el grupo de investigación en modelación hidrológica y ambiental de la Universidad Politécnica de Valencia, se describe, resaltando especialmente los nuevos módulos desarrollados en esta tesis (algoritmo de calibración automática del sub-modelo sedimentológico, módulo de retención de sedimentos en pequeños embalses, etc.) Sucesivamente, el modelo se aplica a tres cuencas con diferente disponibilidad de datos de sedimentos. El primer caso de estudio es la cuenca Goodwin Creek (Mississippi, EE.UU.), una cuenca experimental con elevada disponibilidad de datos de transporte de sedimentos. Se han evaluado las prestaciones del modelo, y se han realizado algunas consideraciones sobre la estimación del volumen de sedimentos depositados en la red de drenaje al comienzo de una tormenta. El segundo caso de estudio es la cuenca Rambla del Poyo (Valencia, España), una cuenca semiárida de tamaño medio que drena a una laguna costera con graves problemas de sedimentación. El sub-modelo sedimentológico de TETIS ha sido calibrado y validado utilizando volúmenes de sedimentación acumulados en pequeños diques forestales como un estimador del transporte de sedimentos total. Una descripción detallada de la estratigrafía del depósito de un dique que drena una subcuenca de $12,9 \mathrm{~km}^{2}$ se ha utilizado como información indirecta para la implementación del modelo. También se ha desarrollado otra aplicación en la misma cuenca para investigar la posibilidad de calibrar y validar tanto el sub-modelo hidrológico como el de sedimentos mediante el uso de volúmenes de sedimentación de pequeños diques, sin usar registros directos de caudal líquido y sólido. El tercer caso de estudio es la cuenca del río Ésera (Huesca, España), una cuenca pirenaica de $1,500 \mathrm{~km}^{2}$, drenada por un gran embalse. La evolución del volumen de sedimentos depositados en el embalse ha sido reconstruida y utilizada para la 
implementación del sub-modelo de sedimentos. A continuación, los resultados del modelo se han comparado con los datos de sedimentos en suspensión medidos con el fin de verificar la robustez del modelo. Los resultados de esta tesis indican que el modelo TETIS es una herramienta robusta que proporciona una reconstrucción fiable del ciclo de los sedimentos a escala de cuenca. Su ejecución está sujeta a la disponibilidad de datos, tanto para la estimación de parámetros y para la calibración y validación de modelos. Sin embargo, esta tesis ha demostrado que las mediciones directas de sedimentos pueden ser sustituidas por volúmenes de sedimentación en embalses con resultados satisfactorios, teniendo en cuenta la eficiencia de retención del embalse y la densidad aparente de los sedimentos. Se han propuesto dos metodologías para la implementación del modelo de sedimentos, dependiendo de la disponibilidad de datos. Estas metodologías han demostrado ser consistente y han proporcionado una estimación correcta del transporte de sedimentos. Sin embargo, se necesita ulteriores estudios para hacer frente a las limitaciones de los modelos y para reducir la incertidumbre de los resultados. 


\section{Resum}

L'erosió de sòl pot causar importants pèrdues de sòl agrícola, desertificació, contaminació de l'aigua, sedimentació dels embassaments, excés d'erosió ( com soscavació de ponts ) o deposició local, etc. Per aquesta raó, l'avaluació de l'erosió del sòl i el transport de sediments és un component clau de la gestió integrada de les conques. Una de les eines més útils i noves a disposició dels administradors de conca és la modelació distribuïda de l'erosió del sòl i del transport de sediments. Al llarg de les últimes dècades, s'han desenvolupat i aplicat molts models sedimentològics distribuïts per a una àmplia gamma de climes i conques. El seu principal avantatge és que permeten la interpolació o extrapolació espacial dels seus resultats. No obstant això, el seu ús està encara limitat per alguns inconvenients. Una de les limitacions més importants a la utilització d'aquests models és la manca de dades mesurades de transport de sediments per al calibratge i validació de models. És àmpliament reconegut que tant les sèries de cabal sòlid com els mesuraments d'erosió del sòl estan disponibles només en unes poques conques experimentals, habitualment de mida petita o mitjana. L'objectiu d'aquesta tesi és explorar la possibilitat d'utilitzar les dades de sedimentació en els embassaments com una font d'informació indirecta per al calibratge i validació d'un model sedimentològic. Per dur a terme aquesta tasca, un model sedimentològic distribuït anomenat TETIS ha estat utilitzat en un conjunt de conques amb diferent disponibilitat de dades de sediments. En primer lloc, el model TETIS, desenvolupat en els últims anys pel grup de recerca en modelització hidrològica i ambiental de la Universitat Politècnica de València, es descriu, ressaltant especialment els nous mòduls desenvolupats en aquesta tesi (algorisme de calibratge automàtica del sub-model sedimentològic, mòdul de retenció de sediments en petits embassaments, etc.) Successivament, el model s'aplica a tres conques amb diferent disponibilitat de dades de sediments. El primer cas d'estudi és la conca Goodwin Creek (Mississippi , EUA), una conca experimental amb elevada disponibilitat de dades de transport de sediments. S'han avaluat les prestacions del model, i s'han realitzat algunes consideracions sobre l'estimació del volum de sediments dipositats a la xarxa de drenatge al començament d'una tempesta. El segon cas d'estudi és la conca Rambla del Poyo (València , Espanya), una conca semiàrida de mida mitjana que drena a una llacuna costanera amb greus problemes de sedimentació. El sub-model sedimentològic de TETIS ha estat calibrat $\mathrm{i}$ validat utilitzant volums de sedimentació acumulats en petits dics forestals com un estimador del transport de sediments total. Una descripció detallada de l'estratigrafia del dipòsit d'un dic que drena una subconca de $12,9 \mathrm{~km}^{2}$ s'ha utilitzat com informació indirecta per a la implementació del model. També s'ha desenvolupat una altra aplicació en la mateixa conca per investigar la possibilitat de calibrar i validar tant el sub-model hidrològic com el de sediments mitjançant l'ús de volums de sedimentació de petits dics, sense usar registres directes de cabal líquid i sòlid. El tercer cas d'estudi és la conca del riu Ésera (Huesca, Espanya) , una conca pirinenca de $1,500 \mathrm{~km}^{2}$, drenada per un gran embassament. L'evolució del volum de sediments dipositats a l'embassament ha estat reconstruïda i utilitzada per a la implementació del submodel de sediments. A continuació, els resultats del model s'han comparat amb les dades de sediments en suspensió mesurats per tal de verificar la robustesa del model. Els resultats d'aquesta tesi indiquen que el model TETIS és una eina robusta que proporciona una 
reconstrucció fiable del cicle dels sediments a escala de conca. La seva execució està subjecta a la disponibilitat de dades, tant per a l'estimació de paràmetres i per al calibratge i validació de models. No obstant això, aquesta tesi ha demostrat que els mesuraments directes de sediments poden ser substituïdes per volums de sedimentació en embassaments amb resultats satisfactori, tenint en compte l'eficiència de retenció de l' embassament i la densitat aparent dels sediments. S'han proposat dues metodologies per a la implementació del model de sediments, depenent de la disponibilitat de dades. Aquestes metodologies han demostrat ser consistents i han proporcionat una estimació correcta del transport de sediments. No obstant això, es necessita ulteriors estudis per fer front a les limitacions dels models i per reduir la incertesa dels resultats. 


\section{Index}

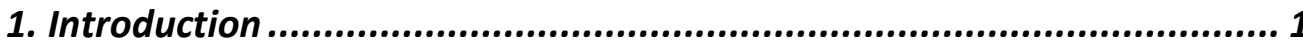

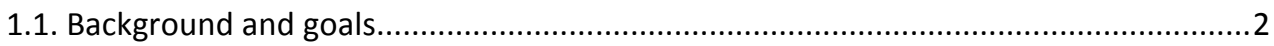

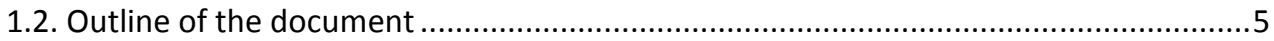

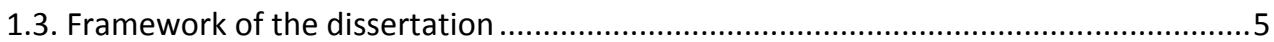

2. Modelling the sediment cycle ........................................................ 7

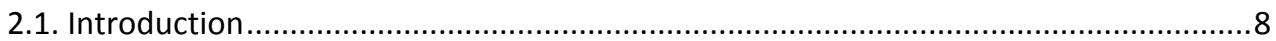

2.2. Erosion, transfer and deposition processes .......................................................... 8

2.3. Mathematical modelling of the sediment cycle ....................................................... 10

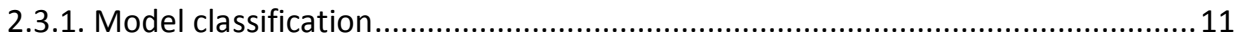

2.3.2. Sediment model calibration ................................................................................. 13

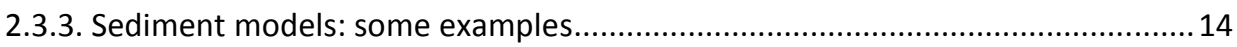

2.3.4. Main limitations of sediment models ................................................................ 19

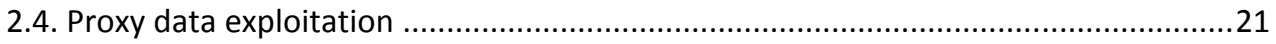

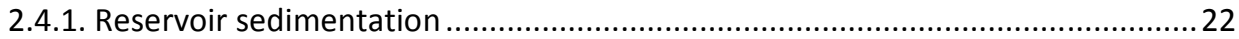

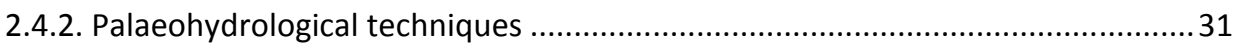

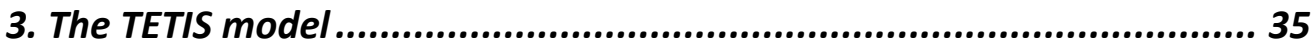

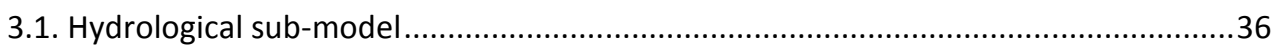

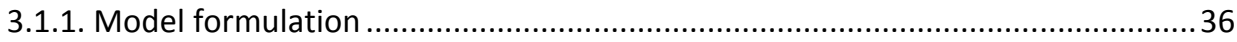

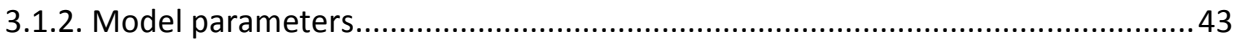

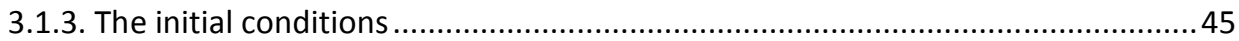

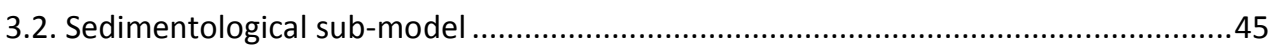

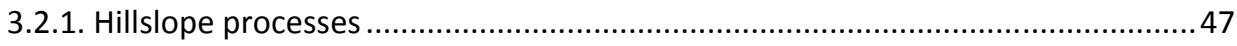

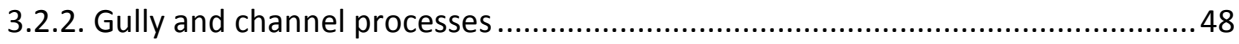

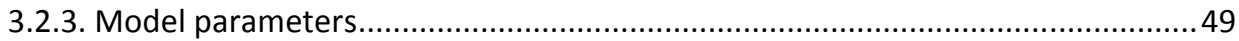

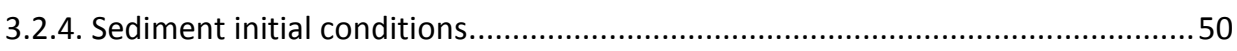

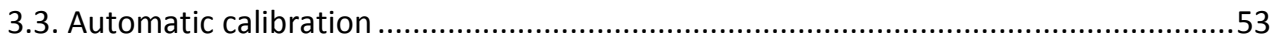

3.4. Small reservoir sedimentation sub-model ............................................................54

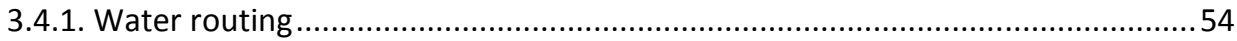

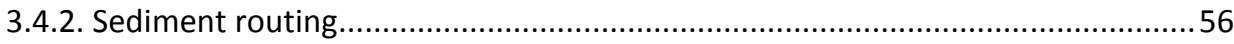


4. Goodwin Creek: gauged data 59

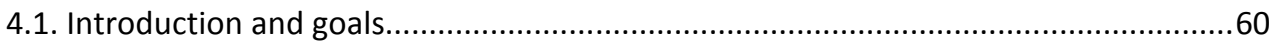

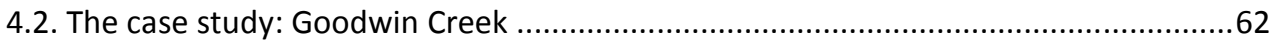

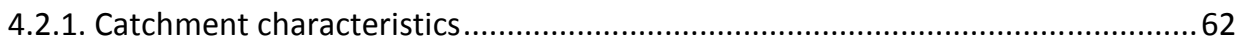

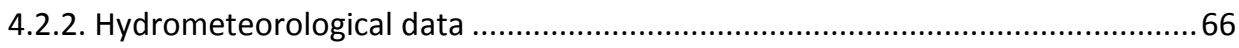

4.2.3. Sediment data

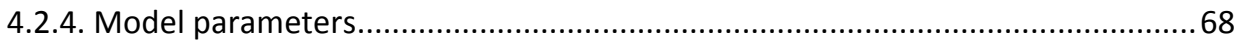

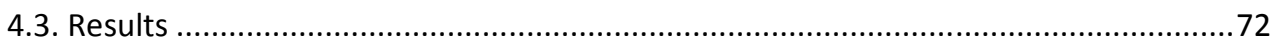

4.3.1. Hydrological sub-model calibration and validation......................................... 73

4.3.2. Sedimentological sub-model calibration and validation ......................................76

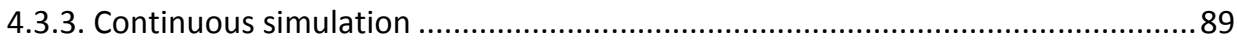

4.4. Conclusions

5. Rambla del Poyo: proxy data ........................................................ 93

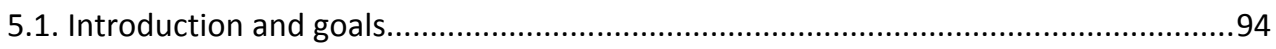

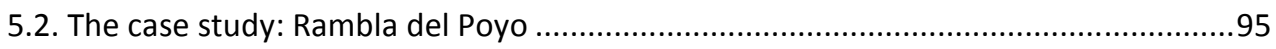

5.2.1. Catchment characteristics ...............................................................................95

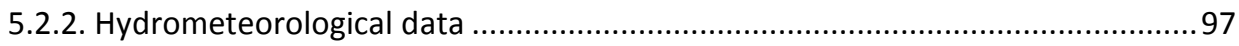

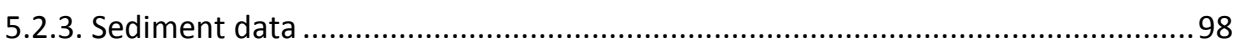

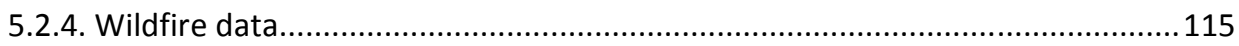

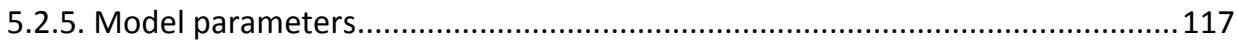

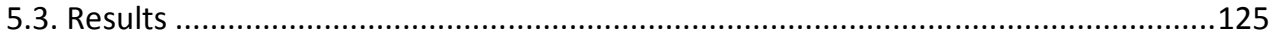

5.3.1. Hydrological sub-model calibration and validation........................................125

5.3.2. Calibration and spatial validation of the sedimentological sub-model...............128

5.3.3. Alluvial infill volume estimation of check dam 2 ..............................................130

5.3.4. Temporal validation of the sedimentological sub-model ..................................133

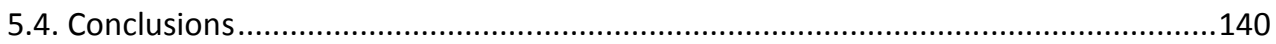

6. Rambla del Poyo: transfer of information ......................................143

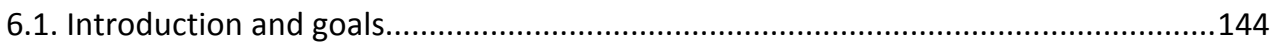

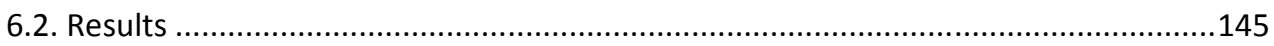

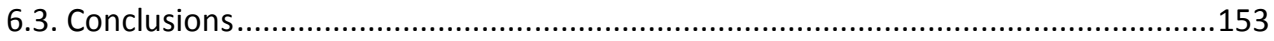

7. Ésera River: proxy and gauged data ...........................................155

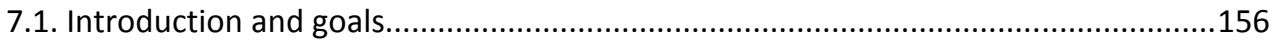




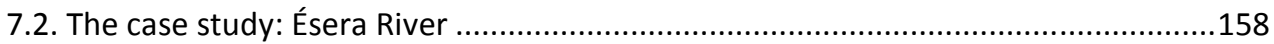

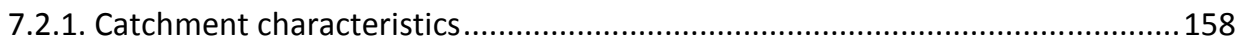

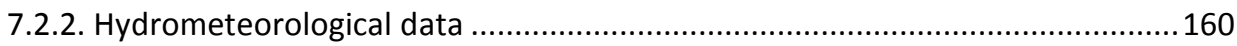

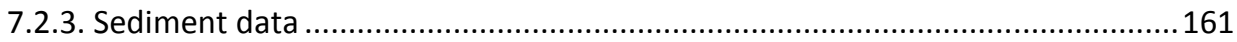

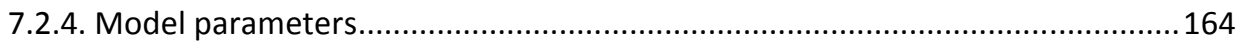

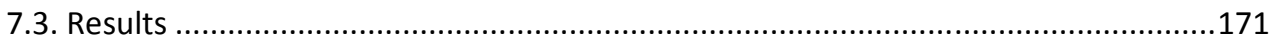

7.3.1. Hydrological sub-model calibration and validation....................................... 171

7.3.2. Sedimentological sub-model calibration and validation ..................................174

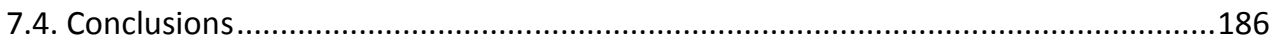

8. Conclusions .......................................................................189

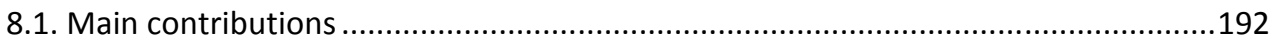

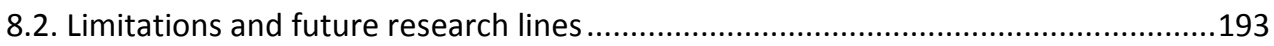

9. References .......................................................................................197 



\subsection{Background and goals}

Soil erosion and sediment redistribution are natural processes of paramount importance. They may cause environmental concerns as land degradation, soil and habitat loss, water pollution or ecosystem alteration. In addition, they may also have severe consequences on human infrastructures, such as bridges or reservoirs. The integrated management of soil erosion at the catchment scale has always been a key issue for agriculture, and it has also acquired a great importance in other fields, such as ecology and water science. Its relevance derives from the importance of soil as basic support for vegetation and ecosystems, as well as the role of sediment particles as main carrier of water contaminants.

A common way to assess and quantify sediment production and transport at the catchment scale is through a mathematical modelling approach. Mathematical modelling of soil erosion and landscape evolution is a fundamental tool for reproducing the sediment cycle at the catchment scale. Nevertheless, sediment cycle is one of the most complex natural processes, as well as a key aspect in catchment management. Among the most relevant goals of sediment modelling at the catchment scale, the following purposes can be cited: quantifying and forecasting the sediment volumes transported by a stream, designing a reservoir, calculating its useful life and establishing operational rules, supporting decisionmaking for agriculture, supporting hydraulic infrastructure design, assisting ecohydrological modelling for habitat evolution forecasting etc.

The physical processes which lie behind the sediment cycle are complex and have not been totally understood yet. At the actual state of the art, the knowledge about soil erosion and sediment transport at the laboratory or plot scale is satisfactory, and research in this field accomplished many of its objectives. The same can be said for sediment cycle modelling at the scale of small hillslopes or small experimental catchments. Nevertheless, the results of sediment cycle modelling at the catchment scale are often disappointing when studying "real" catchments (not experimental catchments), due to scarce data availability, very high topographical and pedological complexity and high spatial variability of all hydrological characteristics. Errors on forecasted erosion rates and sediment yield (SY) often reach, and overcome, the order of magnitude of the same object variable.

One of the factors which most contribute to the lack of knowledge about erosion, transport and deposition processes at the catchment scale is the shortage of gauged data regarding sediment fluxes and production. This is due to the complexity of implementing monitoring techniques at a higher scale than a small plot or hillslope (up to a few square kilometres). The lack of measurements at the catchment scale makes model parameter estimation very difficult, given the high amount of information required by many models. It also prevents from carrying out a complete and satisfactory calibration and validation process. The result is that the great majority of the models are fully applicable only to small experimental watershed. Their extension to ungauged or poorly gauged catchments often provides disappointing performances.

This PhD thesis aims to face the problem of sediment model implementation, especially focusing on "real-life" situations, i.e. real practical engineering problems. Model 
implementation is intended as model calibration and validation in order to obtain a reliable and robust model to be used in catchment management and sediment forecasting. In order to analyse and overcome the problem of data shortage, the focus of this thesis is the calibration and validation of the TETIS model, a conceptual and spatially distributed hydrological and sediment model, in various case-studies, in different data availability scenarios, from an experimental catchment to a completely ungauged catchment.

This PhD thesis forms part of the research activities of the Research Group of Hydrological and Environmental Modelling (GIMHA), from the Universitat Politècnica de València, directed by Prof. Félix Francés. This dissertation gives continuity to a research line of this research group: the distributed modelling of the sediment cycle, started with Juan José Montoya's PhD Thesis (2008). In that study, the TETIS model was developed, starting from the existing TETIS hydrological model and the CASC2D-SED sediment model conceptualization (this one was developed by the research group directed by Prof. Pierre Julien in Colorado State University).

In this dissertation, the behaviour of the TETIS model is firstly tested in an experimental catchment, Goodwin Creek, located in Mississippi (US). The aim of this application is to introduce a calibration and validation strategy for well gauged catchments, by means of the TETIS new automatic calibration tool, developed within this thesis. This application is developed at the event scale. In order to model the sediment cycle at the event scale, some consideration on initial conditions estimation (soil moisture and amount of loose sediment in the drainage network at the beginning of the event) is also done. The model performance is also checked.

The second application presented in this study has the aim of implementing TETIS in a sediment ungauged catchment, i.e. a catchment with no sediment flux records. This is done by applying the model to the Rambla del Poyo catchment, located in the east of Spain (Valencia), where water discharge data are available but no sediment transport measurement exists. Proxy information is used in order to calibrate and validate the sediment model, i.e. the sediment volumes trapped behind some small check dam. In order to do so, the reservoir sedimentation dynamic needs to be analysed and modelled. Moreover, palaeohydrological techniques are employed in order to carry out a stratigraphical analysis of a reservoir deposit and separate layers deposited by different floods. This allows carrying out a temporal validation.

The third application is also implemented in the Rambla del Poyo catchment. In this case, the catchment is supposed as if it was completely ungauged (no water and sediment discharge measurement), the sediment reservoir deposits are used for hydrological submodel calibration and validation, and the gauged water discharge series is used to verify the model performance. The transfer of information between sediment cycle and water cycle is analysed, i.e. the feedback which allows to gain information from sediment cycle to constrain hydrological model calibration.

The last application of this thesis is in a mountainous and highly erodible catchment located in the northeast of Spain, the Ésera River catchment. This catchment is provided with various water discharge stream gauges and it drains to a large reservoir (Barasona), which 
provides sediment proxy data for model calibration and validation. The model is verified with a suspended sediment discharge data series measured in a subcatchment.

The main goals of this PhD dissertation are defined as follows.

The first goal is to present the TETIS model and its last and new improvements. Within this dissertation, new features must be developed within the TETIS model. An example is the automatic calibration tool of the sedimentological sub-model, an essential instrument for accurate model calibration and validation in case of good data availability. Moreover, a new pre-processor is developed in order to manually set sediment initial deposits, providing the model user a further control on this process.

Another relevant tool to be developed within the TETIS model is the small reservoir sedimentation module. This module is fundamental for check dam and small reservoir trap efficiency computation. Given that in this study check dam reservoir sedimentation volumes are going to be used for sediment transport estimation, this is one of the key goals of this dissertation.

The second goal of this dissertation is to analyse the effect of initial sediment deposits in model calibration and validation. It is widely known that sediment deposits strongly affect the total sediment export at the catchment outlet, but little is known about how to model this effect in the framework of a distributed modelling approach. For this reason, different estimation techniques are investigated in this dissertation, and their results are analysed both in terms of sedigraph and sediment rating curve (hysteresis loop) reproduction.

Another goal is to explore the possible applications of the model in different data availability scenarios, that is, model testing in different case-studies. As stated above, lack of data is one of the most relevant limitations to model implementation. For this reason, a very important goal of this dissertation is to test TETIS model in different scenarios of data availability, in order to investigate its capacity to reproduce the natural sediment cycle.

A further and relevant goal is to investigate the opportunities offered by sediment proxy data such as reservoir sedimentation deposits for model implementation. Given that sediment records are generally scarce, a potential source of data can be identified in reservoir sedimentation volumes. This kind of data can be relatively easy to find, given the high number of reservoirs in the world. For this reason, the applicability of this data for distributed model calibration and validation must be investigated and is a main goal of this dissertation. In this framework, the aim of this dissertation is to present a new methodology for model calibration and/or validation in catchments with no sediment data availability, by taking advantage of the flood sediment proxy information obtained from check dam infills or of the reservoir sedimentation volumes computed from bathymetries.

Lastly, this dissertation has the aim of investigating the possibility of calibrating and validating a hydrological model without employing water discharge records, which are usually taken as a reference for hydrological model calibration. This is to be done by exploring the interaction between water and sediment cycle and using the sediment submodel to constrain hydrological sub-model calibration. 


\subsection{Outline of the document}

This document was written following the structure showed below:

1. A literature review is presented in the field of sediment modelling, calibration and validation of sediment models and proxy data use in sediment modelling. A few theoretical concepts are also underlined, aiming to clarify the terms which is used along the document.

2. The hydrological and sediment cycle model TETIS is presented.

3. The three case studies are presented, as previously mentioned, describing for each one the following points:
a. Introduction and goals;
b. The case study;
c. The data set;
d. The model parameters;
e. Results;
f. Conclusions.

4. The main conclusions are presented and the fundamental contributions of this study are underlined.

\subsection{Framework of the dissertation}

This dissertation was carried out in the framework of the following research projects (funding supplied by the Spanish Ministry of Economy and Competitiveness, previously Ministry of Science and Innovation):

- INTEGRA: "Modelling the interactions between sediment, vegetation and water quality in semiarid Mediterranean forests at plot and basin scales". CGL201128776-C02-01.

- SCARCE: "Assessing and predicting effects on water quantity and quality in Iberian rivers caused by global change". CSD2009-00065.

- FLOOD-MED: "Flood hazards in Mediterranean rivers in the context of climate variability and environmental change". CGL2008-06474-C02-01/02.

The hydrometeorological data were provided by:

- $\quad$ The Spanish Meteorological Agency (AEMET);

- The hydrological monitoring automatic system (SAIH) of the Júcar River Basin Authority (Rambla del Poyo catchment) and the Ebro River Basin Authority (Éserra catchment);

- The National Sedimentation Laboratory and the Agriculture Research Service of the United States Department of Agriculture (Goodwin Creek catchment);

- $\quad$ The Experimental Studies Centre (CEDEX) for discharge and reservoir data.

The parameter maps of the Goodwin Creek catchment were estimated by Juan José Montoya. The hydrological parameter maps of the Rambla del Poyo catchment wre 
estimated by Sergio Salazar. The hydrological parameter maps of the Ésera River catchment were estimated by Lina Ramírez Solano with the supervision of the author.

The wildfire extension records for the Rambla del Poyo catchment were provided by the local government (Conselleria de Gobernación, Dirección General de Prevención, Extinción de Incendios y Emergencias, Generalitat Valenciana).

The check dam locations for the Rambla del Poyo catchment were provided by VAERSA (environmental services agency of the Valencia regional government).

The measured suspended sediment discharge series of the Isábena River was provided by the fluvial geomorphology research group of the University of Lleida (Spain), especially by José Andrés López-Tarazón.

The stratigraphical description of the Rambla del Poyo check dam sedimentation was carried out by Gerardo Benito, Xavier Rodríguez-Lloveras (CSIC - National Museum of Natural Sciences), Yolanda Sánchez-Moya and Alfonso Sopeña (Universidad Complutense de Madrid). 


\subsection{Introduction}

In this chapter, some basic concepts of soil erosion, sediment transport and particle deposition are presented, as well as some generic concepts concerning mathematical modelling of the sediment cycle. Some of the most known models in scientific literature are also described and their calibration procedure is presented. Then, the possibility of using proxy data from reservoir deposits for model calibration and validation is analysed from a literature point of view. The last advances related to this topic are showed. Lastly, some short notions of palaeohydrology are introduced, and the possibility of coupling palaeohydrological techniques and distributed sediment modelling is investigated.

\subsection{Erosion, transfer and deposition processes}

Erosion caused by water flow can be originated by natural phenomena, such as rainfall or snow melting, or by human-induced phenomena, such as irrigation. The detachment of soil particles can happen when a raindrop hits the soil surface, exceeding the interstitial forces which keep the soil grains together. This phenomenon is called raindrop splash, or rainsplash and it is shown in Figure 2.1. As long as the precipitation effect continues, water infiltrates in the soil, depending on its infiltration capacity and on the rainfall amount. Exceeding water (i.e. the water which does not infiltrate) accumulates in small depressions (ponds). When the water depth is sufficient, generation of overland flow takes place along the steepest slope, entraining soil particles. Soil particles can be dissolved, in suspension, or entrained on the soil surface, originating sediment transport.

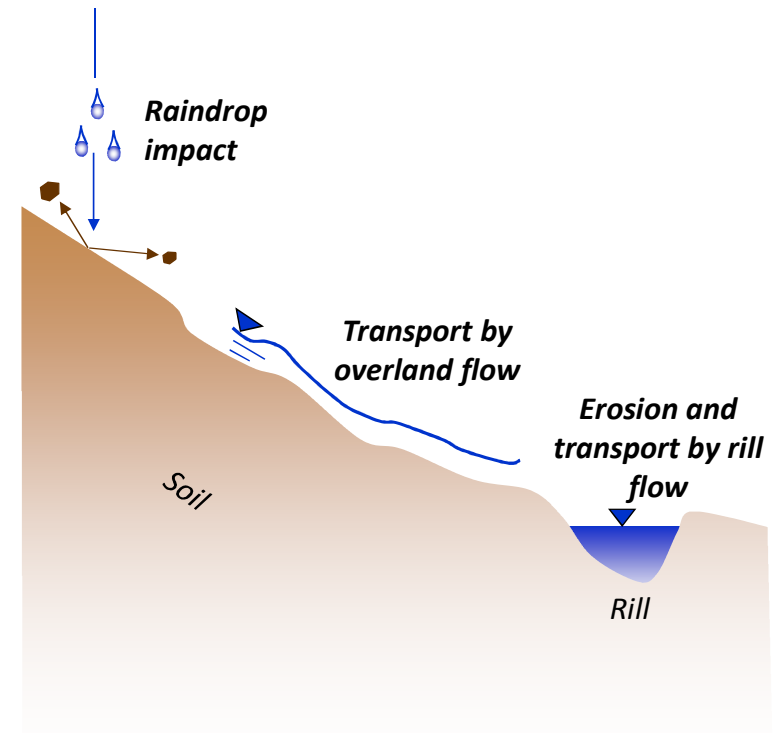

Figure 2.1 - Hillslope erosion (modified from Doe and Harmon [2001]) 
Natural catchments are usually classified between hillslope zones and channel zones, due to the different physical processes that take place. On hillslopes, superficial flow is conceptually divided into rill flow and inter-rill flow, which takes place between rills. In these zones the flow is a thin layer of water often called sheet flow. As long as the flow drains towards downstream and concentrates into steepest flowpaths, its erosive potential increases, and, depending on the soil availability, the amount of soil particles carried by the flow increases. From this processes, the rills originate and evolve towards broader channels, i.e. the gullies. These three areas are the main different sources of sediments in a catchment (Inter-rill, rills and gullies, Figure 2.2).

If there is enough water flow through the gullies, the water discharge reaches channels with a well-defined structure, which also transport the sediment load towards downstream. If the water velocity decreases (e.g. due to a slope change), some of the sediment particles can be eventually deposited, given that the transport capacity decreases.

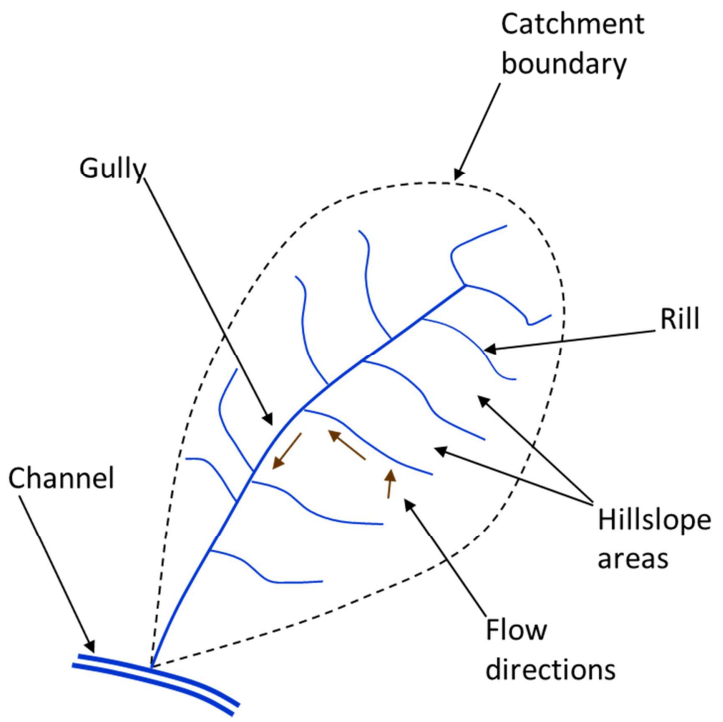

Figure 2.2 - Sediment sources within a catchment (modified from Doe and Harmon [2001])

The transport capacity is the maximum amount of sediments (in terms of mass or volume) that a flow can carry without deposition. Transport capacity and soil erodibility are correlated. Their interaction controls the equilibrium between erosion and deposition.

The amount of sediment passing through a river section depends on the erosion and deposition processes which take place on the hillslopes and in the river network, upstream of the section. The total mass of sediment through a section is called sediment load. The velocity at which sediments pass through a section is called sediment transport rate. The sediment discharge is the product of the sediment transport rate and the cross section area.

The total volume of sediment travelling through a given point of the catchment in time is called sediment yield (SY), and it is formed by eroded sediments from hillslopes and from 
the stream network, plus local contributions from landslides or rock detachment, and subtracting the amount of sediment which are deposited before reaching the given river section. A simple way to estimate the total volume passing through a section is to apply the sediment delivery ratio (SDR) method, which is defined as the fraction, or percentage, of the total eroded material and the amount of sediment passing through a section:

$S D R=V O L / E R O S$

where $V O L$ is the total sediment volume passing through a given section in time, and EROS is the total gross erosion in the whole catchment drained by the giver cross section, in the same time [Doe and Harmon, 2001]. Despite its apparent simplicity, SDR can be considered a much more intricate concept, and it is currently subject to debate (see de Vente et al. [2007]).

\subsection{Mathematical modelling of the sediment cycle}

Integrated management of soil erosion and sediment redistribution at the catchment scale has acquired a great importance during the last decade [Owens and Collins, 2006]. A common way to assess sediment production and transport is through a mathematical modelling approach [Harmon and Doe, 2001]. Mathematical models are useful instruments for land management decision support in different scenarios. For example, sediment yield models are fundamental tools for determining soil redistribution subject to environmental changes [Van Rompaey et al., 2005].

As of the years 60s and 70s, many mathematical models for soil erosion and transport simulation were developed, both at the plot scale and at the catchment scale. During these years, the knowledge about processes and physical phenomena has highly improved, providing more efficient models. Every model represents all relevant processes contributing to erosion and sediment transport in the spatial and temporal context for which the model was developed [Favis-Mortlock et al., 2001]. For this reason, there is a huge variability of sediment model in literature, depending on the case-study background. Given that, at different temporal and spatial scales, different processes become relevant [Kirkby, 1998], a plot scale model must represent different processes than a catchment model or a landscape model, and a historical scale model may not include all processes described by an event scale model. Analogously, models always depend on the location for which they were developed: the erosion and transport processes described in a semi-arid zone model are different than the ones described in a temperate area model.

Sediment cycle is one of the most challenging processes in environmental modelling and catchment management. As stated by Boardman [2006], the development of new models for the sediment cycle must tend to produce multi-objective and multi-scale tools. Van Rompaey et al. [2005] remark that a sediment model is a useful tool for determining soil redistribution, subject to environmental changes, especially in areas characterized by long dry periods followed by heavy bursts of erosive rainfall. Although in the last 60 years the advances in sediment research activities have been relevant, erosion and sediment 
transport models are still inadequate in many situations [Favis-Mortlock et al., 2001]. Only few models have been scientifically validated, and many of them succeeded only under particular circumstances, giving disappointing results out of their application domain.

There are many theoretical approaches to sediment modelling; a review of the state-of-art can be found for example in Jetten et al. [1999], Merritt et al. [2003] and Aksoy and Kavvas [2005]. The most recent review is contained in Karydas et al. [2012], although in that study the authors especially focus on geospatial characteristics of the models.

Sediment cycle models can be classified in different ways:

- $\quad$ By the conceptual structure of the model: empirical models, conceptual models and physically based models.

- $\quad$ By the temporal scale: event scale models and continuous simulation models.

- $\quad$ By the spatial scale: landscape models, catchment models and hillslope models.

\subsubsection{Model classification}

\subsubsection{According to the conceptualization}

Empirical models are developed from experimental data and are limited to the conditions in which they were developed. Conceptual models represent the catchment such as a tank structure, and physically based models are built from the mass conservation equation [Aksoy and Kavvas, 2005].

Among the empirical models, the most known and used is the Universal Soil Loss Equation USLE [Wischmeier and Smith, 1961]. This model originated from an empirical analysis of a great amount of data taken from several experimental plots spread over more than 40 study sites in the US. During the 70s, this equation was widely used in order to calculate sediment production, and different versions were developed, such as RUSLE [Renard et al., 1991]. Many models based on the USLE production equation were also developed, such as AGNPS [Young et al., 1989], or, more recently, WATEM/SEDEM [Van Rompaey et al., 2001]. These models use the USLE for sediment production computation and also include a routing module in order to calculate the sediment transfer.

Physically based models are composed by submodels which simulate all erosion, transport and deposition processes. This kind of model is theoretically more complete and exhaustive, but its parameters are usually numerous and difficult to estimate or measure. Moreover, the measurement scale is often very different from the model scale. Some relevant examples are WEPP [Laflen et al., 1991a], EUROSEM [Morgan et al., 1998] and LISEM [Jetten et al., 1999]

The conceptual or parametric approach is probably the methodology with the best perspective, although its calibrated parameters lack of physical meaning [Dickinson et al., 1986; Ferro and Minacapilli, 1995; Takken et al., 2005]. In the last 15 years, many conceptual models were developed, such as LASCAM [Viney and Sivapalan, 1999] and CASC2D-SED [Johnson et al., 2000]. 


\subsubsection{According to the temporal scale}

Sediment cycle models can also be classified according to the temporal scale of simulation they were designed for. The majority of sediment models were developed at the event scale (for example EUROSEM or CREAMS), although some of them evolved and was adapted to continuous simulation of large temporal gaps (i.e. WEPP). The temporal resolution also is a very important factor. For example, the WATEM-SEDEM model computes the annual SY rates of a catchment, while the CASC2D-SED model (and many others) simulates the sediment flow with a high temporal resolution (to the author's knowledge, the shorter time step used within a CASC2D-SED application is 5 minutes).

The main advantages of the event scale approach compared to the continuous simulation approach are the reduced computational time and the high non-linearity of the watersediment discharge relationship. This means that, for higher water discharge, much higher sediment discharge, with an exponential proportionality. This phenomenon was noted by many authors. Bennett [1974] and Morgan et al. [1998] reported that only a few extreme rainfalls cause the great majority of the sediment transport. They affirm that it is possible to calculate a catchment erosion rate over a large time period by knowing the erosion rates of the most important floods occurred during that time period.

Nevertheless, event scale approach has some disadvantages. Probably the most limiting one is the initial condition estimation. Using the event scale approach, an initial state is required for starting the simulation. The initial state is the values to assign to all model state variables when the simulation starts. The continuous simulation approach overcomes this inconvenient by using a warm up period preceding the simulation period. Moreover, the strictly event scale models cannot be used for climate change or land use change studies [Jetten et al., 1999], or, in general, for catchment management studies over a large time period.

Among the event scale models, two families exist: models based on steady surface flow profile (such as CREAMS and WEPP) and models based on a fully dynamic approach (such as EUROSEM). The first kind of model only computes the total sediment load corresponding to a single rainstorm, while the second kind is able to reproduce the sedigraph and all its characteristics [Morgan et al., 1998]. Modelling the hydrograph shape may result very important for the comprehension and correct reproduction of the soil erosion and sediment transport catchment dynamics. For example, the rising limb of the sedigraph is related to the flow-induced erosion, while the falling limb is related to the rain induced-erosion in the catchment headwater [Parks et al., 1982].

\subsubsection{According to the spatial scale}

Sediment cycle models can also be classified according to their spatial scale. The basic classification is usually the following (Table 2.1 [Doe and Harmon, 2001]):

- Plot/Hillslope

- Catchment

- Landscape 
The hillslope models, such as USLE or CREAMS, describe the soil loss, or hillslope erosion, but do not reproduce the sediment routing towards downstream. Their main limitation is that in most cases the relationship between local hillslope erosion and regional large scale SY is not direct. An adaptation to the regional scale is often required [Pilotti and Bacchi, 1997].

With the development of new GISs (Geographical Information Systems) tools and the great improvement of the computational power available to modellers, many spatially distributed catchment models were developed. These models can reproduce the sediment dynamics in larger and more complex catchments. These new models can identify sediment sources and sinks. Their main limitation is that they are not suitable for long or very long-term simulations due to the lack of complementary modules, such as vegetation evolution, aquifer interactions, soil generation, etc. [Jetten et al., 1999], although recent developments in earth sciences point to more complete and interdisciplinary models.

\begin{tabular}{cc}
\hline Scale & Extension of physical domain \\
\hline Plot/Hillslope & $<40$ ha \\
Catchment & $40 \mathrm{ha}<x<10000$ ha \\
Landscape & $>10000$ ha \\
\hline
\end{tabular}

Table 2.1 - Sediment model scales [Doe and Harmon, 2001].

\subsubsection{Sediment model calibration}

Model calibration can be seen as a methodology for adjusting the model results to the reality, or to the representation of natural behaviour given by gauged data. Following Beven [2001], model calibration is similar to a multiple regression adjustment, carried out in order to optimize model parameters and reduce residual errors. If some residual error still appears, the model forecast holds uncertainty (this is always the case of distributed hydrological and sediment modelling). Similarly to the multiple regression theory, these uncertainties are greater as the simulation conditions are different to the calibration conditions [Vélez, 2003].

In hydrological models, three sources of uncertainty are usually identified:

- $\quad$ structural or conceptual errors, or model errors;

- parameter estimation errors;

- $\quad$ input data errors.

This can be extended for sediment models, given that erosion and transport strongly depend on catchment hydrology and hydraulics.

When using physically based models, the detailed description of flow depth and velocity is more important than model parameter calibration, despite the sensibility of the model to those parameters [Smith et al., 1999; Aksoy and Kavvas, 2005]. Nevertheless, when using spatially distributed conceptual models, the first issue to face is the scale effect. This is due to the fact that transport equations were developed at the reach scale, while the scale the model usually works at is the cell scale (often the digital elevation model scale), which may be different from the reach scale. This issue causes an increase in the uncertainty. 
Additionally, field measurements cannot reproduce the whole spatial heterogeneity of soil characteristics, and, analogously, errors on boundary conditions are frequent. Some of the parameters cannot be measured directly, such as the soil erodibility, and must be estimated using regression techniques or empirical formulae. Lastly, uncertainty on model conceptualization is still high, at the present state of the art [Brazier et al., 2000]. Consequently, the error propagation is a key issue for distributed modelling, and for these reasons models need specific calibration for each case study [Jetten et al., 1999].

Following a review of many studies concerning calibration and validation of a sediment model, modellers usually focus on hydrological sub-model calibration or on observed/simulated sediment volume adjustment. Sediment parameters calibration is generally more difficult to carry out, basically due to the lack of data. Nevertheless, some examples of sediment parameter calibration exist, such as $\mathrm{n}$ Folly et al. [1999] for the EUROSEM model, Van Rompaey et al. [2001] and Van Oost et al. [2005] for WATEM/SEDEM, and de Roo and Jetten [1999] for LISEM.

\subsubsection{Sediment models: some examples}

In this chapter, a brief description of some of the most used models in literature, which special focus to the model calibration and validation procedures, following the case studies found in bibliography. Table 2.2 resumes the model references.

\begin{tabular}{ll}
\hline Model & Reference \\
\hline USLE & Wischmeier and Smith, 1961 \\
ANSWERS & Beasley et al., 1980 \\
CREAMS & Knisel, 1980 \\
KINEROS & Smith, 1981 \\
SEM & Storm et al., 1987 \\
WESP & Lopes, 1987 \\
AGNPS & Young et al., 1989 \\
WEPP & Laflen et al., 1991 \\
GUEST & Misra and Rose, 1996 \\
SHESED & Wicks and Bathurst, 1996 \\
LISEM & de Roo et al., 1996b \\
SWAT & Arnold et al., 1998 \\
EUROSEM & Morgan et al., 1998 \\
LASCAM & Viney and Sivapalan, 1999 \\
SEDD & Ferro and Porto, 2000 \\
WATEM/SEDEM & Van Rompaey et al., 2001 \\
CASC2D-SED & Ogden and Heilig, 2001 \\
WASA-SED & Mamede, 2008
\end{tabular}

Table 2.2 - Literature reference of the main sediment cycle models (in bold the models described below). 


\subsubsection{ANSWERS}

The ANSWERS model (Areal Nonpoint Source Watershed Response Simulation) includes a hydrological conceptual model and a physically based erosion model. The erosion process assumes that the sediment movement can be triggered by the rainfall or by the runoff, while the transport is only due to the runoff. The ANSWERS model divides the catchment into independent elements (cells of a regular grid), within that runoff and erosion are treated as independent functions of the hydrological and sediment parameters. The rill effect is described by the Manning roughness coefficient, and for this reason is not explicitly treated.

In the ANSWERS model, the particles which cannot be transported are dropped back to the soil, and will need the same force to be detached from the soil another time (deposited material is treated the same way as the parental material). Bank erosion is considered as negligible in the first version of the model. During 80s, Parks et al. [1982] added a new sediment transport module, using the Foster and Meyer [1972] equation. As all physically based models, the ANSWERS model requires complex and large data collection and preprocessing. The original model was thought to be used without calibration, in ungauged catchments.

A more recent version was developed, called ANSWERS-2000 [Bouraoui and Dillaha, 1996]. These authors observed that uncalibrated model results are usually satisfactory in small catchments, while in larger catchments the errors on sediment discharge estimation may be greater than $200 \%$. In these cases, the authors calibrated the sediment module by adjusting two parameters related with the particle detachment, improving the results.

In Bhuyan et al. [2002] the ANSWERS model is compared to other sediment models. The authors stated that the most influent parameters are the $\mathrm{K}$ factor of the USLE, the Manning Roughness coefficient and the roughness height.

\subsubsection{KINEROS - KINEROS2}

The structure of the KINEROS (KINematic EROsion Simulation) model is based on a channel and reservoir network all interconnected. The erosion component of the KINEROS model is based on the mono-dimensional continuity equation for unsteady flow. The erosion/deposition rates are calculated by a combination of rain erosion and runoff erosion. The splash erosion is calculated by means of an empirical equation, in which the erosion rate is proportional to the square of the rainfall intensity. The runoff erosion is estimated as proportional to the transport capacity deficit, i.e. the difference between the actual flow sediment concentration and the maximum theoretical concentration in steady flow. The transport capacity is computed by the Engelund and Hansen equation [Engelund and Hansen, 1967]. The KINEROS model does not separate explicitly the rills from the inter-rill zone. Channel erosion is treated like the hillslope erosion, without considering the splash erosion.

The new version of this model, KINEROS2, considers five granulometrical classes and uses a different conceptualization of the infiltration. Both models were developed as event scale 
sediment models, although the new version can be adapted to continuous simulation, as it describes in detail the water redistribution and the soil infiltration loss during the rainstorm [Smith et al., 1999]. In this last work, the KINEROS2 model is calibrated by adjusting the following parameters: splash coefficient, soil cohesion, Manning coefficient, and mean $\mathrm{K}$ factor, using multipliers applied to all elements. The calibration is carried out by visual fitness on the sedigraph, without using any objective function.

\subsubsection{AGNPS}

The AGNPS (AGricultural NonPoint Source) model is an event scale model which was developed for reproducing runoff, sediment transport and nutrients in agricultural catchments. The catchment is divided into square cells uniformly distributed. The erosion and sediment transport calculation are based on the USLE, and the sediment routing is calculated following the continuity equation in steady flow. The eroded soil is classified into five textural classes: clay, silt, small aggregates, large aggregates and sand.

Many AGNPS applications are present in literature. In these studies, the calibration is usually limited to the hydrological sub-model, especially the Lutz or the Curve Number methods parameters, depending on the version [Grunwald and Norton, 2000; Kliment et al., 2008]. Haregeweyn and Yohannes [2003] suggested that only a few parameters strongly affect the model results in terms of runoff volume, water peak discharge and sediment peak discharge. These parameters are the initial soil moisture conditions and the P USLE factor. They concluded that the calibration of the P factor of USLE affects heavily the simulated sedigraph.

\subsubsection{WEPP}

The WEPP (Water Erosion Prediction Project) model was developed in order to compute soil erosion and sediment transport in agricultural field, rural zones, forest areas, grasslands and urban areas. In its last version, it is a continuous simulation model with a daily time step.

The WEPP model calculates separately the rill and the inter-rill erosion, using the steady flow continuity equation. The inter-rill erosion is as proportional to the square of the rainfall intensity. Rill erosion takes place if the flow shear stress is greater than the critical shear stress of the particle. The transport takes place if the sediment load is less than the maximum transport capacity.

The results demonstrate that WEPP is a reliable model, especially in predicting average inter-annual soil losses in cultivated catchment.

Nearing et al. [1990] carried out a sensitivity analysis of the WEPP model. The WEPP model is very sensible to the hydrological parameters, while the most influent sediment parameters are the ones which describe the rill characteristics. This study also demonstrates that the sensibility of the model to the parameters depends on the rainstorm characteristics and the catchment characteristics. For example, the hydraulic conductivity is important for short events, and the hillslope soil cover is a key parameter only if the hillslope erosion is relevant. Vegetation parameters are not very influent. 
The original version of the WEEP model was not designed to be calibrated. Nevertheless, many WEPP application and parameter calibrations can be found in literature [Zeleke, 2001; Zhang, 2004]. For example, Zeleke [1999] calibrated the hydraulic conductivity of the Green and Ampt formulation and the soil erodibility parameters, using as objective function the mean squared error and the Nash and Sutcliffe efficiency [NSE - Nash and Sutcliffe, 1970]. In Zhang [2004], an automatic algorithm for the calibration of the hydraulic conductivity was developed, aiming to compare the optimized values with field measurement. In this study, the hydric stress factor, the crop factor and the energy/biomass rate were calibrated. The chosen objective function was the square of the sum of the water discharge errors.

Bhuyan et al. [2002], in their work, identified the hydraulic conductivity, the soil erodibility, and the critical shear stress as the most influent parameters.

\subsubsection{EUROSEM}

The EUROSEM (European Soil Erosion Model) model is a physically based small catchment or plot - scale model for the prediction of soil erosion. It was designed at the event scale, given that the authors maintain that soil erosion is dominated by a few rainfall events per year.

EUROSEM is a dynamic model which can simulate soil erosion, sediment transport and deposition, distinguishing between inter-rill zone, rills and gullies. The model can compute the total runoff, the soil loss, the hydrograph and the sedigraph.

In the EUROSEM model conceptualization, the soil detachment starts with the raindrop impact, before superficial runoff is generated. The initial sediment concentration is greater than zero. Hillslope erosion is divided into three parts: hillslope without rills, hillslope with rills and hillslope with a very dense rill network. Channel erosion is treated similarly to rill erosion, although the rainsplash erosion is not considered. The bank erosion is not taken into account.

In Folly et al. [1999], the EUROSEM model was applied to the Catsop catchment (Netherlands) and compared to other models such as LISEM and EROSION2D/3D. The results show that EUROSEM is a solid model and a reliable tool, especially for short storm events with a unique peak. In that study, the model is calibrated by adjusting its most influential parameters, i.e. the capillary depth, the initial soil moisture, the saturated hydraulic conductivity, the soil cohesion, the soil detachment coefficient. The calibration is a trial and error calibration, using the visual fit as objective function.

In Morgan et al. [1998] a trial and error calibration is carried out, varying the parameters within a realistic and plausible range. In Veihe and Quinton [2000] and Veihe et al. [2000], the model sensibility is analysed by means of a Monte Carlo analysis. The results show a strong sensibility to some hydrological parameters, such as the saturated hydraulic conductivity and the net capillary suction. Regarding the sediment parameters, the most influent ones are the soil cohesion coefficient and the soil detachment coefficient. 


\subsubsection{LASCAM}

The LASCAM model was born from the integration of a continuous simulation daily conceptual sediment model and an existing water balance model. Its goal was, at the beginning, the prediction of the land use change and climate change consequences on water quantity and quality in forest catchments of West Australia.

The LASCAM model is a conceptual model for sediment erosion and transport calculation. Hillslope erosion depends on the C factor of the USLE, and the channel processes are described by an adapted formulation from the SPNM model [Williams, 1980], function of water discharge, velocity and drainage area. Results demonstrate that daily and monthly model application reproduce satisfactorily the sediment transport. The model was later coupled with a conceptual model for nutrient mobilization and transport.

The LASCAM model needs calibration as it is a conceptual model. The hydrological submodel is calibrated by adjusting six parameters and the sedimentological sub-model by other 6 . The calibration is carried out by means of the SCE-UA automatic optimization algorithm [Duan et al., 1993]. The sedimentological sub-model also requires information about the initial sediment storage in the drainage network.

In Viney and Sivapalan [1999], the calibration process was divided into two phases. During the first one, the hydrological parameters were automatically calibrated, using as objective function the sum of the square errors on water discharge (ten stream gauge stations were used for calibration, assigning a weight to each one depending on the drainage area). Then, the six sediment parameters were optimized by reproducing the observed sedigraph in one of the ten stations. The initial sediment storage conditions were estimated by continuous simulation of a warm up period.

In Viney et al. [2000], a new version of the LASCAM model were proposed, integrating water and sediment balace sub-models and a nutrient cycle sub-model. The final model has 29 parameters, the majority of which has to be calibrated. The suggested procedure was, as before, the automatic calibration of hydrology parameters, then the calibration of sediment parameters and lastly the calibration of nutrient parameters, although the model offers the chance of a global calibration of all parameters.

\subsubsection{LISEM}

The LImburg Soil Erosion Model (LISEM) is one of the first sediment models which make use of a GIS. Although its structure is physically based, the majority of its equations are empirical or semi-empirical. The LISEM model takes into account channel erosion and forest road erosion.

For the erosion prediction, many indexes are uses, such as the topographic index used in TOPMODEL [Beven and Kirkby, 1979], which is used in order to determine possible flow paths, wet and dry areas and runoff production zones, which can cause erosion. The model also uses the power index (product of the drainage area and the slope) and the transport capacity index (function of the drainage area and the slope). The LISEM model does not 
reproduce interflow and base flow, and for these reasons, its applicability is limited to superficial runoff prone catchments [de Roo and Jetten, 1999].

De Roo et al. [1996a] identified, through a sensibility analysis of the LISEM model, eight influent hydrological parameters and two influent sediment parameters. The most influent ones are the hydraulic conductivity and the roughness. In de Roo et al. [1996b], the authors calibrated the initial piezometric depth, as it was considered the most relevant and uncertain parameter. In de Roo and Jetten [1999], a modified version of the LISEM model was used. The Green and Ampt infiltration equations were introduced, and the calibration was carried out by comparing observed and simulated discharge, and adjusting the hydraulic conductivity, the suction head at the wetting front and the initial soil moisture content. No sediment parameters were calibrated.

In Hessel et al. [2003], the LISEM model was calibrated in a separate way: first of all, the hydrological component were calibrated, and then an adjustment were carried out in order to reproduce the total sediment volume. The calibrated parameters were the hydraulic conductivity, the initial suction head, the Manning roughness and the channel length. The calibration was carried out using visual fit.

\subsubsection{WATEM-SEDEM}

WATEM-SEDEM is a distributed sediment model. The soil erosion and the mean annual transport capacity are calculated by RUSLE-derived equations. The transport phase is conceptualised as a function of the particle travel distance and the route characteristics. Once the mean annual erosion and the mean annual transport capacity have been calculated, a routing algorithm is used to determine the particle movement through the drainage network. For each time step, a sediment balance is carried out, and the model computes erosion, deposition or bare transport. The WATEM-SEDEM model cannot reproduce the observed sedigraph. Its output is the mean annual SY.

One of the hypotheses of the WATEM-SEDEM model is that the sediment particles, once they reach a permanent channel, are directly transported to the catchment outlet. For this reason, its applicability is limited to medium to small catchment.

Given that the WATEM-SEDEM model uses the RUSLE formulation, a calibration of the R, K, $\mathrm{C}$ and $\mathrm{P}$ factors is needed, apart from two transport capacity coefficients (for arable lands and for no erodible lands). In Van Rompaey et al. [2001] and Van Rompaey et al. [2005], only the two transport capacity coefficients were calibrated, due to the lack of available data. In both studies, the parameter calibration is carried out by means of a Monte Carlo analysis, i.e. generating random values of the parameters within a fixed range, and calculating for each couple of parameters the objective function, which is usually the NSE [Nash and Sutcliffe, 1970].

\subsubsection{Main limitations of sediment models}

Sediment cycle modelling research has obtained in the last 60 years very important improvements. Nevertheless, the erosion and sediment transport models are still 
inadequate in several contexts [Favis-Mortlock et al., 2001; Cerdà et al., 2013]. Despite the efforts made in the last decades, sediment models cannot provide answers to fundamental questions such as where is erosion occurring? Why is it happening, and who is to blame? How serious is it? Who does it affect? What should be the response? Can we prevent it? What are the costs of erosion? [Boardman, 2006]. Only a few models have been validated in a scientifically acceptable way, and many of them obtain good performances only under specific circumstances. Out of their limited application domain, they provide disappointing results.

A strong limitation to the application of many existing sediment models is the need for a reliable calibration and validation [Jetten et al., 1999], which is required in order to prove the model robustness and trustworthiness. In the past, modelling research studies highlighted the importance of calibration and validation for hydrological [Klemeš, 1986; Beven, 1989] and sedimentological models [de Roo and Jetten, 1999; Folly et al., 1999; Van Oost et al., 2005; Verstraeten, 2006; Polyakov et al., 2007]. While the calibration problem has already been faced for hydrological models, only a few papers described clear and scientifically acceptable calibration and validation procedures for sedimentological models. Moreover, the use of automatic calibration algorithms in erosion and sediment modelling, as seen in Freedman et al., [1998] and Santos et al. [2003, 2010] for WESP model, Viney and Sivapalan [1999] for LASCAM model and Ogden and Heilig [2001] for CASC2D-SED model, is still not very common.

Many questions can be raised concerning sediment model calibration and validation. For example: how to select calibration and validation periods, which objective function(s) is(are) to be used, which calibration technique is the most appropriate, etc. One of the main problems, for example is the estimation of the initial condition (defined as the initial value of model state variables). Typically, the most influent variables to be estimated at the beginning of a simulation are the soil moisture, the groundwater level, the river flow and the available in-channel sediment. While the hydrological component of the initial condition has been thoroughly investigated [Beven, 2001], there is a lack of studies regarding the influence of initial sediment availability on model calibration and operation.

The main limitations to sediment cycle models can be resumed as follows:

- process representation;

- data availability;

- $\quad$ spatial and temporal scale effects;

- $\quad$ model sensibility to its parameters.

The first two issues are somehow related: it is very difficult to check whether the catchment conceptualization provided by a model is correct or not without (or with a few) observed data. In the great majority of the world's catchments, no sediment transport measures are available. Only a few catchments are regularly gauged, although the only gauged variable is the suspended sediment transit, or, sometimes the total sediment transport. Comparing observed and simulated sediment transport series at the catchment outlet may not be sufficient to properly validate a model. Other sources of data would be needed, such as sediment storage, location of erosion areas and deposition reaches, etc. 
During the last years, the great progress made in model developing has been much higher than the development of new data set for model validation. A valuable exception is described in Van Oost et al. [2005]. These authors proposed to validate a model by means of a combination of sediment discharge series, soil evolution maps and erosion maps. That study demonstrated that the equifinality problem (the same model result can be reached using different calibration sets) strongly affects sediment models. This issue cannot be solved without a proper validation, and, as a consequence, new sediment data sets are strongly needed.

Model complexity and model data requirement are proportional to the model uncertainty, especially if the model is not calibrated [Brazier et al., 2000]. This conclusion from Brazier et al. [2000] comes from a sensibility analysis of the WEPP mode. The authors demonstrated that the uncertainty was higher in the UK catchments rather than the USA catchments, where the model was developed, in spite of the physical bases of WEPP, which should be valid all over the world. In literature, many other papers show the sensibility of sediment models to their parameters [Folly et al., 1999; Brazier et al., 2000; Veihe and Quinton, 2000; Takken et al., 2005].

Following these considerations, some key issues can be identified and taken into account when implementing a new sediment cycle model.

- Model complexity is an advantage from the point of view of real dynamics reproduction, but it has some very relevant disadvantages, such as the strong sensibility to all its parameters, the limited transferability to different catchments and the lack of clear calibration validation procedures.

- A coherent model must reproduce both the outlet sedigraph and the internal sediment dynamics of the catchment.

- In order to apply a model in a generic catchment, to properly validate it and check its internal functioning, new sediment data set are required, and, given the scarcity of monitored catchments, new sediment data sources are needed.

The lack of data is therefore one of the most important limitations for developing and implementing a sediment model. For this reason, the exploitation of indirect data and the finding of new sources of sediment information are essential to the sediment modelling research activity.

\subsection{Proxy data exploitation}

As stated above, data availability is a key question for sediment cycle modelling [Cerdà et al., 2013]. A way to overcome this problem is to improve the monitoring networks, although the trend of the last years has been clearly a diminution of the active gauging stations almost all over the world. Another way to overcome the data availability issue is to develop new modelling techniques in order to exploit proxy and soft data in order to gain information and to constrain model calibration, which is the goal of this dissertation. 
Seibert and McDonnell [2002] defined soft data as "qualitative knowledge from the experimentalist that cannot be used directly as exact numbers but that can be made useful through fuzzy measures of model simulation and parameter value acceptability", while Blöschl [2001] defined proxy data as an indirect measurement or qualitative observation. Proxy data and soft data can be used jointly with hard data, i.e. directly gauged data, in order to improve model reliability and to reduce model uncertainty.

In the chapters, a literature review is presented about how to exploit sediment proxy data, with a special focus on the use reservoir sedimentation deposits as an estimation of the total SY.

\subsubsection{Reservoir sedimentation}

As streams enter reservoirs, their flow velocity reduces, decreasing the stream sediment transport capacity and causing sedimentation [Julien, 1995, 2010]. Due to this phenomenon, part of the sediments transported by the stream may be retained behind the dam, forming a deposit. It is estimated that the annual loss in storage capacity of the world's reservoirs due to sediment deposition is around $0.5-1 \%$ [Verstraeten et al., 2003]. For many reservoirs, however, annual storage reduction rates are much higher and can reach $4 \%$ or $5 \%$, such that they lose the majority of their capacity after only $25-30$ years [Verstraeten et al., 2003].

Since it is very difficult to obtain direct SY measurements for validating model results, at the regional scale and for long periods, the sediment accumulation in lakes and reservoirs may be used as an indirect validation method [Van Rompaey et al., 2003]. This techniques consists in [Avendaño Salas and Cobo Rayán, 1997]:

- Measuring the reservoir siltation;

- Determining the sediment dry bulk density;

- Determining the reservoir TE;

- Calculating the total SY.

The total SY is defined as the total amount of sediments drained by a river network, measured in a reference cross section during a given time period [Vanoni, 1975; Avendaño Salas and Cobo Rayán, 1997]. It is usually expressed as tons per squared kilometre or hectare per year $\left(\mathrm{t} \mathrm{km}^{-2} \mathrm{y}^{-1}\right.$ or $\left.\mathrm{t} \mathrm{ha}^{-1} \mathrm{y}^{-1}\right)$ or mega grams per squared kilometre or hectare per year $\left(\mathrm{Mg} \mathrm{km}^{-2} \mathrm{y}^{-1}\right.$ or $\left.\mathrm{Mg} \mathrm{ha}^{-1} \mathrm{y}^{-1}\right)$.

This methodology is usually applied to large reservoirs, where bathymetries are periodically carried out. Its aim is to calculate SY at the regional scale and over a long time period. The large spatial scale is basically due to the scale of the catchments drained by reservoirs (in Spain usually $10^{2}$ or $10^{3} \mathrm{~km}^{2}$ ). The large temporal scale is due to the fact that bathymetries are usually repeated each 5-10 years or more.

Reservoir sediment deposits were used since the 50s as an estimate of the catchment SY to compare with the results of empirical equations [ICOLD, 1989; Avendaño Salas et al., 1995; Avendaño Salas and Cobo Rayán, 1997]. Nevertheless, this technique was not extensively employed until the '80 [Jolly, 1982; Le Roux and Roos, 1982; Duck and McManus, 1993]. 
In Spain, the first organic study of reservoir sedimentation at the national scale was carried out by the CEDEX (Centros de Estudios y Experimentación de Obras Públicas) [Avendaño Salas et al., 1995, 1997]. For example, Avendaño Salas et al. [1997] estimated SY for Spanish catchments by using 60 reservoirs distributed throughout Spain, finding that the mean SY was between 0.18 and $9.64 \mathrm{t} \mathrm{ha}^{-1} \mathrm{y}^{-1}$ (Figure 2.3).

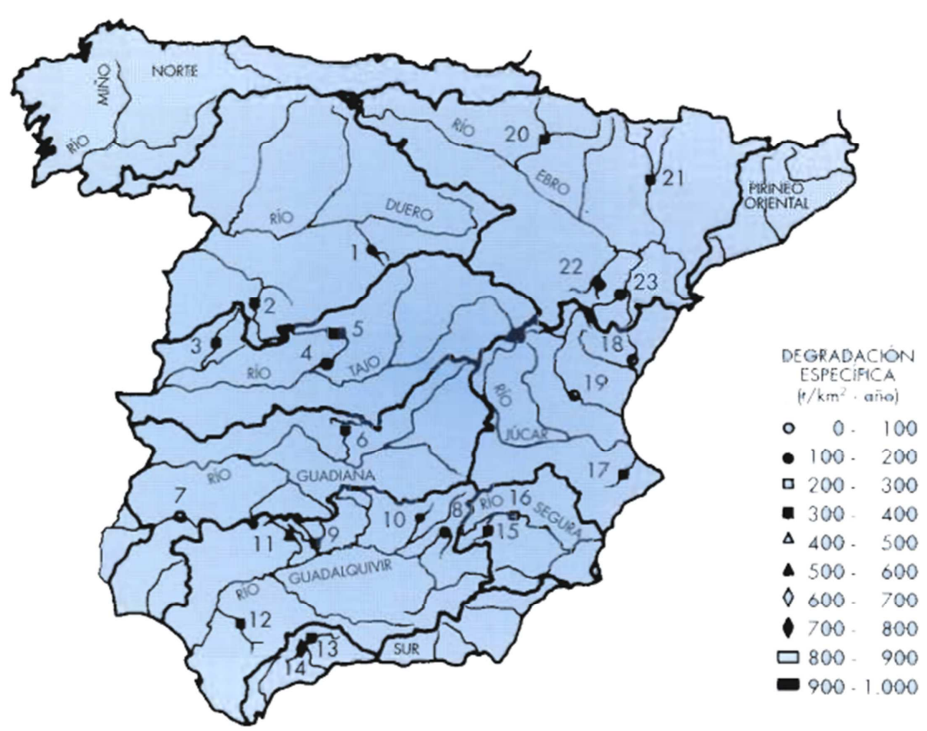

Figure 2.3 - Localization and results of the study by Avendaño Salas et al. [1995].

SY from reservoir deposits can be calculated by two methods [Foster, 2006]. The first one consists in estimating the storage capacity loss of the reservoir by bathymetric surveys and measuring or estimating the sediment density in order to obtain the sediment mass deposited into the reservoir bottom, as shown in White et al. [1996]. The second one consists in ground surveys of sediment volume and density during a dry period or a drawdown, as shown in Duck and McManus [1987]. Once the sediment deposit lying at the bottom of a reservoir has been quantified, the average SY is calculated as follows:

$S Y=\frac{V \times d B D \times T E}{T \times A}$

$S Y=S Y\left(t h a^{-1} y^{-1}\right)$

$V=$ volume of reservoir sedimentation deposit $\left(\mathrm{m}^{-3}\right)$

$d B D=$ dry bulk density $\left(\mathrm{t} \mathrm{m}^{-3}\right)$

$T E=$ Trap Efficiency (-)

$T=$ number of years during which the sedimentation has settled (y)

$A=$ catchment area (ha) 
In literature, the aim of the SY estimation by using reservoir sedimentation was usually the calibration or validation of some empirical formulae or regression for the regionalization of some SY model (e.g. Baade et al. [2012]). For example, Avendaño Salas et al. [1997] built a regression against the catchment area, although only $17 \%$ of the observed variability could be explained. Verstraeten et al. [2003] used the same data set and applied an index model, finding that topography, vegetation cover, shape, geology and presence of gullies in the vicinity of the reservoir could explain the SY variability.

Recently, reservoir sediment deposits were also used for distributed model validation, as showed in Srinivasan et al. [1998] de Vente et al. [2005], de Vente et al. [2008], Alatorre et al. [2010] and Haregeweyn et al. [2013]. In de Vente et al. [2005], the FSM model [Verstraeten et al., 2003] and the PSIAC model [Pacific South West Inter-Agency Committee, 1968], both semi-quantitative models for mean annual SY estimation, are compared, and their results contrasted versus reservoir sedimentation rates. In de Vente et al. [2008], the reservoir sedimentation rates were used to compare the results of three distributed approaches for soil erosion rates and long-term SY rates estimation: the WATEM/SEDEM model [Van Rompaey et al., 2001], the PESERA model [Kirkby et al., 2008] and the SPADS model [de Vente et al., 2008]. In Alatorre et al [2010], the WATEM/SEDEM model is calibrated using the depositional story of the Barasona reservoir (Spain) and then used for Ésera river SY modelling, providing mean annual erosion and SY.

All these studies calculated interannual soil erosion rates, or SY, averaged over several years. With the above-mentioned models it is not possible to determine the temporal dynamics of the soil erosion and sediment transport at a smaller temporal scale, such as, for example the daily scale. Some attempt to calibrate and validate daily models with reservoir sedimentation volumes was also carried out in the last years. For example, Raclot and Albergel [2006] applied the WEEP model to a catchment in Tunisia, and calibrated it by using siltation volumes of a small reservoir. Nevertheless, their results were disappointing concerning reproduction of the sediment transport.

Not only large reservoir deposits such as the Spanish data set mentioned above [Avendaño Salas et al., 1997] can be used for model calibration and validation, but also smaller reservoirs, for example the ones formed by check dams, water supply ponds, irrigation ponds, etc. Verstraeten and Poesen [2000] quantify the number of these structures in a few million dams, distributed all over the world, defining small ponds as retention structure with a storage capacity between 50 and $5 \times 10^{6} \mathrm{~m}^{3}$.

In Spain many small check dams were built during the last 50 years. Their scopes were:

- $\quad$ to reduce soil loss;

- $\quad$ to retain sediments;

- to laminate floods;

- $\quad$ to correct the channel slope.

They are usually called "diques de corrección hidrológica" [Romero-Díaz, 2008; Romero-Díaz et al., 2011], or "diques de retención de sedimentos" [Martínez-Lloris et al., 2001], if its principal function is to retain sediments, such as in Castillo et al. [2007]. 
The large number of small dams in the world has a high potential for SY assessment and modelling [Romero-Díaz, 2008], due to the high availability of small reservoir and to the high spatial coverage, at least in Mediterranean catchments. Verstraeten and Poesen [2000] calculated the error on SY estimation in 21 Belgian catchments in different ways, including with small ponds reservoirs. In that study, the authors calculated the error on SY estimation for 21 catchments located in central Belgium using small reservoir deposits and concluded that this is a suitable methodology for medium-sized catchments $\left(10^{1}-10^{4} \mathrm{~km}^{2}\right)$ and for mid-term SY estimations $\left(10^{0}-10^{2}\right.$ years). Nevertheless, errors on topographical surveys, $\mathrm{dBD}$ and TE must be taken into account, although the mean accuracy is comparable with other methodology for SY estimation such as sediment rating curves or suspended sediment sampling.

Some examples of SY studies based on sedimentation deposits in small reservoirs are McManus and Duck [1985], Van den Wall Blake [1986], Neil and Mazari [1993], Foster and Walling [1994], White et al. [1996], and, more recently, Romero-Díaz et al. [2007], BoixFayos et al. [2008], Sougnez et al. [2011] and Bellin et al. [2011].

All the above-mentioned works emphasize the fact that, in order to estimate the SY at the reservoir inlet section, it is necessary to calculate first the dBD of the deposit and the percentage of total sediment that settled into the reservoir, i.e. the TE. In the next two chapters these two concepts are explained.

\subsubsection{Dry bulk density}

In order to convert a sediment mass from weight to volume, the specific dry weight of the particle mix is needed, i.e. the dry bulk density (dBD). The dBD is the soild mass per unit of volume, including the voids [Julien, 2010]. The $\mathrm{dBD}$ and the deposit volume change in time due to consolidation phenomena [Avendaño Salas and Cobo Rayán, 1997], although the deposit weight does not vary.

For coarse materials $(<0.1 \mathrm{~mm})$, the $\mathrm{dBD}$ value does not vary significantly in time. Its value is around $1.475 \mathrm{t} \mathrm{m}^{-3}$ with a porosity of 0.43 [Julien, 2010]. If the sediment texture is finer, the dBD can change in time. Butcher et al. [1993], for example, studied the sedimentation rates of 28 small reservoirs in the UK and found density values from 0.198 to $0.96 \mathrm{t} \mathrm{m}^{-3}$. Therefore, it is fundamental to know the dBD of a reservoir deposit in order to calculate the SY. DBD can be estimated the following ways [Verstraeten and Poesen, 2001b]:

- $\quad$ Taking undisturbed samples;

- Using gamma probes (e.g. Rausch and Heinemann [1984]);

- Using established empirical equations based on reservoir data.

Although the first option is quite easy to implement, the third option is the most used, especially for large reservoir in which is very difficult to take an undisturbed sample from the reservoir bottom. The dBD estimation equations take into account several factors [Avendaño Salas and Cobo Rayán, 1997]:

- $\quad$ the particle size (texture);

- the operational functioning of the reservoir; 
- $\quad$ the age of the deposits, i.e. the consolidation degree.

For example, Wu and Wang [2006] found the equation (2.3), depending on texture (Figure 2.4):

$\rho_{m d \cong 1600+300 \log d_{50}}$

$\rho_{m d}=$ deposit specific weight $\left(\mathrm{kg} \mathrm{m}^{-3}\right)$

$d_{50}=50^{\text {th }}$ percentile of the deposit grain distribution $(\mathrm{mm})$

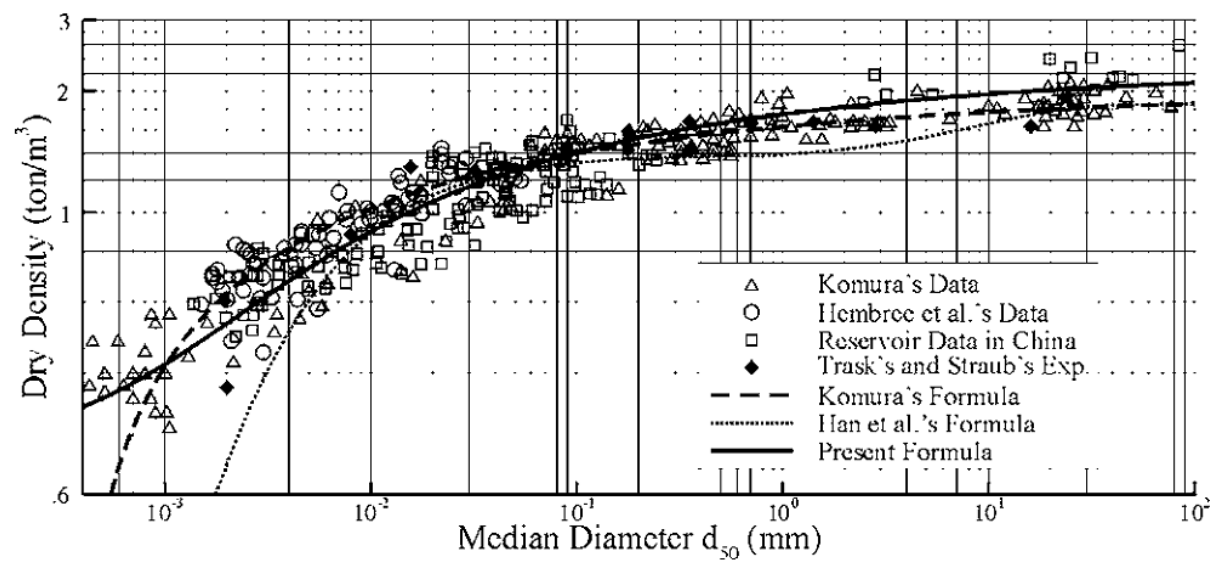

Figure 2.4 - $d B D$ vs particles median diameter (taken from Wu and Wang).

Another factor affecting the deposit density is the pressure due to consolidation, which can be supposed as logarithmic:

$d B D_{T}=d B D_{1}+K \log T$

$T=$ age of the deposit $(y)$

$d B D_{T}=$ dry bulk density after $T$ years $\left(\mathrm{t} \mathrm{m}^{-}{ }^{3}\right)$

$d B D_{1}=$ initial dry bulk density $\left(\mathrm{t} \mathrm{m}^{-}{ }^{3}\right)$

$K=$ consolidation factor $\left(\mathrm{t} \mathrm{m}^{3}\right)$

Following Miller [1953], consolidation follows this equation:

$d B D_{T}=d B D_{1}+0.43 K \log \left(\frac{T \ln T}{T-1}-1\right)$

$K$ and $d B D_{1}$ values can be calculated as follows, using (2.6) and (2.7) and knowing the texture of the deposit: 


$$
\begin{aligned}
& d B D_{1}=\frac{d B D_{1_{\text {sand }}} \% \text { sand }+d B D_{1_{\text {silt }} \% \text { silt }}+K d B D_{1_{\text {clay }} \% \text { clay }}}{100} \\
& K=\frac{K_{\text {sand }} \% \text { sand }+K_{\text {silt }} \% \text { silt }+K_{\text {clay }} \% \text { clay }}{100}
\end{aligned}
$$

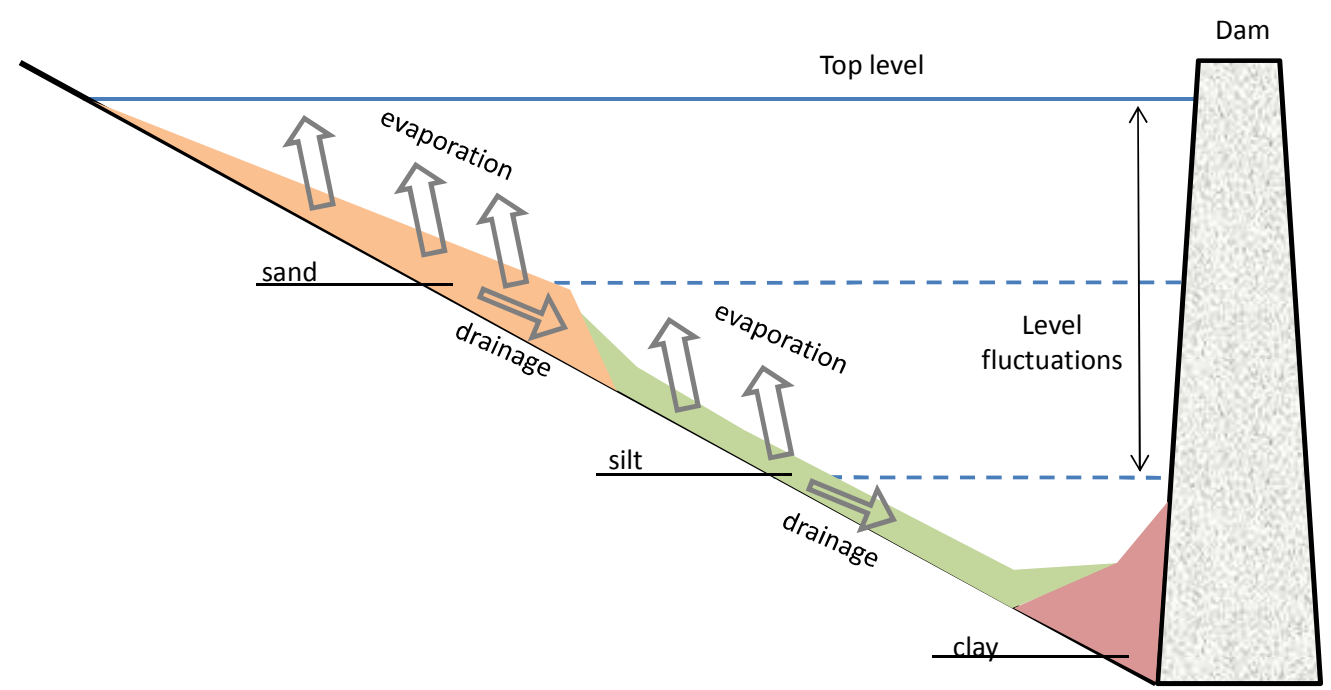

Figure 2.5 - Simplified distribution of the reservoir bottom sediments (modified from Avendaño Salas and Cobo Rayán, 1997).

The values of $K$ and $d B D_{1}$ depend on the deposit texture and on the emptying/filling cycle frequency, i.e. on the reservoir operational regime. This last factor is fundamental, and probably the most relevant [Avendaño Salas and Cobo Rayán, 1997]. This is because, if the reservoir level is lower than the top level, part of the reservoir deposit will be in contact with the atmosphere. In this case, evaporation and drying processes increase the density of the sediments (Figure 2.5).

Some authors measured or estimated all Miller formula coefficients [Lane and Koelzer, 1943; Koelzer and Lara, 1958; Komura, 1963; Lara ad Pemberton, 1963]. Two examples can be seen in Table 2.3 and Table 2.4 .

It can be noticed that coarse sediments do not vary its density in time (no consolidation). The same happens if the sediments are always dry, regardless of their texture.

More recent studies, e.g. Verstraeten ad Poesen, [2001b], confirmed the high variability of the $\mathrm{dBD}$ depending on the deposit texture and the hydrological conditions of the reservoir. 


\begin{tabular}{|c|c|c|c|c|c|c|}
\hline \multirow{2}{*}{ Reservoir operation } & \multicolumn{2}{|c|}{ Sand } & \multicolumn{2}{|c|}{ Silt } & \multicolumn{2}{|c|}{ Clay } \\
\hline & $d B D_{1}$ & $\kappa$ & $d B D_{1}$ & $\kappa$ & $d B D_{1}$ & $\kappa$ \\
\hline $\begin{array}{l}\text { Sediment always } \\
\text { submerged or nearly } \\
\text { submerged }\end{array}$ & 1.490 & 0 & 1.041 & 0.091 & 0.481 & 0.256 \\
\hline $\begin{array}{l}\text { Normally a moderate } \\
\text { reservoir drawdown }\end{array}$ & 1.490 & 0 & 1.185 & 0.043 & 0.737 & 0.171 \\
\hline $\begin{array}{l}\text { Normally considerable } \\
\text { reservoir drawdown }\end{array}$ & 1.490 & 0 & 1.266 & 0.016 & 0.961 & 0.096 \\
\hline \multirow{2}{*}{ Reservoir normally empty } & 1.490 & 0 & 1.314 & 0 & 1.245 & 0 \\
\hline & \multicolumn{6}{|c|}{ Table 2.3 - $\mathrm{dBD}_{1}$ and $\mathrm{K}$ values following Lane and Koelzer (1943). } \\
\hline \multirow{2}{*}{ Reservoir operation } & \multicolumn{2}{|c|}{ Sand } & \multicolumn{2}{|c|}{ Silt } & \multicolumn{2}{|c|}{ Clay } \\
\hline & $d B D_{1}$ & $K$ & $d B D_{1}$ & $\kappa$ & $d B D_{1}$ & $K$ \\
\hline $\begin{array}{l}\text { Sediment always } \\
\text { submerged or nearly } \\
\text { submerged }\end{array}$ & 1.150 & 0 & 1.120 & 0.091 & 0.416 & 0.256 \\
\hline $\begin{array}{l}\text { Normally a moderate } \\
\text { reservoir drawdown }\end{array}$ & 1.150 & 0 & 1.140 & 0.029 & 0.561 & 0.135 \\
\hline $\begin{array}{l}\text { Normally considerable } \\
\text { reservoir drawdown }\end{array}$ & 1.150 & 0 & 1.150 & 0 & 0.641 & 0 \\
\hline Reservoir normally empty & 1.550 & - & 1.170 & - & 0.961 & - \\
\hline
\end{tabular}

Table 2.4- $\mathrm{dBD}_{1}$ and $\mathrm{K}$ values following Lara and Pemberton (1963).

\subsubsection{Trap efficiency}

All the studies on SY estimations from reservoir sedimentation emphasize the fact that, in order to estimate the SY at the reservoir inlet section, it is necessary to calculate first the percentage of total sediment that settled into the reservoir, i.e. the TE.

The TE is the proportion between the solid load deposited at the bottom of the reservoir and the total SY entering the reservoir [Heinemann, 1984; Verstraeten and Poesen, 2000]:

$T E \%=\frac{S_{\text {in }}-S_{\text {out }}}{S_{\text {in }}} \times 100=\frac{S_{\text {dep }}}{S_{\text {in }}} \times 100$

$S_{\text {in }}=$ incoming sediments $\left(\mathrm{m}^{3}\right)$

$S_{\text {out }}=$ outgoing sediments $\left(\mathrm{m}^{3}\right)$

$S_{\text {dep }}=$ deposited sediments $\left(\mathrm{m}^{3}\right)$

The reservoir TE depends on several factors, which can be resumed in two categories:

- $\quad$ particle settling velocity;

- retention time inside the reservoir. 
The settling velocity mainly depends on the particle characteristics, such as its texture and structure. The retention time depends on the inflow characteristics (flood volume, peak discharge, base flow, etc.) and the reservoir characteristics (operational rules, surface, height/volume curve, reservoir shape, kind and shape of the bottom outlet, localization of the bottom outlet, initial storage, etc.).

The TE can be measured through sediment reservoir inlet and outlet records and/or bathymetries. Bathymetries are commonly carried out for large reservoir. In Spain, up to now, a bathymetric survey was carried out every 10 - 20 years in average for large reservoirs. Sediment inlet and outlet gauging is quite infrequent, and continuous records are very rare.

If no measurement is available, the TE can be estimated by empirical methods. These methodologies usually relate the TE with some reservoir characteristics (such as the storage capacity) and some flow characteristics (e.g. the total accumulated volume in a time period). For example, Brown [1943] developed a curve which provides TE depending on the ration of the reservoir storage capacity and the drainage area, as showed in Figure 2.6.

Nevertheless, this curve does not take into account the catchment hydrological regime, which is very important for TE estimation. Churchill [1948] took into account more variables, such as the retention time and the flow velocity. He developed a sedimentation index which represents the ratio between the retention time and the mean velocity. Churchill curve is shown in Figure 2.7.

This curve obtained satisfactory results for reservoirs with good data availability, but its application is problematic in scarce data areas.

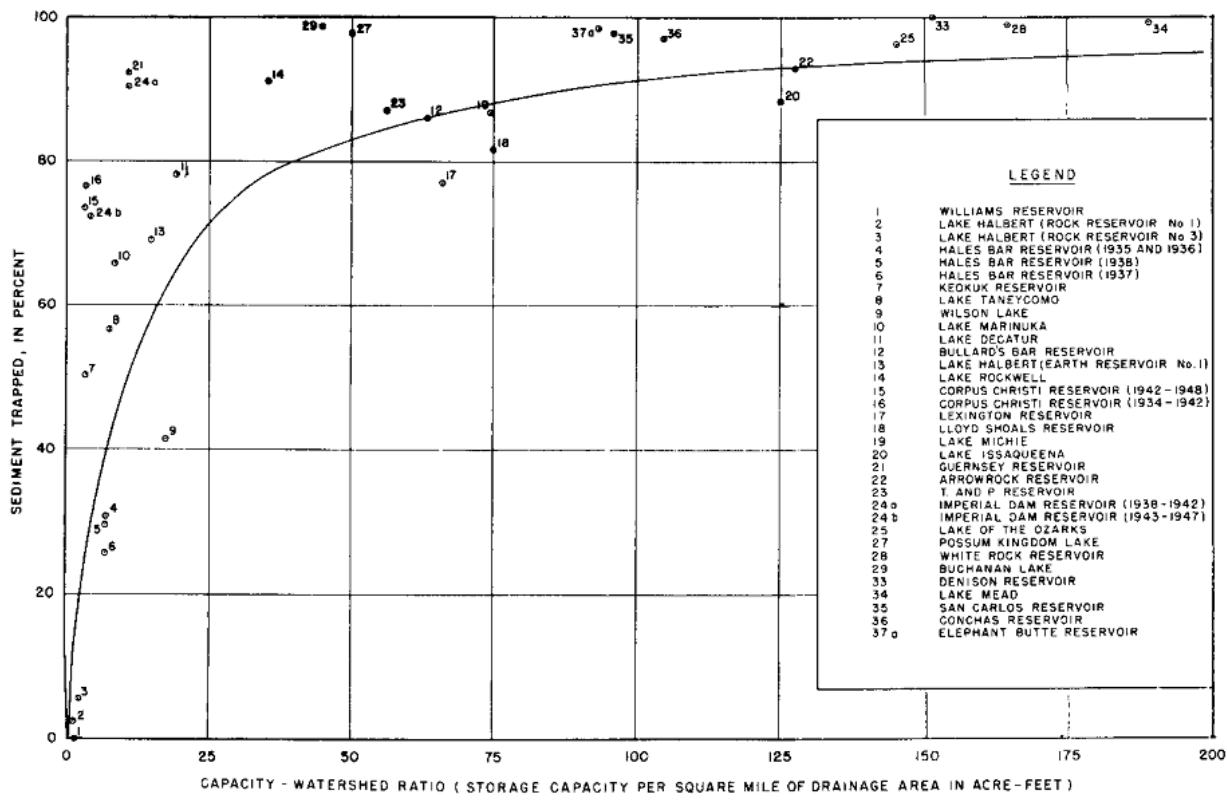

Figure 2.6-Brown curve. 


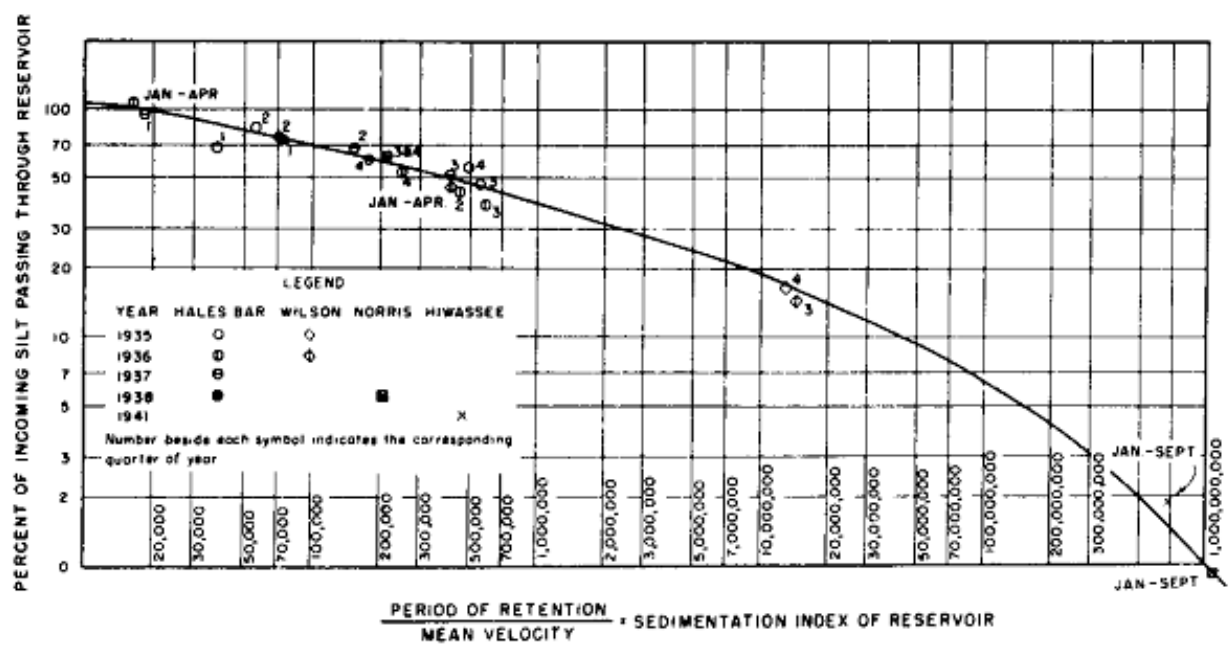

Figure 2.7 - Churchill curve (1948).

One of the most used methodology for TE computation in literature (used during the last 60 years, and still very frequently employed) is the Brune methodology [Brune, 1953], which consists in three curves (Figure 2.8). These curves relate the TE with the ratio between the reservoir storage capacity and the mean annual inflow. This methodology was developed by measurements made on 41 reservoirs located in the United States, with different shapes and dimensions. The curves are shown in the Figure 2.8

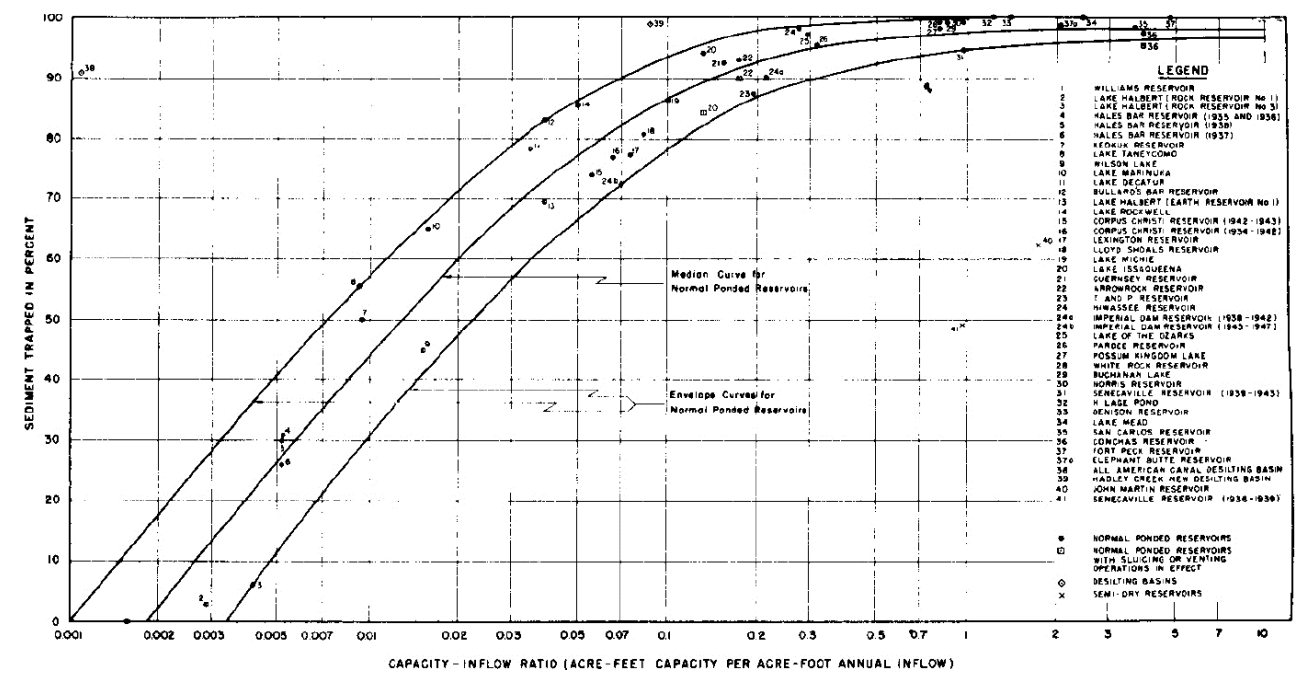

Figure 2.8 - Brune curve (1953).

It can be noticed that three curves exist. They were defined by Brune as the median, the maximum and the minimum envelope. The difference between the three curves is due to the point dispersion in the plot (every points indicates a reservoir). Similar envelope curves 
could be drawn for the other graphs shown above (Churchill and Brown curves), although they were not shown in the original journal articles.

The dispersion was interpreted by the USDA-SCS (United States Department of Agriculture Soil Conservation Service) in 1983 as due to the sediment texture. The USDA-SCS suggested that the superior envelope should be used for coarse sediments while the lower envelope for fine sediments [Maidment, 1993].

The TE of a reservoir changes through the time, given that the reservoir storage capacity also changes. This variation is described by the Brune curves as a modification of the capacity/inflow ratio. If the reservoir storage capacity decreases, the TE also decreases, and vice versa.

During the last 30 years, with the aim of analysing more in detail the sediment redistribution dynamics into a reservoir, many mathematical models were developed for reservoir sediment deposition modelling. These models also take into account, for example, sediment texture, the spillway and outlet shape or the flood event characteristics. A complete review of the reservoir sedimentation modelling state of the art can be found in Verstraeten and Poesen [2000]. This review especially focused on small retention ponds or small and medium reservoirs, given that large reservoir TE is usually very close to $100 \%$. On the other hand, the TE estimation uncertainty for small reservoir increases considerably.

Some examples of these models are:

- $\quad$ DEPOSITS [Ward et al., 1977];

- $\quad$ CSTRS [Wilson and Barfield, 1984];

- $\quad$ BASIN [Wilson and Barfield, 1985] .

These three models are event scale models, and were designed for reservoir design and verification. For this reason, they are not able to provide a mean TE value on the mid- or long-term. Other models can be better adapted to the mid-term or long-term TE estimation, such as:

- WEPPSIE [Lindley et al., 1988], based on the sediment cycle model WEPP;

- $\quad$ STEP [Verstraeten and Poesen, 2001a].

The STEP model (Sediment Trap Efficiency for small Ponds) is described more in detail in the model description chapter.

\subsubsection{Palaeohydrological techniques}

Reservoir sedimentation rates are a very helpful tool for estimating catchment SY, but indeed this methodology has some weaknesses:

- the quality of the reservoir storage capacity estimation is sometimes questionable, especially for the first estimate (empty reservoir);

- the calculated SY is averaged over a large time;

- the total deposit volume do not give information about temporal patterns and variability. 
The development of techniques for dating reservoir deposits is therefore fundamental in order to overcome these disadvantages [Foster, 2006].

For example, laminated sediments provide very useful information for dating sediment layers. Other methodologies, such as the ones based on radionuclide measurement, can facilitate sediment dating but do not permit reaching the same level of precision. In the case of large reservoirs and artificial lakes, sediment coring and paleolimnological techniques, including geochronological dating ( $\mathrm{Cs}-137, \mathrm{~Pb}-210)$, have been used for temporal characterisation of sediment rates, as in the artificial Lake Matahina in New Zeland [Phillips and Nelson, 1981] or in the Brno reservoir in CzechRepublic [Nehyba et al., 2011].

The word "palaeohydrology" came out for the first time in Leopold and Miller [1954]. They referred to the study of the interactions between climate, vegetation and runoff in the past, by analysing fluvial chronologies. Since the $80 \mathrm{~s}$, this discipline is gaining importance and increasing its interdisciplinarity, proposing collaboration between experts from other scientific fields, probably due to the improving interest on climate change.

One of the sub-fields of the palaeohydrology is the study of laminated sediments contained into slackwater deposits (SWDs - Baker [1987]). The slackwater deposits are coarse sediment accumulations transported by the flow as suspended sediments during a flood and deposited in a low energy flow zone [Baker, 1983], such as a reservoir (Figure 2.9).

In a slackwater deposit, different layers represent the sediment deposition of different flood. The separation is represented by a break in the depositional structure of the slackwater deposit (roots, evidence of air exposure, cracks, etc.). The detailed analysis of their alluvial stratigraphy may provide quantitative information for specific events, such as the number of events, timing, and deposited volume(s) of an individual flood or floods. Similar techniques have been used in the reconstruction of the magnitude and frequency of past floods using geological evidence [Baker, 2008; Kochel and Baker, 1982], being southeastern Spain one of the most studied areas (the most recent examples are Benito et al. [2003b], Thorndycraft et al. [2005], Thorndycraft and Benito [2006], Benito et al. [2008], Benito et al. [2010] and Machado et al. [2011]).

In Mediterranean ephemeral streams a large number of check dams were built to prevent or reduce sediment inputs into perennial streams during the first winter or rainy season following a wildfire [Boix-Fayos et al., 2008]. In these check dams, infill deposits record pulses of sediments produced during discrete flood events. The coarse texture of the flood deposited material prevents coring but allows the use of fluvial palaeohydrological techniques. 

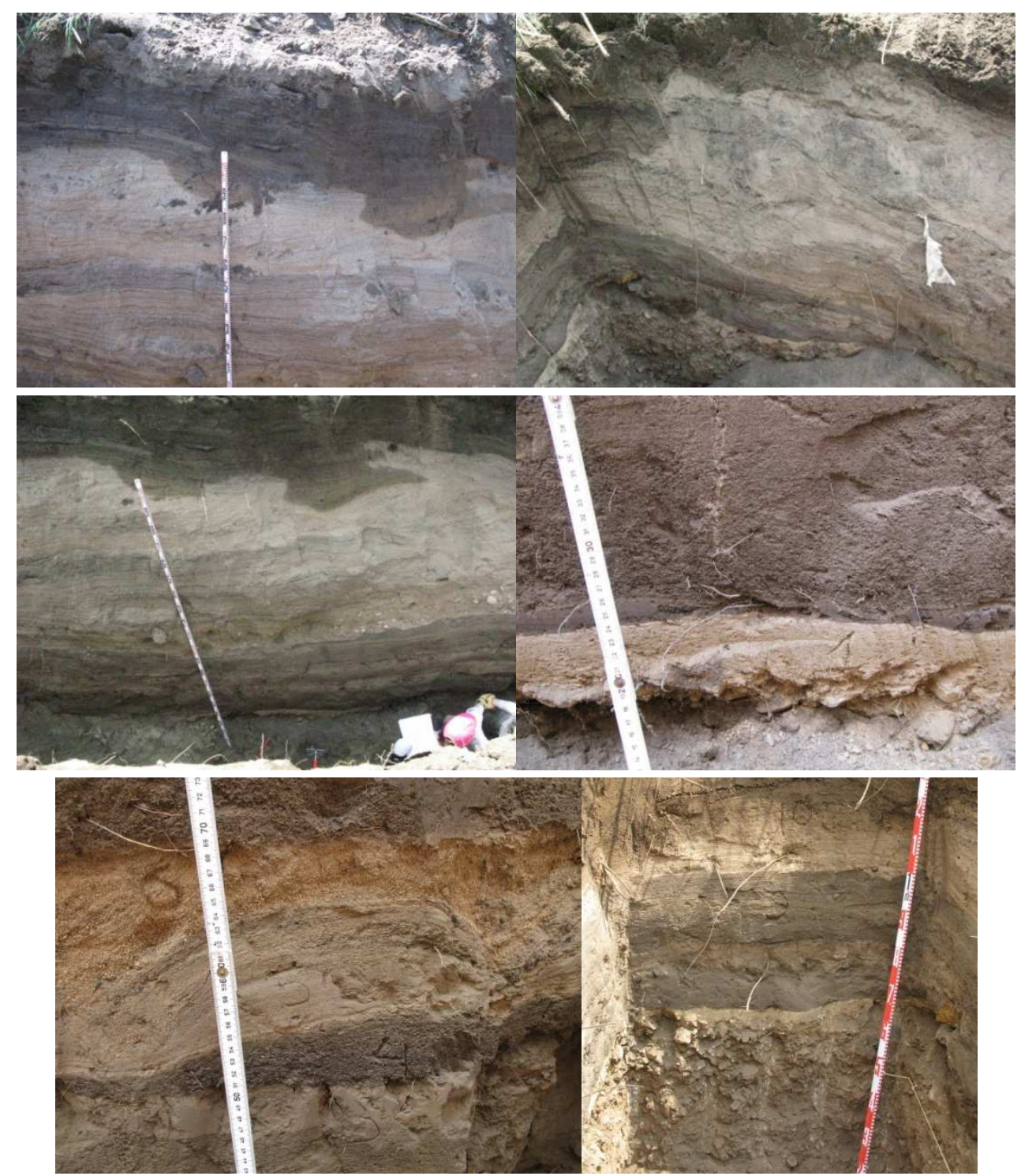

Figure 2.9-Laminated deposit behind a small check dam. 

The TETIS model is a mathematical model which represents the catchment as a regular mesh of square cells. All cells are interconnected among them by the topography, derived by a Digital Elevation Model (DEM). The model incorporates the spatial variability of the hydrological and sediment cycle. Its conceptual basis lies on the actual state of the art and follows the parsimony principle (given similar model behaviours, the simplest one in terms of parameterization is always chosen).

The TETIS model includes two principal components: the hydrological sub-model and the sedimentological sub-model. Given that the sedimentological cycle is subordinate to the hydrological cycle, the hydrological sub-model is first introduced, followed by the sedimentological sub-model.

\subsection{Hydrological sub-model}

\subsubsection{Model formulation}

The TETIS model is a distributed conceptual hydrological model, developed for continuous simulation of the hydrological cycle. The model has been satisfactorily applied to a wide range of climates (from semi-arid to humid), different spatial resolutions (square cells from $30 \times 30$ to $500 \times 500 \mathrm{~m}$ ) and different catchment areas (from less than $1 \mathrm{~km}^{2}$ up to 60,000 $\mathrm{km}^{2}$ ). Many examples of its application are present in literature [Vélez et al., 1999, 2009; Francés et al., 2002, 2007; Morales de la Cruz and Francés, 2008; Guichard-Romero et al., 2009; Andrés-Doménech et al., 2010; Cowpertwait et al., 2013; Salazar et al., 2013].

In the TETIS model, the runoff production is reproduced through simple conceptual schemes adapted to the cell scale. The runoff production is based on the water balance in each cell, assuming that water is distributed on six levels, or conceptual storage tanks, as showed in the Figure 3.1. The vertical conceptualization scheme in every cell is based on the description of the interactions between the atmosphere, the vegetation, the soil and the aquifer through six conceptual tanks (Figure 3.1). Every tank represents a process related with the hydrological cycle (snow melting, vegetation interception, soil capillary retention, surface runoff, subsurface runoff and aquifer dynamics), although, if one of these processes should be negligible, the flexibility of the model structure allows to simplify the model by reducing the number of tanks.

The flow between tanks is a function of the water storage of each tank, and the state variables are represented by tank levels. The relationship between the flow and the storage depends on the conceptual scheme adopted to describe every process, and on the morphological and pedological characteristics of the cell soil. 


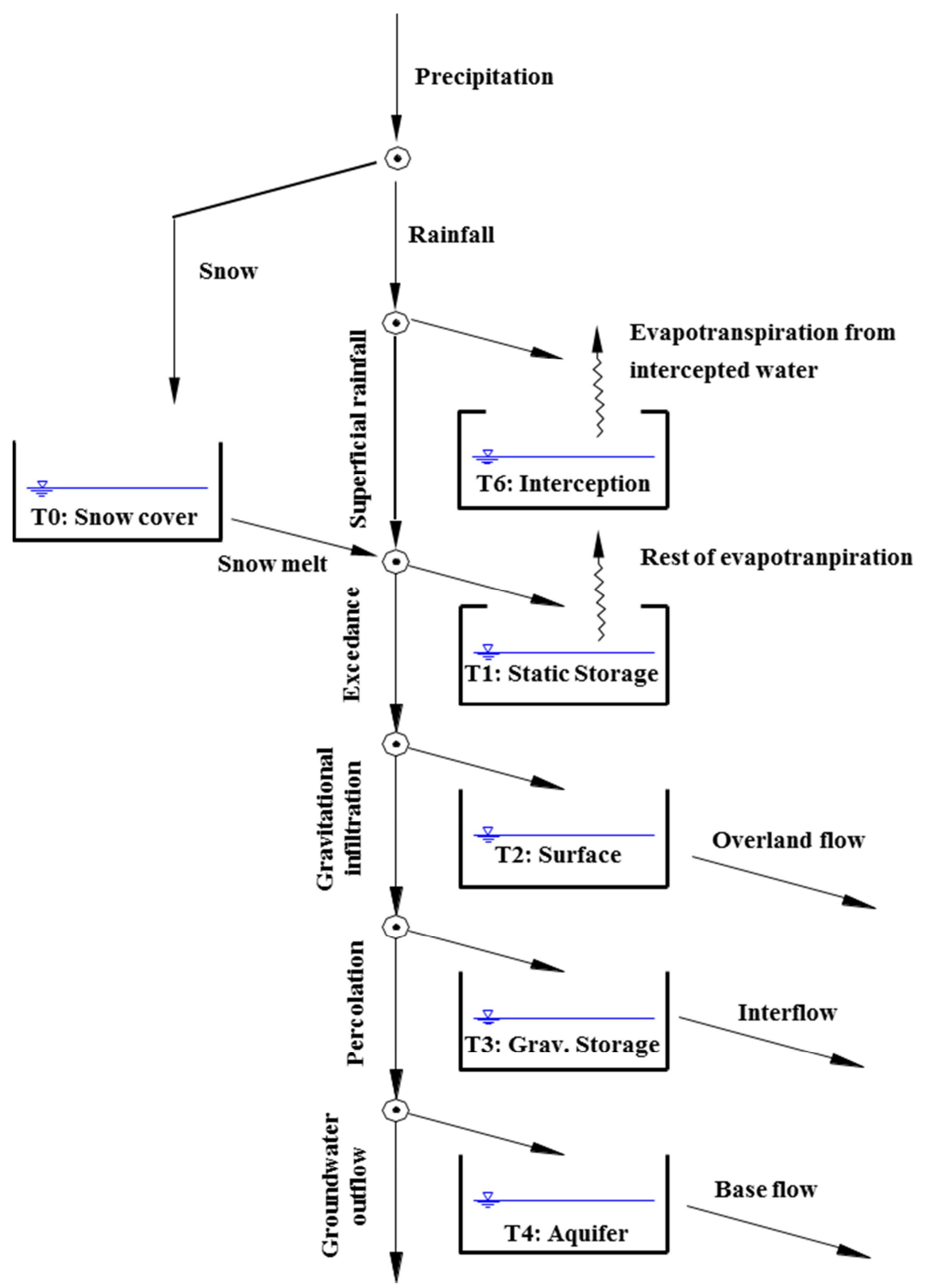

Figure 3.1 - Conceptual scheme of the TETIS hydrological sub-model at one cell.

The first tank (T1) corresponds to the sum of the soil capillary retention and surface and vegetation interception and it is called static storage; its only exit is evapotranspiration. The second tank (T2) reproduces the surface water, i.e. the part of precipitation which generates overland flow. The third tank (T3) corresponds to the gravitational storage of the upper soil; it generates the interflow. The fourth tank (T4) corresponds to the aquifer, which produces base flow. The percolation process is modelled according to both soil saturation 
conditions and vertical hydraulic conductivity, and the remaining water in $T 3$ is available to feed the interflow. The relationships between tanks, representing the different hydrological processes, are described by simple linear reservoirs and flow threshold schemes.

Following, a brief description of the most relevant processes is provided. The letter $X$ represents the internal fluxes (i.e. the vertical flows between tanks), the letter $Y$ the outflows (i.e. evapotranspiration runoff, interflow and base flow), the letter $H$ the storages (i.e. the amount of water stored into tanks usually defined in $\mathrm{mm}$ ) and the letter $T$ just indicates the tank number.

\subsubsection{Static storage}

The first storage, called static tank $T 1$, represents water detention in ponds and retained water by capillary forces in the upper part of the soil (rooting zone). Therefore, this tank must have a maximum capacity denoted by $H_{u}$.

The maximum static storage $H_{u}$ is calculated as the sum of the maximum capillary storage and the superficial pond storage capacity. The maximum capillary storage is the available water between the wilting point and the soil field capacity, as shown in the equation (3.1).

$\mathrm{H}_{\mathrm{u}}=\frac{\rho_{b} p(F C-W P)}{\rho_{w} 100}+$ MaxPond

where:

$H_{u}$ is the maximum static storage $(\mathrm{mm})$;

$\rho_{b}$ is the dry soil bulk density $\left(\mathrm{gr} / \mathrm{cm}^{3}\right)$;

$\rho_{w}$ is the water density $\left(\mathrm{gr} / \mathrm{cm}^{3}\right)$;

$p$ is the soil depth $(\mathrm{mm})$;

$F C$ is the soil field capacity (\%);

$W P$ is the wilting point (\%).

MaxPond is the maximum water storage in the superficial ponds, or initial abstractions $(\mathrm{mm})$.

Given that some the required soil physical properties are not usually measured, the use of pedotransfer functions is needed, in order to estimate the soil hydrological properties depending on the soil texture, organic matter, salinity, etc.

The water from $T 1$ only comes out by evapotranspiration (Y1), without contributing to the runoff. According to the model, the precipitation plus the snow melting (X1) is derived (D1) to the static tank, until the maximum capacity is reached. In this case, the excess water is defined as: 


$$
X 2=\operatorname{Max}\left\{0, X 1-H_{U}+H 1\right\}
$$

$H 1$ is the tank 1 level. All the tank levels are denoted with the letter $H$.

The actual evapotranspiration $Y 1$ has been included in the model in a simple way, as a function of the available water, the reference evapotranspiration, ETO, and the vegetation cover index $\lambda$, which can be a function of time:

$Y 1=\operatorname{Min}\left\{E T 0 \times \lambda^{*}(t), H_{1}\right\}$

\subsubsection{Surface storage}

The second tank (T2) represents the water on the hillslope surface, which either can flows over the surface as direct runoff or can infiltrates. Therefore, this tank and its residence time must be coherent with the behaviour of the actual slopes along the basin. After ponding of the static tank, gravitational infiltration capacity can be approximated by the saturated soil hydraulic conductivity, $k_{s}$, and the gravitational infiltration (X3) will be:

$$
X 3=\operatorname{Min}\left\{X 2, \Delta t k_{s}\right\}
$$

$\Delta t$ is the time step.

The overland flow at each cell can be represented by a set of small canals. Assuming a constant velocity and applying the continuity equation, the direct runoff is given by a linear reservoir:

$Y 2=\alpha_{2} H 2$

where the discharge coefficient of the linear reservoir is computed from:

$\alpha_{2}=1-\frac{\Delta x}{v \Delta t+\Delta x}$

$v$ represents the hillslope velocity, which can be estimated from empirical relationships and $\Delta x$ is the cell side length.

\subsubsection{Gravitational storage}

The third tank level (T3) can be understood as gravitational storage in the upper part of the soil, between field capacity and saturation. The outflows of this tank are deep percolation (X4) and hill slope interflow (Y3). The percolation capacity $k_{p}$ can be estimated from the saturated hydraulic conductivity of deep soil or base rock. In order to estimate the interflow (Y3) and following the analogous formulation presented for the surface tank (T2), a linear reservoir is assumed, where in this case: 
$\alpha_{3}=1-\frac{\Delta x}{k_{s s} \Delta \mathrm{t}+\Delta \mathrm{x}}$

where $k_{s s}$ represents the horizontal hydraulic conductivity of the soil, defined by its macropore structure. The interflow is given by a linear reservoir:

$Y 3=\alpha_{3} H 3$

\subsubsection{Aquifer storage}

The fourth level (T4) represents saturated storage, where outflows correspond to underground losses (X5) and base flow (Y4). The underground losses are expressed as a function of a maximum capacity $k_{p s}$. Base flow is usually approached in the literature with a linear reservoir, with a discharge coefficient which can be related with the aquifer saturated hydraulic conductivity with the expression:

$\alpha_{4}=1-\frac{\Delta x}{k_{p} \Delta \mathrm{t}+\Delta \mathrm{x}}$

where $k_{p}$ represents the horizontal hydraulic conductivity of the aquifer. The base flow is given by a linear reservoir:

$Y 4=\alpha_{4} H 4$

\subsubsection{Horizontal conceptualization}

The horizontal structure of the TETIS hydrological sub-model is represented by a 3D mesh (in Figure 3.2 a 2D simplification is showed).

The last tank (T5) corresponds to gully or river channel storage, representing the stream network of the catchment, which is not necessarily present in all cells. The gully and river channel starting cells are defined by two drainage area thresholds. Every cell receives inflows from upstream and drains downstream following a 3D scheme generated from a Digital Elevation Model.

The three lower tanks (T2, T3 and T4) drain towards the corresponding downstream cell; once both flows reach a cell whose drainage area is greater than the threshold drainage area corresponding to gullies, flows exiting from T2 and T3 move into T5 tank. In the same way, base flow (Y4) is routed to T4 of downstream cell until it reaches a second threshold drainage area (for river channels), and then it moves into T5. Table 3.1, Table 3.2 and Table 3.3 illustrate this concept. 


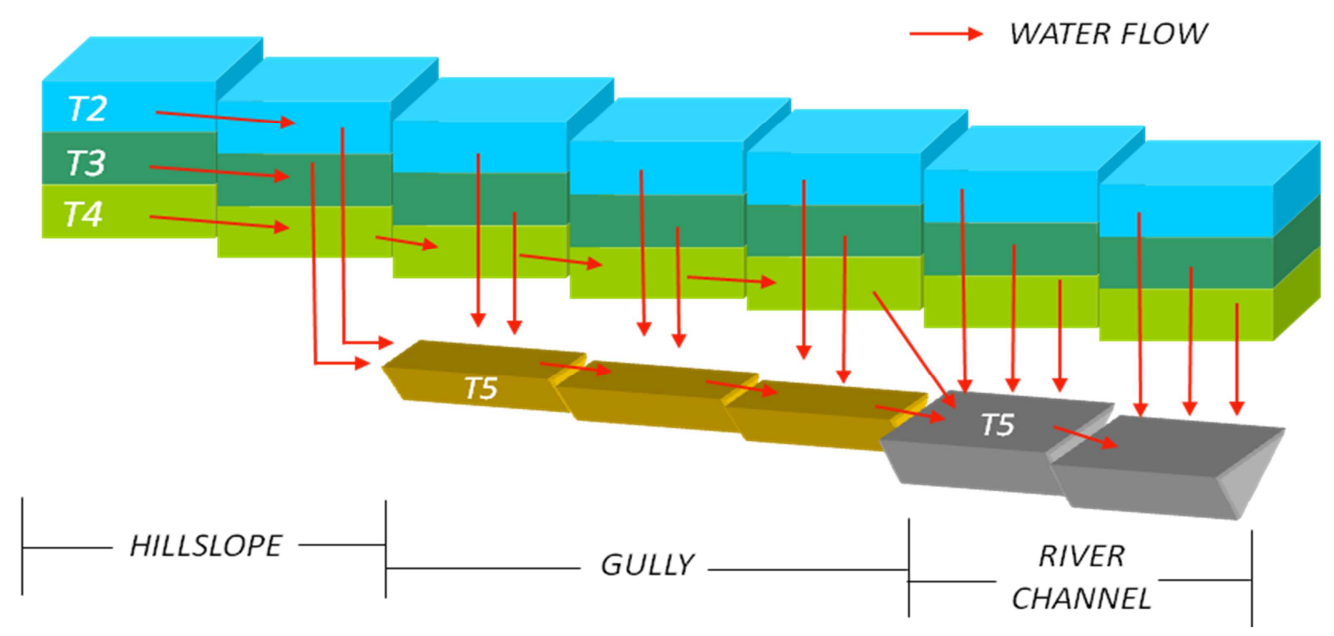

Figure 3.2 - Horizontal water movement in TETIS (2-dimensional simplification).

\begin{tabular}{|c|c|c|c|}
\hline TANK 2 & & & \\
\hline Origin cell $\rightarrow$ & \multirow{2}{*}{ HILLSLOPE } & \multirow{2}{*}{ GULLY } & \multirow{2}{*}{ CHANNEL } \\
\hline Receiving cell $\downarrow$ & & & \\
\hline HILLSLOPE & Tank 2 & - & - \\
\hline GULLY & Tank 5 & Tank 5 & - \\
\hline CHANNEL & Tank 5 & Tank 5 & Tank 5 \\
\hline
\end{tabular}

Table 3.1 - Outflow from T2, depending on the origin and receiving cells.

\begin{tabular}{|c|c|c|c|}
\hline TANK 3 & & & \\
\hline Origin cell $\rightarrow$ & \multirow{2}{*}{ HILLSLOPE } & \multirow{2}{*}{ GULLY } & \multirow{2}{*}{ CHANNEL } \\
\hline Receiving cell $\downarrow$ & & & \\
\hline HILLSLOPE & Tank 3 & - & - \\
\hline GULLY & Tank 5 & Tank 5 & - \\
\hline CHANNEL & Tank 5 & Tank 5 & Tank 5 \\
\hline
\end{tabular}

Table 3.2 - Outflow from T3, depending on the origin and receiving cells.

\begin{tabular}{|c|c|c|c|}
\hline TANK 4 & & & \\
\hline Origin cell $\rightarrow$ & \multirow{2}{*}{ HILLSLOPE } & \multirow{2}{*}{ GULLY } & \multirow{2}{*}{ CHANNEL } \\
\hline Receiving cell $\downarrow$ & & & \\
\hline HILLSLOPE & Tank 4 & - & - \\
\hline GULLY & Tank 4 & Tank 4 & - \\
\hline CHANNEL & Tank 5 & Tank 5 & Tank 5 \\
\hline
\end{tabular}

Table 3.3 - Outflow from T4, depending on the origin and receiving cells. 
Therefore, this pair of threshold drainage areas divides the catchment in three classes of cells: pure hillslope cells (without T5 tank), gully cells (with T5 tank and no connection between aquifer and gully) and river channel cells (with the T5 tank and connection between aquifer and channel). These threshold areas can be defined by field observation and orthophotograph analysis.

\subsubsection{Runoff propagation}

Flow routing along the stream channel network was carried out using the Geomorphologic Kinematic Wave methodology. This methodology estimates river channel cross sections and roughness assuming regional geomorphologic power laws [Vélez, 2001]. The shape of the channel section in each cell forming the drainage network can be obtained by hydraulic geometry relationships developed by Leopold and Maddock [1953]. These relationships associate the flow cross section dimensions (depth, width and velocity) with exponential equations.

These are the equations:

Drainage area $\Lambda$ and bankful discharge $Q_{b}$ :

$\Lambda=Q_{\mathrm{b}}^{\varphi}$

Cross section width at bankful discharge $W_{b}$ and bankful discharge $Q_{b}$ :

$\mathrm{W}_{\mathrm{b}}=\mathrm{a}_{1} \mathrm{Q}_{\mathrm{b}}^{\alpha_{1}}$

Cross section width $W$ and corresponding discharge $Q$ :

$\mathrm{W}=\mathrm{Q}^{\alpha_{2}}$

Sediment diameter $d$, slope $S$ and flow depth $h$ :

$\mathrm{d}=\mathrm{c}_{\mathrm{d}}(\mathrm{Sh})^{\vartheta}$

Roughness $n$ and sediment diameter $d$ :

$\mathrm{n}=\mathrm{c}_{\mathrm{n}} \mathrm{d}^{\xi}$

Coefficients and exponents of the hydraulic geometry relationships can be estimated using linear regression from a small number of cross section surveys. In the Table 3.4 the range of variation of the coefficients and exponents is showed.

\begin{tabular}{cc}
\hline Parameter & Range of variation \\
\hline$\kappa$ & $0.5-0.75$ \\
$\varphi$ & $0.65-0.8$ \\
$a_{\square}$ & $0.5-5.75$ \\
$\alpha_{1}$ & $0.34-0.55$
\end{tabular}




\begin{tabular}{cc}
\hline Parameter & Range of variation \\
\hline$\alpha_{2}$ & $0.05-0.2$ \\
$C_{d}$ & $0.5-50$ \\
$\theta$ & $0.5-2.75$ \\
$C_{n}$ & $0.025-0.07$ \\
$\xi$ & $0.125-0.18$ \\
\hline
\end{tabular}

Table 3.4 - Range of variation of the Leopold and Maddock coefficients and exponents (after F. Francés et al, 2007).

\subsubsection{Model parameters}

The parameters of a model describe the characteristics of the system to be modelled, depending on model structure and conceptualization. Given that TETIS is based on a regular mesh, it is necessary to characterize every cell with a parameter value.

The simplest approach is assuming that a measured value in a point lying inside the cell is representative of all the cells. From a hydrological point of view, a cell (which can vary between a few metres and a few kilometres) behaves in a different way as a point. For example, in the case of a hydraulic conductivity parameter, the laboratory measurements are carried out on a soil block of a few cubic centimetres. The measured value is usually not representative of the entire cell [Grayson and Blöschl, 2001].

Another possibility is to adjust the parameter in order to bring the simulation results closer to the observed values of the variable to be reproduced. This process is called parameter calibration. The parameter loses its physical meaning, and represents something like a mean cell value. This parameter is called effective parameter (Figure 3.3).

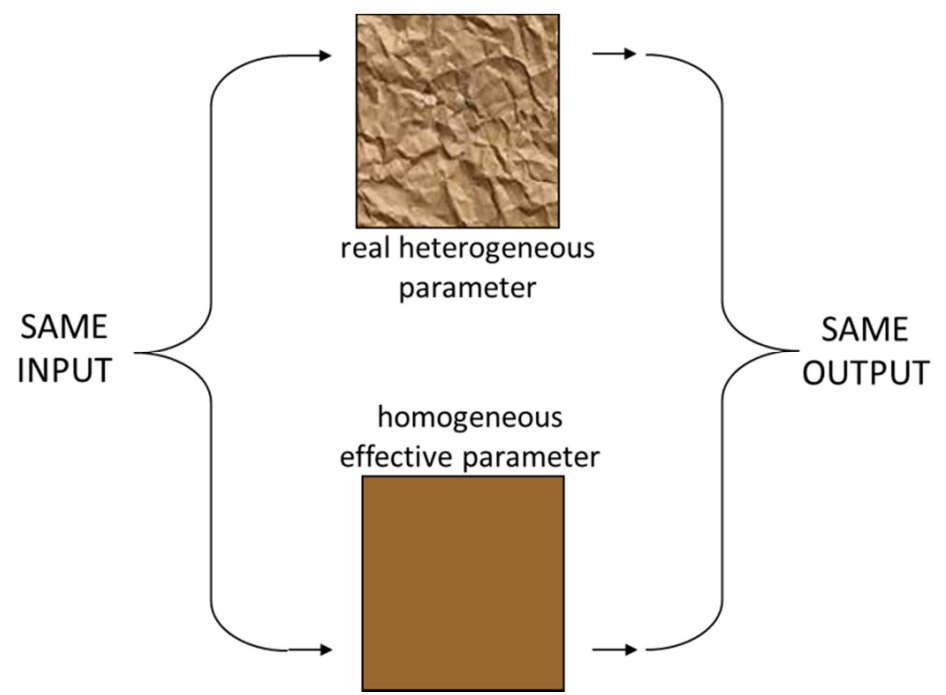

Figure 3.3 - Conceptual representation of the effective parameter (after Grayson and Blöschl [2001]) 
The effective parameter approach tries to overcome the conceptual problems associated with parameter point values. Effective parameters reproduce the behaviour of a finite area or volume. They cannot be measured directly, and they do not need to be related with point measurements. Parameter calibration is a process with allows to concentrate into the parameter values every possible error source, minimizing the residual errors following a cost function (or objective function). In hydrological modelling, the error sources usually are:

- Model conceptual errors;

- Input data errors;

- Parameter estimation errors and scale effects.

The TETIS hydrological sub-model uses a split parameter structure [Francés et al., 2007]. The parameter value in a cell is given by the product of:

- $\quad$ soil physical characteristics, estimated following the available information and the optimum scale (i.e. measured parameter value);

- correction factors.

Physical characteristics describe the field or laboratory value for each cell. They describe the spatial variability of the parameter and have physical meaning. Correction factors include all sources of error cited above. The assumption of spatial homogeneity of the correction factors along the catchment (or, at least, in homogeneous regions) is not proven, although this hypothesis is completely reasonable. At least, the scale effects are the same for all catchment cells, given that the cell size is the same for the whole catchment.

The following equation describes the effective parameter split structure:

$\theta_{i, j}^{*}=R_{i} \theta_{i, j}, \quad \mathrm{j}=1, \ldots, \mathrm{n} ; \quad \mathrm{i}=1, \ldots, \mathrm{p}$

where $\theta_{i, j}^{*}$ is the $i$-th effective parameter for the cell $j, R_{i}$ is the correction factor of the $i$-th parameter, common for all cells, $\theta_{i, j}$ is the estimated parameter for the $j$-th cell, $n$ is the cell number and $p$ is the parameter number per cell.

The principal advantage of this structure is that the number of variables to be adjusted during calibration is strongly reduced. Only up to $p$ correction factors need to be calibrated, instead of $n p$ parameters. This way, the TETIS hydrological sub-model can be calibrated adjusting only nine parameters, or correction factors (Table 3.5).

\begin{tabular}{clc}
\hline $\begin{array}{c}\text { Correction } \\
\text { factor }\left(\boldsymbol{R}_{\boldsymbol{i}}\right)\end{array}$ & Parameter name $\left(\theta_{i, j}^{*}\right)$ & Symbol \\
\hline CF1 & Maximum static storage & $H_{u}$ \\
CF2 & Vegetation index & $\lambda$ \\
CF3 & Infiltration capacity & $\kappa_{s}$ \\
CF4 & Hillslope runoff velocity & $u$ \\
CF5 & Percolation capacity & $K_{p}$
\end{tabular}




\begin{tabular}{clc}
\hline $\begin{array}{c}\text { Correction } \\
\text { factor }\left(\boldsymbol{R}_{\boldsymbol{i}}\right)\end{array}$ & Parameter name $\left(\theta_{i, j}^{*}\right)$ & Symbol \\
\hline CF6 & Interflow velocity & $k_{s s}$ \\
CF7 & Deep percolation capacity (losses) & $K_{p s}$ \\
CF8 & Base flow velocity & $K_{s a}$ \\
CF9 & Channel flow velocity & $v$ \\
\hline
\end{tabular}

Table 3.5 - Correction factors and corresponding parameters.

\subsubsection{The initial conditions}

In order to run a simulation, model state variables needs to be initialised. The TETIS hydrological sub-model requires the values of the following state variables as an input of a simulation:

- $\quad$ Equivalent water level in the snow tank $(\mathrm{HO})$;

- $\quad$ Actual static storage level (H1);

- $\quad$ Superficial storage level $(H 2)$

- Gravitational storage level $(H 3)$

- $\quad$ Aquifer storage level $(H 4)$

- Channel discharge (H5)

- Canopy interception storage level $(H 6)$

These values are different for each cell, i.e. the state variables are spatially distributed. A simple way to obtain an initial condition map is the warm up simulation. The warm up simulation consists in simulating a period preceding a rainfall event and getting a map of all state variable at the moment of the end of the simulation as a final state. This final state can be used as initial state for the simulation of the period of interest. The length of the warm up simulation depends on the hydrological behaviour of the catchment.

The static storage presents a maximum value, defined as the soil storage capacity between the wilting point and field capacity plus the superficial abstractions $\left(H_{u}\right)$. The same is done for the channel storage, defined as a percentage of the bankful discharge. The static storage level is defined as a percentage of $H_{u}$. The other state variables are represented as a cell specific volume $\left(\mathrm{m}^{3} / \mathrm{m}^{2}\right)$.

\subsection{Sedimentological sub-model}

The TETIS sedimentological sub-model [Montoya, 2008] is based on the model formulation developed for the CASC2D-SED model [Rojas, 2002]. The CASC2D-SED model is an event scale hydrological and sediment model which reproduces the hillslope processes in two dimensions, while the channel approach is mono-dimensional. In the TETIS adaptation, both processes are mono-dimensional. 
Once a particle has been eroded, it starts forming part of the flow, and it is transported downstream. A particle that passes in a channel control section have necessarily been eroded upstream and transported by the flow [Einstein, 1951].

Einstein [1964] also stated that these two conditions may limit the rate of sediment transport: (1) the transporting capacity of the stream; and (2) the material availability in the watershed. The amount of sediment transported in a stream therefore depends on two groups of variables [Julien, 1995]:

1) those governing sediment transport capacity of the flow (channel geometry, width, depth, shape, wetted perimeter, alignment, slope, vegetation, roughness, velocity distribution, tractive force, turbulence, and uniformity of discharge);

2) those reflecting the quality and quantity of material available for transport, including watershed topography, geology, magnitude-intensity-duration of rainfall and snowmelt, weathering, vegetation, cultivation, grazing and land use, soil type, particle size, shape, specific gravity, resistance to wear, settling velocity, mineralogy, cohesion, surface erosion, bank cutting, and sediment supply from tributaries.

This concept is illustrated in the Figure 3.4. The total sediment load is divided into the fine sediment fraction coming from upstream, also called washload, and the coarser grain sizes from the bed material load. Typically, finer material, which is easily carried in large amounts by the flow, has limited availability in the watershed (sediment supply curve, increasing with the grain size). The coarse material is much more difficult to move by the flow, so its rate of movement is limited by the transport capacity of the flow (transport capacity curve, decreasing with the grain size) [Rojas, 2002].

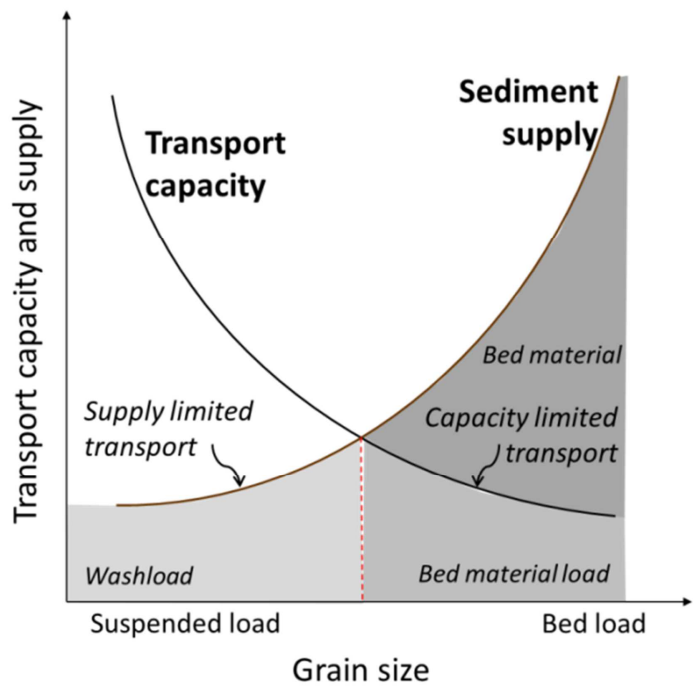

Figure 3.4 - Sediment availability and transport capacity curve (modified from Julien [1995]). 
Because the washload depends on sediment supply rather than transport capacity, it is impossible to determine the total sediment load from the sediment transport capacity based on flow characteristics alone (i.e. from one of the existing literature equations). In the TETIS model, sediment production, transport and deposition rates are controlled by these two characteristics, sediment availability and stream transport capacity (Figure 3.4).

The TETIS model separates the sediment particles into three categories, sand silt and clay, as done in Julien [1995] (Table 3.6).

\begin{tabular}{ccc}
\hline Class & Diameter $(\mathrm{mm})$ & Velocity $(\mathrm{mm} / \mathrm{s})$ \\
\hline Sand & 0.35 & 36 \\
Silt & 0.016 & 0.22 \\
Clay & 0.001 & 0.00086 \\
\hline Table 3.6-Mean grain size and mean settling velocity used in TETIS.
\end{tabular}

The critical training velocity depends on the particle size, being little for suspended clay and silt and high for sand and gravel [Rojas, 2002]. This is important for predicting the movement of differently sized particle. Erosion, transport and deposition model mechanisms were implemented bearing in mind this principle.

\subsubsection{Hillslope processes}

The TETIS sedimentological sub-model uses the Kilinc and Richardson equation for hillslope sediment production computing [Kilinc and Richardson, 1973]. This equation was modified by Julien [1995], and depends on the water discharge, the terrain slope, the soil type and the land use.

The TETIS model describes hillslope sediment erosion and transport processes by means of the Kilinc and Richardson equation, which depends on discharge and terrain slope. The sediment discharge per unit width is given by:

$q_{h}=\alpha S_{o}^{1.66}\left(\frac{Q}{W}\right)^{2.035} \quad\left[\right.$ tons $\mathrm{m}^{-1} \mathrm{~s}^{-1}$ ]

which is a function of the water discharge per unit width $\left(Q\left[\mathrm{~m}^{3} / \mathrm{s}\right]\right.$, cell overland discharge, divided by a representative width, $W[\mathrm{~m}]), S_{o}$ is the terrain slope $[\mathrm{m} / \mathrm{m}]$ and $\alpha$ a dimensional and empirical parameter (around 25,000 for sandy bare soil with the expressed units). This equation is consistent with many sediment transport equations, as it was demonstrated by Julien and Simons [1985]. In order to consider land use, cropping management and soil characteristics effects, Julien [1995] modified the original equation introducing the corresponding USLE factors (Universal Soil Loss Equation; [Wischmeier and Smith, 1961]). The sediment volumetric discharge is computed as: 
$Q_{h}=\frac{1}{\gamma_{s}} W \alpha S_{o}^{1.66}\left(\frac{Q}{W}\right)^{2.035} \frac{K}{0.15} C P \quad\left[\mathrm{~m}^{3} \mathrm{~s}^{-1}\right]$

where $\gamma_{s}$ is the specific weight of the sediment [tons $/ \mathrm{m}^{3}$ ] and $K, C, P$ are the USLE soil erodibility, cropping management and support practice factors [-], respectively. Notice that 0.15 is the $K$ value for sandy soil. The hillslope transport capacity calculated by Eq. (3.18) is divided into three parts, proportionally to the textural composition of the transported material (percentage of sand, silt and clay); each transport capacity fraction is used to route the corresponding soil granulometric fraction. These fractional hillslope transport capacities are firstly used to route suspended sediments downstream; then, the residual capacities (according to Figure 3.5) serve to mobilise deposited material, and finally to erode the parent soil. The routed sediments are separated into suspended and deposited particles, depending on their settling velocity, as shown also in Figure 3.5.

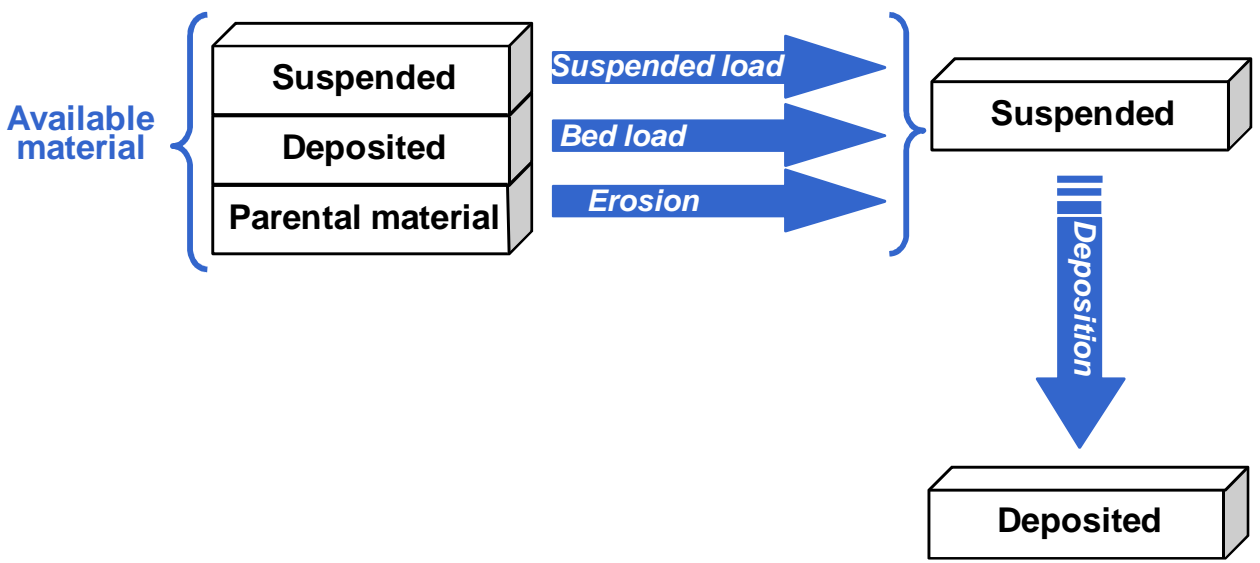

Figure 3.5 - Hillslope processes TETIS conceptualization.

\subsubsection{Gully and channel processes}

The gully and channel erosion and transport processes are described by the Engelund and Hansen equation [Engelund and Hansen, 1967], where the streamflow transport capacity depends on hydraulic radius, flow velocity, friction force and grain characteristics. The maximum sediment concentration is given by [-]:

$$
C_{w_{i}}=\beta\left(\frac{G}{G-1}\right) \frac{V S_{f}}{\sqrt{(G-1) g d_{i}}} \sqrt{\frac{R_{h} S_{f}}{(G-1) d d_{i}}} \quad \text { [tons } \mathrm{m}^{-3} \text { ] }
$$

where $G$ is the specific gravity of the sediment $[-], V$ the flow velocity $[\mathrm{m} / \mathrm{s}], S_{f}$ the energy slope [ - ], $g$ the gravity acceleration $\left[\mathrm{m} / \mathrm{s}^{2}\right], d_{i}$ the grain diameter of textural class $i[\mathrm{~m}], R_{h}$ the hydraulic radius $[\mathrm{m}]$ and $B$ is a non-dimensional calibration coefficient (not existing in the original expression). The streamflow transport capacity for the textural class $i$ is expressed as follows $\left[\mathrm{m}^{3} / \mathrm{s}\right]$ : 
$Q_{s, i}=\frac{Q C_{w_{i}}}{\gamma_{s}}$

where $Q$ is the stream (gully or river channel) discharge $\left[\mathrm{m}^{3} / \mathrm{s}\right]$. As for hillslopes, the streamflow transport capacity given by Eq. (3.20) for each textural class is firstly used to route sediments downstream and then, if there is residual capacity, to mobilise deposited soil particles. The TETIS model does not consider parent material erosion in gullies and channels (Figure 3.6). This is because it has been proven that, in many catchments, the most important source of sediment in the channels is loose material previously deposited by preceding floods, which is easier to move [Piest et al., 1975]. In any case, parent material can be simulated by means of a large initial sediment deposit in the stream network.

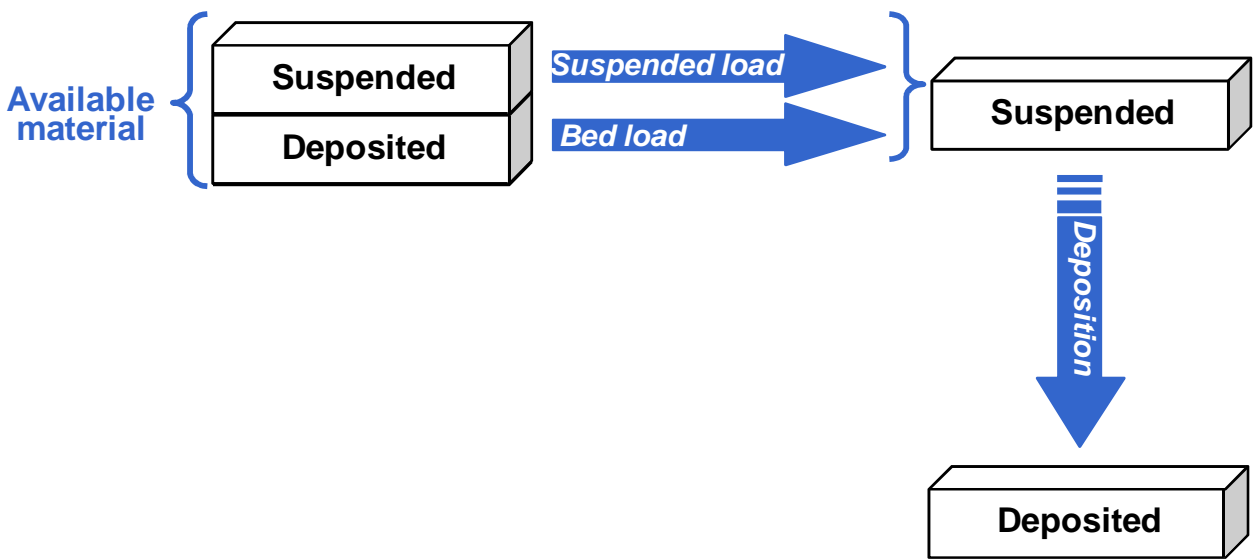

Figure 3.6 - Gully and channel processes TETIS conceptualization.

\subsubsection{Model parameters}

As has been explained before, TETIS needs distributed information about three USLE factors (C, K and P) used in the modified Kilinc and Richardson formula, and about topsoil texture (sand, silt and clay percentage, following the USDA classification). These parameters introduce a further source of uncertainty, to be added to the uncertainty due to model conceptualization and to the data uncertainty. For this reason, model calibration is fundamental in order to implement a reliable and robust model.

TETIS sedimentological sub-model calibration is carried out through the adjustment of three parameters, or correction factors: the $\alpha$ parameter in equation (3.18) for hillslope transport capacity, and two different 6 coefficients in equation (3.19) for gully and river channels transport capacity, as showed in the equations (3.21), (3.22) and (3.23).

\begin{tabular}{cl}
\hline Correction factor & Parameter \\
\hline$\alpha$ & Transport capacity in hillslopes \\
$\beta_{1}$ & Transport capacity in gullies \\
$\beta_{2}$ & Transport capacity in channels \\
\hline
\end{tabular}

Table 3.7-Sediment correction factors and corresponding parameters. 


$$
\begin{aligned}
& q_{t}^{*}=\alpha q_{t} \\
& C_{w_{i}}{ }^{*}=\beta_{1} C_{w_{i}} \\
& C_{w_{i}}{ }^{*}=\beta_{2} C_{w_{i}}
\end{aligned}
$$

\subsubsection{Sediment initial conditions}

The available volume of sediments deposited in the drainage network strongly affects the total sediment load at the catchment outlet [Thornes, 1980]. The sediment transport during a single rainstorm event depends not only on the rills and gullies network development, but also on the bed material stability. It has been demonstrated that the sediment load depends on flow duration and volume, although flow duration seems to be more relevant. This is due to the fact that channel available sediments are detached and transported during the rising limb of the flood hydrograph. For example, studies on a catchment located in lowa, USA, demonstrated that one third of the total annual rainfall, concentrated in May and June, caused four fifths of the total sediment transport. It was demonstrated that the cause of this phenomenon was that in May - June the availability of loose material on the channel beds was greater than other months, due to the spring hydrological regime [Piest et al., 1975]. In the same study, the authors observed that May and June floods sediment production was approximately double of other floods. This phenomenon is known as gully cleanout [Piest et al., 1975]. It consists in the detachment and mobilization of previously deposited material from the gully and channel beds during the rising limb of the flood hydrograph.

This phenomenon is also called bulldozer effect, and, as shown by Regüés et al. [2000], it happens when the sediment transport peak occurs before the water discharge peak. In these cases, the runoff production takes place all over the catchment while the sediment production is concentrated in the lower zones of the hillslopes and in the channel network. In the Vallcebre catchment (East Pyrenees, Spain), Gallart et al. [2005] observed that, even if the most relevant source of erosion are the badlands hillslopes, the sediment dynamics of the catchment is controlled by the gully and channel processes. The reason of this paradox is the following. In summer, short and intense rainfall events cause high hillslope sediment production, although the sediment transport in the channel network is small, because no or little flow is present in the drainage network. In winter, longer and less severe rainfall events cause smaller hillslope erosion, but produce sediment transport in the drainage network, cleaning the gullies and channels form the loose material deposited during summer.

The presence of loose sediments prepared to be transported at the beginning of a flood event also causes a delay between the suspended sediment peak and the water discharge peak. This phenomenon is especially evident in a plot showing the relationship between the water discharge and the sediment discharge, where it appears as a hysteresis loop (Figure 3.7). This delay depends on the catchment outlet location, the contributing areas 
distribution, the hillslope and channel network erosion dynamics, and the rainstorm intensity.

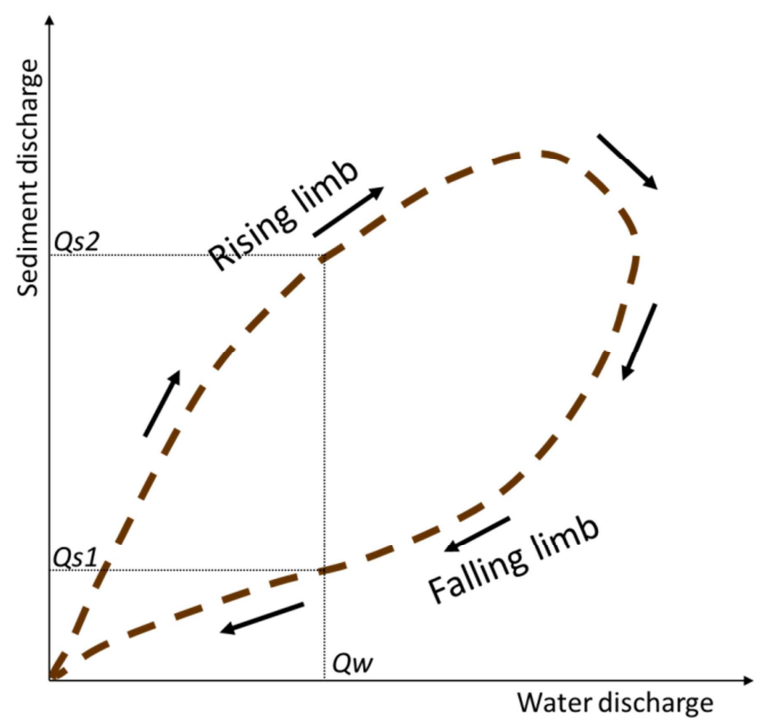

Figure 3.7-Clockwise hysteresis loop in the relationship water-sediment discharge. Given a water discharge value (Qw), two sediment discharge values correspond to it. A greater value (Qs2) corresponds to Qw during the rising limb of the hydrograph, and a lower value (Qs1) during the falling lim. Modified from Nistor and Church [2005].

The beginning of a rainstorm usually drives to the detachment of the loosest material, normally the sediments deposited by previous floods. This causes a decrease in the sediment availability during the same event [Thornes, 1980]. For this reason, the sediment load during an event is usually greater during the rising limb of the hydrograph than during the falling limb.

The model presented in Figure 3.7 is the most frequent (Clockwise Loop, Williams [1989]). It indicates a decrease in the sediment supply along the flood. This means that the catchment is dominated by sediment availability in the drainage network. Nevertheless, many water sediment discharge relationships exist [Nistor and Church, 2005]. For example, the counterclockwise loop [Williams, 1989] indicates that the sediment discharge peak occurs after the water discharge peak. Other examples of simple hysteresis loop shapes are shown in Figure 3.8 .

Another possible cause triggering this phenomenon may also be a transient hydraulic effect: due to variations in local energy slope, the stream velocity during the rising limb is higher than during the falling limb for the same discharge [Boiten, 2003]. Given that the sediment discharge strongly depends on the stream velocity, this may cause a clockwise hysteresis loop. This possibility must be taken into account, although it is rather unlikely in small headwaters catchment as the Goodwin Creek or the Rambla del Poyo catchment (some of the case study employed in this dissertation). 
Given the sensitivity of the model results to the sediment initial conditions, the TETIS software also provide a tool for manually adjusting the sediment deposits in the drainage network, distinguishing between hillslope, gully and channel cells. The term "sediment initial conditions" refers to the loose sediment volume deposited by previous floods and available to be transported by the actual flood. The TETIS sedimentological sub-model needs input values of:

- Initial conditions in the hillslope cells, divided in soil textural class (sand, silt and clay);

- Initial conditions in the gully cells, divided in soil textural class (sand, silt and clay);

- Initial conditions in the channel cells, divided in soil textural class (sand, silt and clay).
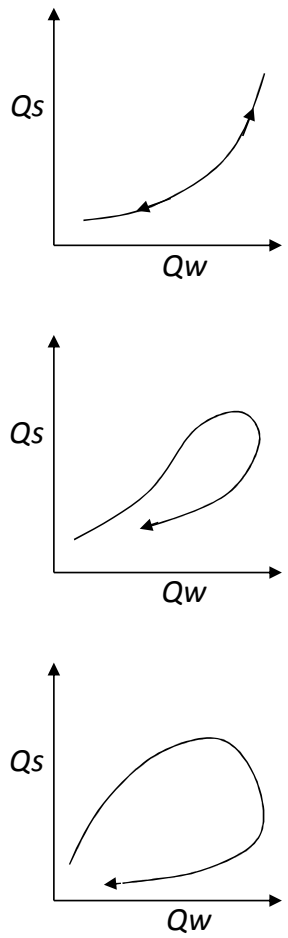

Variation - broader loop: the loop width depends on the decrease in sediment availability

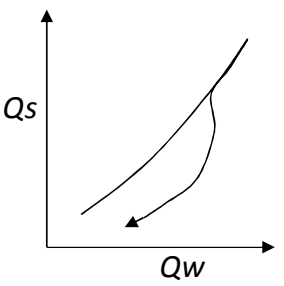

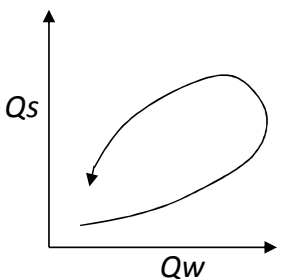

\section{Counterclockwise}

loop: sediment transport peak is delayed compared to the water discharge peak

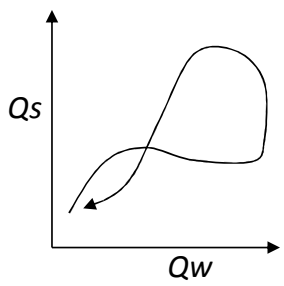

Variation - eight

figure: during the rising limb, the sediment availability decreases, and during the falling limb increases

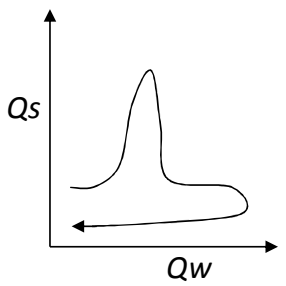

Random: more than one sediment discharge peaks exist, and they are not related to any water discharge peak

Loop and unique curve: sediment availability decreases up to a threshold 
Table 3.8 - Hysteresis loop types for one-peak hydrographs. Modified from Nistor and Church [2005]. Qs is the sediment discharge and $Q w$ is the water discharge.

\subsection{Automatic calibration}

The TETIS model holds an automatic calibration algorithm, in order to obtain better adjustments during the calibration phase of the hydrological sub-model [Vélez, 2003]. In this dissertation, the automatic algorithm was extended to the sedimentological sub-model.

The chosen algorithm was the Shuffled Complex Evolution of the University of Arizona, initially proposed by Duan et al. [1992], and later modified by Duan et al. [1993], Duan et al. [1994] and Sorooshian et al. [1993].

This optimization algorithm is based on four concept [Vélez, 2003]:

- Probabilistic and deterministic approximations;

- $\quad$ Systematic evolution of a cluster of parameter sets within a feasible range towards the global optimum;

- Competitive evolution;

- Complex shuffling.

The SCE-UA optimization algorithm was firstly used for lumped hydrological modelling with positive results. The algorithm was later used in semidistributed modelling. The first application with a distributed model was developed by Senarath et al. [2000], coupled with the CASC2D model. A general description of the algorithm is presented in Duan et al. [1994], who listed the steps to follow:

- Generation of a sample of $s$ random parameter sets in the feasible space and calculation of the objective function corresponding to each set.

- $\quad$ Set classifications, i.e. the $s$ sets are arranged in a decreasing order, assuming that the aim is to minimize the objective function.

- Partition in complexes. The $s$ sets are divided into $p$ complexes containing each $\mathrm{m}$ sets.

- Complex evolution. Each complex is treated by the Complex Competitive Evolution (CCE) algorithm, which uses the Simplex method combined with random search and complex evolution.

- Complex shuffling. The best sets from each complex are combined in a single complex, arranged and divided again in $p$ complex, following the step 3.

- Convergence check. If the convergence criteria previously established are fulfilled, the algorithm stops the search, otherwise it continues.

- Complex number reduction check. If the minimum number of required complexes $p_{\text {min }}$ is lower than $p$, the "worst" complexes are excluded.

Sorooshian et al. [1993] proposed a modification. Analysing the algorithm results, the authors observed that, once the algorithm has converged to a small region of a feasible space, it is not necessary to retain all the original parameter sets in order to continue the search. The algorithm was therefore modified. The minimum number of complexes $p_{\min }$ was 
set to INT( $p / 2)$, where the INT operator trunks the number to its integer value. The authors observed a reduction of the computational times.

More information about SCE-UA applications with the TETIS model can be found in Francés et al. [2007], Vélez et al. [2002a, 2002b, 2005, 2009] and Vélez and Francés [2005]. In Francés et al. [2007] the split parameter structure is introduced, reducing the number of parameters to be calibrated with the SCE-UA algorithm. The results show a very efficienct and satisfactory behaviour. In Vélez et al. [2009], an automatic calibration algorithm procedure for initial condition calibration is presented and applied to three catchments. The authors demonstrated that the SCE-UA algorithm excellently performs also for initial condition optimization.

\subsection{Small reservoir sedimentation sub-model}

The TETIS model was coupled with a small reservoir sedimentation sub-model, in order to reproduce the sedimentation dynamics of a small reservoir or check dam during a flood event. An existent model, called Sediment Trap Efficiency for small Ponds (STEP, Verstraeten and Poesen [2001a]), was adapted and coupled to the TETIS model.

The advantages of this model are:

- Its conceptualization is simple and parsimonious, and requires a small amount of data;

- It is one of the most recent reservoir sedimentation models that can be found in literature;

- It was developed for small ponds;

- It was developed for long-term TE estimation and for continuous simulation;

- It is compatible with the TETIS model, given that it only requires the inlet water and sediment discharge as input, which can be provided by TETIS.

The STEP model is based on two mass balances, one for water routing and one for sediment routing. In the next chapter, the STEP model is described, as well as its adaptation to the TETIS model.

\subsubsection{Water routing}

As for other models, the STEP model divides pond into several finite volumes. For STEP this is done on the basis of equal surfaces. In order to model the change of the water volume in the pond, a continuity equation is used (3.24).

$\mathrm{V}_{(\mathrm{i})}=\mathrm{V}_{(\mathrm{i}-1)}+\frac{\left(\mathrm{Q}_{\mathrm{in}(\mathrm{i})}+\mathrm{Q}_{\mathrm{in}(\mathrm{i}-1)}\right)}{2} \Delta \mathrm{t}-\frac{\left(\mathrm{Q}_{\mathrm{e}(\mathrm{i})}+\mathrm{Q}_{\mathrm{e}(\mathrm{i}-1)}\right)}{2} \Delta \mathrm{t}$

being $V$ the pond volume, $Q_{\text {in }}$ the inflow discharge, $Q_{e}$ the effluent discharge and $\Delta t$ the time step considered. 
The subscript $i$ refers to the current time step, $i-1$ to the previous one. This continuity equation is used to model the change of the water level near the outlet ( $h w$ in Figure 3.8). It is therefore necessary to provide the model a discharge level - volume curve for each considered reservoir.

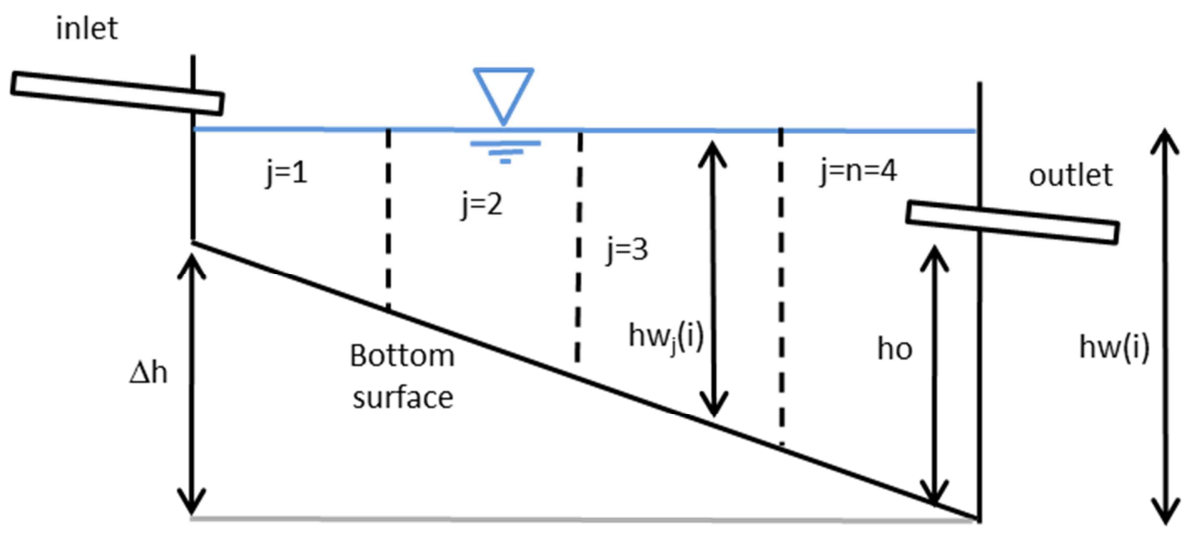

Figure 3.8 - Longitudinal section of a small pond reservoir divided into sectors (modified from Verstraeten and Poesen [2001a]).

Observing Figure 3.8, it is clear that the bottom surface of the pond it is not horizontal, and the level of the bottom surface of the pond is higher near the inlet than near the outlet. Consequently, the water level in every finite volume can vary:

$\mathrm{hw}_{\mathrm{j}(\mathrm{i})}=\mathrm{hw}_{(\mathrm{i})}-\Delta \mathrm{h}\left(\frac{\mathrm{n}-\mathrm{j}+0.5}{\mathrm{n}}\right)$

Where $h w_{j(i)}$ is the mean water level in finite volume $j, \Delta h$ the height difference between inlet and outlet and $n$ the number of finite volumes. Finite volume 1 is located close to the inlet; finite volume $n$ is close to the outlet. The bottom slope implies that in some cases one or more finite volumes near the inlet are dry and no sediment deposition will take place there. During flood, however, there always will be a minimum water level in these finite volumes and sediment will be deposited. Therefore, the water level in all finite volumes needs to be corrected. The water volume in a normally dry finite volume will equal $1 / n$ times the inflow volume during the previous time step. The water volume in the other finite volumes also needs to be reduced, in order to keep the mass balance correct (Figure 3.9).

$\mathrm{V}_{(\mathrm{i}) \operatorname{cor}}=\mathrm{V}_{(\mathrm{i})}-\mathrm{n}_{1} \frac{\Delta \mathrm{V}_{(\mathrm{i})}}{\mathrm{n}}$

where $V_{(i) \text { cor }}$ is the corrected water volume in the finite volumes that are not dry and $n_{1}$ the number of empty finite volumes in the previous time step. This corrected water volume is used to calculate the corrected water level near the outlet, or $h w_{\text {corr }}$, which is used to compute the outlet discharge, supposing a free spillway above the dam body (typical of Mediterranean check dams), whose length is given and whose coefficient is 0.35 . 


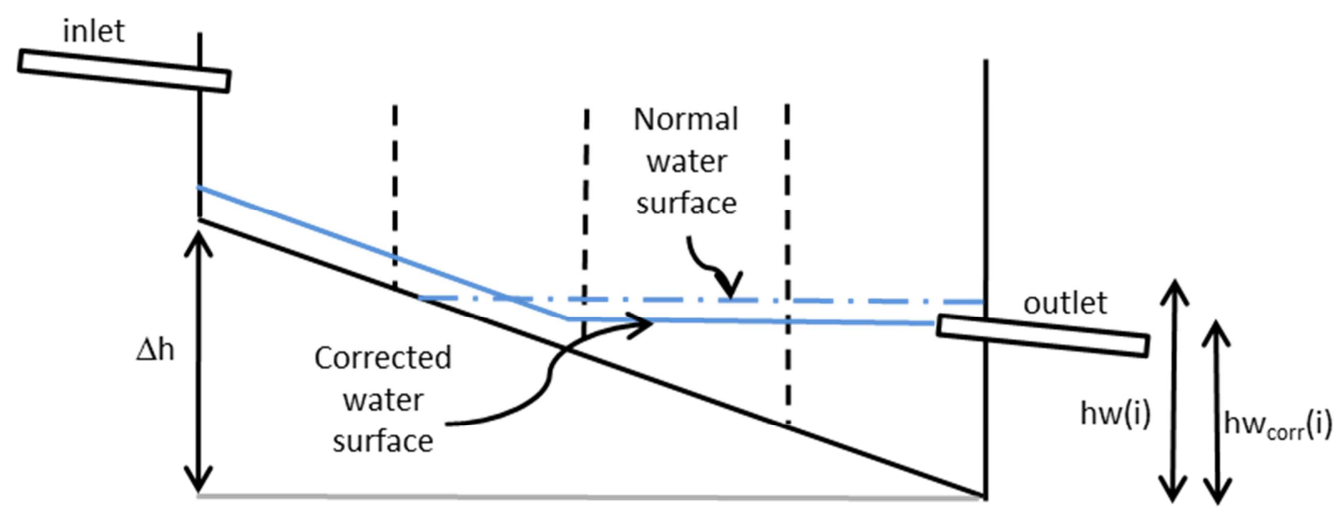

Figure 3.9 - Water level correction when one or more sectors are empty (modified from Verstraeten and Poesen [2001a]).

\subsubsection{Sediment routing}

The mass balance equation (3.27) is used for each finite volume in order to carry out the sediment routing.

$\frac{d V^{j} C^{j}}{d t}=Q_{i n}^{j} C_{i n}(t)^{j}-Q_{e}^{j} C(t)^{j}-S_{d}(t)^{j}$

where $C^{j}$ is the sediment concentration in finite volume $j, V j$ the water volume in finite volume $j, Q_{i n}^{j}$ and $C_{i n}$ are the inflow rate and the influent sediment concentration in finite volume $j$ respectively, and $Q_{e}^{j}$ the outflow rate from the finite volume $j$. The outflow sediment concentration from finite volume $j$ equals the present sediment concentration in this finite volume $C^{j}$ and $S_{d}{ }^{j}$ represents the deposition rate in finite volume $j$. The inflow sediment concentration for the first finite volume is derived from the TETIS inflow sedigraph, and the effluent sediment concentration of the last finite volume is used to calculate the pond effluent sedigraph. Within each finite volume, water and sediment are mixed: no stratification of the sediment is modelled. This can be considered a reasonable assumption in small pond systems.

Another simplification in STEP is the way sediment deposition is calculated. In STEP, a simple settling approach is used (3.28), taken from Chen [1975].

$$
\left.S_{d}^{j}=V^{j} C^{j}\left(1-e^{\left(1-\frac{v_{s}}{h w_{j}} \Delta t\right.}\right)\right)
$$

where $v_{s}$ is the settling velocity of sediment particles and $h w_{(i)}$ the water level in finite volume $j$.

To calculate the sediment mass that is routed from one finite volume to the next finite volume, the outflow rate of the finite volume is used $\left(Q_{e}^{j}\right)$. If the inflow and outflow rates 
for the total pond are different, this means that $Q_{e}^{j}$ will differ for each finite volume. The water volume that is routed from finite volume $j$ to finite volume a $j+1, V^{j \rightarrow j+1}$ is determined by the equation (3.29).

$\mathrm{V}^{\mathrm{j} \rightarrow \mathrm{j}+1}=\mathrm{Q}_{\mathrm{in}}\left(\frac{\mathrm{n}-\mathrm{j}}{\mathrm{n}}\right) \Delta \mathrm{t}+\mathrm{Q}_{\mathrm{e}}\left(\frac{\mathrm{j}}{\mathrm{n}}\right) \Delta \mathrm{t}$

Multiplying equation (3.29) with the actual sediment concentration in finite volume $j$ yields the inflow sediment mass for finite volume $j+1$.

The deposited and outflow sediment masses for each finite volume need to be corrected because the sediment that is deposited cannot be transmitted to the next finite volume, and vice versa (Figure 3.10). This is done by taking into account the critical water depth for sediment deposition and the ratio of transmitted water volume to the actual water volume in the finite volume.
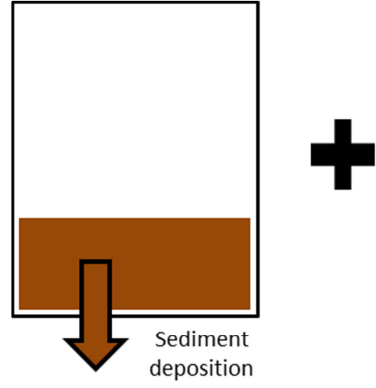
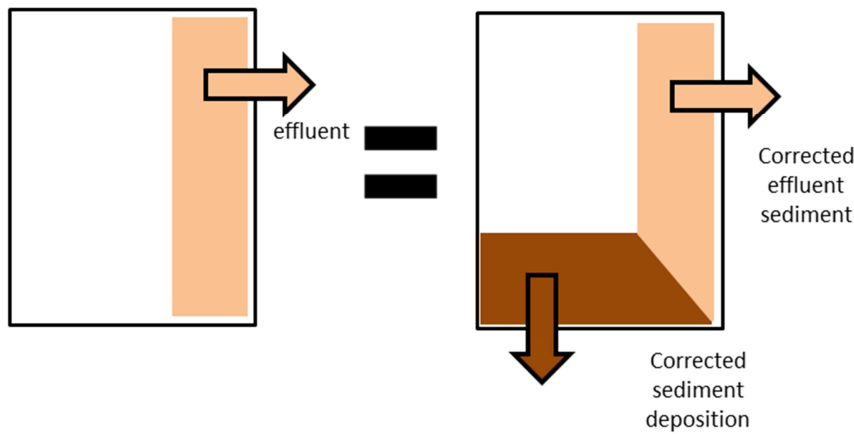

Figure 3.10 - Sediment routing modification from a finite volume to another (modified from Verstraeten and Poesen [2001a]).

The critical depth $h w_{c r}$ is the maximum depth at which the TE is $100 \%$ during the whole time step. This value is different for each textural class and is $h w_{c r}=v_{s} \Delta t$ for non-turbulent conditions. For turbulent conditions, the critical depth is theoretically infinite, and for this reason, the STEP model computes the depth at which $99 \%$ of sediments are deposited (3.30).

$h w_{c r}=\frac{v_{s} \Delta t}{5.6052}$

The constant 5.6052 is obtained by solving equation (3.28) for $S_{d}^{j}=0.99$.

Deposited sediment masses and effluent sediment masses are reduced with an equal amount of sediment:

$\left.S_{d}^{j}=V^{j} C^{j}\left(1-e^{\left(1-\frac{v_{s}}{h w_{j}} \Delta t\right.}\right)\right)-\frac{h w_{c r_{j}} V^{j \rightarrow j+1} C^{j}}{11.2104 h w_{j}}$ 
$\mathrm{Q}_{\mathrm{e}}^{\mathrm{j}} \mathrm{C}^{\mathrm{j}}=\mathrm{V}^{\mathrm{j} \rightarrow \mathrm{j}+1} \mathrm{C}^{\mathrm{j}}-\frac{h w_{c r_{j}} \mathrm{~V}^{\mathrm{j} \rightarrow \mathrm{j}+1} \mathrm{C}^{\mathrm{j}}}{11.2104 \mathrm{hw_{j }}}$

The constant 11.2104 is twice the value obtained for equation (3.30).

The STEP model predicts the reservoir outlet sediment concentration, the outflow rate, the deposited volume and their textural composition. The sediment TE of the pond is calculated by comparing the inlet and outlet sediment masses (3.33).

$S T E=100\left(1-\frac{\sum Q_{e} C^{n} \Delta t}{\sum Q_{\text {in }} C_{i n}^{1} \Delta t}\right)$

The STEP model also can provide the sediment TE value for each texture class.

In order to ensure the right functioning of the STEP model, the time step and the number of finite volumes must be defined. The time step must be short, and the model time step cannot be used (this is usually between 5 minutes and 1 day). The Courant-FriedrichsLowry criterion establishes that the chosen time step must be equal or lower than the time a particle takes to travel from one point to an adjacent point [Anderson, 1995; Verstraeten and Poesen, 2001a]. Adapting these principles to the STEP model means that the mean residence time should be approximately equal to the time step. The time step choice therefore strongly depends on the number of finite volumes.

Furthermore, a too short time step is not advisable, given that it will cause a very high number of finite volumes, and the perfect mixing hypothesis might give as a result a very low TE and very high computational times. 


\section{Goodwin Creek: gauged data}




\subsection{Introduction and goals}

Although in the last 60 years the advances in sediment modelling research have been very relevant, erosion and sediment transport models are still inadequate in many situations [Favis-Mortlock et al., 2001]. A strong limitation to the application of many existing sediment models is the need for a reliable calibration and validation [Jetten et al., 1999], which is required in order to prove the model robustness and reliability. In the past, modelling research studies highlighted the importance of calibration and validation for hydrological [Klemeš, 1986; Beven, 1989] and sedimentological models [de Roo and Jetten, 1999; Folly et al., 1999; Van Oost et al., 2005; Verstraeten, 2006; Polyakov et al., 2007]. While the calibration problem has already been faced for hydrological models, only a few papers described clear and scientifically acceptable calibration and validation procedures for sedimentological models. Moreover, the use of automatic calibration algorithms in erosion and sediment modelling, as seen in Freedman et al., [1998] and Santos et al. [2003, 2010] for WESP model, Viney and Sivapalan [1999] for LASCAM model and Ogden and Heilig [2001] for CASC2D-SED model, is still not very common.

Many questions can be raised concerning sediment model calibration and validation. For example: how to select calibration and validation periods, which objective function(s) is(are) to be used, which calibration technique is the most appropriate, etc. One of the main problems is the estimation of the initial condition (defined as the initial value of model state variables). Typically, the most influent variables to be estimated at the beginning of a simulation are the soil moisture, the groundwater level, the river flow and the available inchannel sediment. While the hydrological component of the initial condition has been thoroughly investigated [Beven, 2001], there is a lack of studies regarding the influence of initial sediment availability on model calibration and operation.

Initial condition of available sediments, i.e. material deposited by previous erosive events into the drainage network, may seriously affect the total sediment load [Thornes, 1980], for example by means of the gully cleanout phenomenon. As explained in the previous chapter, this phenomenon consists in the mobilisation of sediment deposited by previous floods. This may cause a time gap between sediment concentration peak and water discharge peak, resulting in a clockwise hysteresis loop in the relationship between suspended sediment concentration and water discharge (or between sediment discharge and water discharge). As is shown for example in Nistor and Church [2005], there are many kinds of hysteresis loops. As stated by many authors (e.g. Smith and Dragovich, 2009), hysteresis loop patterns can provide information about sediment erosion and transport interaction, rainfall intensity and duration, runoff production, sediment availability, etc. Each kind depends, among other factors, on runoff and sediment transport processes and on the sediment source location(s) [e.g. Williams, 1989; Seeger et al., 2004; Eder et al., 2010]. Particularly, clockwise hysteresis usually demonstrates that the catchment sediment dynamics is dominated by gully and river channel erosion rather than hillslope erosion [Piest et al., 1975; Nistor and Church, 2005]. This situation is quite frequent: as many papers showed, the relative contribution to total sediment yield of gully and river channel erosion and deposition might be very relevant compared to hillslope (or sheet and rill) erosion [Osterkamp and Toy, 1997; Merritt et al., 2003; de Vente et al., 2008; Smith and Dragovich, 2009; Vanmaercke et al., 2012]. 
Initial condition of deposited sediment attains a special importance for event-based modelling. Nevertheless, continuous simulation models also need an initial condition. In this case, while initial soil moisture and initial groundwater level can be estimated by simulating a relatively short warm up period (from a few months to a year), the available sediment strongly depends on the previous extreme events and a warm up period length cannot be established a priori. Moreover, initial condition is also very important in calibration of continuous simulation models when using automatic calibration algorithms. Automatic calibration requires a high number of simulations and, due to computational time limitations (processes as those involved in sediment yield modelling need a fine time discretisation, which is time consuming), the calibration period must be as short as possible, although sufficiently long for an adequate calibration [Klemeš, 1986; Brath et al., 2004]. Very often calibration is done using one or a few individual rainstorm events, thus increasing the influence of initial condition on model results.

The relevance of in-channel sediment deposits has already been highlighted by many authors, as stated above, but, despite the importance of this topic, only a few papers analysed the influence of initial sediment availability on sediment modelling process (e.g. Wicks and Bathurst [1996]). For this reason, the main goal of this chapter is to analyse the effect of initial sediment availability on model calibration and validation.

In this chapter the TETIS model is applied at the Goodwin Creek experimental catchment (Mississippi, USA). This is a highly monitored catchment managed by the ARS-USDA and by the National Sedimentation Laboratory (NSL). The catchment data and information is available online ${ }^{1,2}$. A description of the catchment and of the gauged variables is given in Blackmarr [1995] $]^{3}$ and in Alonso [1996].

The Goodwin Creek catchment presents relevant signs of soil degradation and badlands. The fine sediment transport ( $<0.062 \mathrm{~mm}$ diameter) is continuously monitored since 1981 . These characteristics make Goodwin Creek a suitable catchment to test the correct functioning of the TETIS model and its behaviour facing different phenomena related to erosion and sediment transport.

Within this context, the aims of this study are:

1) to calibrate the TETIS model at the event scale using the SCE-UA algorithm;

2) to analyse the problem of estimating initial sediment deposits, in order to reproduce adequately the catchment stream network dynamics;

3) to evaluate the model behaviour at the continuous simulation scale.

To reach these objectives, this chapter first presents the calibration procedure for the hydrological and sediment parameters, using the SCE-UA optimization algorithm. The model is applied to a catchment whose sediment dynamics is dominated by gully processes and its performance is discussed in terms of comparison between observed and simulated fine sedigraphs $(<0.062 \mathrm{~mm})$ and sediment rating curve.

\footnotetext{
${ }^{1}$ http://www.ars.usda.gov/Business/docs.htm?docid=5120

${ }^{2} \mathrm{ftp}: / /$ hydrolab.arsusda.gov/pub/arswater/

${ }^{3}$ http://www.ars.usda.gov/SP2UserFiles/Place/64080510/Goodwin/GoodwinCreek.PDF
} 
The importance of gully and river processes is analysed by comparing three strategies for estimating the amount and texture of sediment at the beginning of the rainstorm (sediment initial condition). Initial sediment availability, i.e. the amount of loose sediment deposited into the drainage network at the beginning of a model simulation, can be measured or estimated, although direct measurements are not frequent and difficult to carry out. In this chapter, different estimation techniques were investigated. Three sedimentological submodels were calibrated and validated, employing in each a different sediment initial condition estimation strategy: no sediment availability, calibration of the initial condition and estimation by warm up simulation. Manual calibration and simulation of a sufficiently long warm up period are two common techniques for sediment initial condition estimation. The possibility of setting sediment initial condition to zero (i.e. no available sediment in the drainage network) was also investigated in order to provide a reference to compare with the other two options. In order to see the practical implications of the different calibration strategies, a continuous simulation application of the model is also shown, comparing the performance of the four parameter sets previously calibrated.

\subsection{The case study: Goodwin Creek}

\subsubsection{Catchment characteristics}

Goodwin Creek is a $21.3 \mathrm{~km}^{2}$ experimental catchment situated in Panola County (Mississippi, USA, Figure 4.1). The catchment is fully instrumented with 14 stream gauges and 32 raingauges, which continuously monitor precipitation, runoff and SY with a high spatial and temporal resolution. SY is monitored by discontinuous standard pumping samplers for fine solids, manual measurement using a DH-48 intake for sandy sediments and bedload box sampler for gravel loads [Blackmarr, 1995]. Since continuous series of total sediment load were not calculated for every station [Kuhnle et al., 1989], only fine sediment $(<0.062 \mathrm{~mm})$ series were used in this study. 

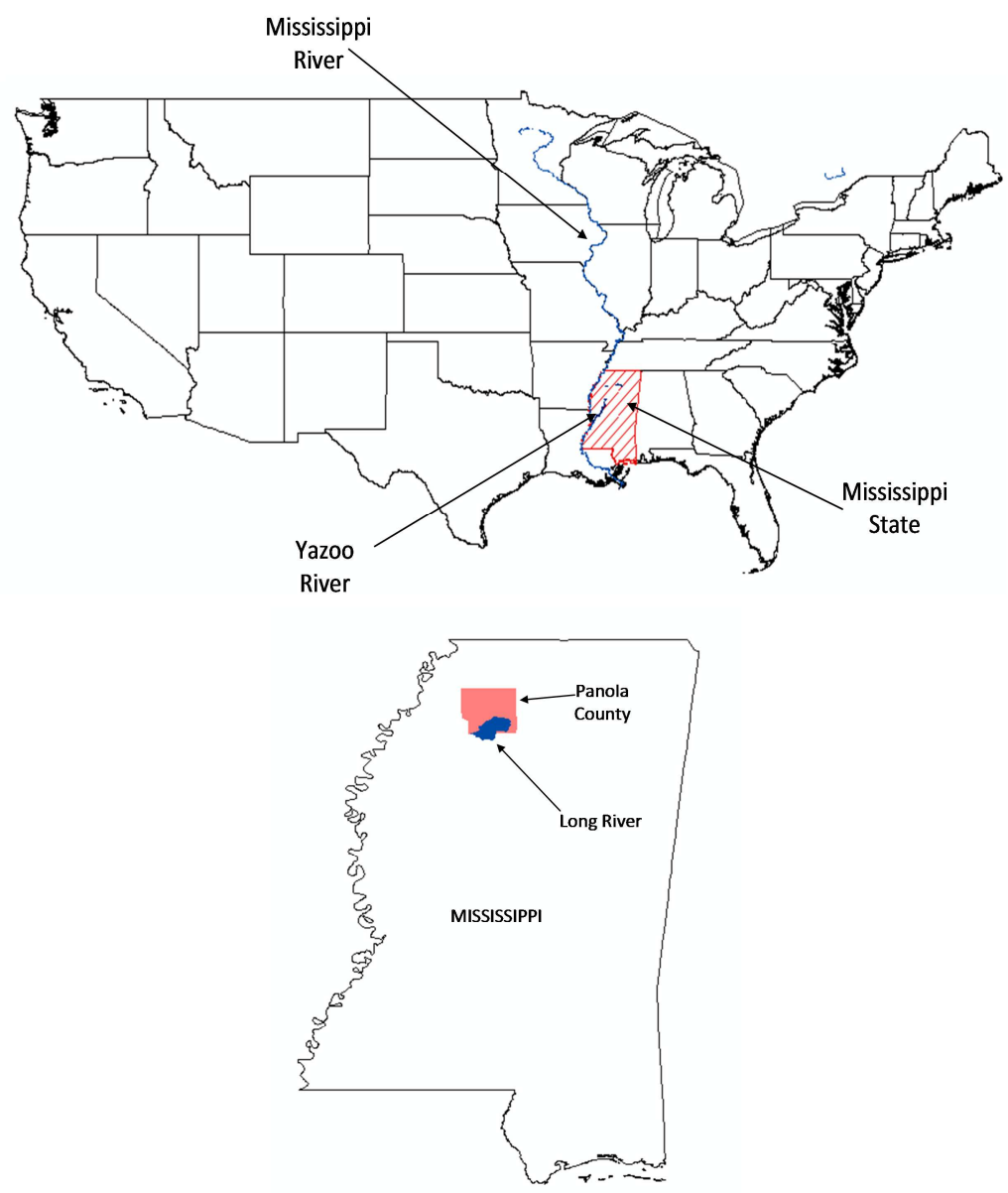

Figure 4.1 - Goodwin Creek location.

Soils are mainly silt loams, and the topography is quite smooth, with elevation ranging from 67 to $121 \mathrm{~m}$ a.s.l. and slope from 0 to $45 \%$ (Figure 4.2). Major land uses are pasture, agriculture and forest (44\%, $13 \%$ and $27 \%$ respectively, Figure 4.3$)$. The land use used in this study is referred to the 80 s (Table 4.1 ) and it is not varied along the analysed period, since the effect of land use change is not among the scopes of this research.

The climate is humid, warm in summer and temperate in winter. Average annual precipitation is $1440 \mathrm{~mm}$, and convective rainfall events are common, especially in summer. The catchment hydrology shows hortonian behaviour, with runoff almost entirely formed by overland flow, and a small and non-permanent base flow at the outlet. The catchment is affected by severe gullying and badlands, and many river stretches are deeply incised. Further information about Goodwin Creek can be found in literature [e.g. Blackmarr, 1995; Alonso, 1996; Kuhnle et al., 1996, 2005; Rojas, 2002]. 


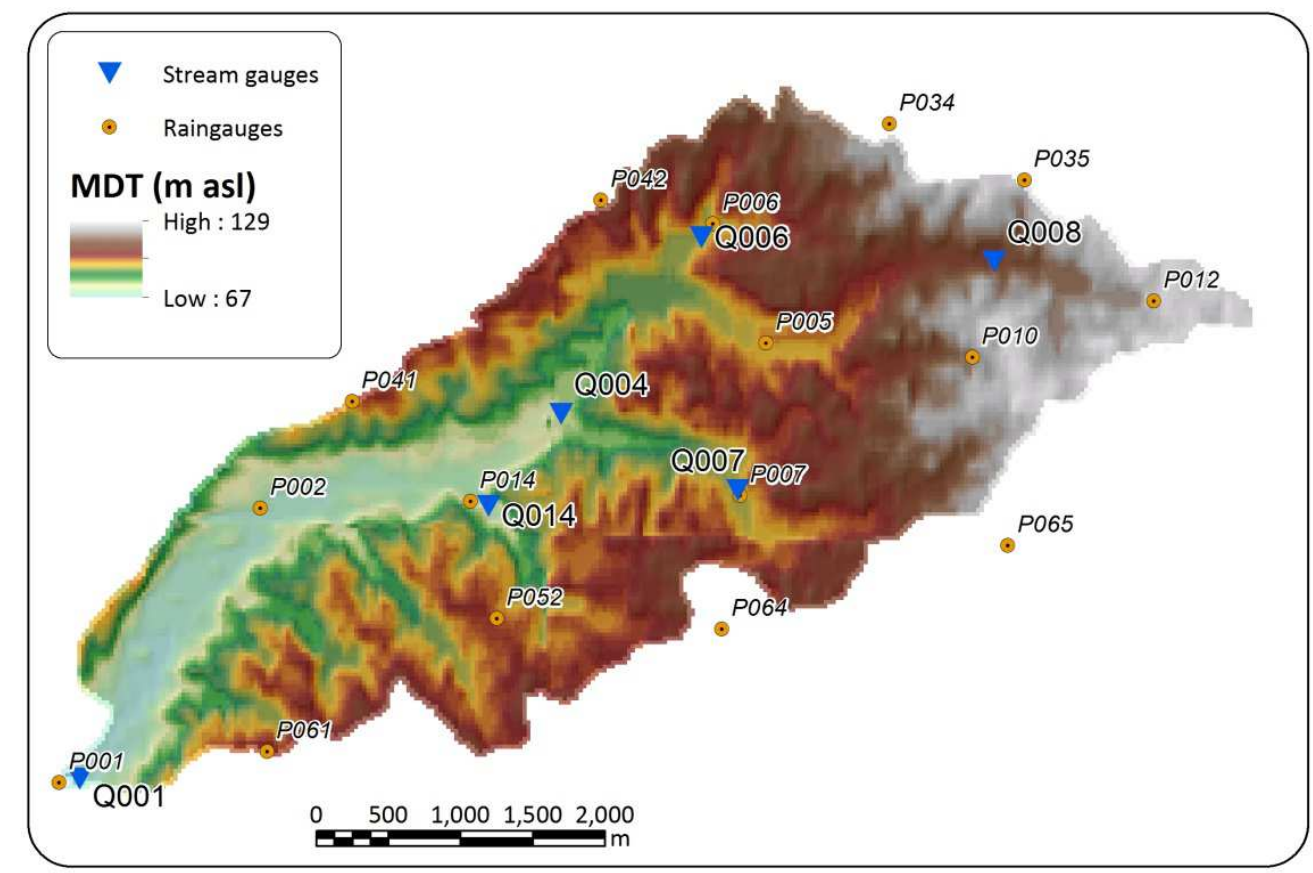

Figure 4.2 - Goodwin Creek catchment - the raingauges and stream gauges used in this study are shown.

Subterranean water does not contribute significantly to superficial runoff. The base flow at the basin outlet is usually lower than $0.05 \mathrm{~m}^{3} / \mathrm{s}$ [Ogden and Heilig, 2001]. Measurements of the piezometric level demonstrated that the aquifer level is several meters deep, and its fluctuations do not overcome 5 or $10 \mathrm{~cm}$. These characteristics, together with the fine soil texture, indicate that the runoff production mainly takes places following the hortonian mechanism.

\begin{tabular}{lcc}
\cline { 2 - 3 } & Area $\left(\mathrm{km}^{2}\right)$ & Badlands $\left(\mathrm{km}^{2}\right)$ \\
\hline Arable & $1.83(8.6 \%)$ & 0.00 \\
Pasture & $10.45(49.0 \%)$ & 0.01 \\
Not used & $2.72(12.8 \%)$ & 0.03 \\
Forest & $5.46(25.6 \%)$ & 0.04 \\
Forest repopulation & $0.87(4.0 \%)$ & 0.01 \\
TOTAL & 21.33 & 0.10 \\
\hline
\end{tabular}

Table 4.1 - Land use in Goodwin Creek and proportion of badland. 


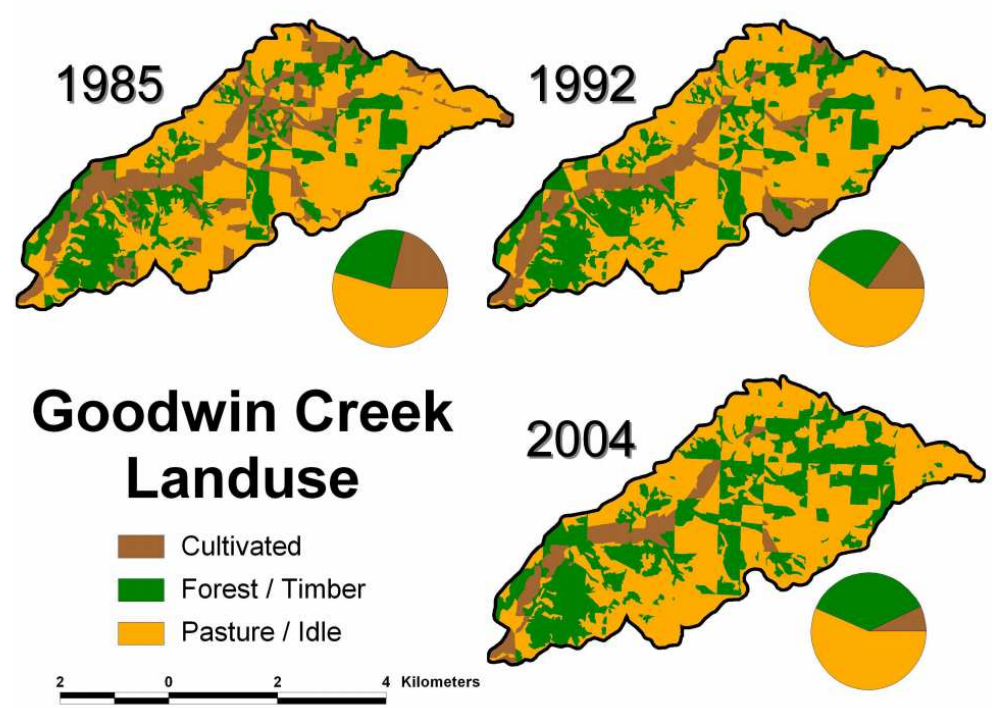

Figure 4.3 - Land use change in Goodwin Creek [Kuhnle et al., 2005].

The climate is humid and hot in summer and temperate in winter. Mean annual precipitation is around $1440 \mathrm{~mm} /$ year (1982-1998), and the mean annual runoff at the catchment outlet is $66 \mathrm{~mm} /$ year. The majority of Goodwin Creek precipitations are convective, and intense rainstorms are common. Table 4.2 shows the maximum expected rainfall values [U. S. Weather Bureau, 1961].

\begin{tabular}{|c|c|c|c|c|c|c|c|}
\hline \multirow{2}{*}{$\begin{array}{c}\text { Event } \\
\text { duration } \\
\text { (hours) }\end{array}$} & \multicolumn{7}{|c|}{ Return period (years) } \\
\cline { 2 - 8 } & $\mathbf{1}$ & $\mathbf{2}$ & $\mathbf{5}$ & $\mathbf{1 0}$ & $\mathbf{2 5}$ & $\mathbf{5 0}$ & $\mathbf{1 0 0}$ \\
\hline 1 & 38 & 44 & 56 & 62 & $\mathbf{7 2}$ & 79 & 89 \\
\hline 3 & 51 & 61 & 76 & 86 & 99 & 109 & 121 \\
\hline 6 & 64 & 76 & 94 & 105 & 119 & 135 & 147 \\
\hline 12 & 74 & 89 & 112 & 127 & 145 & 160 & 178 \\
\hline
\end{tabular}

Table 4.2 - Maximum expected rainfall values $(\mathrm{mm})$.

The most humid season is from November to May, when low pressure front system may produce severe storms. Dry season goes from June to October. During this season, heavy rainfall can also take place. During summer, precipitations usually occur during afternoon, due to convective storm generated by sun warming.

Fifteen per cent of the catchment is affected by soil degradation. Predominant soils are silty and are easily erodible if bare. Historically, erosion has always been a major concern in the catchment. Severe erosion started with deforestation and intensive cotton agriculture in 1830. Nowadays, many river reaches are incised, producing serious problems of bank stability [Kuhnle et al., 1996; Molnár and Ramírez, 1998]. 


\subsubsection{Hydrometeorological data}

In this dissertation, the hydrometeorological series from 1981 to 1987 were used. Thirty one raingauges and six stream gauges were employed (Table 4.4 and Figure 4.2). The Goodwin Creek catchment has 14 stream gauges, but only six were used, given that, for the aim of this study, it is not necessary to model all the sub-catchments.

\begin{tabular}{lll}
\hline Name & $\mathbf{X}(\mathbf{m})$ & $\mathbf{Y}(\mathbf{m})$ \\
\hline P_01 & 231575 & 3791749 \\
P_02 & 233079 & 3793799 \\
P_04 & 235373 & 3794476 \\
P_05 & 236862 & 3795035 \\
P_06 & 236465 & 3795928 \\
P_07 & 236669 & 3793895 \\
P_08 & 238584 & 3795679 \\
P_10 & 238402 & 3794930 \\
P_11 & 239026 & 3795179 \\
P_12 & 239762 & 3795347 \\
P_13 & 233560 & 3793765 \\
P_14 & 234650 & 3793850 \\
P_34 & 237784 & 3796672 \\
P_35 & 238793 & 3796252 \\
P_41 & 233765 & 3794596 \\
P_42 & 235626 & 3796102 \\
P_43 & 236666 & 3796766 \\
P-45 & 239312 & 3796002 \\
P_66 & 240342 & 3795257 \\
P_51 & 233915 & 3792854 \\
P_52 & 234847 & 3792973 \\
P_53 & 235768 & 3793307 \\
P_54 & 236066 & 3794741 \\
P_55 & 237755 & 3794539 \\
P_57 & 238735 & 3794585 \\
P_61 & 233129 & 3791980 \\
P_62 & 234366 & 3791773 \\
P_63 & 235774 & 3792315 \\
P_64 & 236530 & 3792896 \\
P_65 & 238669 & 3793521 \\
P_66 & 240101 & 3794707 \\
\hline T_64 & &
\end{tabular}

Table 4.3 - Raingauges (UTM coordinates).

\begin{tabular}{ccc}
\hline Nombre & $\mathbf{X}(\mathbf{m})$ & $\mathrm{Y}(\mathrm{m})$ \\
\hline Q001 & 231720 & 3791580 \\
Q004 & 235320 & 3794310 \\
Q006 & 236370 & 3795630 \\
Q007 & 236640 & 3793740 \\
Q008 & 238560 & 3795450 \\
Q014 & 234780 & 3793620 \\
\hline
\end{tabular}

The hydrometeorological series were processed in order to obtain 5 minutes time step series. 


\subsubsection{Sediment data}

From a monitoring point of view, sediment transport in Goodwin Creek can be classified in three components: fine sediments $(<0.062 \mathrm{~mm})$, sand $(0.062-2.0 \mathrm{~mm})$ and gravels $(>2 \mathrm{~mm})$. For each granulometric fraction a different sampling method was used.

Fine sediments $(<0.062 \mathrm{~mm})$ were gauged in all the stations by means of automatic and continuous fine sediment concentration samplers (automatic pumping samplers) in Vshaped river sections. This technique is reliable for fine sediment but not advisable for sandy sediment, given that sand concentration may varies considerably along the cross section.

In order to associate a sediment concentration and the water depth, the equation (4.1) is used:

$\mathrm{c}_{\mathrm{f}}=K D H^{E}$

where $c_{f}$ is the fine sediment concentration $(\mathrm{ppm}), K$ is a conversion factor, $D$ and $E$ regression coefficients and $H$ the water depth $(\mathrm{m})$ [Willis et al., 1986].

In order to gauge the sand concentration, manual sampling was carried out, using the US P63 and US DH484 instruments (Figure 4.4). These measurements were carried out in 11 stations. Continuous series of total load were calculated only for stations 1 and 2, using the equations (4.2) and (4.3)

$\mathrm{c}_{\mathrm{S}}=52.4 e^{0.675 H} ; H>1.22 \mathrm{ft}$

$\mathrm{c}_{\mathrm{s}}=97.6 H ; H \leq 1.22 \mathrm{ft}$

where $c_{s}$ is the sand concentration (ppm).
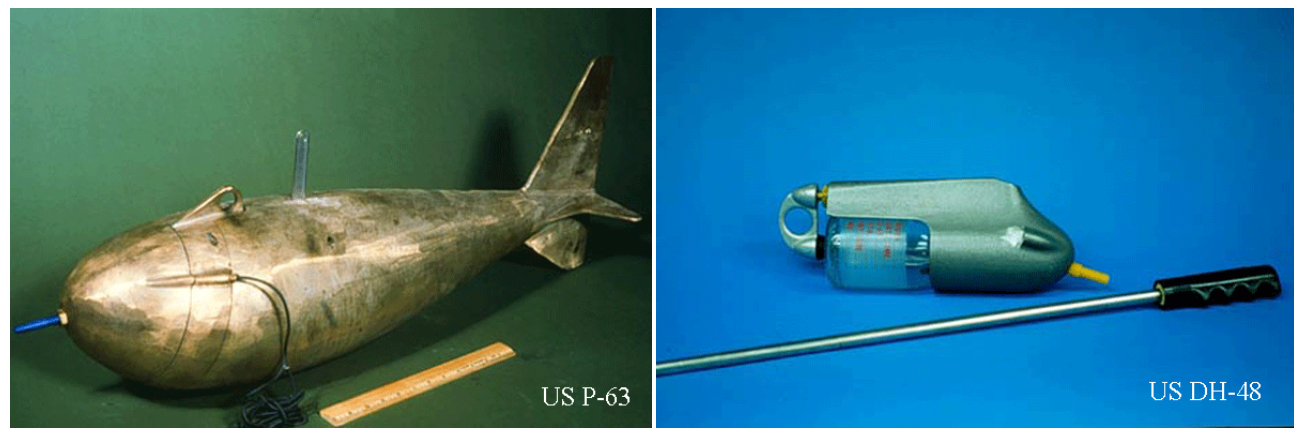

Figure 4.4 - Sampling instruments P63 and DH48.

\footnotetext{
${ }^{4}$ http://pubs.usgs.gov/of/2005/1087/book_2.html
} 
The gravel transport was sampled with a modified Helley-Smith instrument and a box sampler at the stations 1, 2, 3, 13 and 14. This is a manual sampling and two persons are needed to carry it out. For this reason, only a little number of samples was taken.

Kuhnle et al. [1989] estimated the total load for station 2 for the period 1985-1988. They also concluded that it is reasonably possible to do the same for stations $1,3,5$ and 15, although this has not been done yet. Nevertheless, the reliability of the coarse material measurements is often affected by high uncertainty. For this reason, and given that one of the aim of this study is to check the behaviour of the model, not to predict total load, only fine sediment series are used in this chapter. This can be done with TETIS model, given that it separates total sediment transport into textural classes.

As for water discharge, sediment discharge time series were resampled to obtain a 5 minutes temporal resolution. Given the very fine temporal resolution at which the data was collected, the 5-minute time-step resampling did not require any kind of interpolation or data modelling.

In Table 4.5 the main characteristics of five rainfall events are shown. These events were chosen to be used for model calibration and validation at the event scale, as is showed in the next sections.

\begin{tabular}{|c|c|c|c|c|c|c|}
\hline & & $\begin{array}{l}\text { Aug- } \\
1982\end{array}$ & $\begin{array}{l}\text { Mar- } \\
1983\end{array}$ & $\begin{array}{l}\text { May- } \\
1983\end{array}$ & $\begin{array}{l}\text { Nov- } \\
1983\end{array}$ & $\begin{array}{l}\text { Mar- } \\
1984\end{array}$ \\
\hline & Duration (hours) & 8.5 & 25.4 & 14.1 & 8.3 & 9.9 \\
\hline & $\begin{array}{l}\text { Mean accumulated rainfall } \\
(\mathrm{mm})\end{array}$ & 71 & 94 & 63 & 47 & 48 \\
\hline \multirow[t]{2}{*}{ Water } & $\begin{array}{l}\text { Maximum discharge at Q01 } \\
\left(\mathrm{m}^{3} \mathrm{~s}^{-1}\right)\end{array}$ & 38 & 69 & 71 & 33 & 37 \\
\hline & Total volume $\left(\mathrm{Hm}^{3}\right)$ & 0.407 & 1.177 & 0.746 & 0.324 & 0.354 \\
\hline \multirow[t]{2}{*}{ Sediments } & $\begin{array}{l}\text { Maximum fine discharge at } \\
\text { Q01 }\left(\mathrm{m}^{3} \mathrm{~s}^{-1}\right)\end{array}$ & 0.093 & 0.224 & 0.190 & 0.055 & 0.191 \\
\hline & Total volume $\left(\mathrm{m}^{3}\right)$ & 597 & 1654 & 1337 & 306 & 1006 \\
\hline
\end{tabular}

Table 4.5 - Main characteristics of the chosen flood events.

\subsubsection{Model parameters}

In this section the model parameters are shown. They were estimated by exploiting the available information on the Goodwin Creek catchment topography, geology, pedology and hydraulic geometry. These parameters were estimated in a previous application of the TETIS model to the Goodwin Creek catchment [Montoya, 2008]. All distributed parameters were resampled at $30 \times 30 \mathrm{~m}$ square cells resolution, following the DEM resolution. The flow direction, accumulated cells and slope maps were directly derived from the DEM, using the suitable tools of the ESRI software ArcMap 10.1C.

\subsubsection{Hydrological parameters}

The TETIS model needs soil and subsoil hydrological property maps such as maximum static storage $\left(H_{u}\right)$, infiltration capacity $\left(k_{s}\right)$ of the upper soil, interflow velocity $\left(k_{s s}\right)$, percolation capacity $\left(k_{p}\right)$ of the subsoil or aquifer, base flow velocity $\left(k_{s a}\right)$ and losses capacity $\left(k_{p s}\right)$, 
among others. In order to reduce the amount of required information, the hypothesis of $k_{s}=k_{s s}, k_{p}=k_{s a}$ and $k_{p s}=0.1 k_{p}$ was made. The split structure of the TETIS parameters allows calibrating all parameters separately and correcting the possible errors.

The $H_{u}$ and $k_{s}$ parameters were estimated using pedological information (texture, soil classification and soil profiles) and a proper pedotransfer function [Saxton and Raw/s, 2006]. Percolation capacity was derived from geologic maps (the percolation map is not shown, since it was proven not to be influential). Both maps are shown in Figure 4.5 and Figure 4.6.

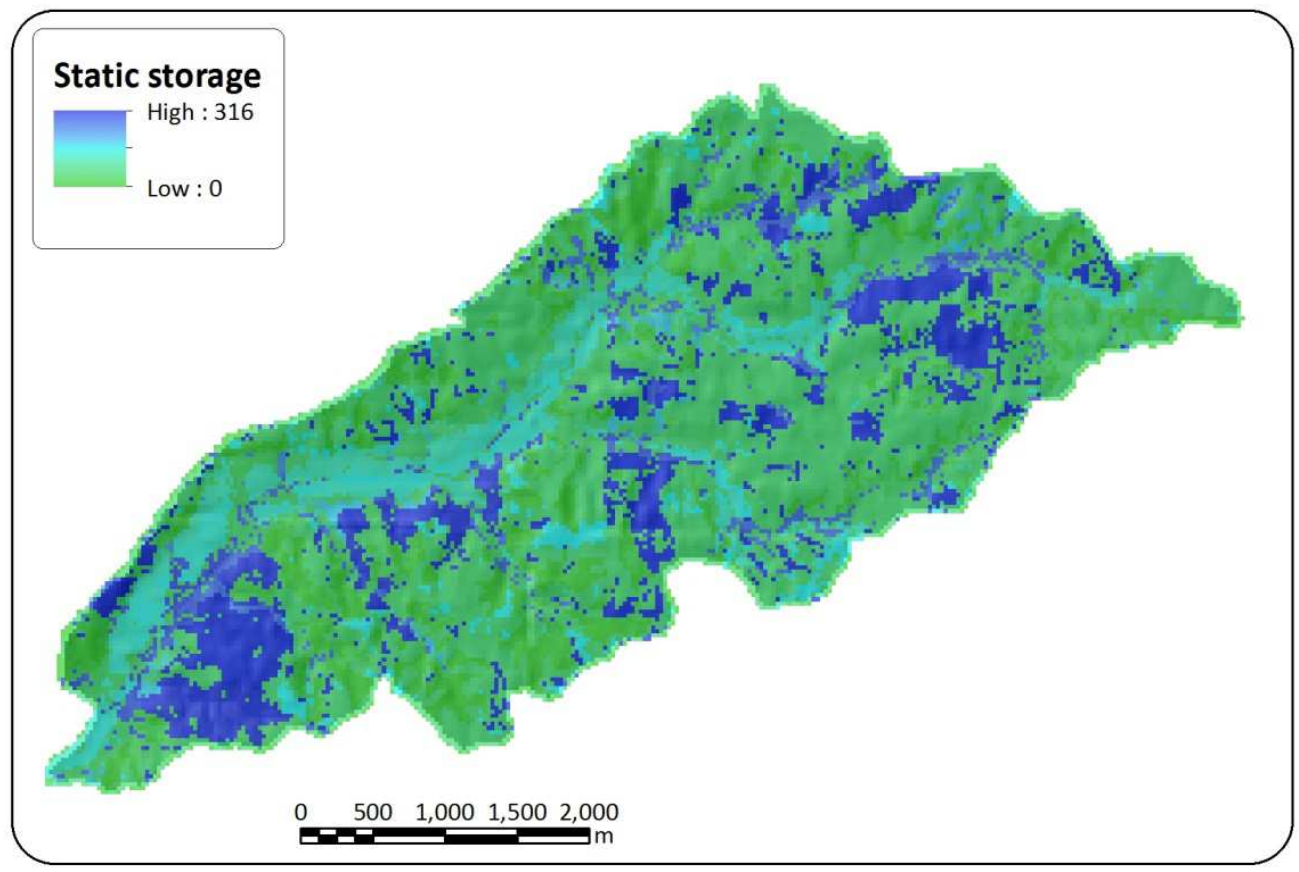

Figure 4.5 - Maximum static storage $\operatorname{map}(\mathrm{mm})$.

\subsubsection{Geomorphological parameters}

Goodwin Creek channels are mainly ephemeral. Base flow is only present in the last three kilometres of the main river channel, and the discharge is very small [Kuhnle et al., 1996].

Concerning flow propagation through the stream network, drainage threshold areas were estimated as $0.01 \mathrm{~km}^{2}$ (representative hillslope size and starting area for gullies) and 15.3 $\mathrm{km}^{2}$ (distinction between gullies and river channels), and the geomorphologic coefficients and exponents for the Geomorphologic Kinematic Wave have been taken from Molnár and Ramírez [1998]. 


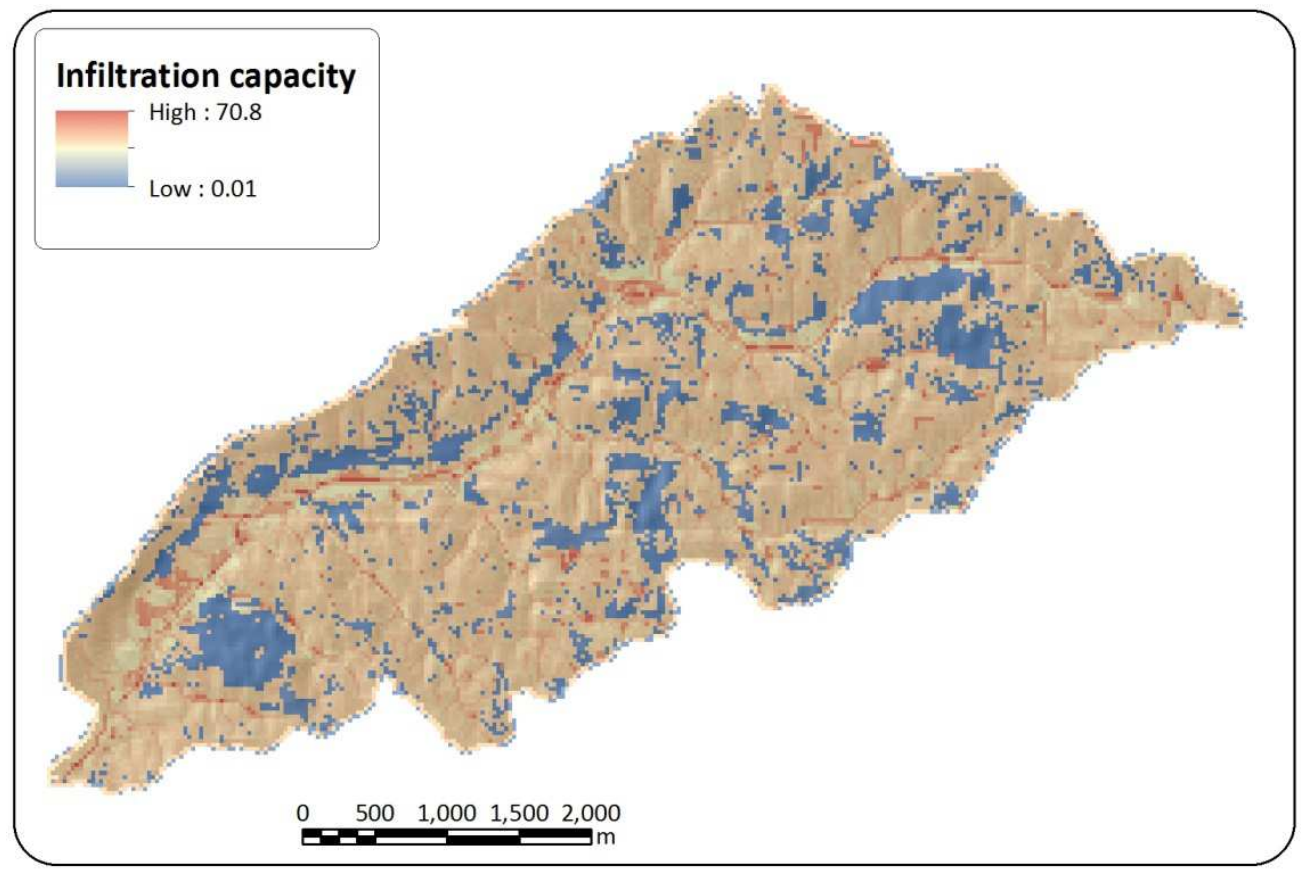

Figure 4.6 - Infiltration capacity $\mathrm{map}(\mathrm{mm} / \mathrm{h})$.

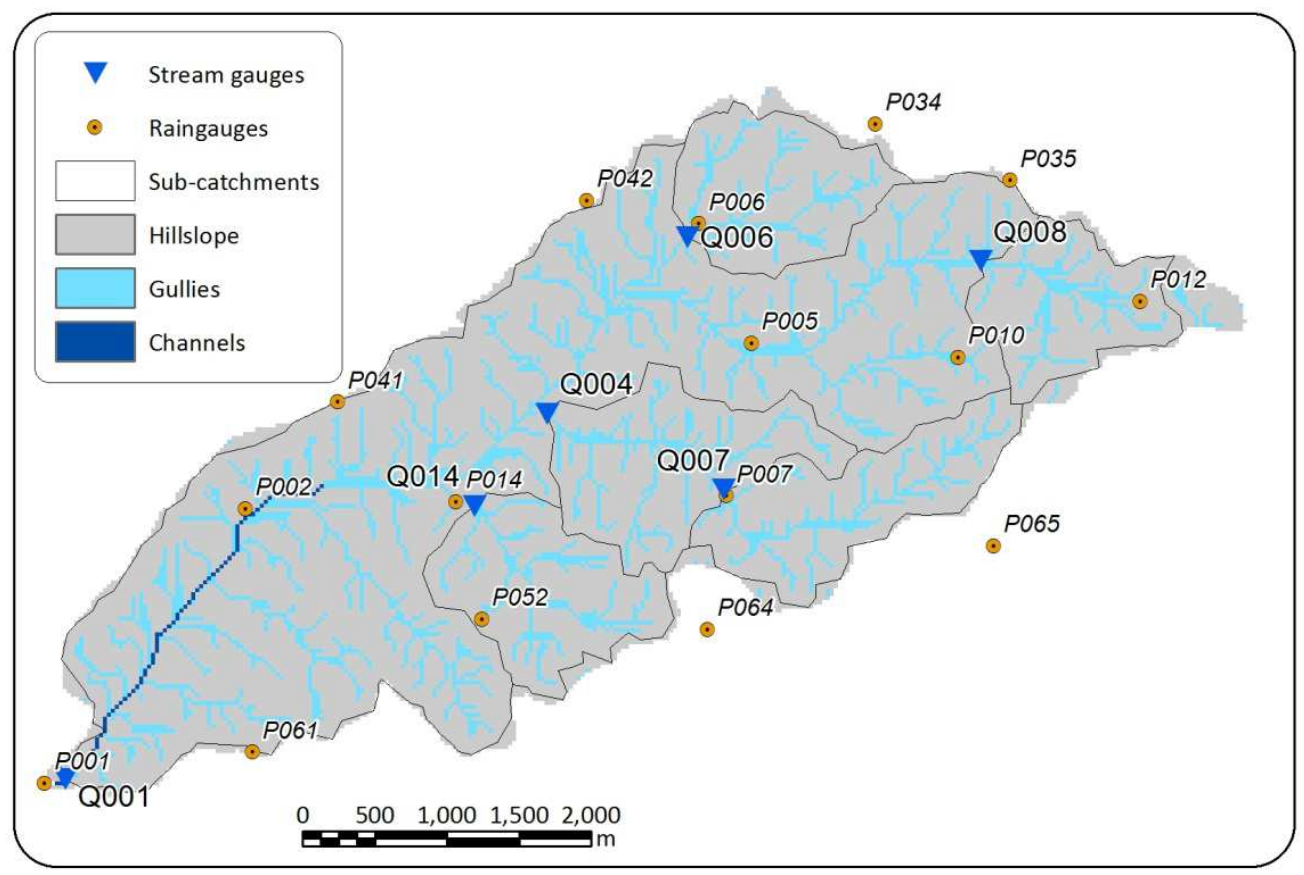

Figure 4.7-Gully and channel cells. 
Geomorphological parameters for hydraulic geometry relationships [Leopold and Maddock, 1953] were taken from Molnár and Ramírez [1998], and can be seen in Table 4.6.

\begin{tabular}{cc}
\hline Parameter & Value \\
\hline$\kappa$ & 0.8684 \\
$\varphi$ & 0.9500 \\
$a_{1}$ & 6.5160 \\
$\alpha_{1}$ & 0.4800 \\
$\alpha_{2}$ & 0.2000 \\
$c_{d}$ & 15.000 \\
$\theta$ & 1.0000 \\
$c_{n}$ & 0.0470 \\
$\xi$ & 0.1667 \\
\hline
\end{tabular}

Table 4.6 - Values for the hydraulic geometry coefficients and exponents.

\subsubsection{Sediment parameters}

Soil textural composition was also employed to estimate the $K$ factor of the USLE, while vegetation cover, crop type and tillage method information were used to estimate the $C$ factor of the USLE. Both maps are shown in Figure 4.8. The $P$ factor of the USLE was set to 1, since no support practice exists. Textural maps are also a direct input of the model, since they define the granulometric composition of eroded parental material from hillslopes (Figure 4.9).
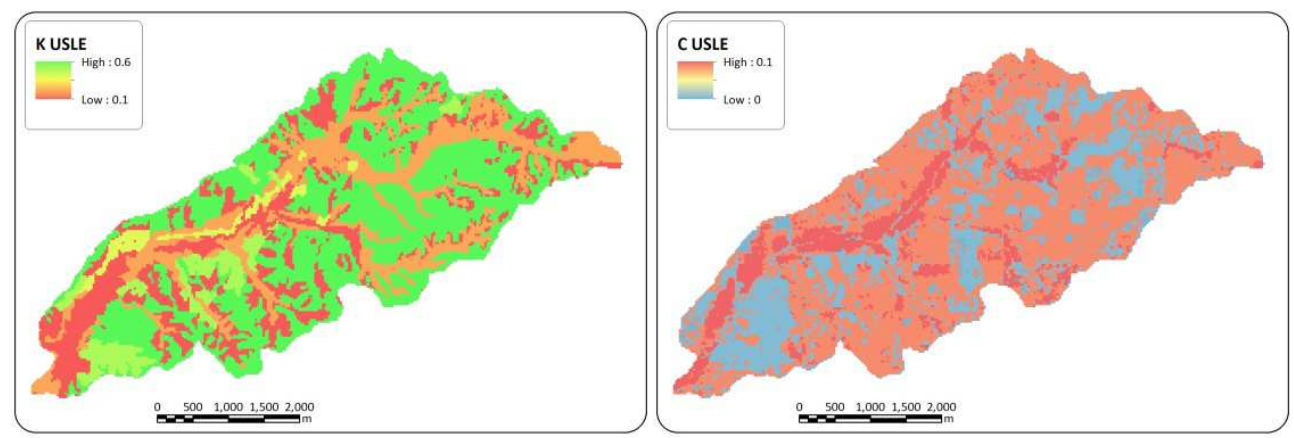

Figure 4.8 - K (left) and C (right) factors for the Goodwin Creek catchment. 


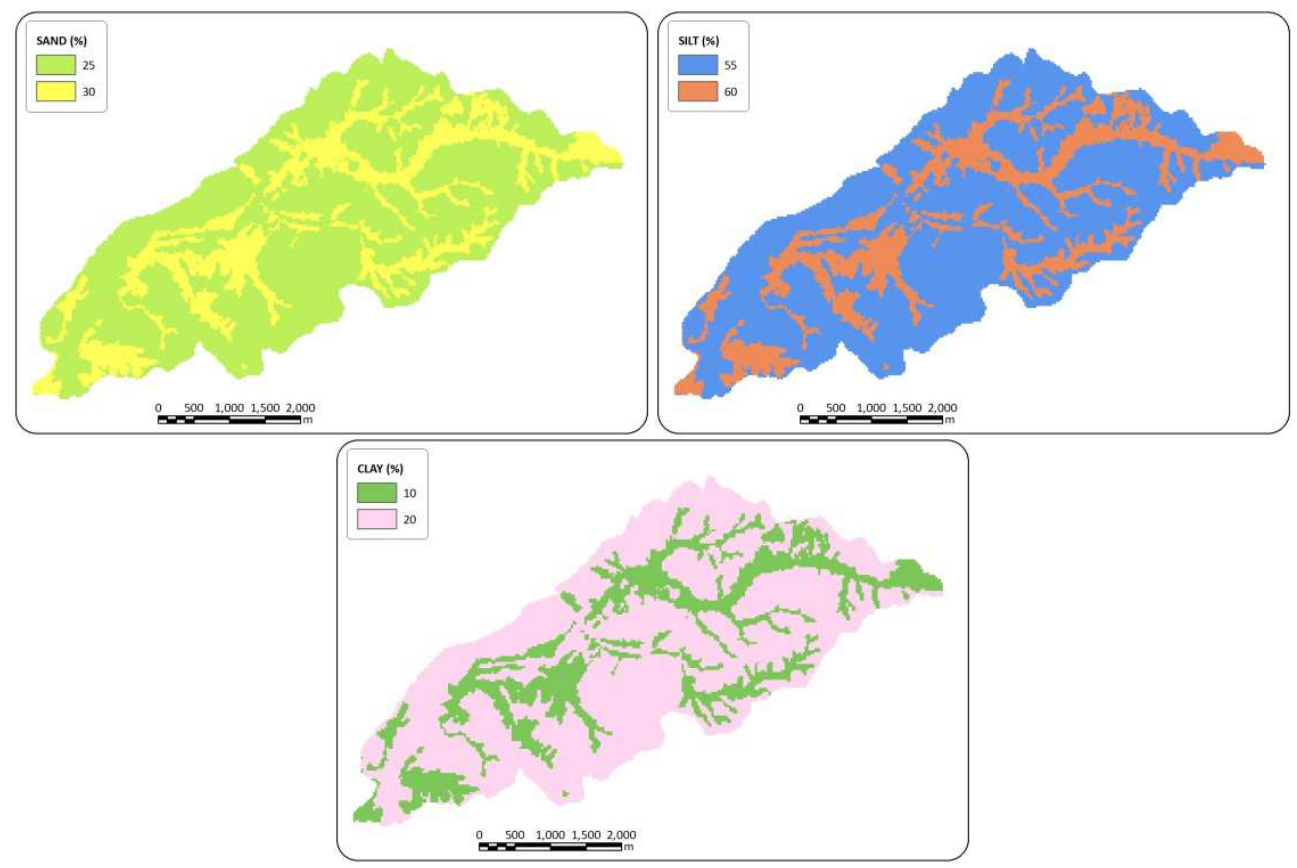

Figure 4.9 - Texture of the Goodwin Creek catchment soils.

\subsection{Results}

Given that soil erosion and sediment redistribution strongly depend on the hydrological cycle, Viney and Sivapalan [1999] proposed a two steps calibration procedure, which was adopted in this study: the hydrological sub-model was calibrated first, followed by the sedimentological sub-model. Both sub-models were implemented with a 5-minute temporal resolution.

The hydrological sub-model calibration was carried out automatically, using SCE-UA algorithm. The NSE index of the observed-simulated water discharge was used as objective function. The calibration was performed at catchment outlet (Q01) using the August 1982 event. The reliability of the calibrated model was further evaluated by checking that hydrological predictions were satisfactory on different storm events and locations (i.e., spatio-temporal validation [Oreskes et al., 1994]). Initial conditions of soil moisture, aquifer level and channel discharge were calibrated for all events.

Once the hydrological sub-model was validated, the sedimentological sub-model could be also calibrated and validated. Due to the model structure, the three sedimentological submodel parameters can be calibrated separately, depending on the availability of stream records and position of stream gauges. For all strategies, the sedimentological sub-model parameters were calibrated following this procedure: first the $\alpha$ parameter for the hillslope transport capacity and the $b_{1}$ parameter for the gully one were automatically calibrated in a small sub-catchment without any river channel cell (i.e., whose area was less than $15.3 \mathrm{~km}^{2}$ 
as defined previously), in this case the Q06 stream gauge station. Then, the $b_{2}$ parameter for the river channel transport capacity was automatically calibrated at the outlet (Q01), keeping fixed the values of $\alpha$ and $B_{1}$. This is possible thanks to the simple and flexible model calibration structure.

The model was calibrated on a single event (1982) in order to emphasise the effect of sediment initial condition on model calibration and validation. As for the hydrological submodel, spatial and spatiotemporal validations were also carried out. The NSE index of observed and simulated fine sediment discharges was the automatic calibration objective function. Moreover, a visual fit of observed and simulated fine sediment-water discharge relationships (the eventual hysteresis loop) was used to discard calibration sets which gave acceptable values of the NSE index but did not reproduce correctly the sediment dynamics of the catchment and to analyse the effect of sediment initial condition.

The sedimentological sub-model calibration and validation procedure was repeated varying the sediment initial condition (while the same hydrological initial condition was maintained), in order to analyse its effect on model implementation and results. First of all, the model was calibrated and validated with no initial deposits, i.e. the initial condition of deposited sediment was set to 0 . This was done in order to confirm the importance of inchannel sediment, as stated by many authors [e.g. Piest et al., 1975; Nistor and Church, 2005] and that the model is able to take it into account.

Then, the sediment initial condition was estimated through two methodologies: i) calibration and ii) simulation of a warm up period. Calibration of initial condition consists in manual adjustment of the initial amount of sediment deposited into the drainage network (where the word "initial" means at the beginning of the event to be simulated). Simulation of a warm up period consists in the simulation of a long period preceding the flood event to be simulated, in order to obtain a final sediment condition that will be used as initial condition for the event simulation. The chosen warm up period was long enough to make model results insensitive to its initial condition. For the sake of clarity, the strategies are called:

- $\quad$ strategy 0: no deposits;

- $\quad$ strategy 1: calibration;

- $\quad$ strategy 2: warm up simulation.

\subsubsection{Hydrological sub-model calibration and validation}

The calibration process was divided in two phases:

- $\quad$ in the first one, the 9 hydrological correction factors (CFs) were manually adjusted in order to find their feasible ranges;

- in the second one, an automatic calibration was carried out using the ranges previously found, obtaining the optimum calibration set.

The calibration was done at the catchment outlet (Q01) using the 1982 event (Figure 4.10 left). The resulting NSE index was higher than 0.95 . The validation was carried out on the remaining stream gauge stations (Q04, Q06, Q07 and Q08) for the same event (spatial 
validation, Figure 4.10 - right) and for all the other event in all stream gauge stations (temporal and spatio-temporal validation, Figure 4.11 and Figure 4.12).

The hydrological sub-model performs very good, following Moriasi et al. [2007] and provides an accurate prediction of stream flow across the catchment area. Moreover, the results provided by TETIS model reproduced the observed hydrological behaviour of the catchment: the runoff is almost entirely due to overland flow (99.6\%), with a little contribution from interflow $(0.4 \%)$ and a negligible contribution from base flow.

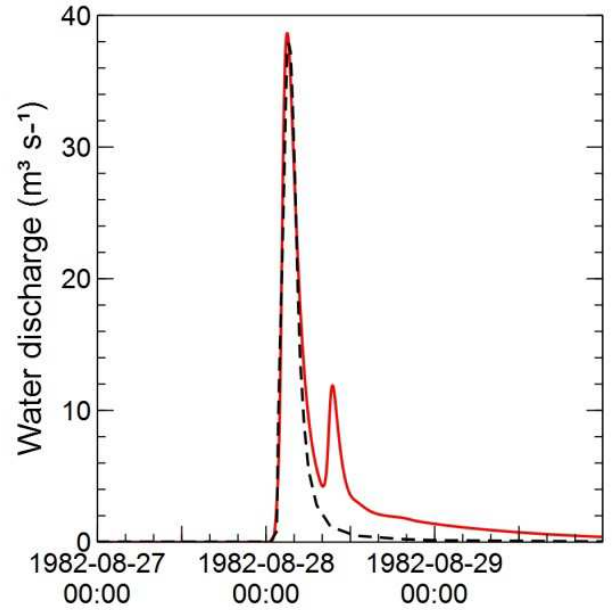

---- Observed discharge

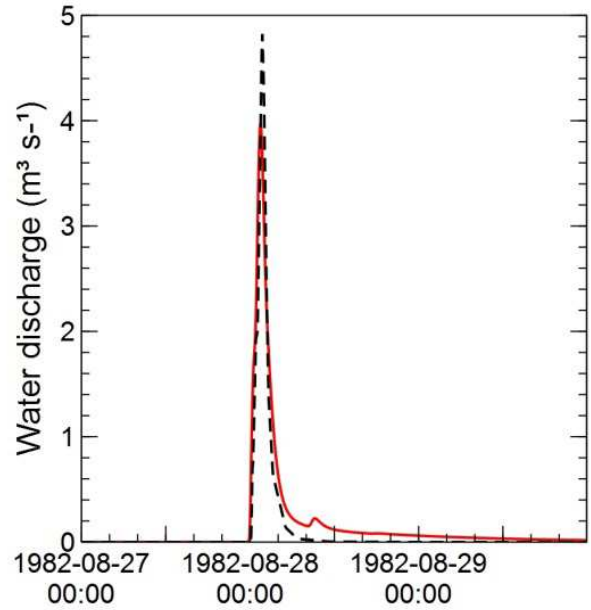

Simulated discharge

Figure 4.10 - Calibration and spatial validation on the August 1982 event in Q01 (left) and Q06 (right).

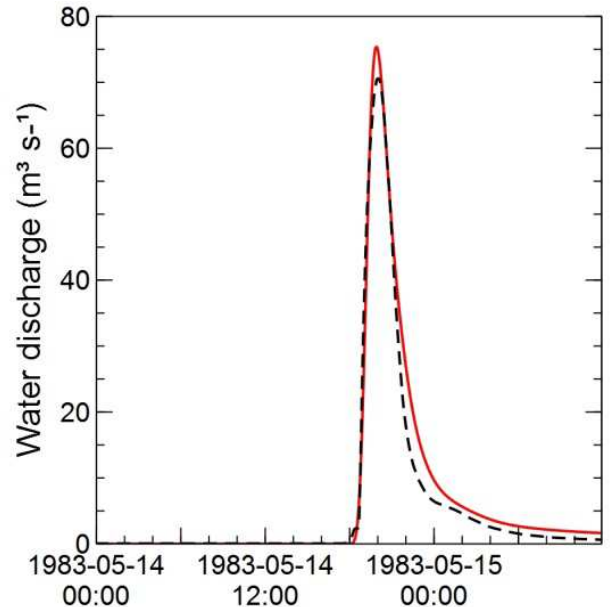

--- Observed discharge

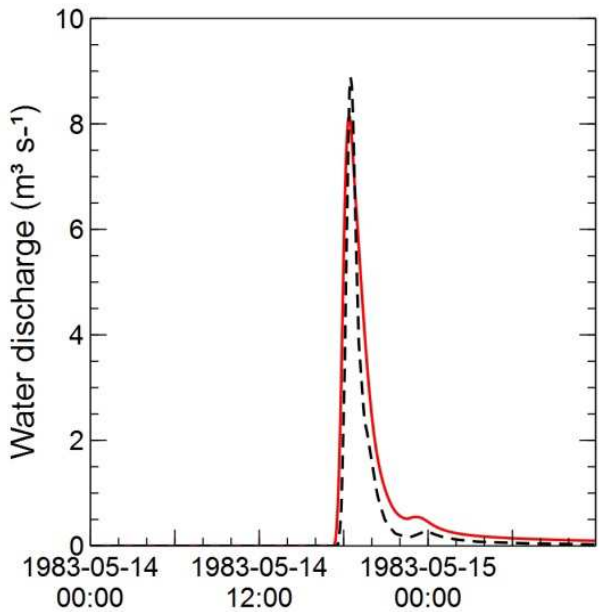

00:00 12:00 00:00

Figure 4.11 - Spatio-temporal validation on the May 1983 event in Q01 (left) and Q06 (right). 

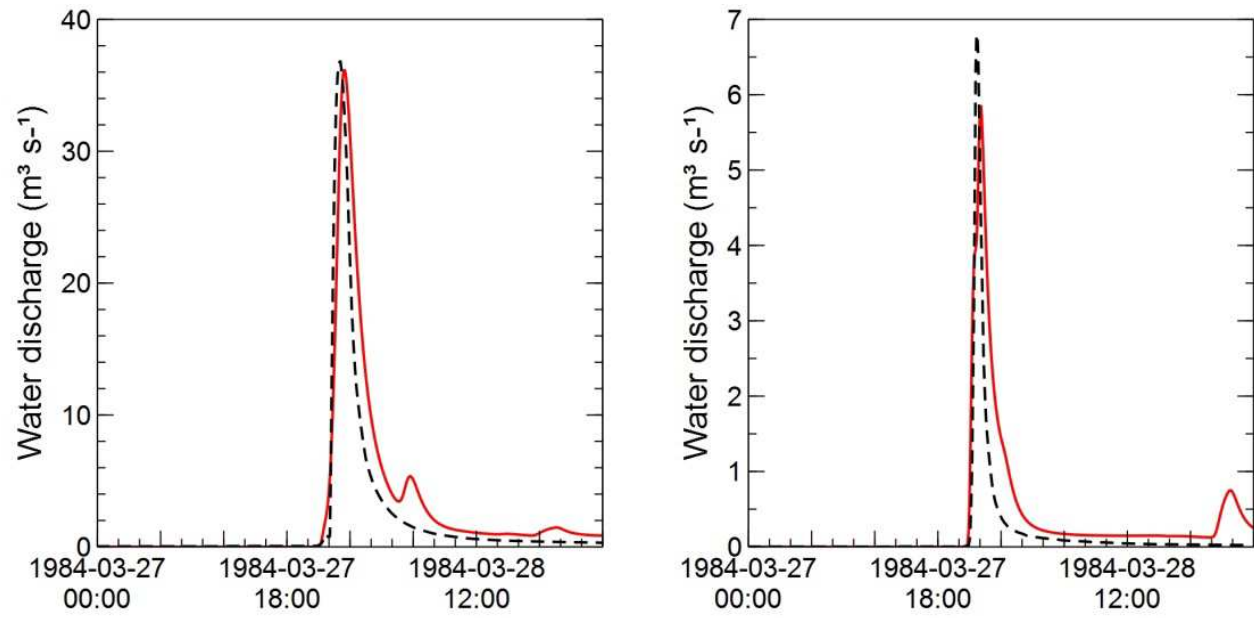

---- Observed discharge

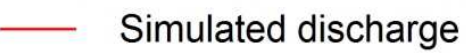

Figure 4.12 - Spatio-temporal validation on the April 1984 event in Q01 (left) and Q06 (right).

\begin{tabular}{|c|c|c|c|}
\hline Event & Station & NSE & VE \\
\hline & Q01 & 0.880 & $65 \%$ \\
\hline & Q04 & 0.917 & $4 \%$ \\
\hline \multirow[t]{5}{*}{$82-08-27$} & Q06 & 0.914 & $48 \%$ \\
\hline & Q07 & 0.772 & $-22 \%$ \\
\hline & Q08 & 0.850 & $-4 \%$ \\
\hline & Q01 & 0.825 & $32 \%$ \\
\hline & Q04 & 0.868 & $28 \%$ \\
\hline \multirow[t]{5}{*}{$83-03-04$} & Q06 & 0.675 & $67 \%$ \\
\hline & Q07 & 0.758 & $25 \%$ \\
\hline & Q08 & 0.695 & $8 \%$ \\
\hline & Q01 & 0.976 & $15 \%$ \\
\hline & Q04 & 0.975 & $8 \%$ \\
\hline \multirow[t]{5}{*}{$83-05-14$} & Q06 & 0.858 & $49 \%$ \\
\hline & Q07 & 0.884 & $-10 \%$ \\
\hline & Q08 & 0.882 & $-4 \%$ \\
\hline & Q01 & 0.890 & $53 \%$ \\
\hline & Q04 & 0.938 & $39 \%$ \\
\hline \multirow[t]{5}{*}{ 83-11-19 } & Q06 & 0.643 & $55 \%$ \\
\hline & Q07 & 0.713 & $61 \%$ \\
\hline & Q08 & 0.824 & $38 \%$ \\
\hline & Q01 & 0.824 & $36 \%$ \\
\hline & Q04 & 0.910 & $1 \%$ \\
\hline \multirow[t]{3}{*}{$84-03-27$} & Q06 & 0.612 & $91 \%$ \\
\hline & Q07 & 0.900 & $-15 \%$ \\
\hline & Q08 & 0.788 & $-19 \%$ \\
\hline
\end{tabular}

Table 4.7 - Hydrological calibration and validation results of the Goodwin Creek catchment TETIS hydrological sub-model. 
In Table 4.8 the calibrated correction factors are shown.

\begin{tabular}{cc}
\hline Correction factor & Value \\
\hline CF1 & 0.5583 \\
CF2 & 1.0000 \\
CF3 & 0.0897 \\
CF4 & 0.1083 \\
CF5 & 1.0000 \\
CF6 & 100.0000 \\
CF7 & 10.0000 \\
CF8 & 0.0000 \\
CF9 & 0.3030 \\
\hline
\end{tabular}

Table 4.8-Correction factor for the Goodwin Creek model.

\subsubsection{Sedimentological sub-model calibration and validation}

Due to the model structure, the sedimentological sub-model parameters can be calibrated separately, depending on the availability of observed stream records and position of stream gauges. For all strategies, the sedimentological sub-model parameters were calibrated following this procedure:

- $\quad$ in a first step the $\alpha$ parameter for the hillslope transport capacity equation (3.18) and the $b_{1}$ parameter for the gully one in equation (3.19) were calibrated in a small sub-catchment without any river channel (i.e., whose area was less than $15.3 \mathrm{~km}^{2}$ as defined previously), in this case the Q06 stream gauge station;

- $\quad$ then, in a second step, the $B_{2}$ parameter in (3.19) for the river channel transport capacity was calibrated at the outlet (Q01), keeping fixed the values of $\alpha$ and $B_{1}$.

The sediment data used were fine sediment discharge series resampled from original observed data with 5-minute time resolution, as specified above.

In Table 4.9 the calibrated correction factors are shown. The results are discussed from here on in.

\begin{tabular}{cccc}
\hline & $\mathbf{0}$ & $\mathbf{1}$ & $\mathbf{2}$ \\
\hline$\alpha$ & 0.666 & 0.597 & 0.051 \\
$\beta_{1}$ & 1.080 & 0.535 & 0.198 \\
$\beta_{2}$ & 2.974 & 4.969 & 1.002 \\
\hline
\end{tabular}

Table 4.9-Goodwin Creek calibrated correction factors

The obtained values for the three different strategies show some relevant differences, providing a preliminary confirmation that sediment initial condition strongly affects the TETIS model calibration. From Table 4.9 it can be seen that strategy 0 provides higher $\alpha$ and $\beta_{1}$ coefficients (i.e. higher transport capacity) than the other strategies. This is due to the strong influence of sediment initial condition on model functioning. If no material is available for gully erosion, the transport capacity must be higher in order to compensate this effect and obtain correct results. 
As expected, it was noticed that textural composition of deposited sediments strongly affected hysteresis loops. For this reason, in strategy 1 the sediment texture was also calibrated, apart from calibrating the sediment volume deposited into the stream network. Table 4.10 shows the sediment volume set as initial sediment condition for strategy 1 . The material set as initial condition is rather coarse. Gully sediment is usually coarser than channel sediment. This is logical, given that fine sediment tends to be washed out and transported downstream while coarser sediment is more likely to be deposited, proportionally to the drainage network slope, usually lower for river channels than for gullies.

\begin{tabular}{ccccc}
\hline & $\begin{array}{c}\text { Volume } \\
\left(\mathbf{m}^{3} \mathbf{m}^{-1}\right)\end{array}$ & Sand (\%) & Silt (\%) & Clay (\%) \\
\hline Aug-1982 & & & & \\
\hline $\begin{array}{c}\text { Gullies } \\
\text { River channels }\end{array}$ & 0.034 & 98 & 2 & 0 \\
\hline Mar-1983 & 0.033 & 100 & 0 & 0 \\
\hline Gullies & 0.042 & 78 & 22 & 0 \\
River channels & 0.033 & 100 & 0 & 0 \\
\hline May-1983 & & & & \\
\hline Gullies & 0.0035 & 96 & 3 & 1 \\
River channels & 0.085 & 39 & 59 & 2 \\
\hline Nov-1983 & & & & 0 \\
\hline Gullies & 0.033 & 100 & 0 & 0 \\
River channels & 0.036 & 91 & 9 & 0 \\
\hline Mar-1984 & & & & 0 \\
\hline Gullies & 0.050 & 67 & 33 & 0 \\
River channels & 0.033 & 100 & & \\
\hline
\end{tabular}

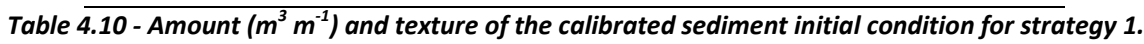

Table 4.11 shows the sedimentological sub-model calibration and validation results in terms of NSE, calculated on observed/simulated fine sediment series. Median NSE values are $0.564,0.598$ and 0.572 for strategy 0,1 and 2 respectively. The standard deviation of all NSE values is higher for strategy 1 , due to some outlier values such as the ones obtained for events March 1983 and May 1983 - station Q06, and lower for strategy 0. The model validation performances were also assessed in terms of Root Mean Square Error (RMSE), providing median values of $0.00231,0.00236$ and 0.00201 respectively, and in terms of Mean Absolute Error (MAE), providing median values equal to $0.000436,0.000591$ and 0.000546 respectively. More information on these performance indexes can be found in Bennett et al. [2013]. Strategy 0 provided the best results in terms of MAE, strategy 1 provided the best results in terms of NSE and strategy 2 provided the best results in terms of RMSE, although all values are substantially similar. Both RMSE and NSE tend provide better results when larger sediment discharges are well reproduced, though RMSE is more influenced by outliers. On the other hand, MAE reduces the bias towards highest peaks [Bennett et al., 2013]. Given that sediment transport is a non-linear time-compressed process, more relevance should be given to higher sediment discharges, i.e. to NSE and 
RMSE. Therefore, it can be stated that strategy 1 and 2 obtained the best results, although the performances of all strategies are comparable and almost equivalent. Furthermore, no dependency could be found between model strategy performance and event magnitude or duration. This means that no conclusion can be stressed on whether a strategy is more suitable than the other two for some given flood event characteristics. The model performances of the three strategies for all events are very similar and there is no evidence that a strategy could perform better than the others under some given event characteristics such as water or fine sediment discharge peak or volume.

The model results in terms of fine sediment volume simulation confirm what stated above: the performances are satisfactory and comparable. The median error is $+2 \%,+16 \%$ and $+5 \%$ for strategy 0, 1 and 2 respectively, and the volume error is included into the $\pm 50 \%$ band respectively for the $48 \%, 44 \%$ and $44 \%$ of the cases. Strategy 1 slightly tends to overestimate fine sediment volume, as the volume error is positive in $60 \%$ of cases, while for strategies 0 and 2 the percentage of positive volume errors is $52 \%$ and $56 \%$ respectively.

\begin{tabular}{|c|c|c|c|c|}
\hline Event & Strategy & 0 & 1 & 2 \\
\hline \multirow{5}{*}{ Aug-1982 } & Q01 & 0.7678 & 0.7860 & 0.7848 \\
\hline & Q04 & 0.3145 & 0.3610 & 0.3482 \\
\hline & Q06 & 0.9126 & 0.9166 & 0.9334 \\
\hline & Q07 & 0.5241 & 0.6375 & 0.5030 \\
\hline & Q08 & 0.5407 & 0.6363 & 0.8279 \\
\hline \multirow{5}{*}{ Mar-1983 } & Q01 & 0.5059 & 0.4336 & 0.6431 \\
\hline & Q04 & 0.6482 & 0.0341 & 0.6346 \\
\hline & Q06 & 0.7024 & -1.8177 & -0.9917 \\
\hline & Q07 & 0.4729 & -0.8129 & 0.5715 \\
\hline & Q08 & 0.3904 & -0.1086 & 0.5042 \\
\hline \multirow{5}{*}{ May-1983 } & Q01 & 0.8849 & 0.9086 & 0.9175 \\
\hline & Q04 & 0.5441 & 0.5980 & 0.8473 \\
\hline & Q06 & -1.8006 & -1.9406 & -1.1217 \\
\hline & Q07 & 0.5637 & 0.5766 & 0.3208 \\
\hline & Q08 & 0.9040 & 0.8905 & 0.8141 \\
\hline \multirow{5}{*}{ Nov-1983 } & Q01 & 0.5449 & 0.6965 & 0.5214 \\
\hline & Q04 & 0.9302 & 0.9157 & 0.9260 \\
\hline & Q06 & -0.2701 & 0.0534 & -1.0347 \\
\hline & Q07 & 0.8981 & 0.8620 & 0.8303 \\
\hline & Q08 & 0.7167 & 0.6850 & 0.6912 \\
\hline \multirow{5}{*}{ Mar-1984 } & Q01 & 0.5743 & 0.7027 & 0.5695 \\
\hline & Q04 & 0.6924 & 0.7706 & 0.5782 \\
\hline & Q06 & 0.5844 & 0.5264 & 0.5412 \\
\hline & Q07 & 0.2946 & 0.4078 & 0.1691 \\
\hline & Q08 & 0.2241 & 0.3540 & 0.2142 \\
\hline
\end{tabular}

Table 4.11 - Sedimentological sub-model calibration and validation results in terms of NSE for all strategies (in grey the calibration event - August 1982 - and the calibration stations - Q01 and Q06). 
Figure 4.13 depicts the scatterplot of observed versus modelled fine sediment volume for each strategy. The results from five flood events and five stream gauge stations are shown.

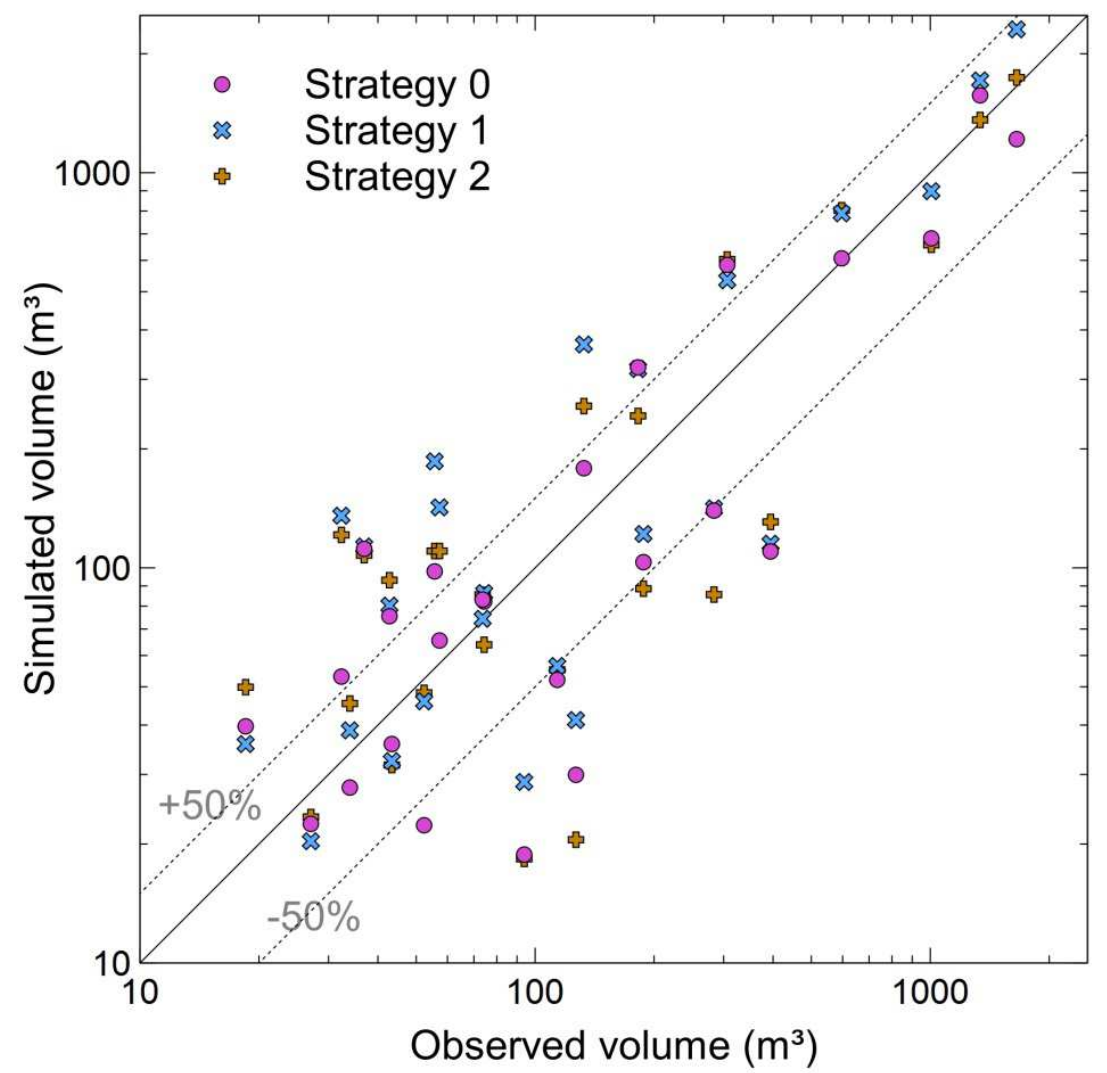

Figure 4.13 - Observed vs simulated fine sediment volume for 5 event and 5 stream gauge stations, for all strategies.

Figure 4.14, Figure 4.15, Figure 4.16, Figure 4.17 and Figure 4.18 show the model results in terms of observed vs simulated sedigraph and observed vs simulated hysteresis loop, for stations Q01, Q04, Q06, Q07 and Q08 respectively. 

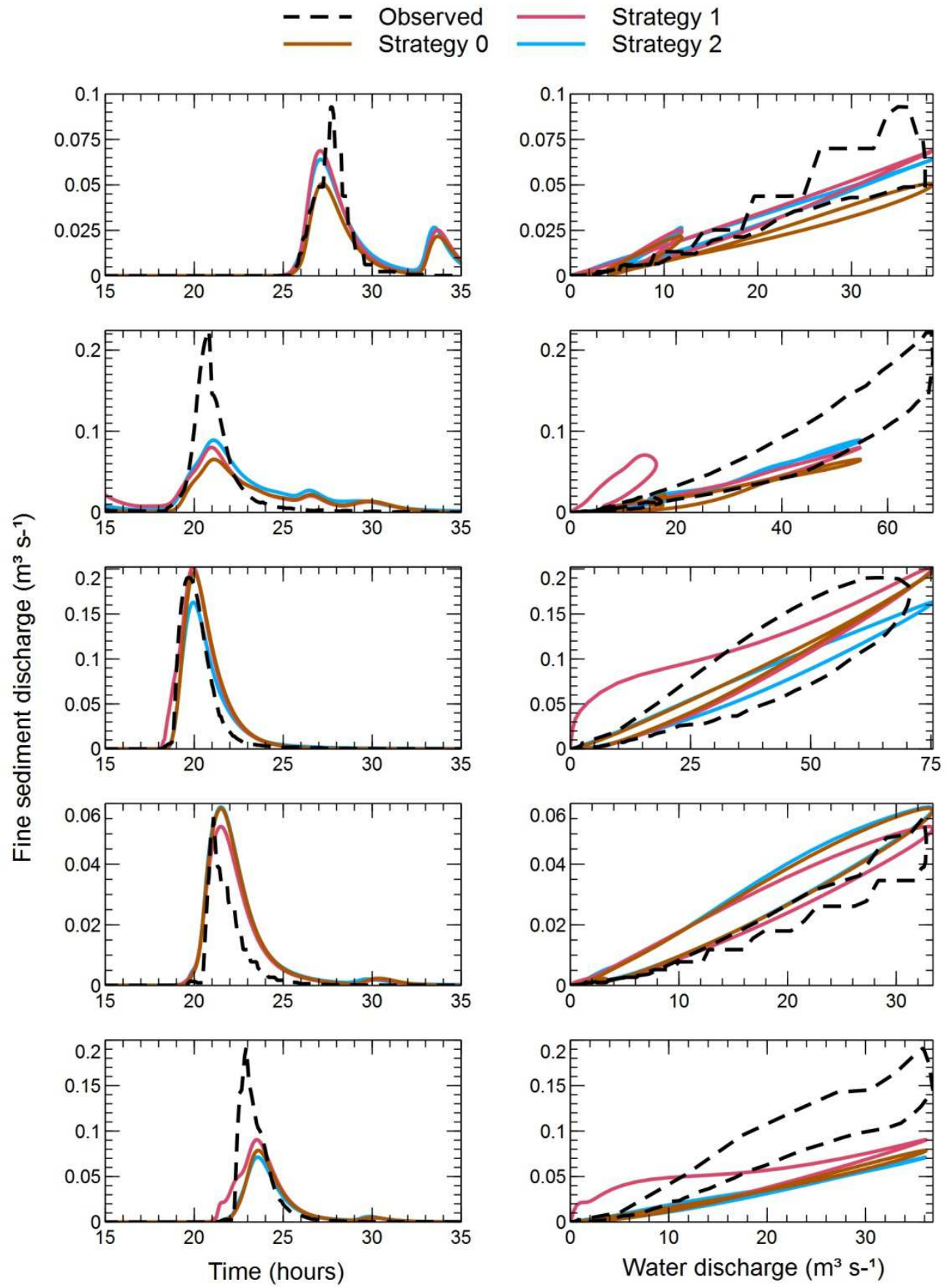

Figure 4.14-Observed and simulated sedigraphs (left) and hysteresis loops (right) for station Q01. 

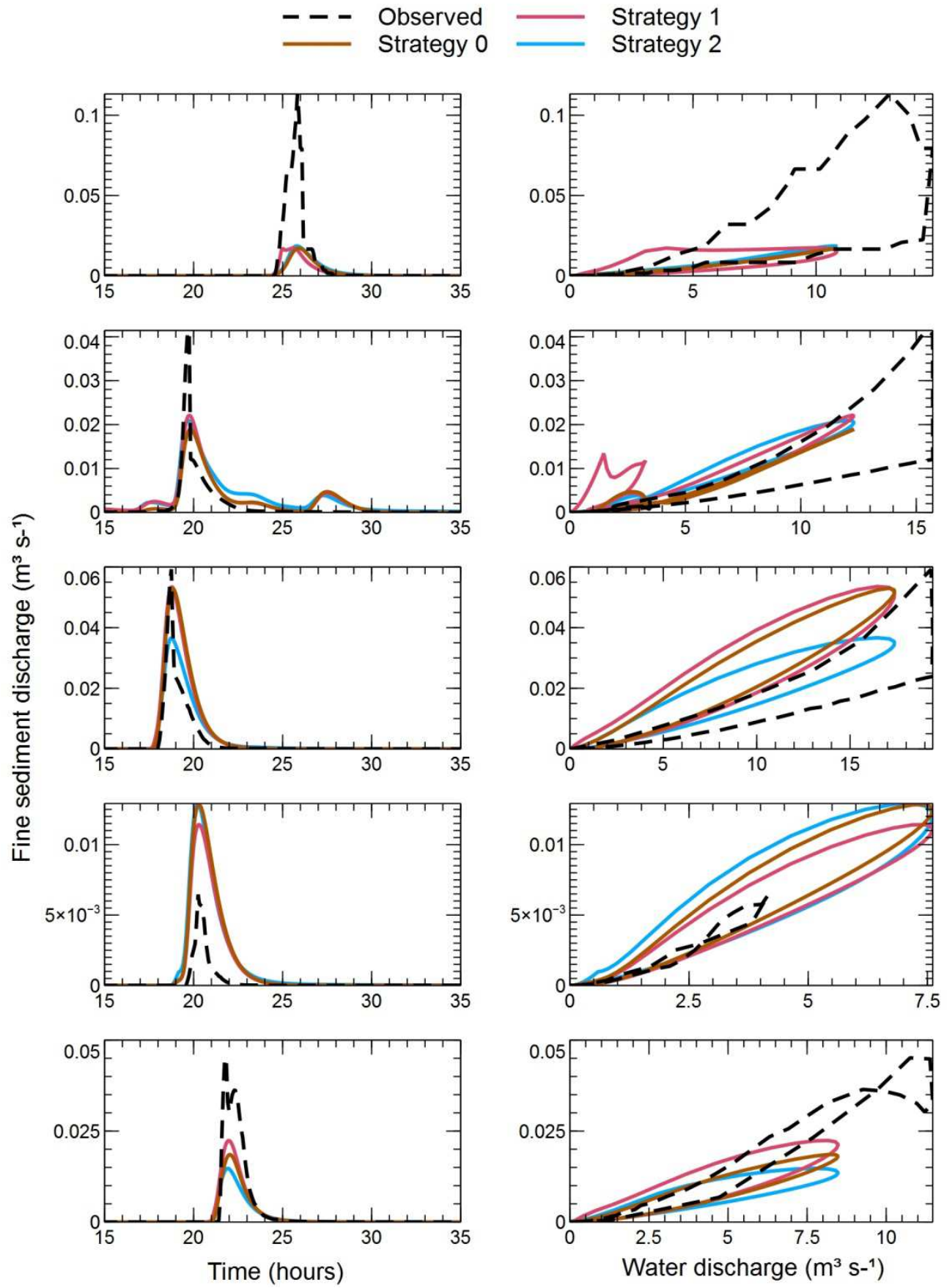

Figure 4.15 - Observed and simulated sedigraphs (left) and hysteresis loops (right) for station Q04. 

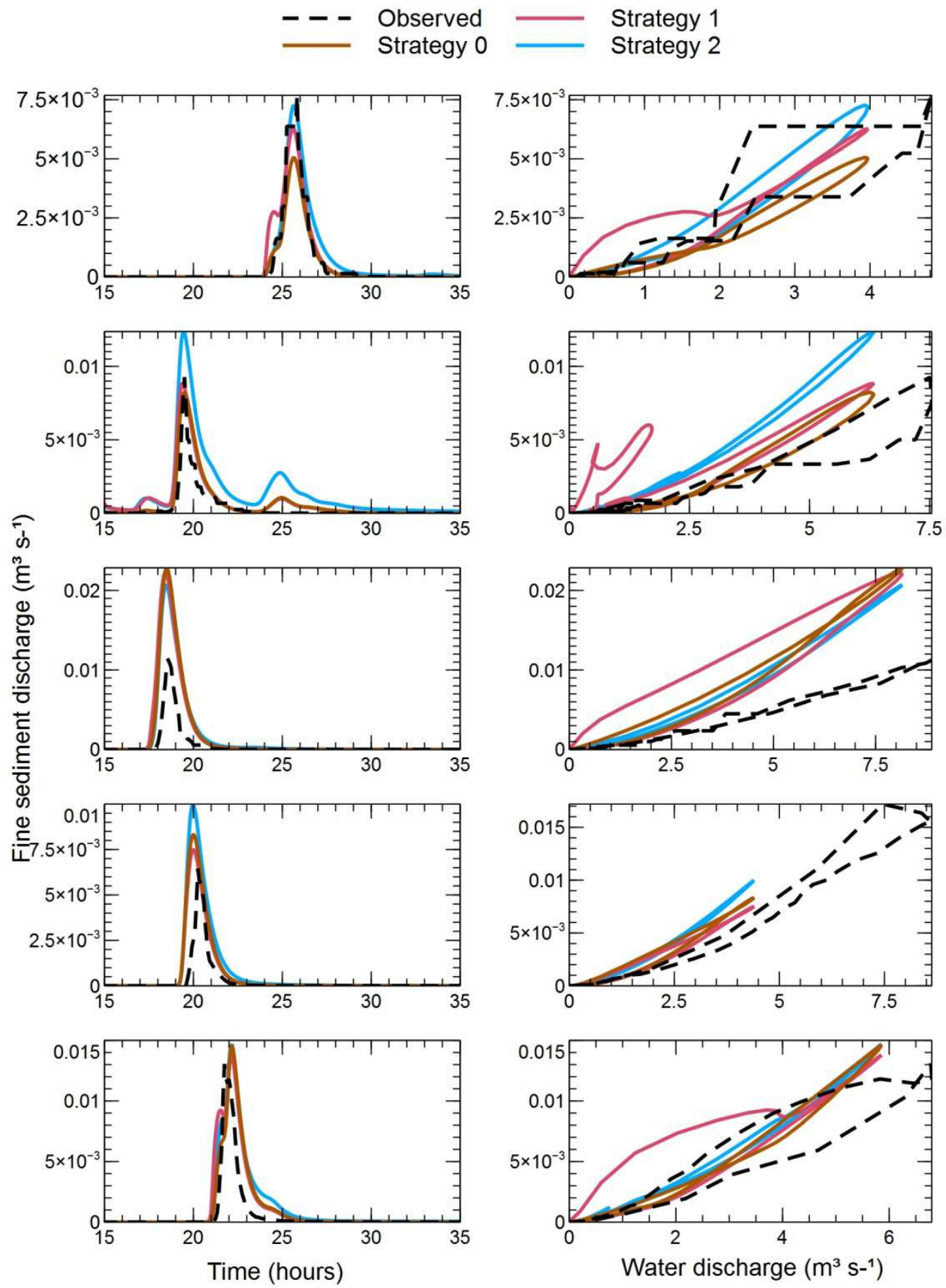

Figure 4.16 - Observed and simulated sedigraphs (left) and hysteresis loops (right) for station Q06. 

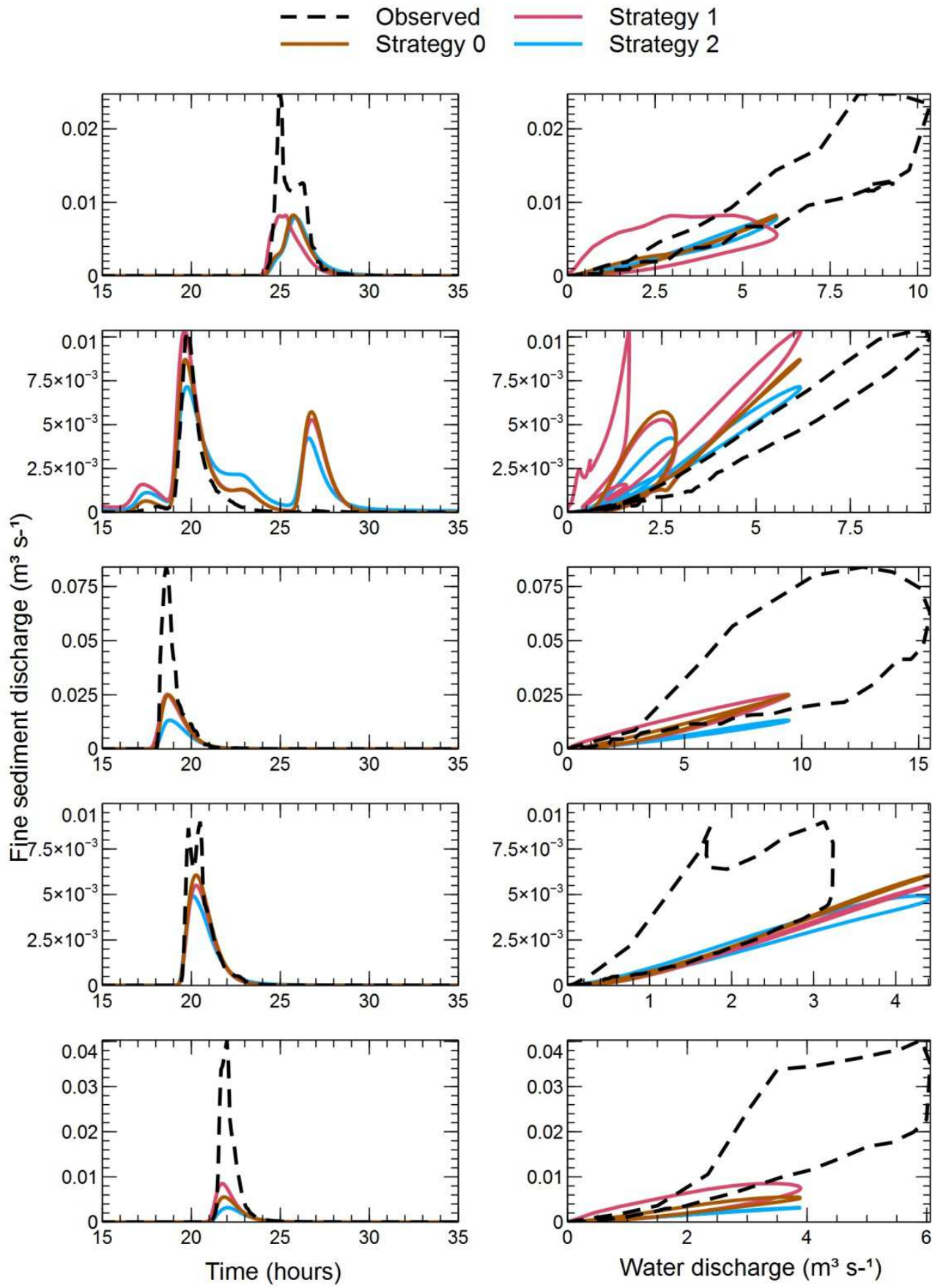

Figure 4.17-Observed and simulated sedigraphs (left) and hysteresis loops (right) for station Q07. 

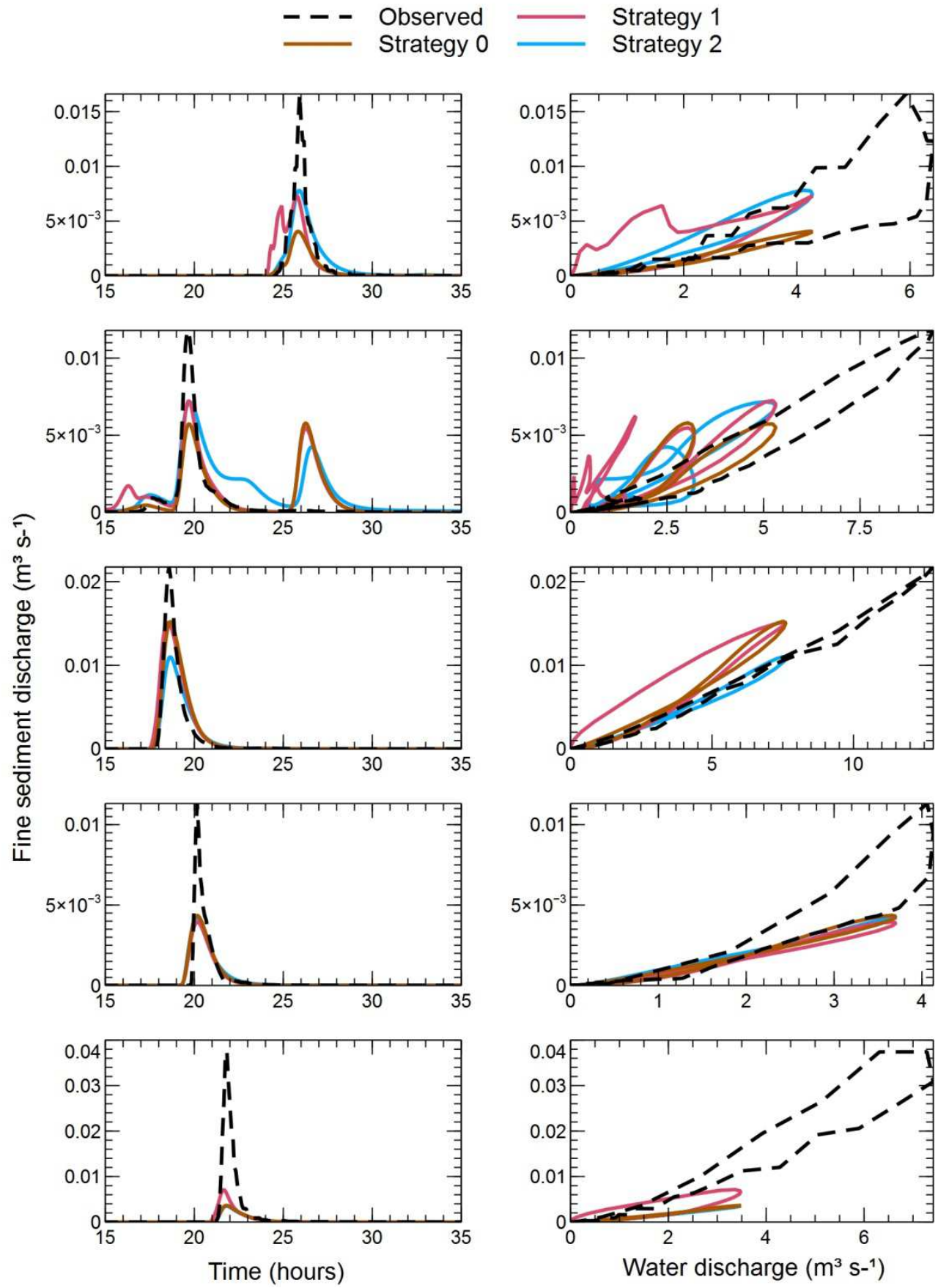

Figure 4.18-Observed and simulated sedigraphs (left) and hysteresis loops (right) for station Q08. 
Table 4.11 and Figure 4.13 show that all strategies provide satisfactory results in terms of fine sediment discharge and volume reproduction for almost all events and stream gauge stations. The model performance is substantially similar for all strategies, and no systematic bias can be found for none of the employed strategies. Nevertheless, a deeper analysis is required in order to assess the model behaviour. For this reason, an exhaustive hysteresis loop analysis, which is discussed as follows, was also carried out.

Figure 4.14 to Figure 4.18 present the hysteresis loops observed in the water discharge fine sediment discharge relationship for all stream gauges. It can be seen that all strategies behave differently in terms of hysteresis loop. In the calibration event, August 1982, the best behaviour was given by the strategy 2, both at Q01 and Q06, although all simulated loops are rather thinner than the observed ones. For March 1983 event, all models failed in reproducing the hysteresis loop at Q01, due to a substantial underestimation of the fine sediment peak discharge. At Q06 only strategy 1 showed a hysteresis loop. Concerning May 1983 event, strategies 1 and 2 obtained an acceptable reproduction of the hysteresis loop at Q01. At Q06, all strategies failed in hysteresis loop reproduction due to overestimation of observed fine sediment peak. Regarding November 1983 event, all strategies obtained a rather good reproduction of the hysteresis loop at Q01, but only strategies 0 and 1 simulated the existence of a loop at Q06. Lastly, for March 1984 event, none of the proposed strategies obtained acceptable performances at Q01, while at Q06 only the results of strategy 1 can be considered acceptable.

The shape of hysteresis loops was also analysed. Among the observed data of the available five events and five stream gauge stations, four types of loops were identified, following Nistor and Church [2005], as shown in Figure 4.19: unique curve (no hysteresis loop), clockwise loop, counter clockwise loop and eight-shaped loop.

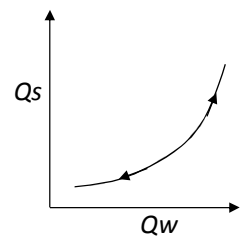

Unique curve

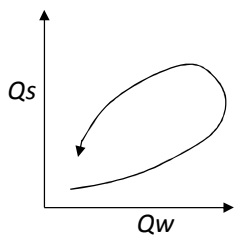

Counter clockwise loop

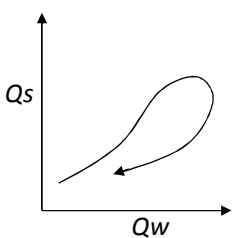

Clockwise loop

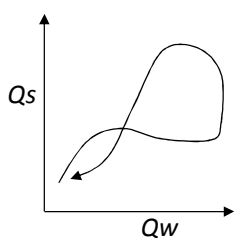

Eight-shaped loop

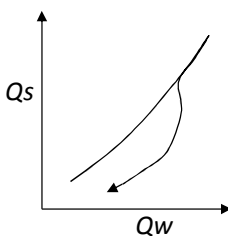

Loop and unique curve

Figure 4.19- Hysteresis loop types (modified form Nistor and Church, 2005). Qs indicates sediment discharge and Qw indicates water discharge.

Clockwise loop was the most frequent type (18 times out of 25), followed by counter clockwise loop (3), eight-shaped loop (3) and unique curve (1). A further type of curve was detected among the simulation results: the loop and unique curve. This last type denotes the development of a hysteresis loop (usually clockwise) which cannot be completed due to an early lack of available material. 
Strategy 0 provided 7 clockwise loops (out of 25 cases), 6 unique curves, 6 eight-shaped loops, 3 counter clockwise loops and 2 loop and unique curves. Strategy 1 provided a clear majority of clockwise loops (20), 2 loop and unique curves, one counter clockwise loop, one eight-shaped loop and one unique curve. Strategy 2 provided 9 counter clockwise loops, 8 clockwise loops, 5 unique curves 2 eight-shaped loops and one loop and unique curve. These results indicate that strategy 0 tends to show no loop (or unique curve), as expected, given that sediment initial condition in gullies and channels is one of the main causes of hysteresis loop generation. On the other hand, strategy 1 tends to provide in almost all cases a clockwise loop. This is can be considered a positive result, given that observed data also show that clockwise loops are the most frequent type of water/sediment discharge relationship. Strategy 2 offers controversial results, as is capable to reproduce all types of loops, but tends to provide many counter clockwise loops which were not observed in measured data.

\begin{tabular}{|c|c|c|c|c|c|}
\hline & & Observed loop & Strategy 0 & Strategy 1 & Strategy 2 \\
\hline \multirow{5}{*}{ Aug-82 } & Q01 & Counter clockwise & Counter clockwise & Clockwise & Clockwise \\
\hline & Q04 & Clockwise & Unique curve & Clockwise & Eight-shaped \\
\hline & Q06 & Clockwise & Eight-shaped & Loop-unique & Counter clockwise \\
\hline & Q07 & Clockwise & Loop-unique & Clockwise & Counter clockwise \\
\hline & Q08 & Eight-shaped & Eight-shaped & Clockwise & Counter clockwise \\
\hline \multirow{5}{*}{ Mar-83 } & Q01 & Clockwise & Counter clockwise & Clockwise & Unique curve \\
\hline & Q04 & Clockwise & Unique curve & Clockwise & Clockwise \\
\hline & Q06 & Clockwise & Counter clockwise & Clockwise & Unique curve \\
\hline & Q07 & Clockwise & Unique curve & Clockwise & Counter clockwise \\
\hline & Q08 & Clockwise & Clockwise & Counter clockwise & Counter clockwise \\
\hline \multirow{5}{*}{ May-83 } & Q01 & Clockwise & Unique curve & Clockwise & Clockwise \\
\hline & Q04 & Clockwise & Clockwise & Clockwise & Clockwise \\
\hline & Q06 & Counter clockwise & Loop-unique & Clockwise & Unique curve \\
\hline & Q07 & Clockwise & Clockwise & Clockwise & Counter clockwise \\
\hline & Q08 & Unique curve & Eight-shaped & Clockwise & Counter clockwise \\
\hline \multirow{5}{*}{ Nov-83 } & Q01 & Clockwise & Clockwise & Clockwise & Clockwise \\
\hline & Q04 & Clockwise & Clockwise & Clockwise & Clockwise \\
\hline & Q06 & Eight-shaped & Loop-unique & Clockwise & Unique curve \\
\hline & Q07 & Clockwise & Unique curve & Unique curve & Clockwise \\
\hline & Q08 & Clockwise & Eight-shaped & Eight-shaped & Eight-shaped \\
\hline \multirow{5}{*}{ Mar-84 } & Q01 & Clockwise & Eight-shaped & Clockwise & Loop-unique \\
\hline & Q04 & Eight-shaped & Clockwise & Clockwise & Clockwise \\
\hline & Q06 & Counter clockwise & Eight-shaped & Loop-unique & Counter clockwise \\
\hline & Q07 & Clockwise & Clockwise & Clockwise & Unique curve \\
\hline & Q08 & Clockwise & Unique curve & Clockwise & Counter clockwise \\
\hline
\end{tabular}

Table 4.12 - Hysteresis loop shape analysis.

In order to evaluate all strategies from a loop reproduction point of view, the number of correct guesses (i.e. the number of times the model reproduce correctly the loop shape) 
was accounted for each strategy. Strategy 0 obtained the right loop shape 8 times, strategy 1 obtained the right loop shape 14 times and strategy 2 obtained the right loop shape 7 times (Table 4.12).

These results show that, although model performances were highly satisfactory in terms of NSE or sedigraph reproduction, the model sometimes fails in reproducing adequately water/sediment relationship, no matter what strategy is used. This indicates that the catchment internal dynamics (i.e. sediment sources, distribution of deposited material, deposition zones and sediment redistribution, etc.) is, in some cases, not properly reproduced by the model, even if the sedigraph reproduction is adequate.

Concerning strategy evaluation, strategy 1 is clearly the most appropriate for hysteresis loop reproduction. Strategy 0 tends to show a unique curve, and for this reason is not adequate for loop simulation. An interesting example of this statement is May 1983 event at Q01 (strategy 0): both visual fit (Figure 4.14, third row, left) and NSE (Table 4.11) indicate a very good performance, but no hysteresis loop is simulated, while the observed data show a clockwise loop (Figure 4.14, third row, right). Strategy 2 looks, in some cases, also rather inadequate for loop reproduction, although it is the only strategy which appears capable of representing all loop types. For example is the only strategy capable to reproduce the counter clockwise loop in March 1984 event, Q06 station.

In order to asses from a quantitative point of view the hysteresis loop simulation performance, the Hysteresis Index ( $\left.H I_{\text {mid }}\right)$ presented by Lawler et al. [2006] was calculated for each event and each station. This index is based on measuring the 'fatness' of the loop at a given intermediate point between the maximum and the minimum water discharge (in this case at the $50 \%$ of the water discharge, as done by Lawler et al. [2006]). This index is calculated by firstly determining the mid-point discharge $\left(Q_{w, \text { mid }}\right)$ :

$$
Q_{w, \text { mid }}=0.5 \times\left(Q_{w, \max }-Q_{w, \min }\right)+Q_{w, \min } \quad\left[\mathrm{m}^{3} \mathrm{~s}^{-1}\right]
$$

Where $Q_{w, \min }$ and $Q_{w, \max }$ are the minimum and maximum water discharge. Then, the two sediment discharge values corresponding to $Q_{w, m i d}$ in the water/sediment discharge plot $\left(Q_{s, R L}\right.$ and $Q_{s, F L}$, sediment discharge corresponding to $Q_{w, m i d}$ on the rising limb and falling limb of the hydrograph, respectively) are computed, and $\mathrm{HI}_{\text {mid }}$ is calculated as follows:

If $Q_{s, R L}>Q_{s, F L}:$

$$
H I_{\text {mid }}=Q_{s, R L} / Q_{s, F L}-1 \quad[-]
$$

If $Q_{s, R L}<Q_{s, F L}$ :

$$
H I_{\text {mid }}=-1 /\left(Q_{s, R L} / Q_{s, F L}\right)+1 \quad[-]
$$

The interpretation of this index is very simple: the greater the hysteresis, the greater $H I_{\text {mid }}$. This index can also distinguish between clockwise and counter clockwise loops, depending on the sign of its value (positive for clockwise and negative for counter clockwise), although 
it does not recognise eight-shaped and unique loops. This index was computed for the 25 observed loops and for the $25 \times 3$ simulated loops. The results are shown in Figure 4.20.

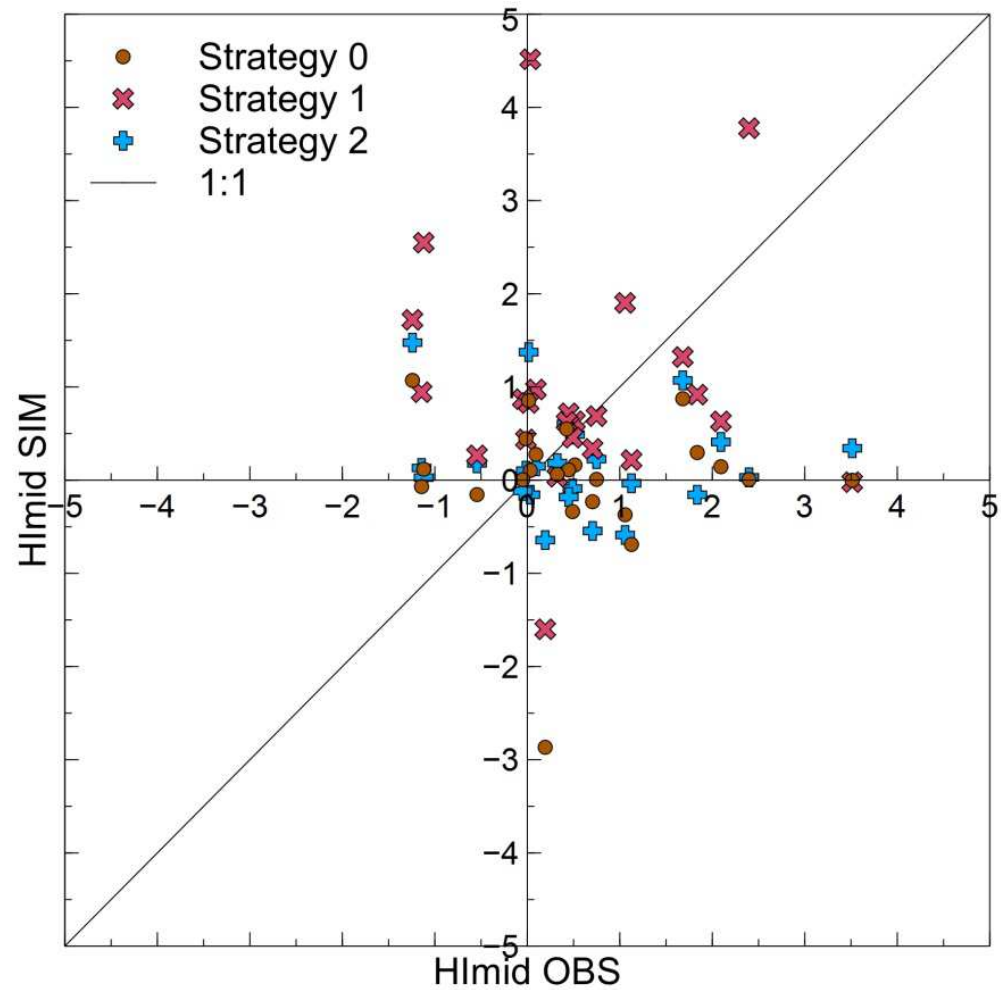

Figure 4.20-Observed vs simulated Hysteresis Index for all strategies.

Nineteen of observed loops showed a positive index value while the other six loops a negative value. As can be seen in Figure 4.20, the model behaviour is acceptable for positive values. In particular, strategy 1 , as previously noticed with a visual loop analysis, provided the best behaviour in reproducing clockwise hysteresis, as it obtained the best model performance in 12 cases out of the 19 positive values. On the other hand, the model is often failing in reproducing negative values, given the high number of points in the up-left quadrant. Only strategy 2 can reproduce some negative value, although only when $\mathrm{HI}_{\text {mid }}$ is close to zero.

In order to evaluate the error between observed and simulated loops, a similarity index was also calculated for each event and each stream gauge, representing the mean Cartesian distance between the observed and the simulated water discharge - sediment discharge points.

$$
I=\frac{1}{n} \sum_{i=1}^{n} \sqrt{\left(Q_{w, i}-\hat{Q}_{w, i}\right)^{2}+\left(Q_{s, i}-\hat{Q}_{s, i}\right)^{2}}
$$


where $I$ is the loop performance index, $n$ is the number of time steps, $Q_{w, i}$ is the observed water discharge, $\hat{Q}_{w, i}$ is the simulated water discharge, $Q_{s, i}$ is the observed fine sediment discharge, $\hat{Q}_{w, i}$ is the simulated fine sediment discharge. This index provides a similarity indicator between observed and simulated hysteresis loop. The median value of all calculated indexes ( 25 values, resulting from 5 events and 5 stations) were respectively $0.124450,0.124449$ and 0.124444 . The best median index value was provided by strategy 2 . Nevertheless, it was found that, among 25 hysteresis loops (5 events and 5 sections), strategy 0 obtained the best performance eight times, strategy 1 twelve times and strategy 2 five times. This analysis also confirms the previous stated conclusions. Strategy 1 is the most adequate strategy for loop reproduction because it obtains the maximum number of best fitting index values, although strategy 2 obtained the lowest index median value, which indicates also a rather positive performance.

\subsubsection{Continuous simulation}

In order to compare the three strategies in a continuous simulation modelling approach, the period September 1981 to September 1984 was selected, with 5 minutes time resolution using the resulting previously 3 sets of parameters. Since no total observed solid load data were available, only fine sediment discharge series $(<0.062 \mathrm{~mm})$ were used.

In Figure 4.21, the simulated volume at the catchment outlet (Q01) of the 22 most relevant storm events during this three year period is shown. It is important to highlight that the model was not calibrated on sediment total volume per event, but on sediment discharge. For the total period, the observed area-specific fine SY is $1.3 \mathrm{Mg} \mathrm{ha}^{-1}$ year $^{-1}$ and the simulated ones are 1.2, 0.6 and $1.4 \mathrm{Mg} \mathrm{ha}^{-1}$ year $^{-1}$ respectively. The total simulated sediment load (including sands) shows the same behaviour, i.e. the strategy 3 gives a lower total sediment volume than the other three strategies.

Strategy 0 tends to overestimate the observed sediment discharge, especially larger events, although low flows are underestimated, leading to a specific SY similar to the observed one. Strategy 1 tends to underestimate observed discharge, probably due to a poor reproduction of the erosion/deposition dynamics in the river.

The root mean square error of the points depicted in Figure 4.21 (observed vs simulated volumes) are, for strategy 0,1 and 2 respectively, 615, 1042 and 485, while the mean NSE index is respectively $0.50,0.14$ and 0.49 . This validation suggests that strategy 1 does not provide a good estimate of the sediment transport on a long time period, and its applicability is limited to the event scale approach. Strategy 2, as expected, offers the best results compared with the observed fine sediment discharge. In fact, this strategy was expected to give the best performance, since the sediment correction factors were calibrated using continuously simulated initial conditions. Strategies 0 also provides acceptable results, although they lack of physical meaning, their behaviour strongly depends on the chosen calibration event, and for these reasons they are not suitable for sediment initial conditions estimation. 


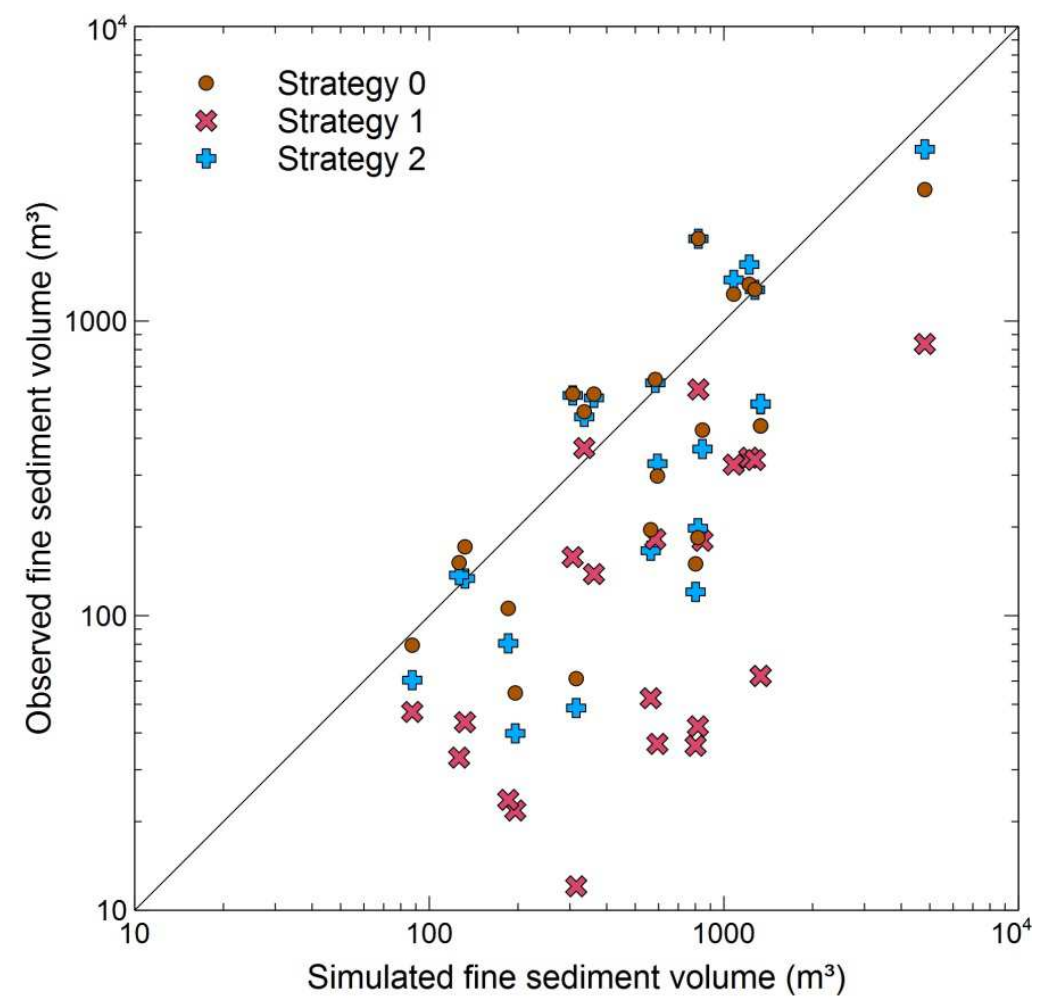

Figure 4.21 - Goodwin Creek continuous simulation results - overall comparison.

\subsection{Conclusions}

In this study, the TETIS model was applied to the Goodwin Creek (Mississippi, USA) experimental catchment. The model was used for assessing the effect of sediment initial condition (sediment volume deposited in the drainage network at the beginning of a model run) on model calibration and validation. For this reason, an automatic calibration algorithm (SCE-UA) was integrated into TETIS, as well as a sediment initial condition setting tool. The sedimentological sub-model calibration structure was also modified in order to allow a more flexible model calibration.

Three strategies for sediment initial condition estimation were implemented: strategy 0 no sediment availability within the drainage network; strategy 1 - calibration of the available sediment volume within the drainage network; and strategy 2 - estimation of sediment initial condition by a warm up simulation. Strategies 1 and 2 were proposed as they are the simplest and most frequent way to estimate sediment initial condition, while strategy 0 was used as reference of model performance.

All three models were automatically calibrated by adjusting the hillslope, gully and channel sediment transport capacity in order to reproduce the observed fine sedigraph of a single storm event, and validated at other four events. The resulting calibration sets show that the 
employed sediment initial condition estimation strategy strongly affects model calibration and behaviour. This study also confirms that gully processes are prominent in Goodwin Creek and the material previously deposited in the stream network can help explaining the catchment sediment dynamics. The results of calibration and validation at event-scale show a strong dependence of sediment load and loop rating curve on the initial conditions of deposited sediment. In fact, sediment rating curves mostly show a clockwise hysteresis loop, probably due to the mobilisation during the initial part of the storm event of loose material previously deposited in the stream network. Therefore, estimation of loose deposited sediments at the beginning of the storm event is fundamental for event scale modelling of soil erosion and sediment transport of the Goodwin Creek catchment.

The results showed that all strategies provided adequate results. The model provided a satisfactory performance in terms of NSE, RMSE, MAE and volume error (median NSE = $0.564,0.598$ and 0.572 for strategy 0,1 and 2 respectively) and fine sedigraph visual fit. From sedigraph analysis, none of the proposed strategies provided significantly better results than the other two, although strategies 1 and 2 appeared to be more reliable than strategy 0 , as expected.

The loop rating curve analysis demonstrated that the choice of initial sediment conditions affected the simulation results. The qualitative and quantitative hysteresis loop analysis showed that, despite the good model performance, the model was sometimes failing to reproduce the catchment erosion and deposition dynamic, as various loops were not correctly simulated. This proved that a good sedigraph validation may not be sufficient to prove the sediment model reliability.

Without any sediment initial condition, the model results were typically inferior to the results with calibration or warm up simulation. Strategy 1 clearly showed the best results in term of clockwise loop reproduction, although it failed in simulating other loop types. Strategy 2 showed the best results in terms of reproducing different loop shapes, although in many cases it also failed in reproduce hysteresis loop. This means that sedigraph reproduction is not a sufficient criterion for model calibration and validation. For example, hysteresis loop reproduction restrictions could be used, although it may deteriorate the model efficiency.

The model results also suggested that TETIS is a complete and solid tool for soil erosion estimation and sediment yield assessment, although further applications are needed in order to fully assess its performances.

The TETIS model has also been compared to other models previously applied in Goodwin Creek (Figure 4.22), and the results can be considered satisfactory. 


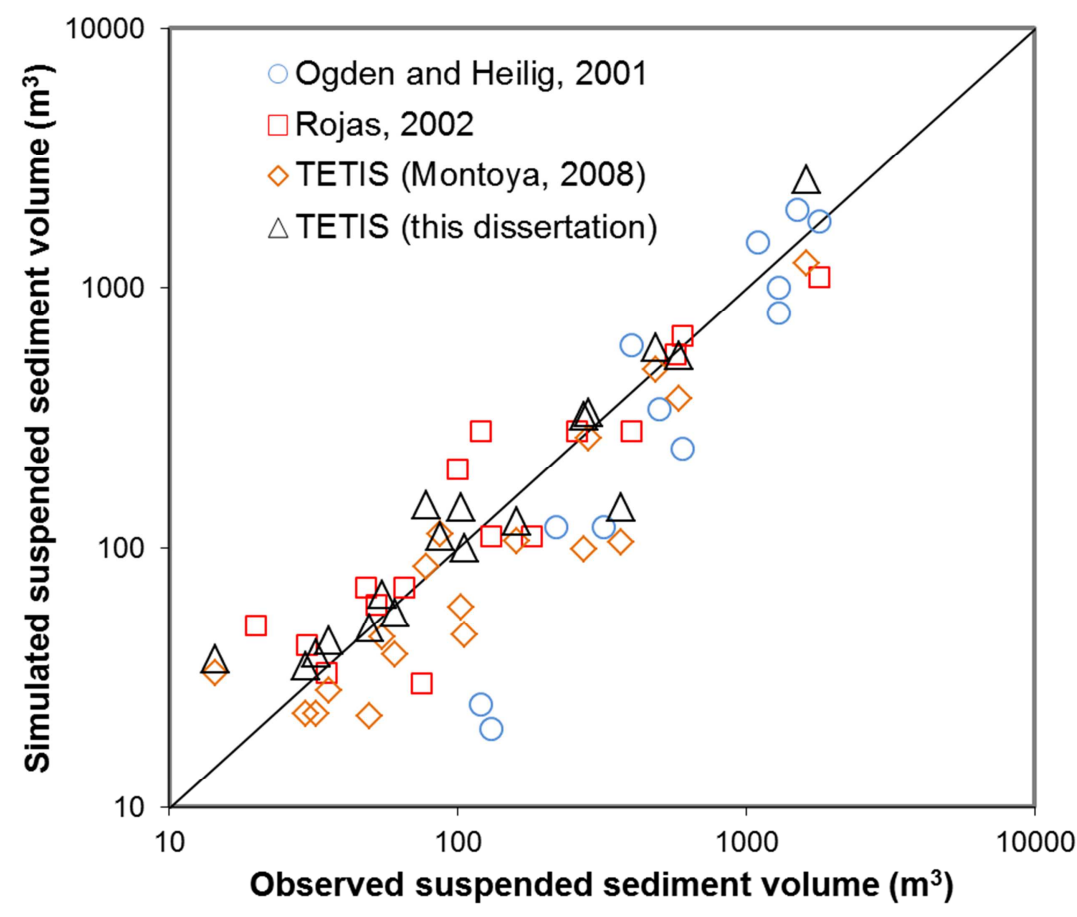

Figure 4.22 - Comparison between the TETIS results and the results of other models in Goodwin Creek.

In this figure, the model behaviour is compared to the CASC2D-SED model [Ogden and Heilig, 2001; Rojas, 2002] and to a previous application of TETIS without automatic calibration and using strategy 0 for initial condition estimation [Montoya, 2008].

The model performance suggests that TETIS is a complete and solid tool for soil erosion estimation and SY assessment, although further applications are needed in order to fully prove its reliability. In the calibration event, the NSE index referred to the sediment discharge was around 0.7 for strategies 1 and 2. Concerning the spatial (1982 event) and temporal (1983 event) validation, for simulations performed with sediment deposits estimated by calibration, the NSE index ranged between 0.6 and 0.9 , and the VE (volume error) between $-52 \%$ and $77 \%$ for strategy 1 , while for strategy 2 the NSE index ranged between -1 and 0.9 and the VE between $26 \%$ and $150 \%$. The comparative analysis of all strategies by a 3-year continuous simulation shows that strategies 1 tend to underestimate total SY, and its performance is very poor in a continuous simulation approach, while the use of a warm-up period in strategy 2 better reproduce the observed sedigraph with the best results. 


\subsection{Introduction and goals}

Modelling sediment yield is a complex task due to the non-linearity of natural processes intervening at slope and basin scale [Schumm and Lichty, 1965; Coulthard et al., 1998; Roering et al., 1999]. Recent computing advances, together with a better understanding of hydrodynamic processes involved in the surface runoff, sediment production and sediment transport, have stimulated the development of physically based and distributed parameter models (e.g. WEPP, EUROSEM and LISEM). The reliability of such sediment yield models depends on a robust calibration and/or validation process that, at ungauged catchments, as it is the case of most of small basins around the world, may limit a broad use of such models.

Different authors have used the sediment volume accumulated in lakes and reservoirs as an indirect validation method for modelling sediment yield at regional scale [Van Rompaey et al., 2003; Grauso et al., 2008]. Reservoir sediment volumes have been used since the 1950s as an estimate of the catchment mean sediment yield for comparison with the results of empirical equations. Some examples are Geiger [1957], Ackermann and Corinth [1962], Rohel [1962], Farnham et al. [1966], Callander and Duder [1979], Jolly [1982], Le Roux and Roos [1982], Duck and McManus [1993], Avendaño Salas et al. [1995, 1997] and Verstraeten et al. [2003]. Furthermore, small reservoir deposits, such as check dams or irrigation ponds, were also used for sediment yield quantification. Some examples are McManus and Duck [1985], Van den Wall Blake [1986], Neil and Mazari [1993], Foster and Walling [1994], White et al. [1996], and, more recently, Romero-Díaz et al. [2007], BoixFayos et al. [2008], Sougnez et al. [2011] and Bellin et al. [2011].

In this chapter, a modelling approach is proposed to reproduce and evaluate erosion and SY processes in a Mediterranean catchment (Rambla del Poyo, Valencia, Spain). The Rambla del Poyo catchment is located $30 \mathrm{~km}$ west of the city of Valencia (Spain). The word "Rambla" in Spanish refers to a watercourse with very long dry periods and fast and severe floods. This catchment was studied in several occasions by the Department of Hydraulics and Environment (DIHMA) of the Technical University of Valencia, and especially by the Research Group of Hydrological and Environmental Modelling (GIMHA). The previous studies concerned extreme rainfall distribution, rainstorm generation, rainfall-runoff transformation, fluvial hydraulics, real time flood forecasting, flood vulnerability ${ }^{5}$ and land use changes [Garcia-Bartual, 1991; Pascual Aguilar, 2002; Pascual Aguilar et al., 2003; Quevedo and Francés, 2008; Salazar et al., 2008, 2009, 2012; Guichard-Romero et al., 2009; Múnera and Francés, 2009]. Up to now, and to the author's knowledge, no catchment-scale sediment cycle study has been carried out yet.

The catchment is being monitored by SAIH ( 5 minutes discharge at the basin outlet and 5 minutes rainfall at the same place since 1989) and by AEMET (daily rainfall, maximum and minimum temperature in various stations, some of them since 1950).

\footnotetext{
${ }^{5}$ http://www.iiama.upv.es/roomfortheriver/home.html
} 
From a hydrological point of view, the Rambla del Poyo catchment shows some interesting features: it is a semi-arid catchment, with a typical Mediterranean hydrological behaviour (representative of, or hydrologically similar to, many medium- and small-size Mediterranean catchment) and the urban pressure on the flood low-lands is high. From a sedimentological point of view, the most interesting issue is that the river mouth is located in a coastal lagoon, called Albufera, which is experimenting a progressive siltation since some decades ago [Benet, 1983; Mintegui, 1986; Sanjaume et al., 1992; Ministerio de Medio Ambiente, 2004].

The Rambla del Poyo catchment can be considered a sediment-ungauged catchment, since there is no availability of sediment records. In order to overcome this problem, the calibration is carried out by comparing model results with the volumes deposited behind some check dams located in the catchment headwaters. Due to the lack of sediment transport records for model temporal validation, a detailed description of the alluvial stratigraphy infilling a check dam that drains a $12.9 \mathrm{~km}^{2}$ sub-catchment was also used as an indirect evidence of SY data. These dam infill sediments showed evidences of at least 15 depositional events (floods) over the time period 1990 - 2009, with a total estimated volume ranging between 1250 and $1435 \mathrm{~m}^{3}$, depending on the calculation approach. The TETIS model was coupled to the Sediment Trap Efficiency for Small Ponds (STEP) model for reproducing reservoir retention, and it was calibrated and validated using the sedimentation volume estimated for the depositional units associated with discrete runoff events.

The aims of this study are:

- Applying the TETIS model to an ungauged catchment (no sediment records available);

- Presenting a practical application of the STEP sub-model for small reservoirs sediment dynamics reproduction;

- Checking the usefulness of small reservoir deposits as a source of sediment proxy data;

- Integrating palaeohydrological techniques and stratigraphical analysis for model implementation.

\subsection{The case study: Rambla del Poyo}

\subsubsection{Catchment characteristics}

The study area is in the headwaters of the Rambla del Poyo catchment, a Mediterranean ephemeral stream located $30 \mathrm{~km}$ west of Valencia (Spain), as showed in Figure 5.1. 


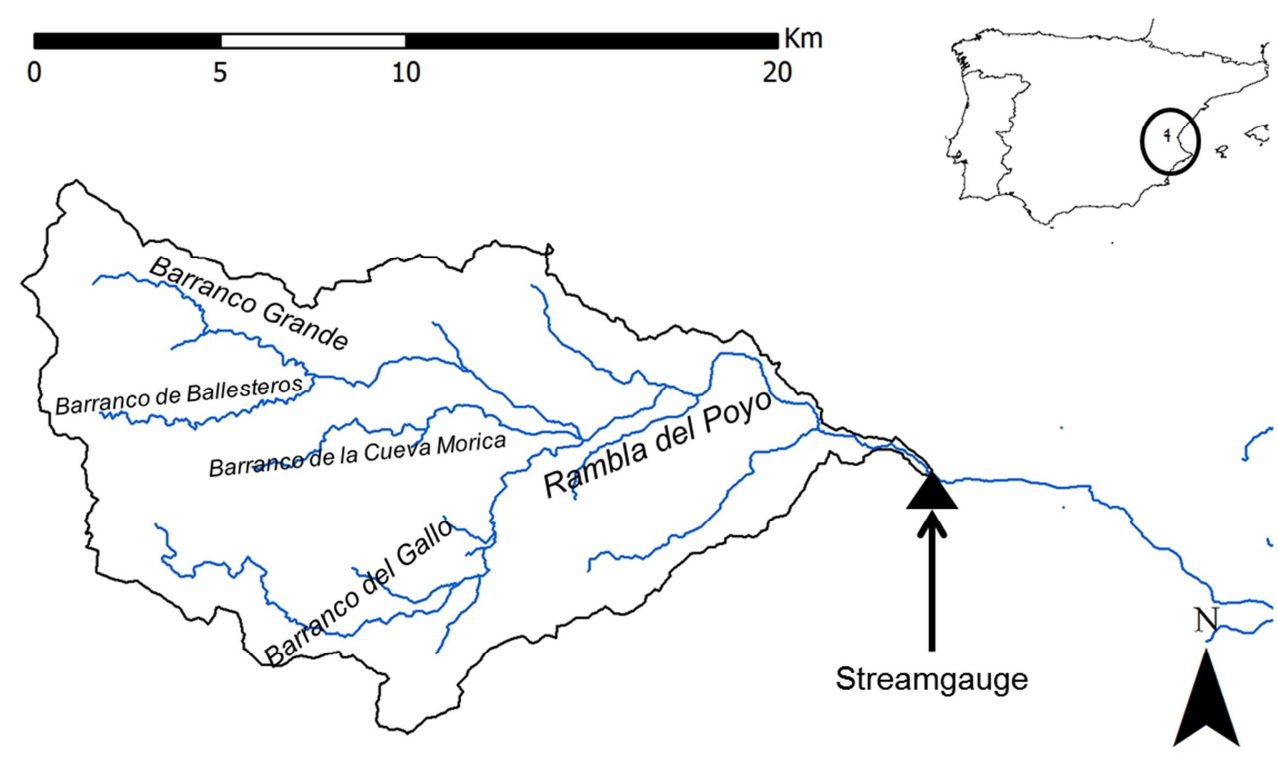

Figure 5.1 - Rambla del Poyo catchment location.

The geology consists of dolomites and limestones in the headwaters and marls in the lower part of the catchment [Camarasa Belmonte and Segura Beltrán, 2001]. The mean annual precipitation is $450 \mathrm{~mm}$ and the mean annual evapotranspiration is 1,100 $\mathrm{mm}$. The Rambla del Poyo catchment at the stream gauge station has an area of $184 \mathrm{~km}^{2}$ (Figure 5.1). The upper part, located at west, is formed by high slopes and reliefs up to $1080 \mathrm{~m}$ a.s.l. Continuous land abandonment during various decades of the $20^{\text {th }}$ century and the previous intensive livestock use, along with frequent wildfires, favoured the development of a rather homogeneous and dense shrubland cover (matorral), leaving only a little portion of pine forest. This phenomenon was already described in literature, e.g. by Cerdà [1998c], Rey Benayas et al. [2007] and Baeza et al. [2007].

The land use of intermediate part is mainly formed by non-irrigated arable land with complex cultivation patterns and transition zones. There is high presence of terraced fields. The catchment lower part is dominated by agricultural land with alternation of urban zones and peri-urban agriculture, mainly orchards and citrus [Salazar et al., 2013]. The soils are mostly silty in the upper and intermediate part of the catchment, and clayey in the lower part. The topsoil texture is silt loam for headwater soils (around $20-60-20 \%$ of sand-silt-clay percentage respectively, following the USDA classification). The content of sand gradually increases from west to east. In the lower catchment, the mean texture is clay loam (around 30-40-30\%), although sandy loam areas can also be found.

The stream network is composed by four major water courses: the Barranco Grande at the north, the Barranco de Ballesteros and the Barranco de la Cueva Morica at the centre and the Barranco del Gallo at the south. 


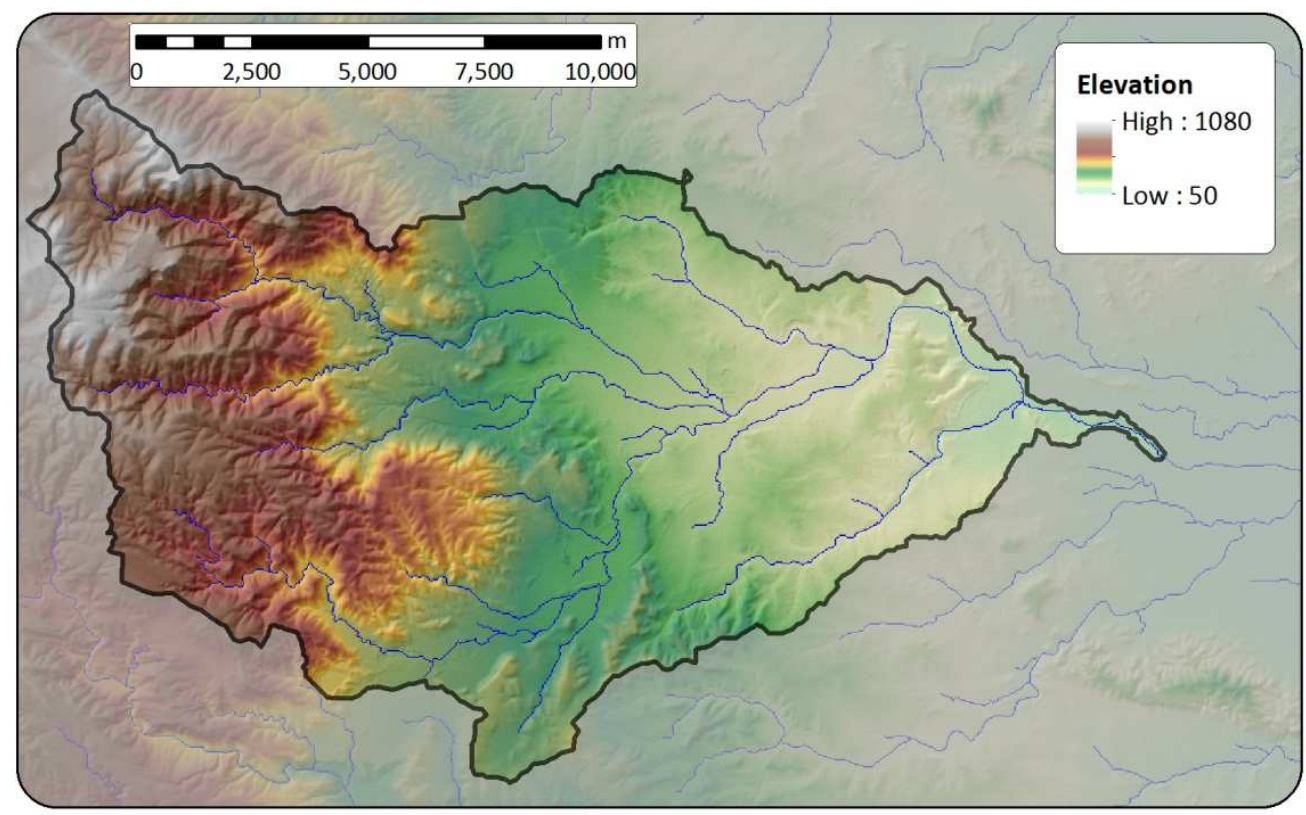

Figure 5.2 - Rambla del Poyo catchment elevation.

\subsubsection{Hydrometeorological data}

The hydrometeorological data available are the following:

- Water discharge at the "Rambla del Poyo" stream gauge (SAIH), with 5 minutes temporal resolution since 1989 (although data preceding 1996 are incomplete). This point is the catchment outlet.

- Rainfall at the" Rambla del Poyo" raingauge (SAIH), located close to the stream gauge, with 5 minutes temporal resolution since 1989.

- Daily precipitation at 13 raingauges (AEMET), period $1950-2003$, although with several no data gaps.

- Daily maximum and minimum temperature at 13 thermometers (AEMET), period 1950 - 2003, although with several no-data gaps.

In order to apply the TETIS model with a continuous simulation approach, reference evapotranspiration $\left(E T_{0}\right)$ in time is required as an input data in one or more points within the catchment. The reference evapotranspiration is the water loss occurring in a system without manipulating the water availability for a specific crop. In this study, the Hargreaves equation [Hargreaves and Samani, 1985; Allen et al., 1998] was used to compute reference evapotranspiration, due to its low data requirement (only temperature and solar radiation). The equation is the following:

$E T_{0}=0.0135 * K T *\left(T_{\text {med }}+17.8\right)\left(T_{\max }-T_{\min }\right)^{0.5} * R_{a}$

where: 
$E T_{0}=$ reference evapotranspiration, $\mathrm{mm} /$ day

$T_{\text {med }}=$ mean daily temperature, $\stackrel{\circ}{ } \mathrm{C}$

$T_{\max }=$ maximum daily temperature, $\stackrel{\circ}{ } \mathrm{C}$

$T_{\text {med }}=$ minimum daily temperature, $\stackrel{\circ}{ } \mathrm{C}$

$K T=$ coefficient, -

$R_{a}=$ extra-terrestrial solar radiation, $\mathrm{mm} /$ day (from tables or formulas depending on latitude and month)

$K T$ coefficient is an empirical coefficient. The authors recommend the value 0.162 for continental regions and 0.19 for coastal regions. In the TETIS model, this parameter is calibrated by the correction factor 2 (CF2), which directly multiplies the $E T_{0}$ values.

\subsubsection{Sediment data}

As stated before, no sediment transport measurements are available in the Rambla del Poyo catchment. For this reason, sediment proxy data are needed. In this study, the sediment proxy data are represented by the sediment volume deposited behind nine check dams, which are described as follows.

\subsubsection{Check dams}

In this chapter, nine check dams and reservoirs are presented. The shape, structure and siltation state are described. The bottom deposits are used for model calibration and validation.

The nine check dams drain an area of $45 \mathrm{~km}^{2}$ (Figure 5.3), out of $184 \mathrm{~km}^{2}$ of the whole catchment. This part of the catchment (headwaters) is characterized by a mountainous morphology, with relevant slopes, incised channels (sometimes canyons) and vegetation cover mainly constituted by shrubland (matorral) and small size trees (up to $1-1.5 \mathrm{~m}$ ). A few pine forests also exist which cover a small area. Soils are mainly silty and sandy, with very little amount of gravels. Gravel deposits can be found in some river reaches, mainly provided by local rock detachment and landslides. 


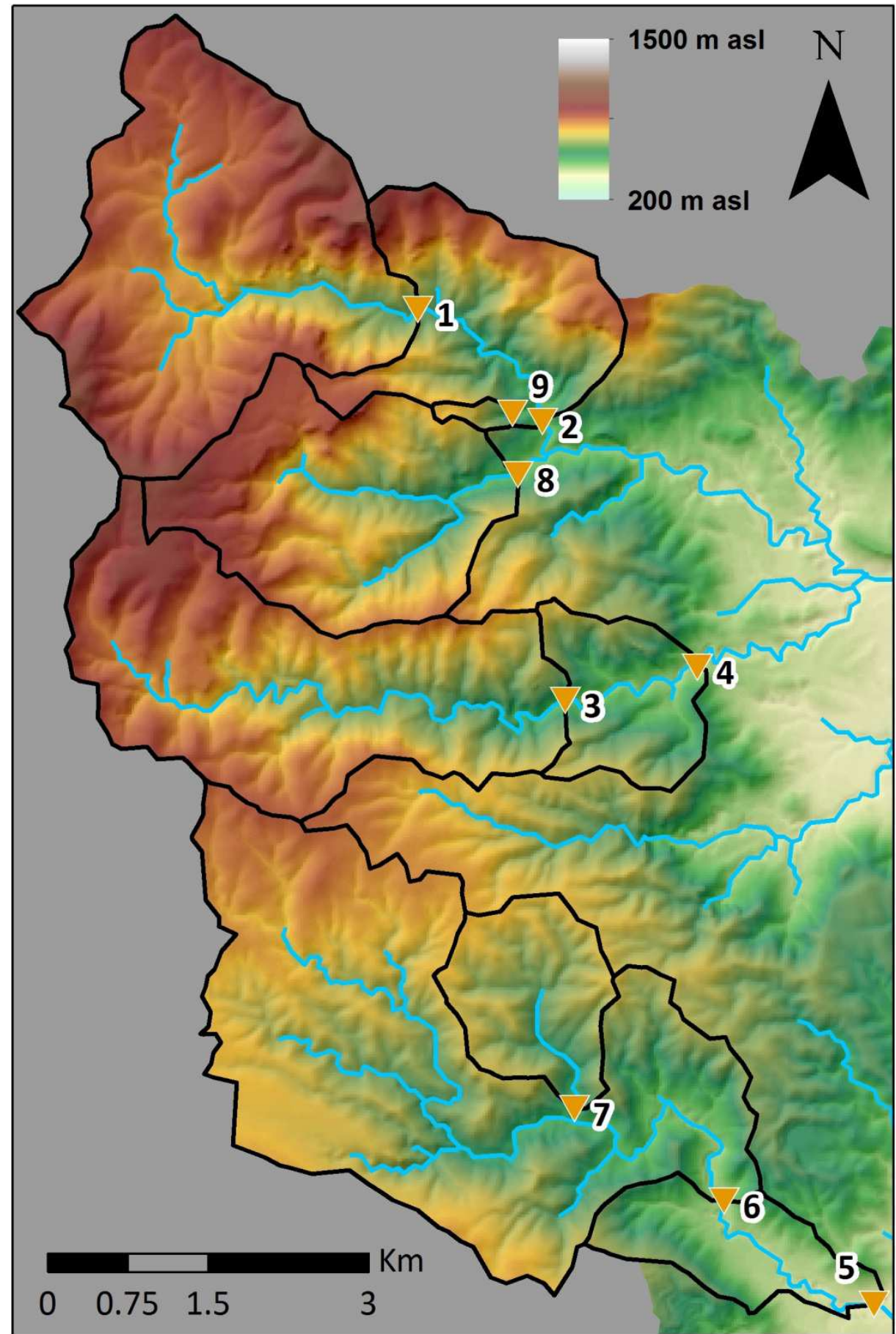

Figure 5.3 - Sub-catchments drained by the nine check dams. 


\begin{tabular}{ll} 
5.2.3.1.1. Dam 1 & \\
\cline { 2 - 2 } Dam number & 1 \\
Watercourse & B. Grande \\
UTM x & $687029 \mathrm{~m}$ \\
UTM y & $4377660 \mathrm{~m}$ \\
z & $608 \mathrm{~m}$ a.s.l. \\
Construction material & Concrete and \\
& stones \\
Drainage area & $9.13 \mathrm{~km}^{2}$ \\
Local slope & 0.229 \\
Estimated sediment deposit volume & $150 \mathrm{~m}^{3}$ \\
\hline
\end{tabular}

Table 5.1 - Dam 1.

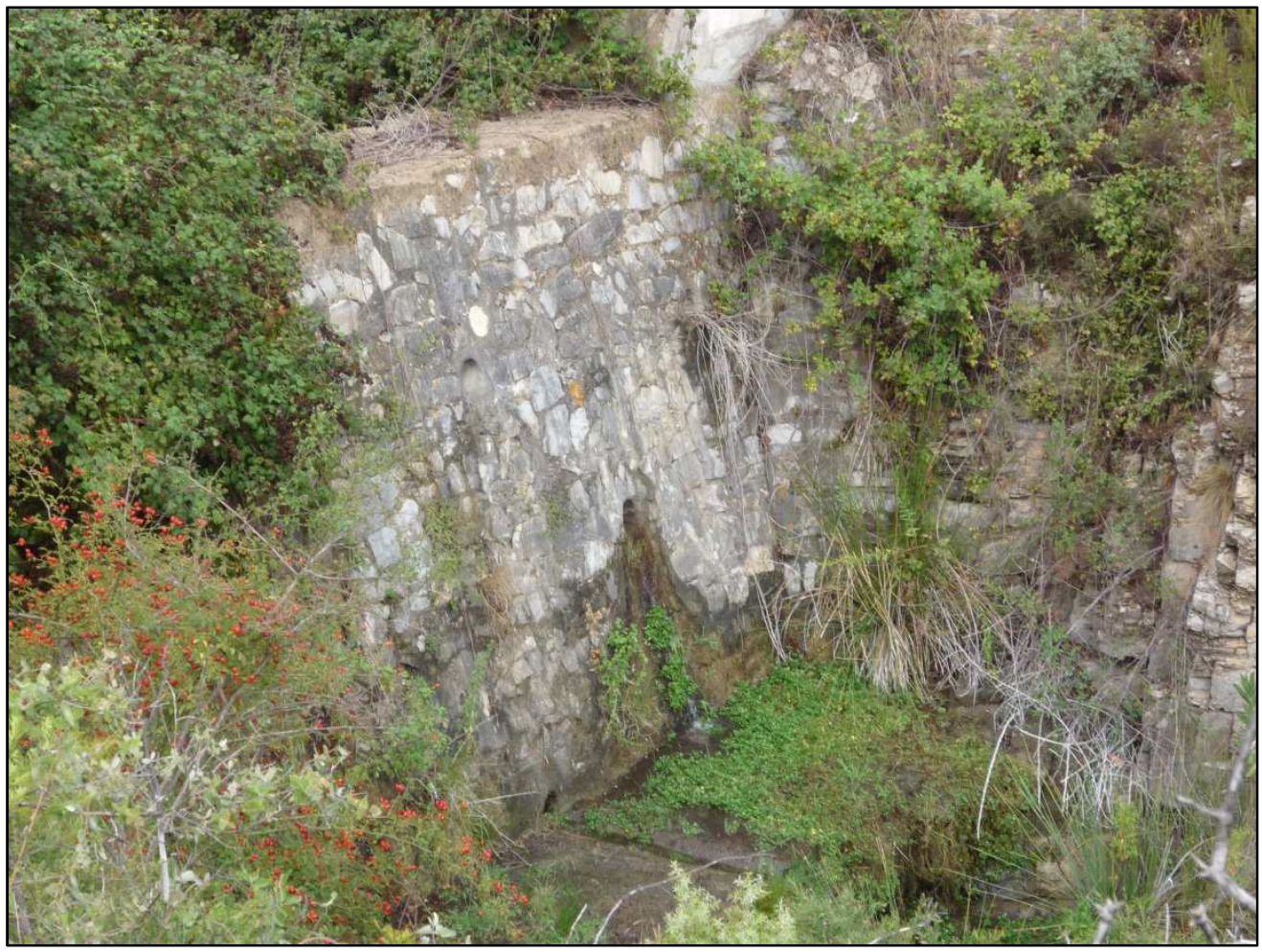

Figure 5.4-Dam 1.

It was not possible to reach the reservoir zone due to the high vegetation density. The sediment deposit volume is approximate. 
Dam 2

\begin{tabular}{ll}
\hline Dam number & 2 \\
Watercourse & B. Grande \\
UTM x & $688528 \mathrm{~m}$ \\
UTM y & $4376445 \mathrm{~m}$ \\
z & $492 \mathrm{~m}$ a.s.l. \\
Construction material & Concrete \\
Drainage area & $12.9 \mathrm{~km}^{2}$ \\
Local slope & 0.077 \\
Estimated sediment deposit volume & $548.26 \mathrm{~m}^{3}$ \\
Sediment texture & Silty loam \\
\hline
\end{tabular}

Table 5.2 - Dam 2.

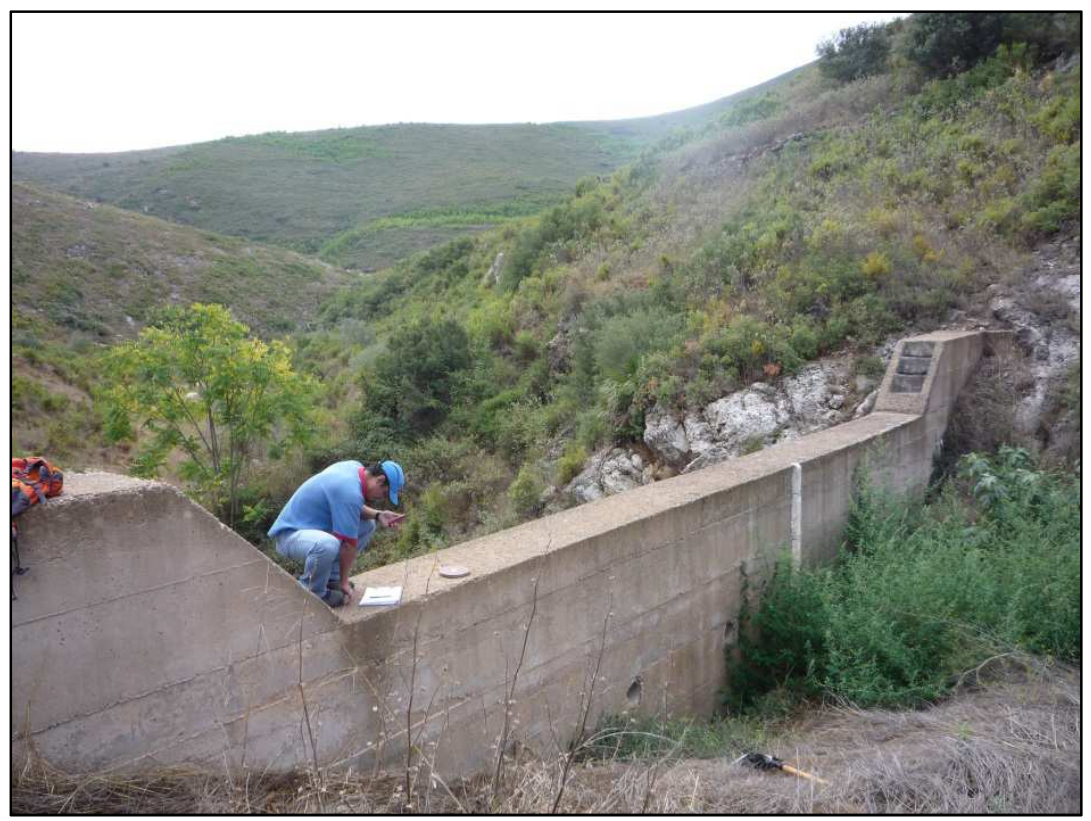

Figure 5.5 - Dam 2.

19.4

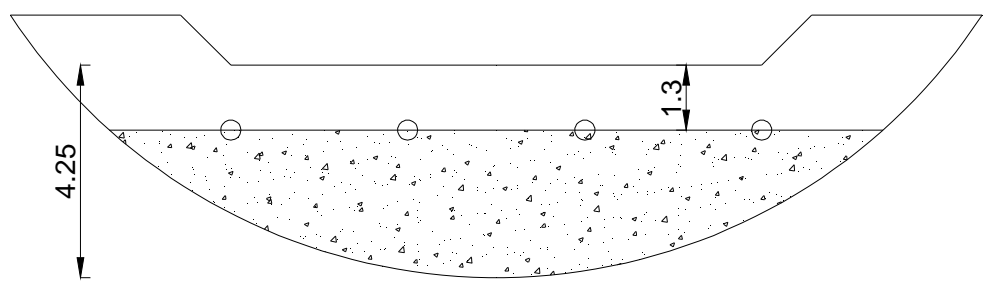

Figure 5.6-Dam 2 - sketch. 


\section{Dam 3}

\begin{tabular}{ll}
\hline Dam number & 3 \\
Watercourse & B. de Ballesteros \\
UTM $x$ & $688528 \mathrm{~m}$ \\
UTM $y$ & $4374350 \mathrm{~m}$ \\
$z$ & $515 \mathrm{~m}$ a.s.l. \\
Construction material & Concrete \\
Drainage area & $8.04 \mathrm{~km}^{2}$ \\
Local slope & 0.102 \\
& 0.040 \\
Estimated sediment deposit volume & $159.09 \mathrm{~m}^{3}$ \\
Sediment texture & Sandy \\
\hline
\end{tabular}

Table 5.3 - Dam 3.

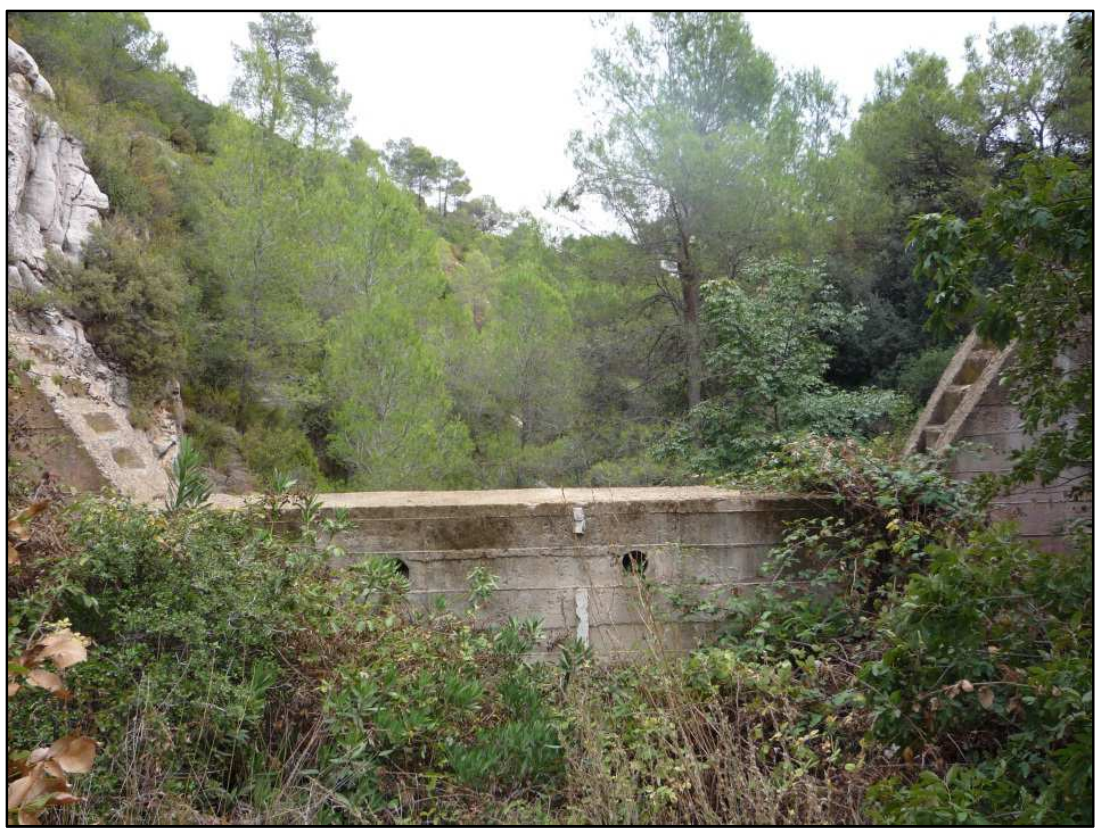

Figure 5.7-Dam 3.

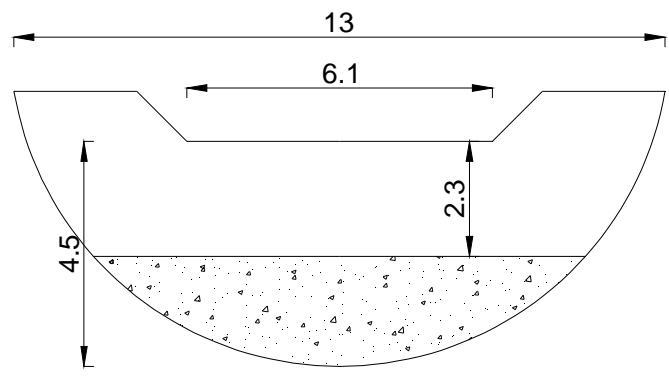

Figure 5.8-Dam 3 - sketch. 


\section{Dam 4}

\begin{tabular}{ll}
\hline Dam number & 4 \\
Watercourse & B. de Ballesteros \\
UTM $x$ & $689739 \mathrm{~m}$ \\
UTM y & $4374350 \mathrm{~m}$ \\
$z$ & $458 \mathrm{~m}$ a.s.l. \\
Construction material & Concrete \\
Drainage area & $10.07 \mathrm{~km}^{2}$ \\
Local slope & 0.109 \\
Estimated sediment deposit volume & $289.72 \mathrm{~m}^{3}$ \\
Sediment texture & Silty loam \\
\hline
\end{tabular}

Table 5.4 - Dam 4.

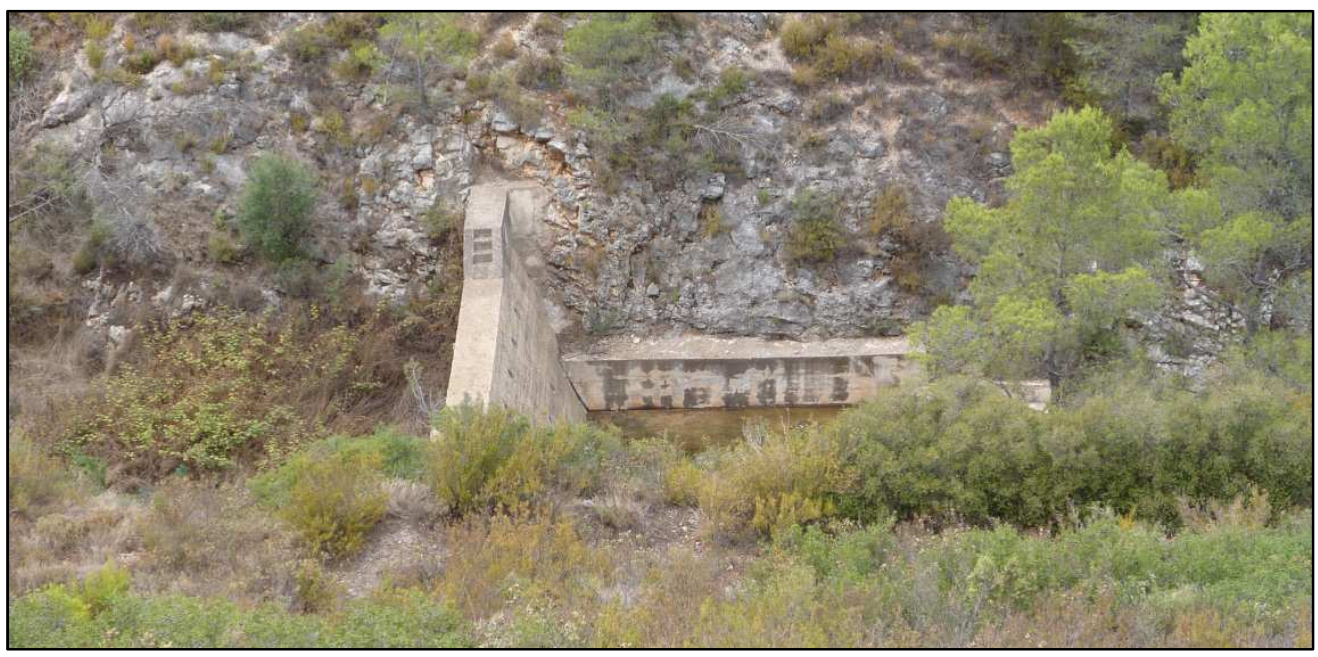

Figure 5.9-Dam 4.

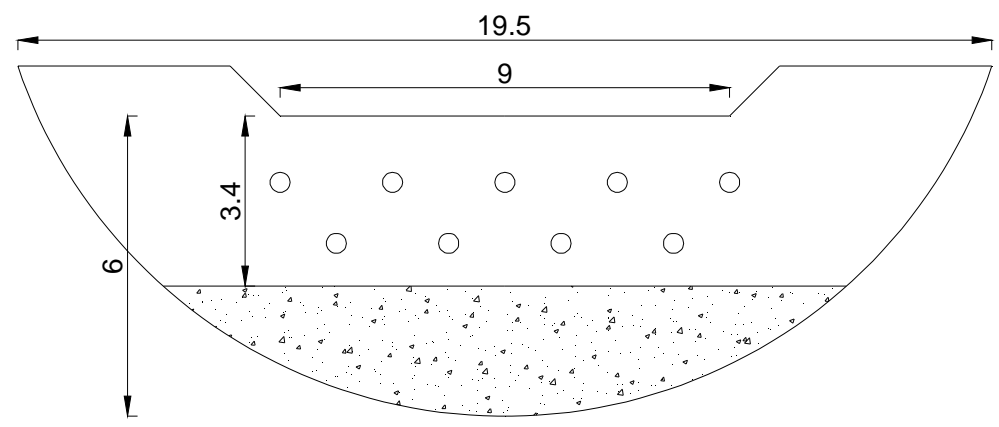

Figure 5.10-Dam 4 - sketch. 


\section{Dam 5}

\begin{tabular}{ll}
\hline Dam number & 5 \\
Watercourse & B. del Gallo \\
UTM x & $691350 \mathrm{~m}$ \\
UTM y & $4368273 \mathrm{~m}$ \\
z & $220 \mathrm{~m}$ a.s.l. \\
Construction material & Concrete \\
Drainage area & $16.6 \mathrm{~km}^{2}$ \\
Local slope & 0.018 \\
Estimated sediment deposit volume & $211.75 \mathrm{~m}^{3}$ \\
Sediment texture & Silty loam \\
\hline
\end{tabular}

Table 5.5 - Dam 5.

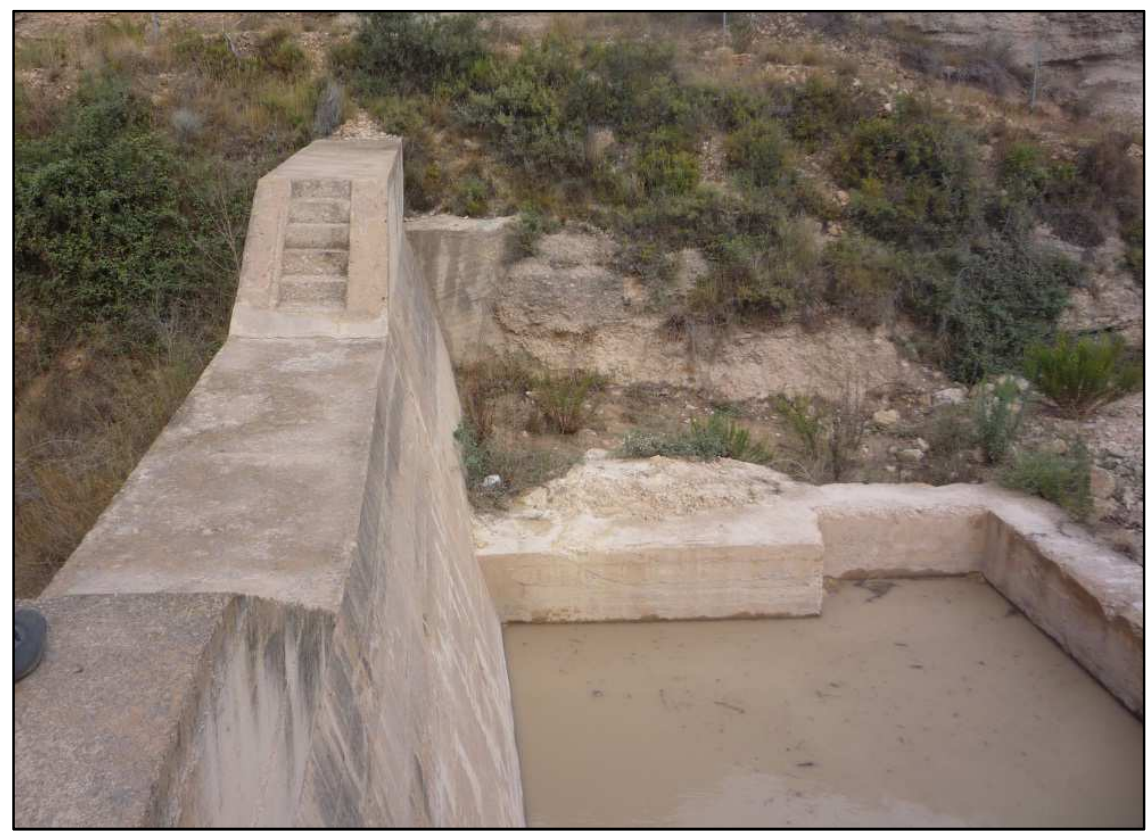

Figure 5.11 - Dam 5.

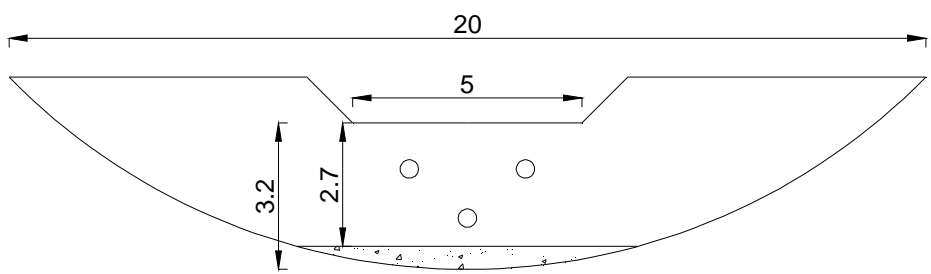

Figure 5.12 - Dam 5 - sketch. 


\begin{tabular}{cl} 
Dam 6 & \\
\cline { 2 - 3 } & Dam number \\
Watercourse & 6 \\
UTM $x$ & B. del Gallo \\
UTM y & $689941 \mathrm{~m}$ \\
$\mathrm{z}$ & $4369256 \mathrm{~m}$ \\
Construction material & $220 \mathrm{~m}$ a.s.l. \\
Drainage area & Concrete \\
Local slope & $14.99 \mathrm{~km}^{2}$ \\
Estimated sediment deposit volume & 0.146 \\
Sediment texture & $340.60 \mathrm{~m}^{3}$ \\
\hline
\end{tabular}

Table 5.6-Dam 6.

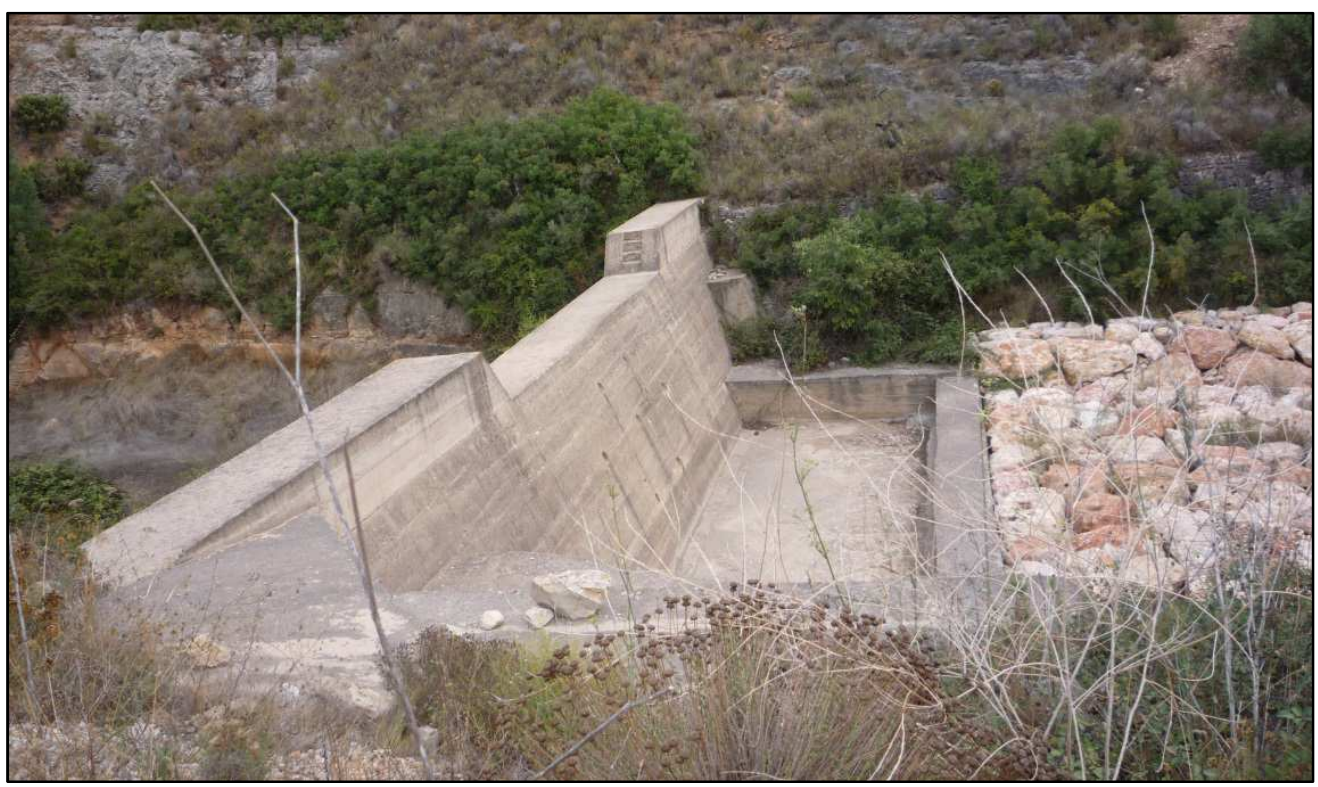

Figure 5.13 - Dam 6.

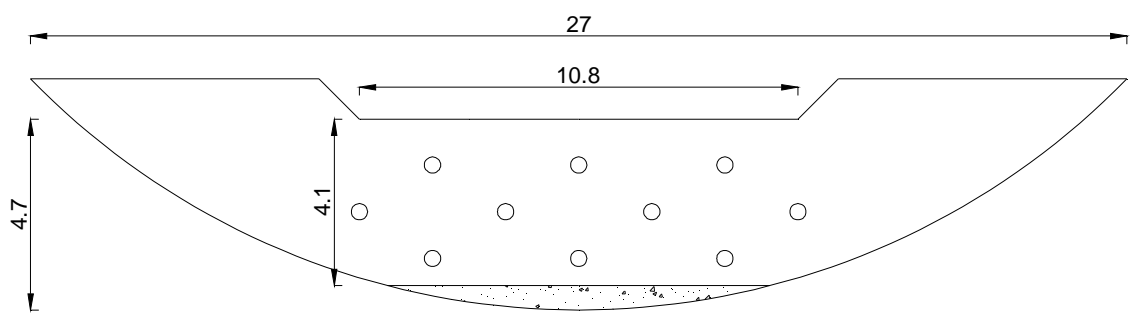

Figure 5.14 - Dam 6 - sketch. 


\begin{tabular}{|c|c|}
\hline Dam number & 7 \\
\hline Watercourse & $\begin{array}{l}\text { B. del Gallo } \\
\text { (tributary) }\end{array}$ \\
\hline UTM $x$ & $688634 \mathrm{~m}$ \\
\hline UTM y & $4370260 \mathrm{~m}$ \\
\hline$z$ & $540 \mathrm{~m}$ a.s.l. \\
\hline Construction material & Concrete \\
\hline Drainage area & $2.33 \mathrm{~km}^{2}$ \\
\hline Local slope & 0.043 \\
\hline Estimated sediment deposit volume & $56.75 \mathrm{~m}^{3}$ \\
\hline Sediment texture & Silty loam \\
\hline
\end{tabular}

Table 5.7-Dam 7.

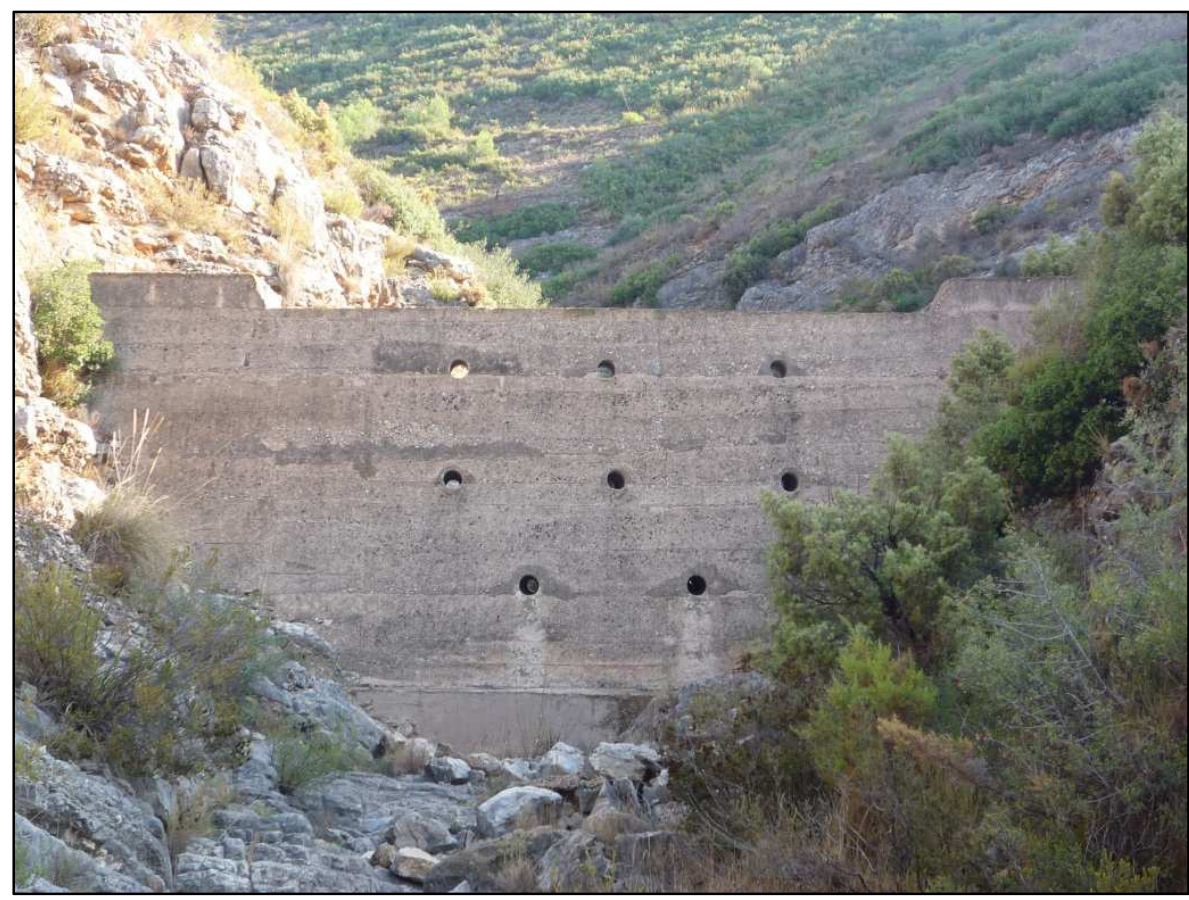

Figure 5.15-Dam 7.

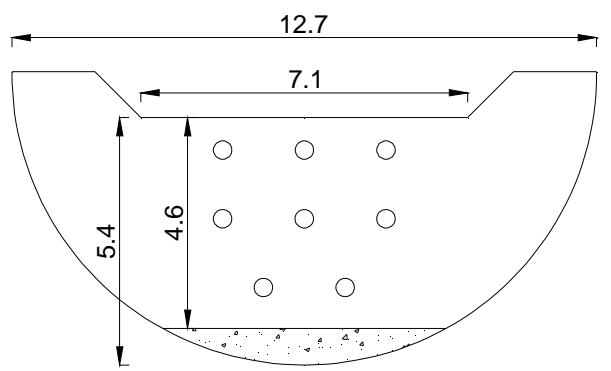

Figure 5.16-Dam 7 - sketch. 
Dam 8

\begin{tabular}{ll}
\hline Dam number & 8 \\
Watercourse & B. De la Parra \\
UTM x & $688041 \mathrm{~m}$ \\
UTM y & $4376250 \mathrm{~m}$ \\
z & $515 \mathrm{~m} \mathrm{s.n.m}$. \\
Construction material & Gabions \\
Drainage area & $5.36 \mathrm{~km}^{2}$ \\
Local slope & 0.043 \\
Estimated sediment deposit volume & $1067.11 \mathrm{~m}^{3}$ \\
Sediment texture & Silty loam \\
\hline
\end{tabular}

Table 5.8-Dam 8.

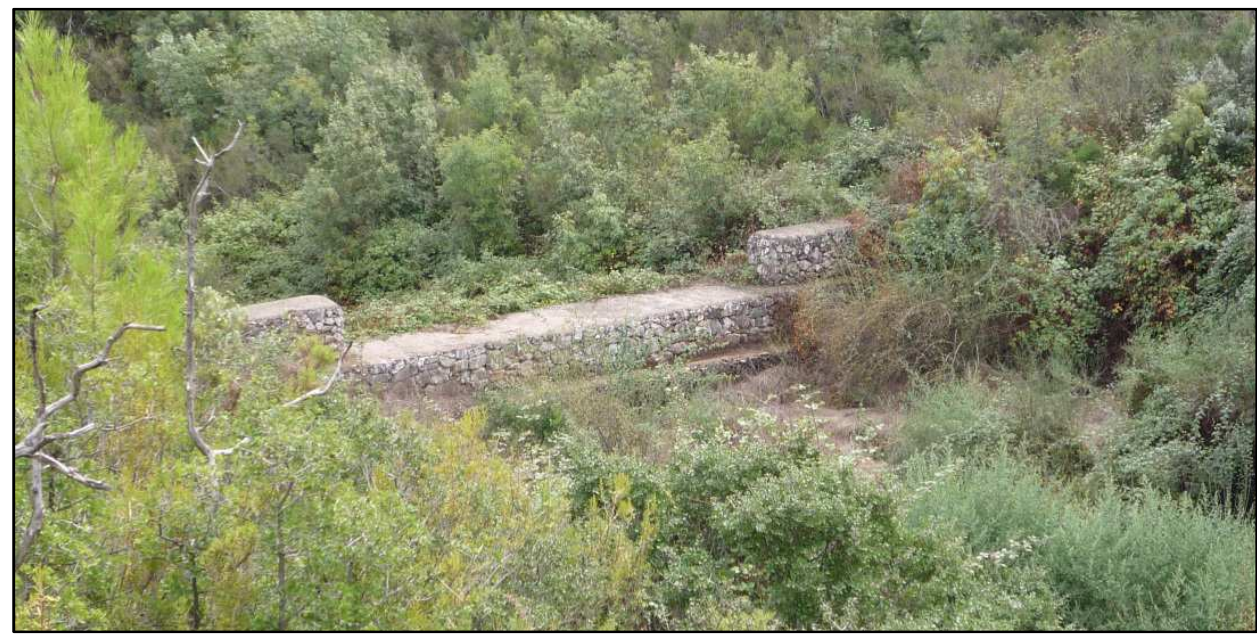

Figure 5.17-Dam 8.

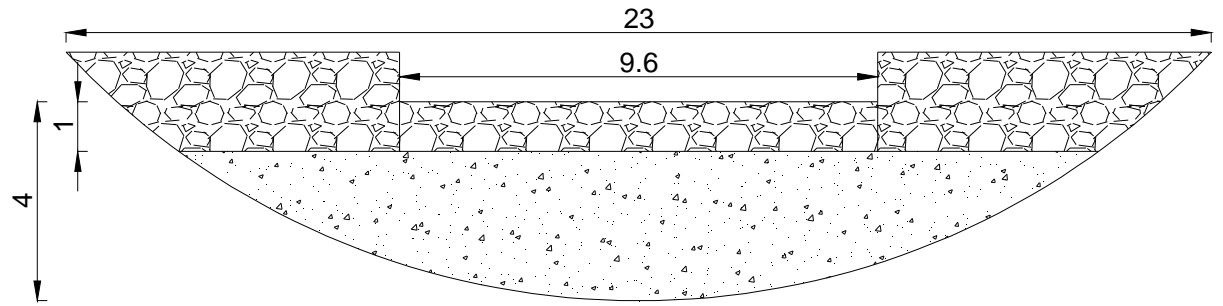

Figure 5.18-Dam 8 - sketch. 
Dam 9

\begin{tabular}{ll}
\hline Dam number & 9 \\
Watercourse & B. Grande \\
& (tributary) \\
UTM $x$ & $688142 \mathrm{~m}$ \\
UTM y & $4376739 \mathrm{~m}$ \\
$z$ & $539 \mathrm{~m}$ a.s.l. \\
Construction material & Gabions \\
Drainage area & $1 \mathrm{~km}^{2}$ \\
Local slope & 0.146 \\
Estimated sediment deposit volume & $74.75 \mathrm{~m}^{3}$ \\
Sediment texture & Loamy with \\
& frequent gravels \\
\hline
\end{tabular}

Table 5.9-Dam 9.

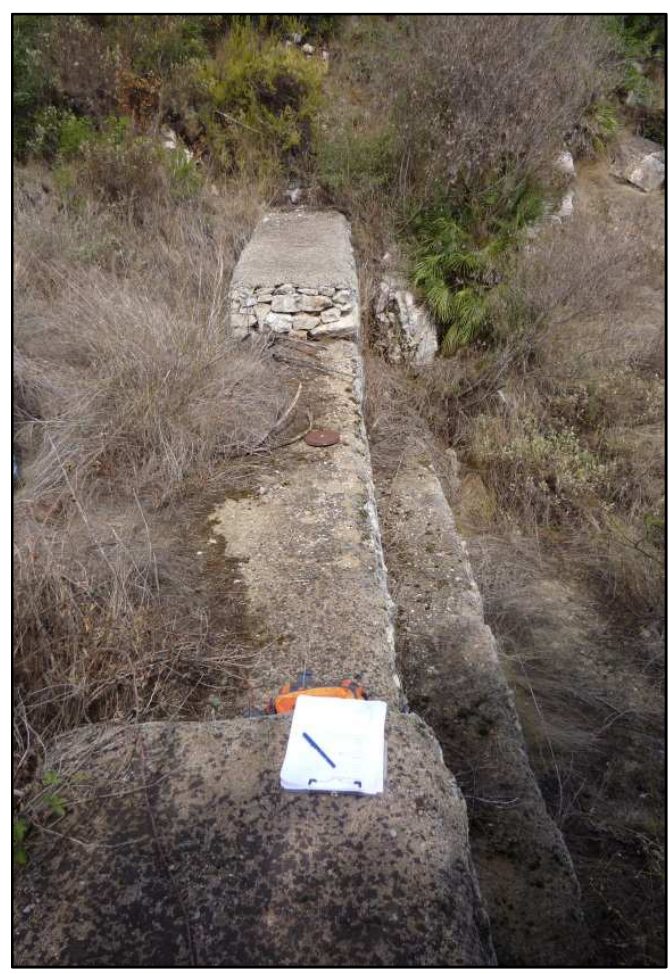

Figure 5.19-Dam 9.

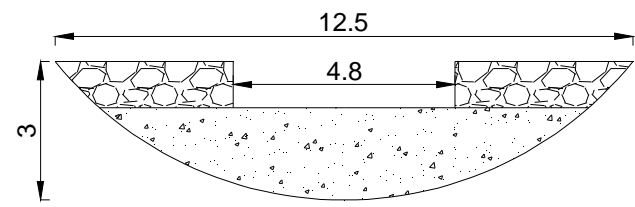

Figure 5.20 - Dam 9 - sketch. 


\section{Reservoir characterization}

Given that all measurements were carried out in 2009, when the check dams were partially filled, the real geometry of the reservoirs is unknown. In order to estimate a height-volume curve for each reservoir, a simple reservoir shape was supposed, as shown in Figure 5.21. This information is required by the STEP sub-model for computing sediment TE and deposition.

$\mathrm{B}+\mathbf{2 C}$

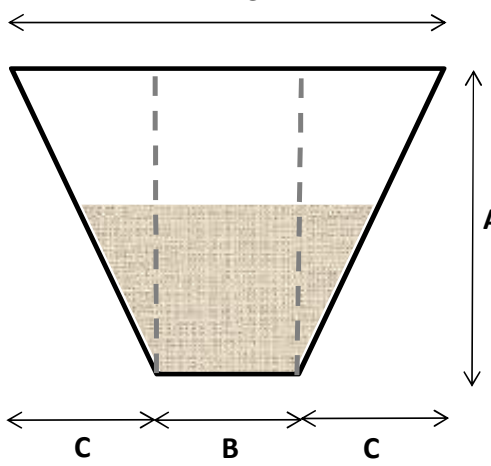

D

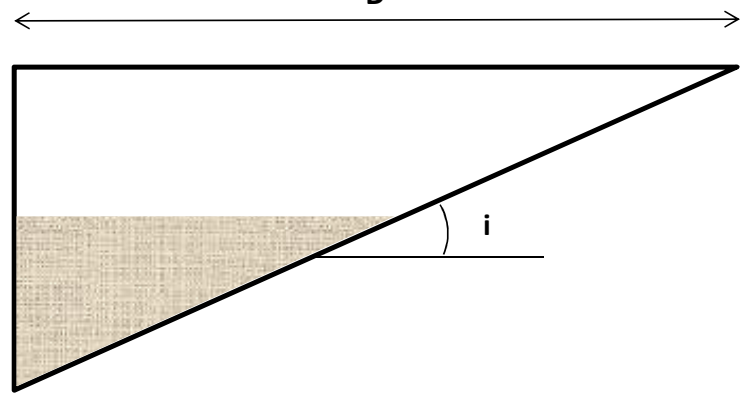

Figure 5.21 - Reservoir geometry.

Given this geometry, the relationship between the water level in the reservoir $(h)$ and the water storage $(V)$ for each reservoir is the following:

$V(h)=\frac{B h^{2}}{2 i}+2 \frac{C h^{3}}{3 A i}$

Starting from this equation, storage curves were computed for all reservoirs (Figure 5.22) and the bottom deposit volumes were also estimated (Table 5.10). Given the errors affecting these values, it is essential to bear in mind the high uncertainty which these measurements and estimations hold.

\begin{tabular}{cccccccccc}
\hline Check dam & $\mathbf{1}$ & $\mathbf{2}$ & $\mathbf{3}$ & $\mathbf{4}$ & $\mathbf{5}$ & $\mathbf{6}$ & $\mathbf{7}$ & $\mathbf{8}$ & $\mathbf{9}$ \\
\hline Depth form donwstream (A) & 5 & 4.25 & 4.5 & 6 & 3.2 & 4.7 & 5.4 & 4 & 2 \\
Width (B+2C) & 15 & 19.4 & 13 & 19.5 & 20 & 27 & 12.7 & 23 & 12.5 \\
River width (B) & 3 & 10.6 & 6.1 & 9 & 5 & 10.8 & 7.1 & 9.6 & 4.8 \\
Depth from upstream & 0.5 & 1.5 & 2.3 & 3.4 & 2.7 & 4.1 & 3.8 & 1 & 0 \\
Local slope & 0.23 & 0.08 & 0.10 & 0.11 & 0.01 & 0.02 & 0.15 & 0.04 & 0.15 \\
C & 6 & 4 & 3 & 5 & 8 & 8 & 3 & 7 & 4 \\
D & 22 & 56 & 44 & 55 & 224 & 266 & 37 & 93 & 14 \\
Maximum storage $\left(\mathrm{m}^{3}\right)$ & 1256 & 2981 & 1752 & 4386 & 10751 & 23656 & 1636 & 5957 & 242 \\
Deposits $\left(\mathrm{m}^{3}\right)$ & 1142 & 1435 & 363 & 700 & 189 & 289 & 121 & 3117 & 242 \\
\hline
\end{tabular}

Table 5.10 - Check dam characteristics from field survey (linear dimensions in $\mathrm{m}$ ). 


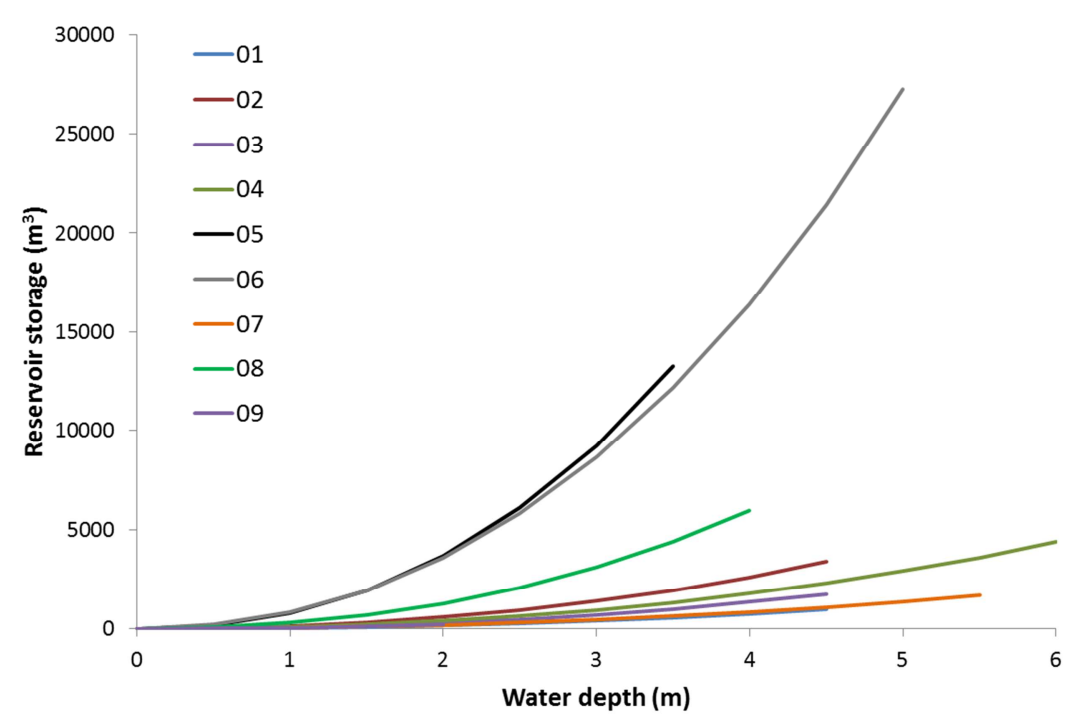

Figure 5.22 - Reservoir storage curves of the Rambla del Poyo check dams.

Deposit dry bulk densities

In order to weight and volume of sediment trapped within the reservoirs, deposit dry bulk density is required. Specific grain density was measured and resulted in around $2.5-2.6$ $\mathrm{t} / \mathrm{m}^{3}$ for all deposits. Nevertheless, porosity was not determined, and for this reason it is not possible to calculate directly a dBD value. For the Rambla del Poyo case study, reservoirs are small (spatial variability of $\mathrm{dBD}$ is negligible) and are dry almost all time (consolidation is small).

For dBD estimation, the Miller [1953] formula and Lane and Koelzer [1943] and Lara and Pemberton [1963] parameters were used. Both methodologies were employed, and the average value was taken as the $\mathrm{dBD}$ of the reservoir bottom deposit (Table 5.11).

\begin{tabular}{lccccccccc}
\hline Method & P1 & P2 & P3 & P4 & P5 & P6 & P7 & P8 & P9 \\
\hline $\begin{array}{l}\text { Lane and } \\
\text { Koeltzer }\end{array}$ & 1.34 & 1.34 & 1.34 & 1.33 & 1.33 & 1.31 & 1.34 & 1.37 & 1.34 \\
$\begin{array}{l}\text { Lara and } \\
\text { Pemberton }\end{array}$ & 1.15 & 1.05 & 1.15 & 1.07 & 1.08 & 1.07 & 1.07 & 1.13 & 1.15 \\
Average & 1.25 & 1.19 & 1.25 & 1.20 & 1.21 & 1.19 & 1.21 & 1.25 & 1.25 \\
\hline
\end{tabular}

Table 5.11 - dBD of the Rambla del Poyo deposits.

In order to validate this value, five measurements of the dry bulk density were carried out at different depths (from 10 to $90 \mathrm{~cm}$ ) for check dam 2. The results range between 1.014 and $1.389 \mathrm{gr} \mathrm{cm}^{-3}$, and the mean value is $1.150 \mathrm{gr} \mathrm{cm}^{-3}$. It is expected that the average dry bulk density of the whole deposit should be slightly higher than the measured value, given that the total depth of check dam 2 is around $2 \mathrm{~m}$. For this reason, the dry bulk density value calculated by means of the Lane and Koelzer approach can be considered adequate for the purposes of this study. 


\section{Trap efficiency}

The check dams TE was firstly computed following the Brune approach (i.e. without taking into account the temporal variation of the reservoir storage and of the water and sediment discharge). The results can be seen in Table 5.12. Annual average water income was calculated following a 20 years continuous simulation by means of the TETIS model.

\begin{tabular}{|c|c|c|c|c|c|c|c|c|c|}
\hline & P01 & P02 & P03 & P04 & P05 & P06 & P07 & P08 & P09 \\
\hline TE min & $0.00 \%$ & $0.00 \%$ & $0.00 \%$ & $0.00 \%$ & $0.00 \%$ & $0.00 \%$ & $14.16 \%$ & $0.00 \%$ & $9.22 \%$ \\
\hline TE mean & $0.00 \%$ & $0.00 \%$ & $0.00 \%$ & $12.36 \%$ & $0.00 \%$ & $0.00 \%$ & $28.84 \%$ & $7.05 \%$ & $24.46 \%$ \\
\hline TE max & $0.35 \%$ & $2.04 \%$ & $10.99 \%$ & $27.36 \%$ & $2.93 \%$ & $8.42 \%$ & $43.53 \%$ & $22.05 \%$ & $39.46 \%$ \\
\hline
\end{tabular}

Table 5.12 - TE following Brune.

The Brune curves provided three values of TE which are very different between them. Moreover, in many cases the TE is zero. This is due to the fact that Brune curves do not apply for the Rambla del Poyo check dams, because they were set up for larger dams.

For this reason, and as anticipated before, the TE was calculated through the STEP model coupled to the TETIS model. The TE depends on:

- $\quad$ Check dam characteristics (height, width, length, slope);

- $\quad$ Food event characteristics (peak discharge, duration, volume);

- $\quad$ Reservoir water storage capacity.

\subsubsection{Stratigraphical description}

Indirect evidence of sediment production at the study area was provided by sediments stored behind the dam 2, a small concrete check dam built around 1990, draining a catchment surface of $12.9 \mathrm{~km}^{2}$. The dam maximum storage volume is $3,000 \mathrm{~m}^{3}$, and at the time of the field survey was about half of its total volume capacity. This dam was chosen for its high siltation rate and for its accessibility.

A field study was carried out to survey the dam body and the sedimentation area, and to describe the infill flood stratigraphy including collection of sediment samples for textural analysis of the sedimentary sequences. A topographic survey was also carried out at the sedimentation area and the surrounding slopes with a real time kinematic differential GPS topographic survey, in order to better estimate the deposited volume [Gabriele et al., 1999; Martín-Rosales et al., 2003].

Two trenches were dug across the check dam sedimentation infill, at $9.5 \mathrm{~m}$ and $22 \mathrm{~m}$ from the embankment respectively, called BG-1 and BG-2 (initials of Barranco Grande, where the check dam is located). In Figure 5.23 a draw of the reservoir situation can be seen, as well as the trench location. 


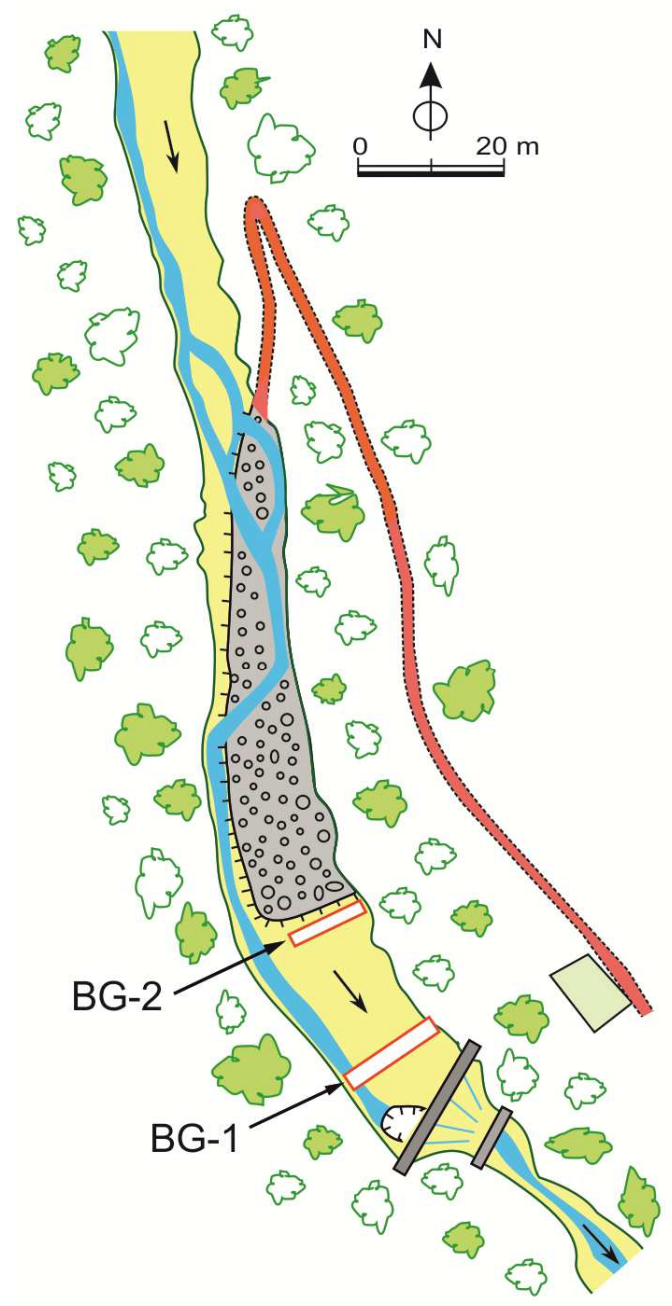

Figure 5.23 - Reservoir 2 seen from above.

The digging phase can be seen in Figure 5.24 and Figure 5.25. Detailed stratigraphic panels were carried out using a 1-m side vertical grid over the trench (Figure 5.26, Figure 5.28 and Figure 5.27), where stakes with reference numbers were put at regular intervals. In these panels all the depositional contacts were traced laterally with emphasis on breaks that indicate sedimentary interruption and post-flood surface exposure. The panels allowed a better detection of lateral interfingering beds, potential erosion and depositional gaps. Correlation between these two panels was possible due to anomalous charcoal content of some reference alluvial beds. Sediment samples for each unit were collected for determination of organic matter and micro-charcoal content (as indicator of fires) and for a complete textural analysis. 


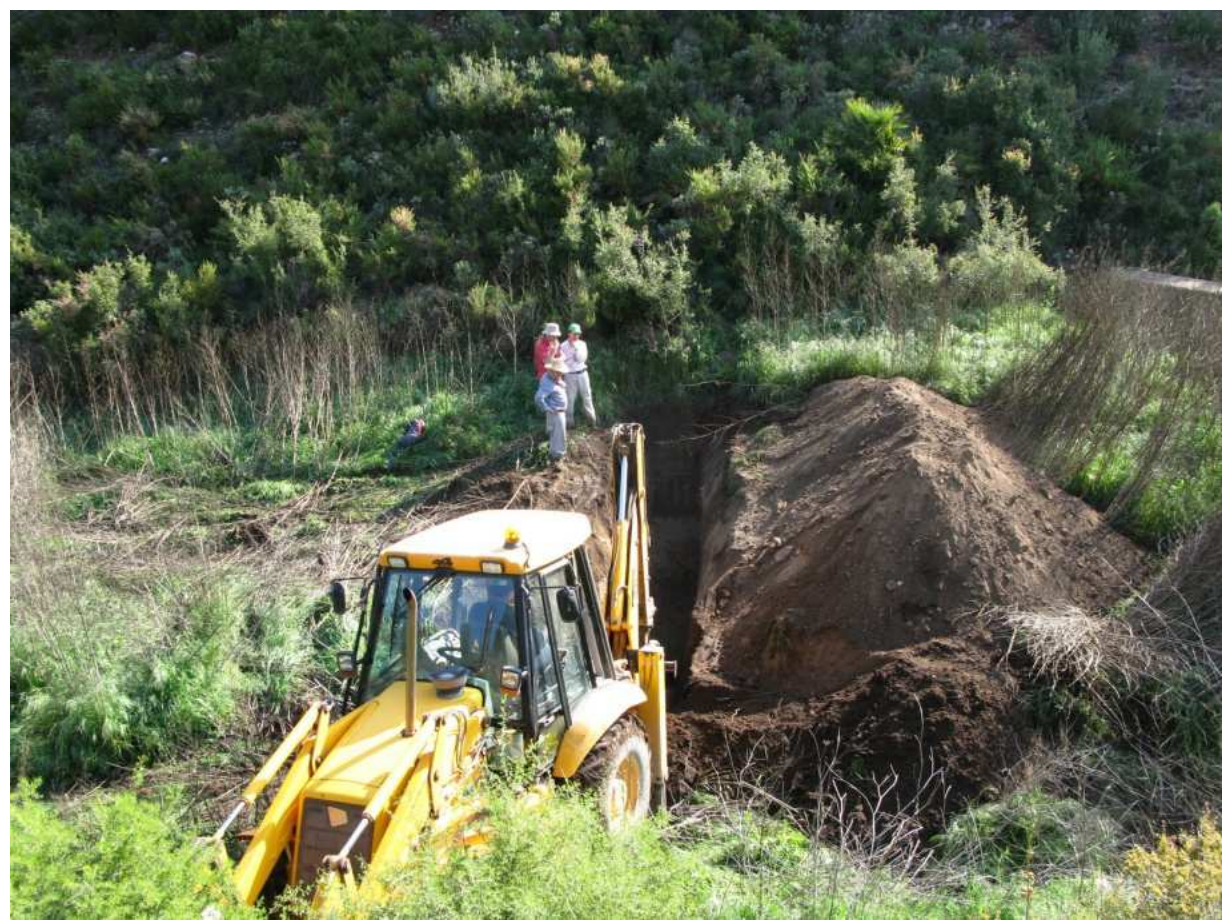

Figure 5.24 - Digging phase (1/2).

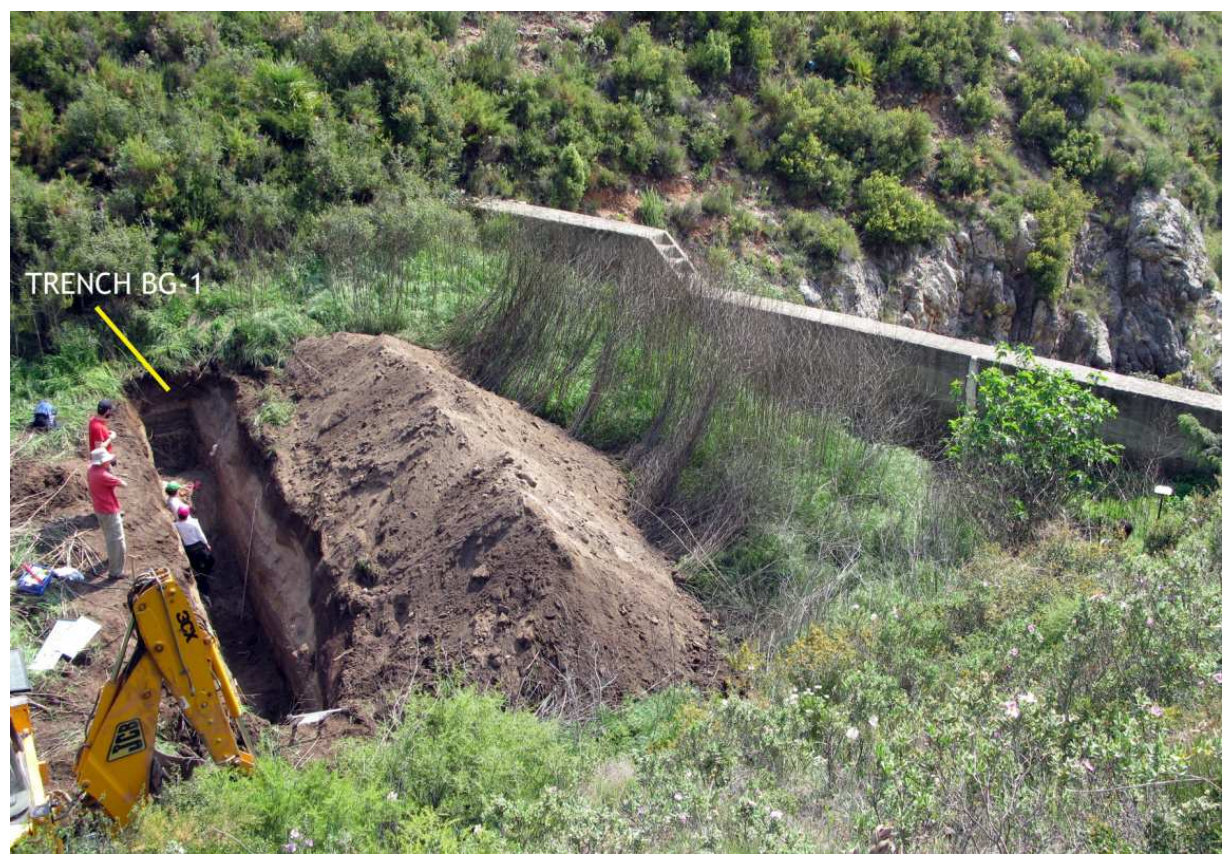

Figure 5.25 - Digging phase (2/2). 

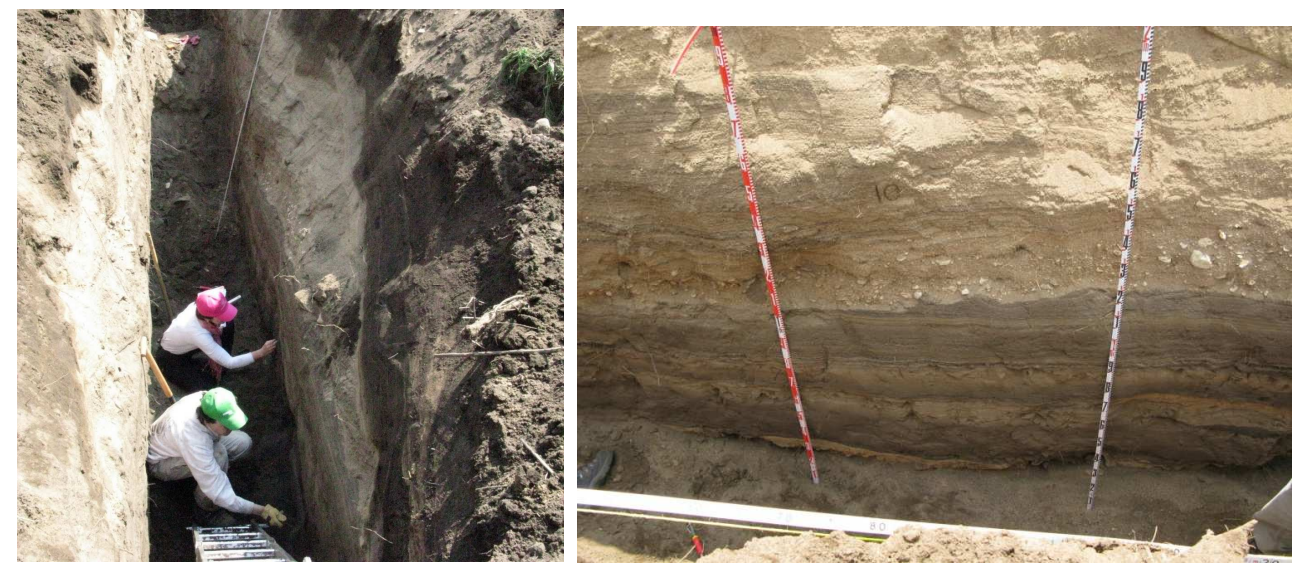

Figure 5.26 - Stratigraphical analysis phase.

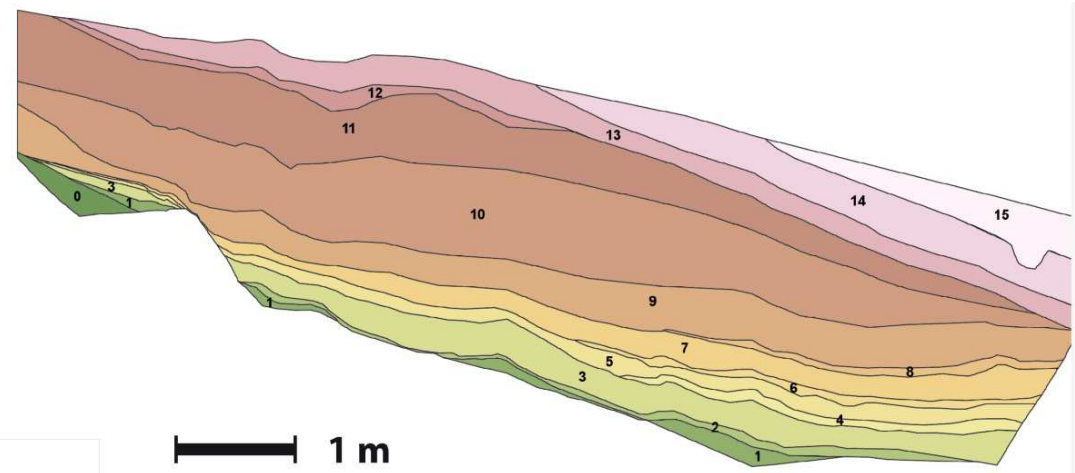

Figure 5.27 - Front view of BG1.

Starting from the reservoir geometry, the GPS survey and the flood unit morphology, the volume of each alluvial layer deposited by an individual flood was estimated by using two different methodologies:

- "wedge" (or geometrical) approach: given the layer depths inside the trenches, the sedimentation length and the distance between trenches, every layer volume was calculated as if each flood unit had a pyramidal shape (such as a wedge);

- proportional (or topographical) approach: given the surface shape and the layer depths inside the trenches, each layer volume was estimated by subtracting from the actual deposits the average accumulated layer depth, considering the thickness difference of each layer in each trench and approaching it as a pyramidal shape. 


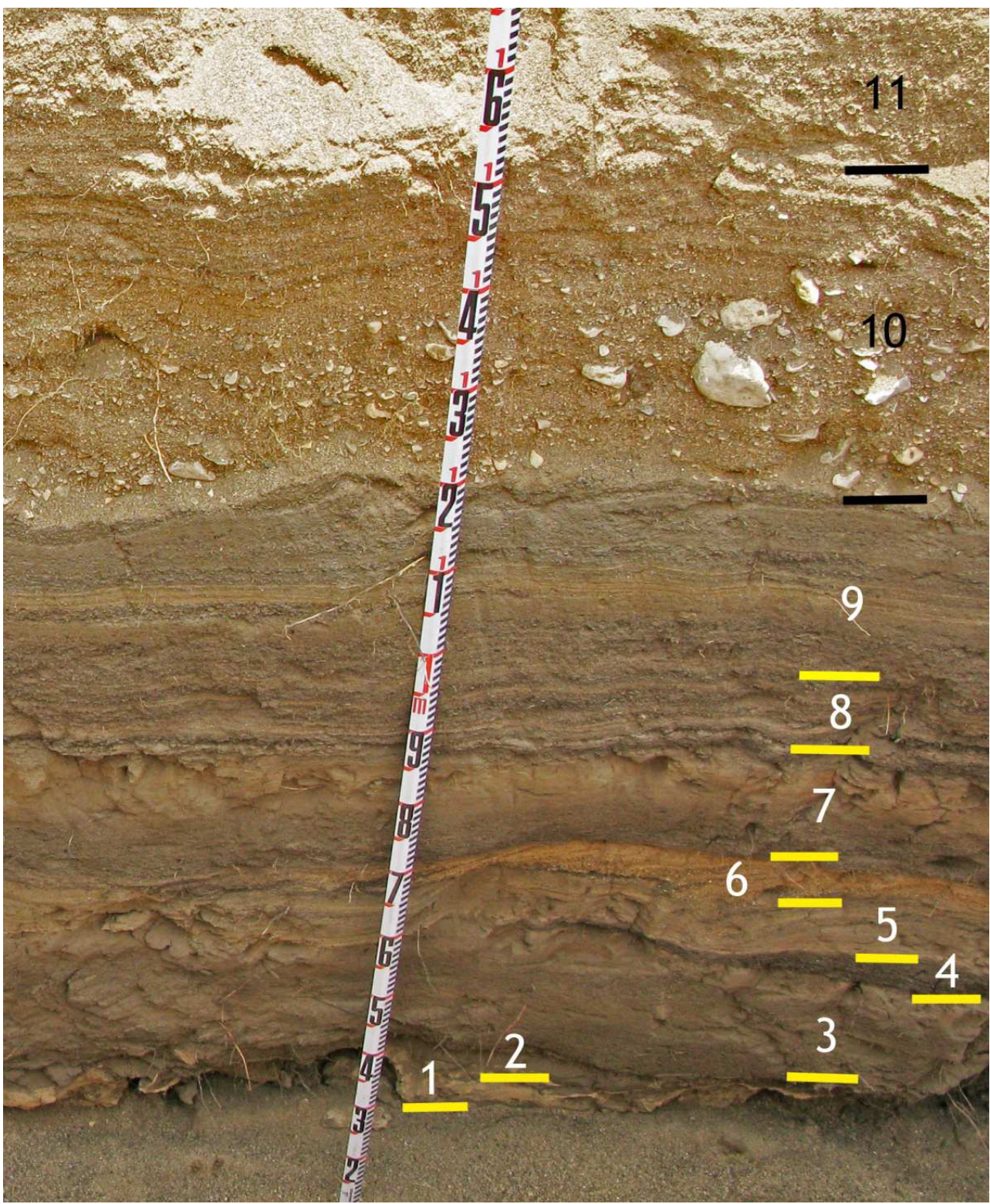

Figure 5.28 - Stratigrahphical profile (front view).

\subsubsection{Wildfire data}

In Mediterranean catchments, the wildfire occurrence is quite frequent. The Rambla del Poyo catchment was subject to several wildfire during the last 20 years. The most relevant ones can be seen in Figure 5.29. In this figure, the extension of each wildfire is shown. The 
wildfires occurred respectively in summer 1993, 1994, 2000 and 2003. The 1994 was especially severe, affecting an extended area $^{6}$.

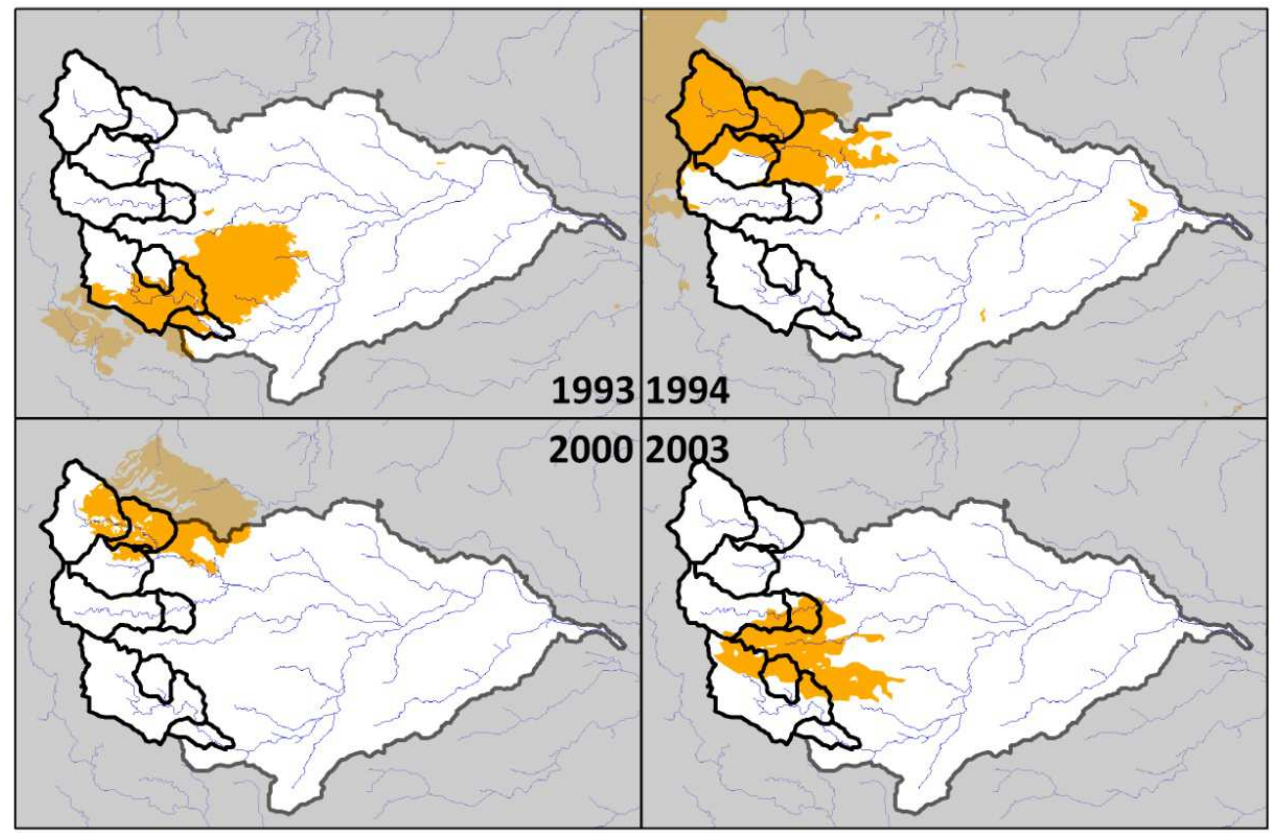

Figure 5.29 - Rambla del Poyo most extended wildfires since 1993.

The effect of wildfires was taken into account by modifying the C USLE factor, which is a TETIS parameter, as illustrated in the model description section, during a "windows of disturbance" (as defined by Prosser and Williams [1998]) after the fires. As demonstrated by Campo et al. [2006] for a plot located close to the Rambla del Poyo catchment, this effect seriously increases SY, especially when a severe rainfall occurs a few days or weeks after the wildfire. The windows of disturbance length was chosen following Andreu et al. [2001], so that the highest susceptibility to soil erosion of burnt areas takes place at the first severe rainfall event after the wildfire, usually in autumn/winter [Shakesby, 2011]. A wildfire usually increases erosion rates due to reduction of the infiltration rate, increase of surface runoff and increase of soil erodibility [Cerdà, 1998a], among other effects. It has been demonstrated that, for Mediterranean shrubland plots, the site recovery is fully achieved after 2-4 years [Cerdà, 1998b] and that the most important runoff and erosion rates alteration occurs within a few months after the fire, depending on the precipitation [Cerdà, 1998a, 1998b; Andreu et al., 2001]. An example of this phenomenon was described by Cerdà and Lasanta [2005]. These authors demonstrated that in a shrubland catchment under natural conditions the erosion rates are low $\left(0.04-0.10 \mathrm{tha}^{-1} \mathrm{y}^{-1}\right)$, but they can increase up to 10 times within the 2-3 years after the fire. For the Rambla del Poyo catchment, no information about fire intensity, duration or ash production was available. In order to reproduce the effect of erosion increase during a window of disturbance, within

\footnotetext{
${ }^{6}$ http://www.lasprovincias.es/valencia/20090810/valenciana/verano-ardio-comunitat-20090810.html
} 
the burnt zones (the extension of both fires was provided by the Valencia Regional Government, Wildfire Management Service), the vegetation cover and management factor (C) was set to high values, since vegetation in burnt areas was almost absent, similarly to what was done by Rulli et al. [2005], to 0.9 for the extreme events that occurred in the following 2 years (for example, December 1995 for the 1994 wildfire and October 2000 for the 2000 wildfire), corresponding with the highest peak of erosion increase. The error introduced with this approximation was corrected by model calibration (by adjusting $\alpha$ and $\beta$ coefficients).

The infiltration capacity was not modified during the windows of disturbance. This was done because the hydrological sub-model was correctly calibrated and validated (as is shown hereafter) without taking into account the eventual infiltration capacity decrease. Furthermore, there was no evidence of such effect when comparing simulated and observed water discharge series. A possible reason for the absence of infiltration decrease is the one suggested by Cerdà and Doerr [2008], who stated that, after a forest fire, a layer of ash may compensate the effect of infiltration capacity reduction. In the Rambla del Poyo catchment a similar behaviour was noticed from model results: the comparison between the model results and the observed water discharge suggests that no sudden increase in runoff took place immediately after the wildfires.

\subsubsection{Model parameters}

Soil data for estimating hydrological and sedimentological model parameters was mainly taken from the LUCDEME project [Rubio et al., 1995]. Fifty-three soil profiles collected within the LUCDEME project and located into or close to the Rambla del Poyo catchment were selcted, within an area of around $1,500 \mathrm{~km}^{2}$. Soil texture data, organic matter content and soil salinity data were used to feed the Saxton and Rawls [2006] pedotransfer functions and to obtain available water content and saturated infiltration capacity. Percolation capacity was estimated by reclassifying the lithological map, considering permeability values taken from literature. The permeability was derived from the geological map of Spain [IGME, 1978]. The maps spatial resolution was set to $100 \mathrm{~m} \times 100 \mathrm{~m}$. This resolution allows reasonable computational time without jeopardising the model precision.

\subsubsection{Hydrological parameters}

The vegetation cover map was estimated by reclassifying the CORINE Land Cover 2000 map (Figure 5.30). For the Rambla del Poyo catchment, these vegetation classes were detected:

- Urban land;

- $\quad$ Arable land cultivated with vegetables;

- Arable land cultivated with rice;

- Arable land cultivated with citrus;

- Dry arable land;

- $\quad$ Dry arable land alternate to some woodland;

- Shrubland (matorral);

- Pine forest;

- Water courses. 


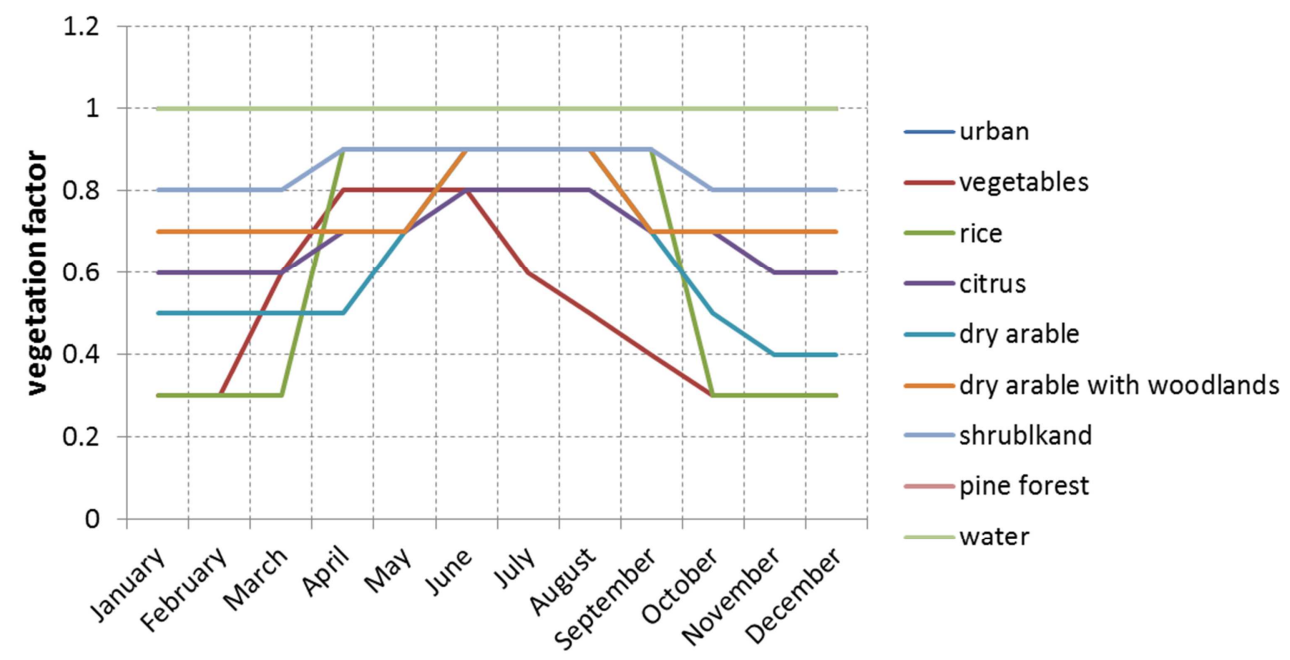

Figure 5.30 - Vegetation factors

For each textural class, 12 coefficients were established, also called vegetation factors (Figure 5.30). These coefficients are conceptually similar to the crop coefficients defined by the Food and Agriculture Organization (FAO), but extended for all kind of vegetation, not only crops. These coefficients are used to multiply the reference evapotranspiration provided as an input to the TETIS model. Each cell of the regular grid has 12 vegetation factors, depending on the vegetation class and on the month.

The Rambla del Poyo headwaters are mainly covered by shrublands with a few pine forests. The intermediate part is a cultivated zone, with predominance of dry land and some citrus trees. The lower zone is a flood plain dominated by a mosaic of urban zones, vegetables and citrus arable lands.

In order to assign pixel values of maximum static storage $\left(H_{u}\right)$ and infiltration capacity $\left(k_{s}\right)$, soil information was used, starting from the spatial distribution represented by the Soil Map of the Comunidad Valenciana (Valencia regional authority) and the LUCDEME soil profiles, which provided the soil texture, organic matter, gravel content and salinity. By means of the Saxton and Rawls pedotransfer functions, values of $H_{u}$ and $k_{s}$ were calculated for each polygon defined by the soil map.

The maximum static storage (Figure 5.32) was calculated by summing the maximum available water content (the water content between the wilting point and the field capacity, also known as maximum capillary storage), the maximum interception capacity, depending on the vegetation type, and the pond retention, depending on the soil roughness, land use and slope.

Given the polygon values, the methodology illustrated in Puricelli [2003] was applied for spatial interpolating the available information following the environmental characteristics of the catchment. 
The static storage is lower in the headwaters, where the most part of the runoff is generated. Static storage is greater for cultivated zones, especially if tree crops. Similarly, the infiltration capacity (Figure 5.33) is lower in the headwater and higher in the low lands.

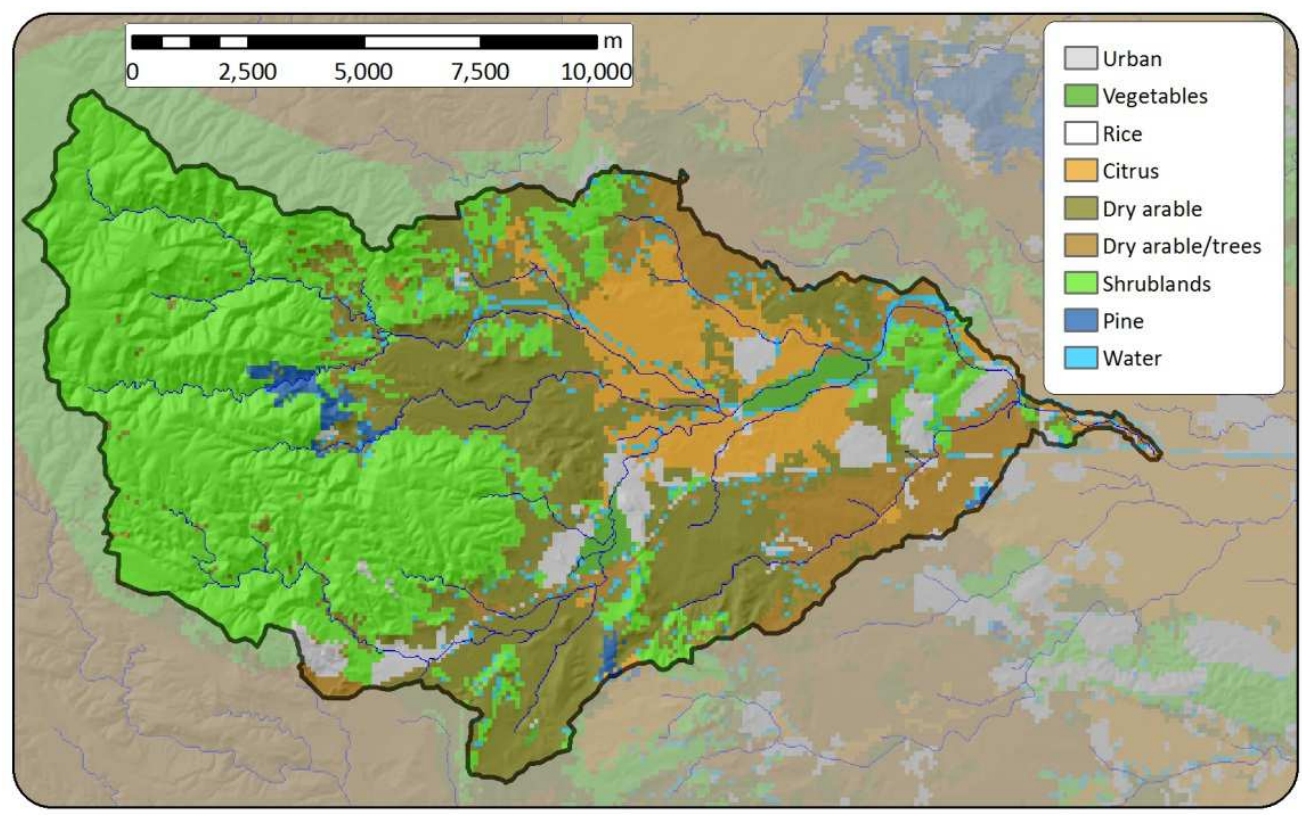

Figure 5.31 - Land use map of the Rambla del Poyo catchment.

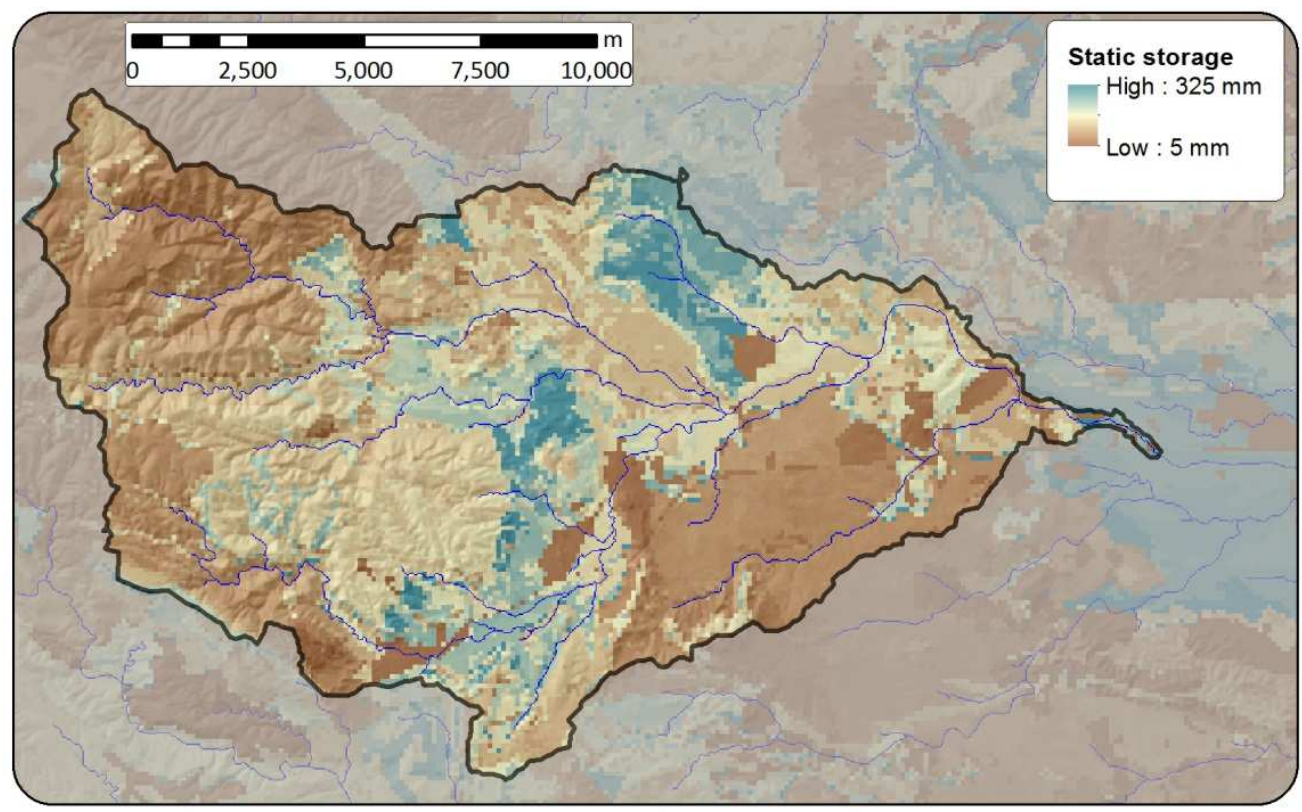

Figure 5.32 - Maximum static storage of the Rambla del Poyo catchment. 


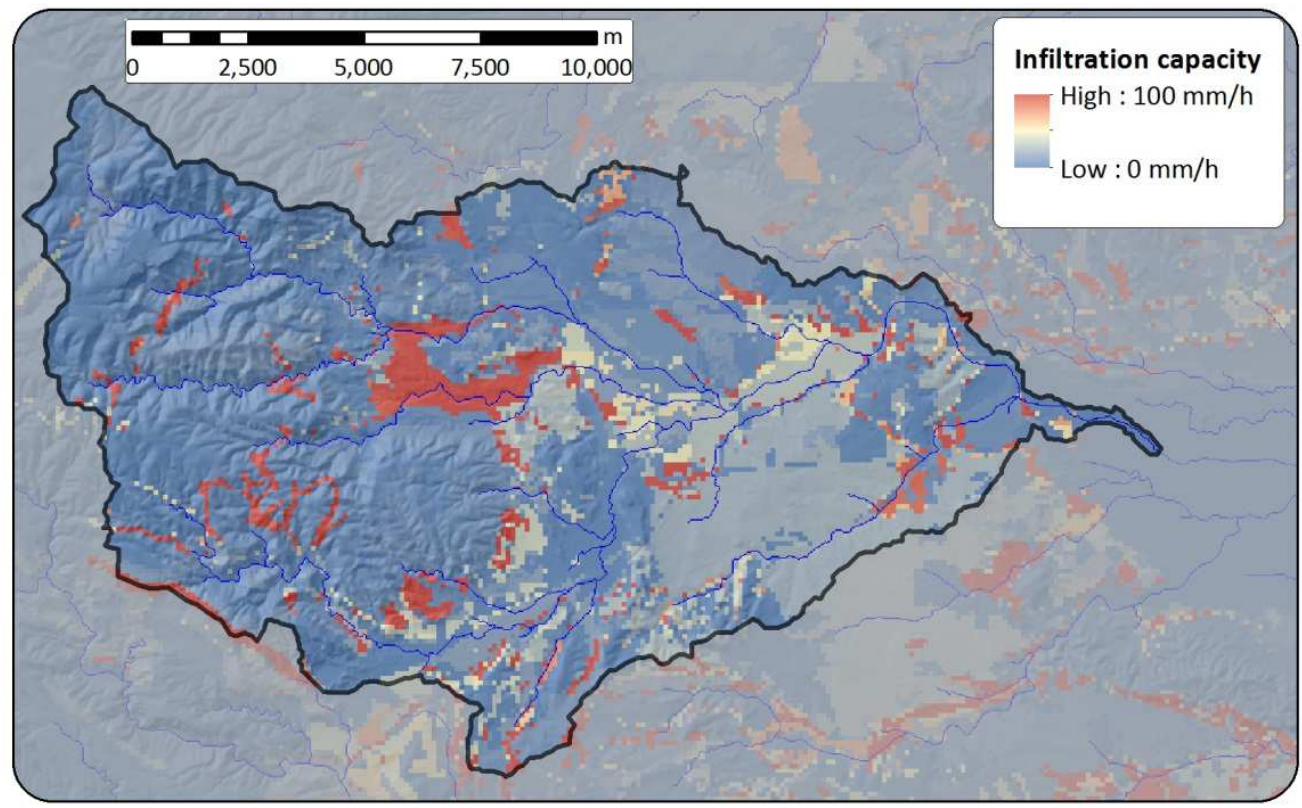

Figure 5.33 - Infiltration capacity of the Rambla del Poyo catchment.

The percolation capacity $\left(k_{p}\right.$ - Figure 5.34$)$ was obtained by reclassifying the geological map depending on the rock type. The percolation values can be seen in Table 5.13.

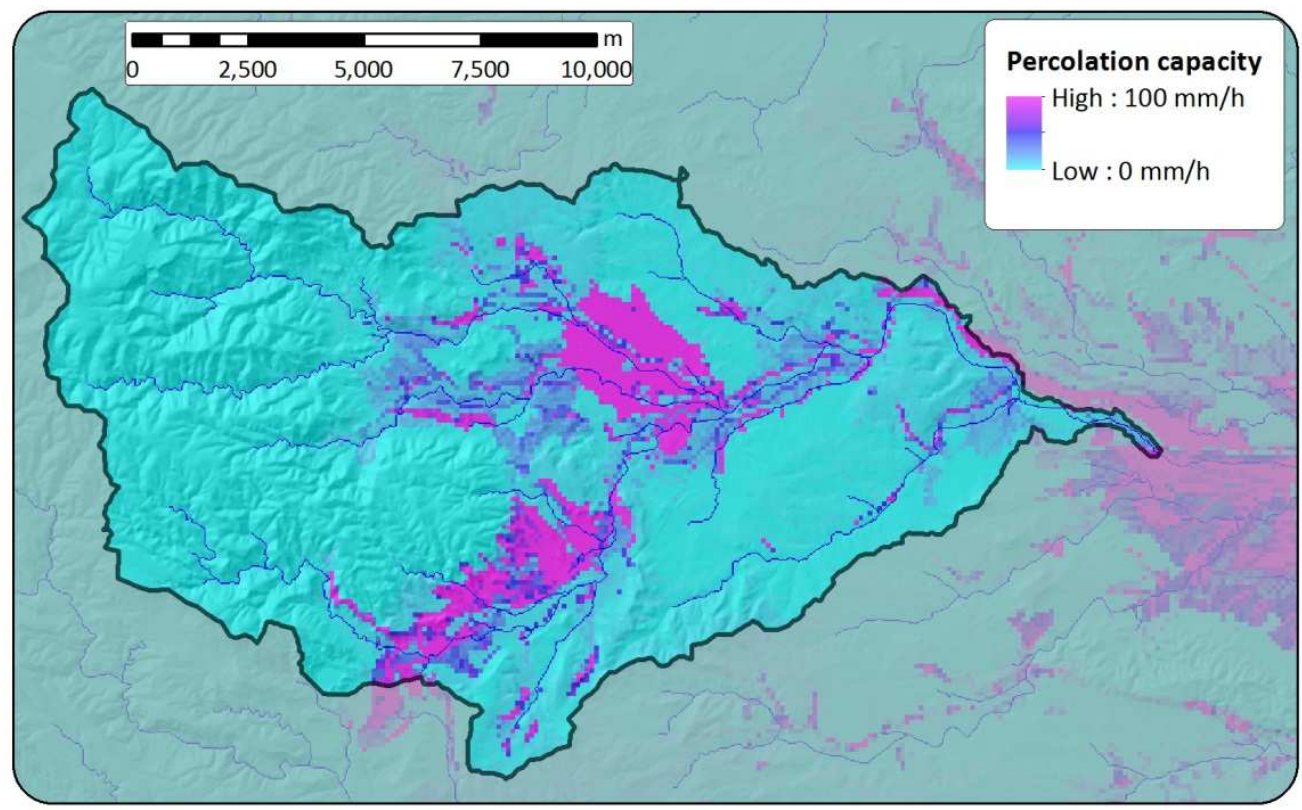

Figure 5.34 - Percolation capacity of the Rambla del Poyo catchment. 
Predominant material

Permeability variation range $\left(K_{p}\right)$

\begin{tabular}{ccccc}
\hline & \multicolumn{2}{c}{$\mathrm{m} / \mathrm{day}$} & & $\mathrm{cm} / \mathrm{h}$ \\
\hline Consolidate rocks & Min & Max & Min & Max \\
\hline Mainly chemical rock & & & & 0.00042 \\
Dolomite & 0.00001 & 0.00010 & 0.00004 & 0.04167 \\
Limestone & 0.00010 & 0.01000 & 0.00042 & 0.41667 \\
Gypsum & 0.01000 & 0.10000 & 0.04167 & 0.04167 \\
\hline Mainly detritical & & & & 0.41667 \\
Claystone & 0.00010 & 0.01000 & 0.00042 & 0.41667 \\
Marl & 0.00100 & 0.10000 & 0.00417 & 4.16667 \\
Limonite & 0.00100 & 0.10000 & 0.00417 & 41.66667 \\
Sandstone & 0.01000 & 1.00000 & 0.04167 & 0.41667 \\
Conglomerate & 0.10000 & 10.00000 & & 0.04167 \\
Not consolidate rocks & & & 0.00417 & 0.41667 \\
Clay & 0.00100 & 0.01000 & 0.04167 & 4.16667 \\
Silt & 0.01000 & 0.10000 & 0.41667 & 41.66667 \\
\hline Sand & 0.10000 & 1.00000 & 4.16667 & \\
\hline Gravel & 1.00000 & 10.00000 & & \\
\hline
\end{tabular}

Table 5.13 - Percolation capacity values depending on the lithology.

Horizontal interflow and base flow velocities were set as equivalent to $k_{s}$ and $k_{p}$, respectively. The loss coefficient was set to $0.1 k_{p}$.

\subsubsection{Geomorphological parameters}

The geomorphological parameters used for the Rambla del Poyo catchment are shown in Table 5.14. These parameters were obtained from a previous study conducted in a similar catchment from a geomorphological point of view [Vélez, 2001]. In this study no hydraulic geometry field work was carried out.

\begin{tabular}{cc}
\hline Parameter & Value \\
\hline$\kappa$ & 0.600 \\
$\varphi$ & 3.260 \\
$a_{1}$ & 20.000 \\
$\alpha_{1}$ & 0.047 \\
$\alpha_{2}$ & 0.750 \\
$c_{d}$ & 0.500 \\
$\theta$ & 0.200 \\
$c_{n}$ & 1.250 \\
$\xi$ & 0.167 \\
\hline
\end{tabular}

Table 5.14 - Geomorphological parameters for the Rambla del Poyo catchment.

The threshold area for gully and channel formation was estimated by field observation, map analysis and trial and error simulations. Gully threshold was set to one cell (i.e. all cells have gullies) and channel threshold to $15 \mathrm{~km}^{2}$. 


\subsubsection{Sediment parameters}

The texture of topsoil was estimated using LUCDEME soil profiles. A texture value was assigned to each cartographic unit (soil map polygon). No spatial interpolation was carried out. Results are shown in Figure 5.35, Figure 5.36 and Figure 5.37. Soils are mainly silty loams to sands. Texture is coarser in the headwater and finer in the low plain.

Data from a previous study done by Antolín Tomás [1998] was employed for estimating C and $\mathrm{K}$ values. In that study, the $\mathrm{C}$ value was estimated as a function of the vegetation type and the cover density, following the guidelines given by Wischmeier and Smith [1978] and Dissmeyer and Foster [1984]. The K factor was estimated from soil analysis (texture, organic matter and salinity) of a data set covering the whole Valencia Region, using the equation proposed by Wischmeier and Mannering [1969], and then interpolated in space. The $C$ and $\mathrm{K}$ value were not changed during calibration process.

Within the Rambla del Poyo catchment, the highest $C$ values $(0.32)$ are located in the headwaters, and correspond to the less dense shrubland areas. The lowest values (0.1) are also located in the headwaters, and correspond to small areas of pine forest that have survived the historical wildfires. The intermediate and lower parts of the catchment are characterised by values around 0.2 . The $\mathrm{K}$ values decrease from the lower floodplain towards the headwater, mainly due to the variation of the soil sand content: up to $50 \%$ in the lower part and decreasing up to $10 \%$ in the headwater, following Rubio et al. [1995]. The main statistics of $\mathrm{C}$ and $\mathrm{K}$ factor are shown in Table 5.15. The $\mathrm{P}$ factor of the USLE was set to 1 , because no support practice is implemented. The results are shown in Figure 5.38 and Figure 5.39.

\begin{tabular}{lcc}
\hline & K & C \\
\hline Min. & 0.100 & 0.104 \\
Max. & 0.450 & 0.318 \\
Mean & 0.275 & 0.240 \\
St. Dev. & 0.1024 & 0.0590 \\
\hline
\end{tabular}

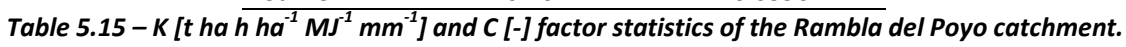




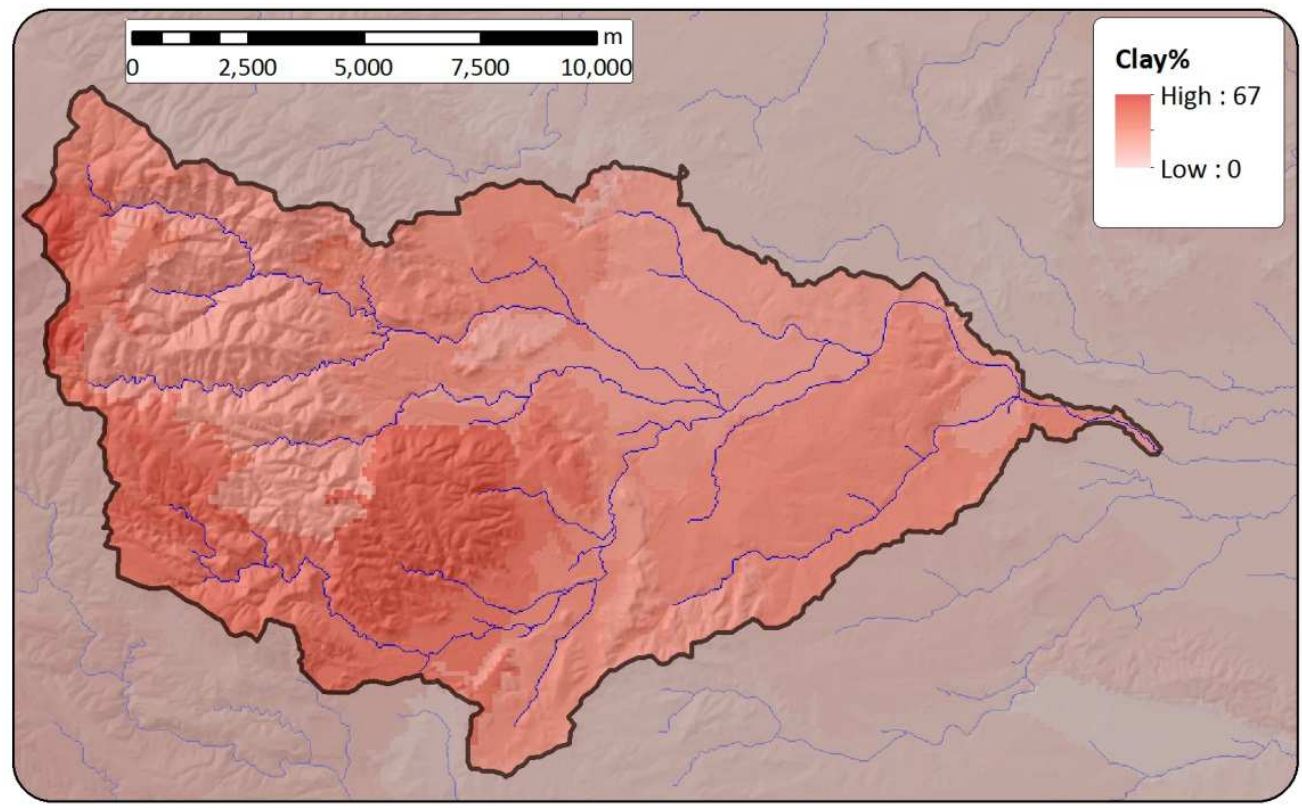

Figure 5.35 - Topsoil clay percentage of the Rambla del Poyo catchment.

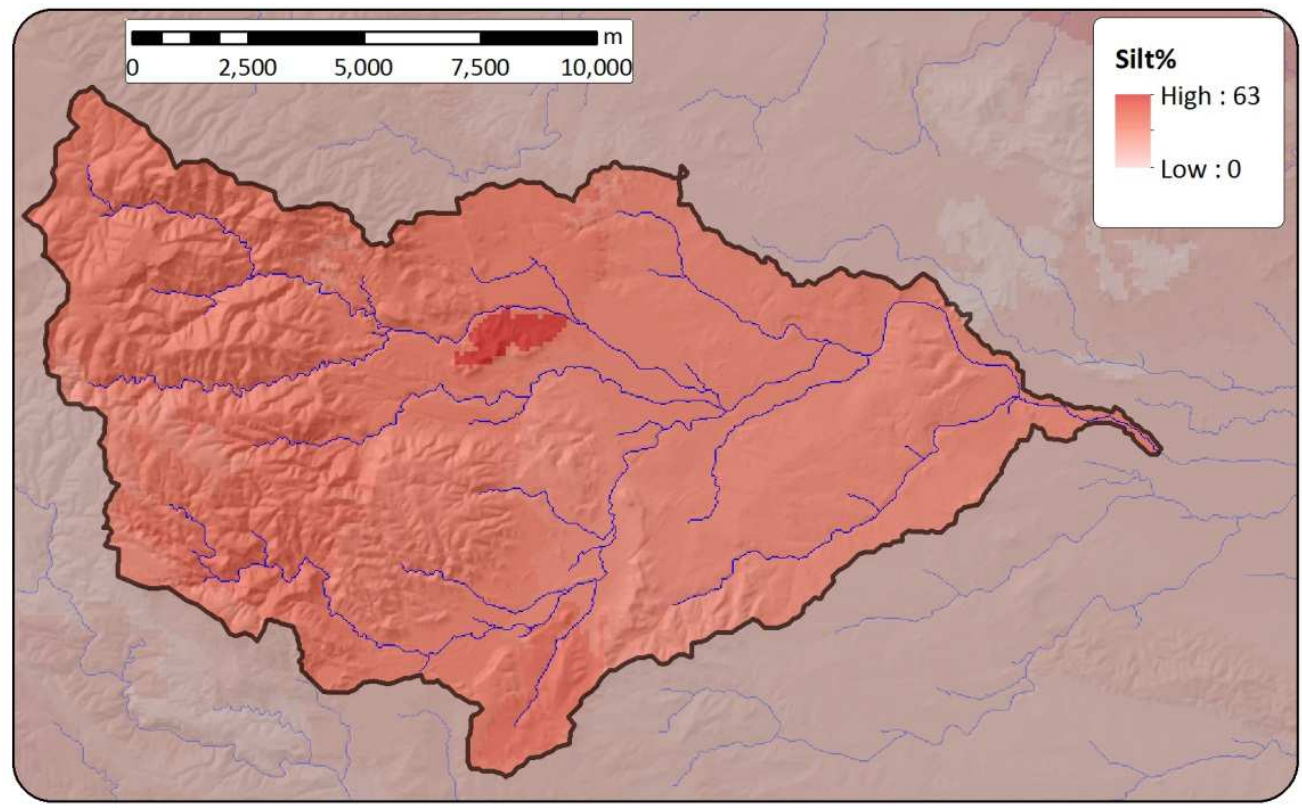

Figure 5.36 - Topsoil silt percentage of the Rambla del Poyo catchment. 


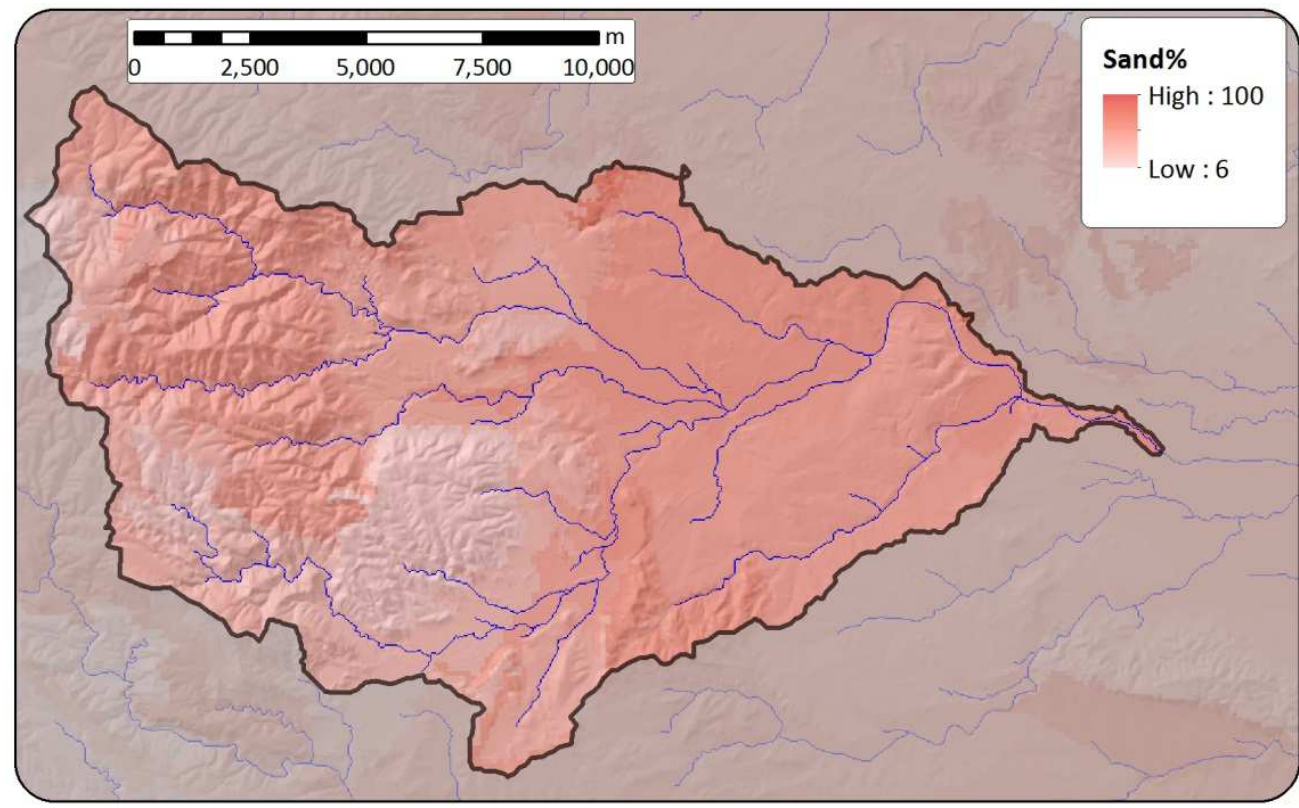

Figure 5.37 - Topsoil sand percentage of the Rambla del Poyo catchment.

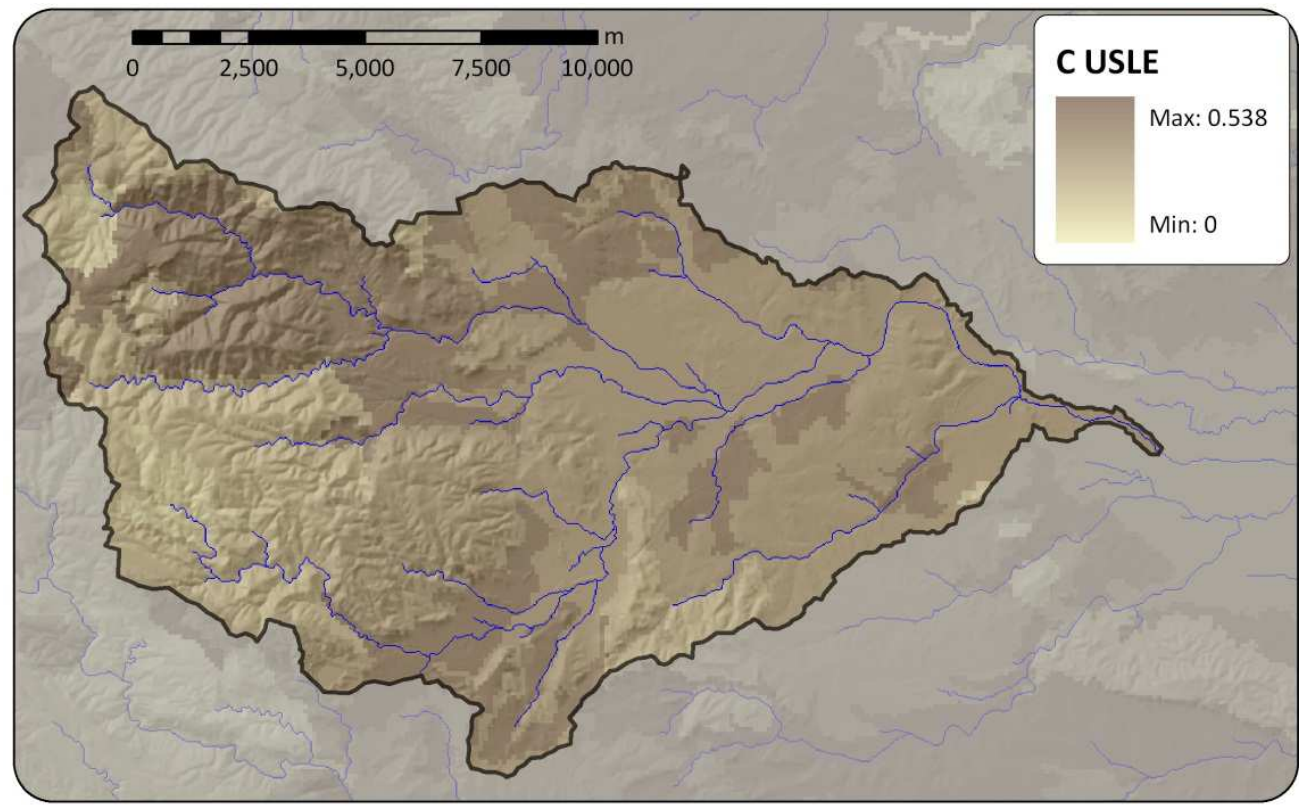

Figure 5.38 - USLE C factor of the Rambla del Poyo catchment. 


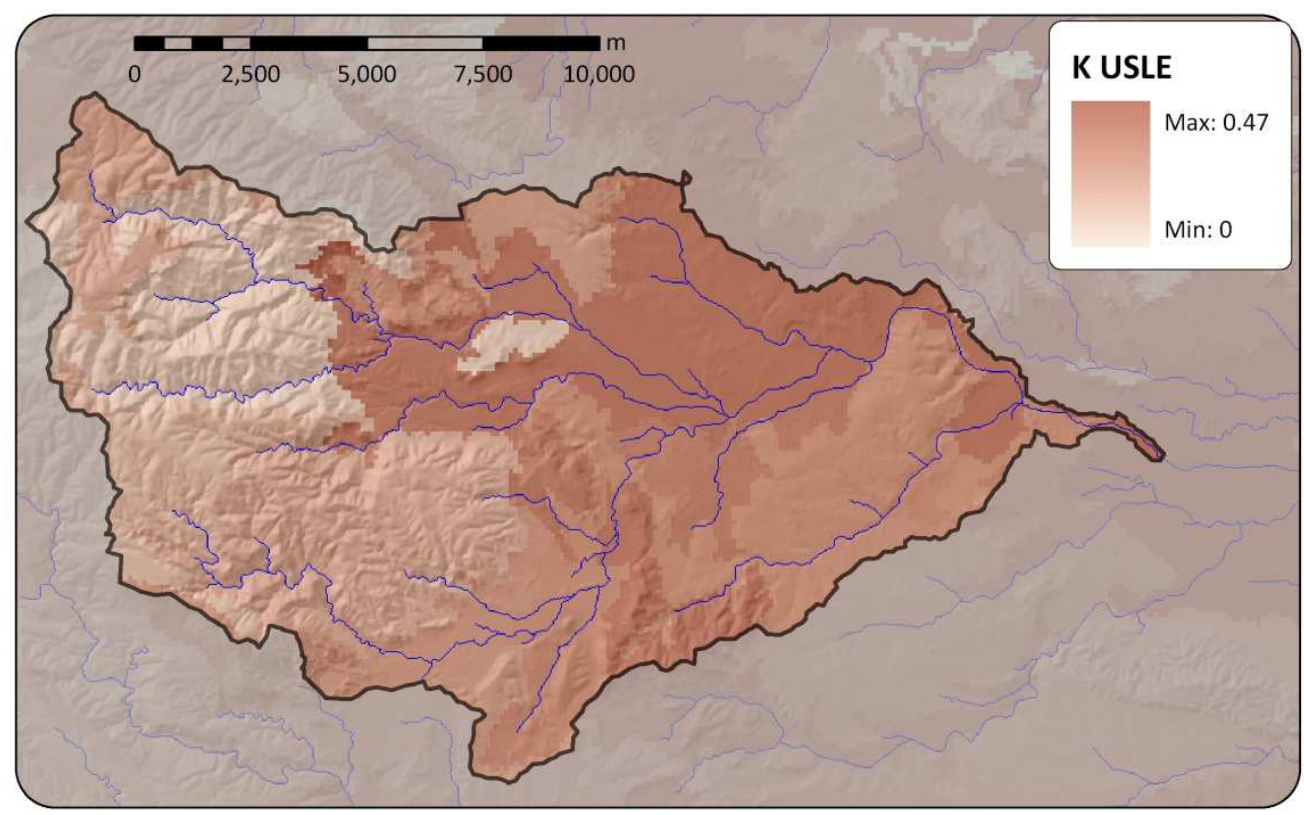

Figure 5.39 - USLE K factor of the Rambla del Poyo catchment.

\subsection{Results}

\subsubsection{Hydrological sub-model calibration and validation}

The first step of this study was the calibration and validation of the TETIS hydrological submodel. It has been proven that, in Mediterranean climate, only a few events scattered over a large time period are responsible for most of the total sediment load [Gallart et al., 2005]. Given that the aim of this study is the SY modelling, calibration and validation focused on the reproduction of large rainfall events.

Two models with different time discretisation were implemented within this study: with 5minutes time step and with a daily time step. The first one (the main model) was used for reproducing with a fine time step only the flood events. The second one simulated the noflood periods, with the objective of estimating the soil moisture initial condition for each flood event. This strategy was employed in order to save computational time.

The daily scale model was automatically calibrated from October 2000 to October 2003, and used for the estimation of the initial soil moisture state for 38 flood events. Its results are shown in Figure 5.40. The calibration gave a NSE of 0.82, and the validation (from 1998 to 2010 excluding the calibration period) provided a 0.72 NSE index, which can be considered a "very good" daily calibration and a "good" daily validation, following the performance classification given by Moriasi et al. [2007]. In Table 5.16 the calibrated correction factors for the daily time step model are shown. 


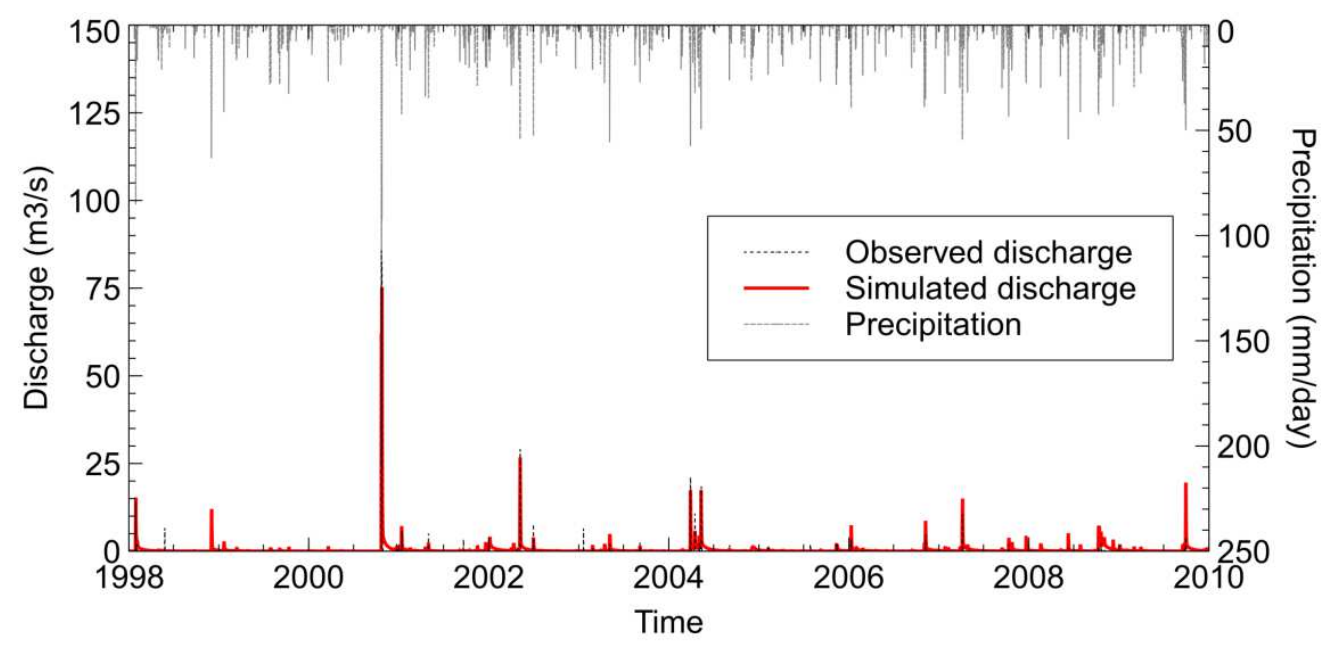

Figure 5.40 - Calibration and temporal validation of the hydrological sub-model at the daily scale at the Rambla del Poyo stream gauge station.

Using the initial soil moisture given by the daily model simulation, the 5 minutes time step model automatic calibration was also carried out. The 5-minutes time step model was calibrated on a single storm event in October 2000, by means of the TETIS automatic calibration algorithm and validated on 37 storm events from 1990 to 2009. The simulated hydrograph for the calibration event is shown in Figure 5.41 (left). The obtained NSE index is 0.78 , with a volume error of $-10 \%$, which can be considered as a very accurate model output (a "very good" model performance, following Moriasi et al. [2007]). The temporal flood validation also provided good results. In Figure 5.41 (right) the January 1998 event is shown. For this event, the NSE index is 0.5 and the volume error was $24 \%$; although there is a time shift between the observed and simulated peaks, maybe due to a poor description of the rainfall spatial distribution, this validation result can be judged as "good", given that the hydrograph shapes are very similar and the peak discharge error, which is very relevant for sediment yield modelling, is relative small (15\%). For all other flood events (Figure 5.42 and Figure 5.43) the model also obtained acceptable performances in terms of NSE index, volume and peak discharge errors and hydrograph visual fit. No spatial validation of the hydrological sub-model was carried out due to the absence of other stream gauges located within the Rambla del Poyo catchment.

The model also reproduced satisfactorily the ephemeral behaviour of the catchment; the base flow is absent, and the channel flow is composed mainly by overland flow with a little contribution of interflow (for heavy flood events, only $0.1 \%$ of total flow), which is in accordance with prior catchment knowledge. The model tended to provide a good estimation of the high peak flows, while the error on small intensity events was greater, probably due to the use of spatially uniform precipitation (only one rain gauge, located at the gauge station, was available for the whole catchment). The initial soil moisture estimation by a warm-up simulation period at the daily scale was proven to be suitable, although some small error can be detected, as for example in the Figure 5.41 (left), where the first peak of the flood is underestimated, probably due to an underestimation of the 
initial soil moisture. In Table 5.16 the calibrated correction factors for the five minutes time step model are shown.

\begin{tabular}{ccc}
\hline Correction factor & Daily model & 5-mins model \\
\hline CF1 & 1.0239 & 2.0010 \\
CF2 & 0.9785 & 0.7051 \\
CF3 & 0.9000 & 4.2370 \\
CF4 & 0.1000 & 0.0290 \\
CF5 & 47.6267 & 1.9500 \\
CF6 & 65.9729 & 0.0504 \\
CF7 & 10000 & 100.0000 \\
CF8 & 0.000 & 0.0000 \\
CF9 & 0.1000 & 1.20000 \\
\hline
\end{tabular}

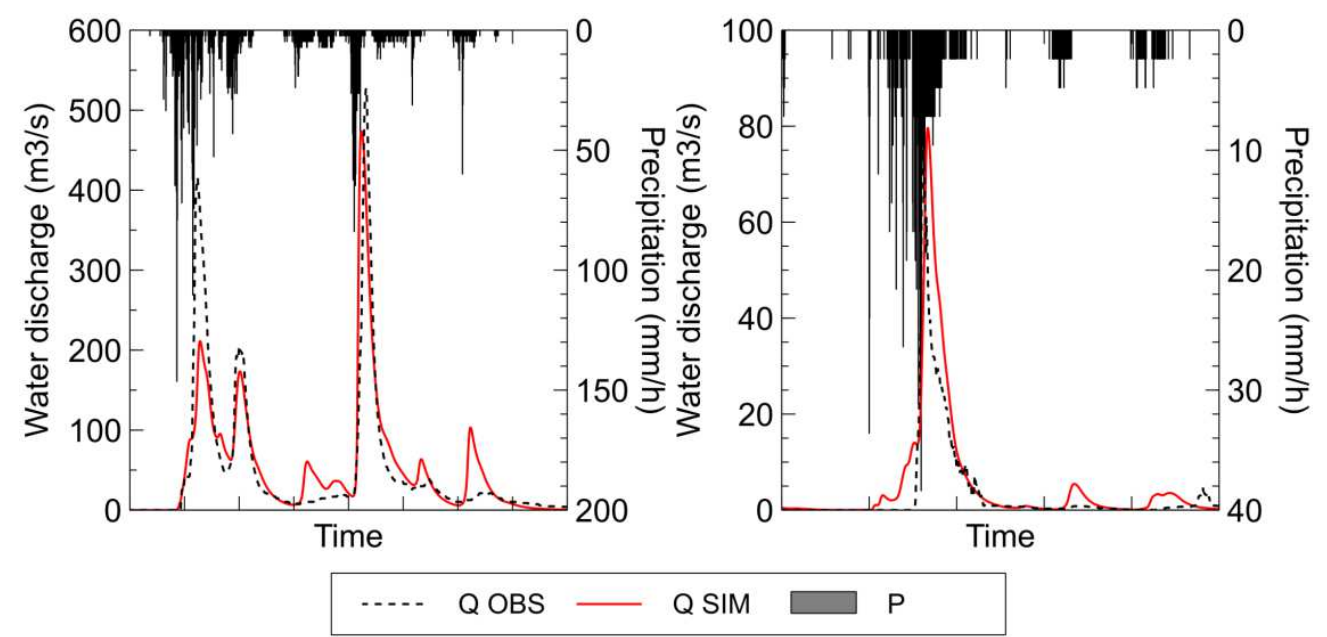

Figure 5.41 - Calibration (right) and temporal validation (left, 1998 event) at the 5-minutal time scale at the Rambla del Poyo stream gauge station. 


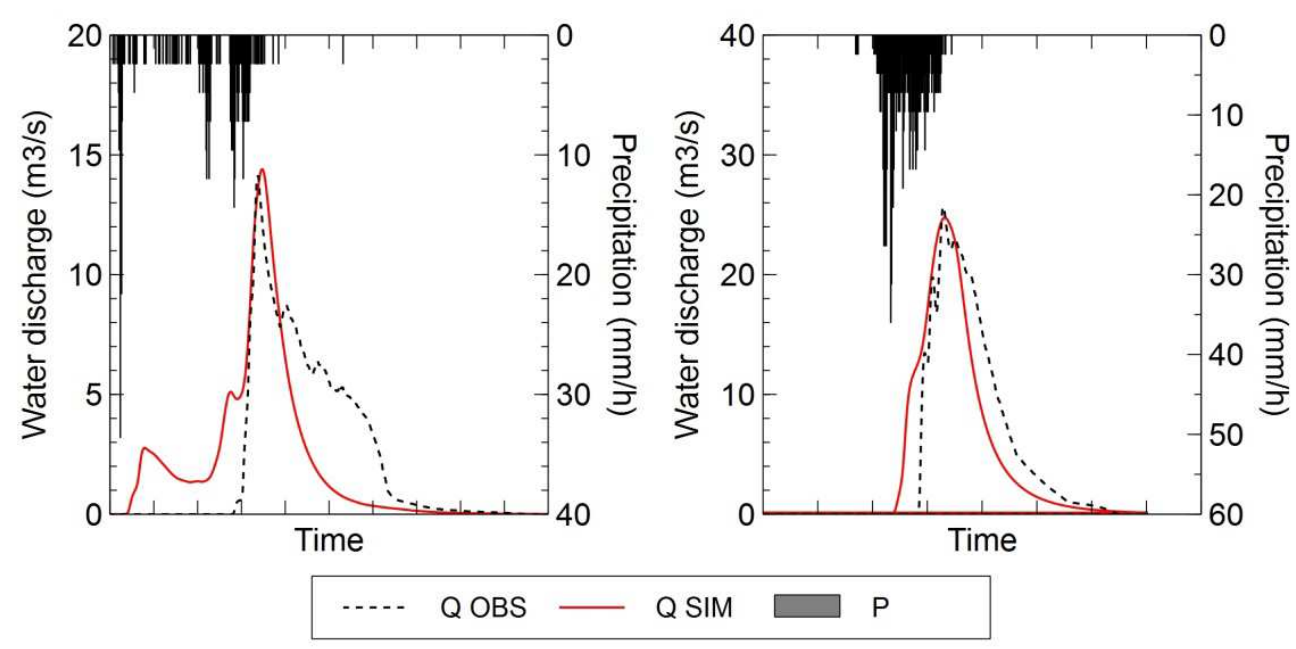

Figure 5.42 - Temporal validation (left, 2006 event; right, 2002 event) at the 5-minutal time scale at the Rambla del Poyo stream gauge station.
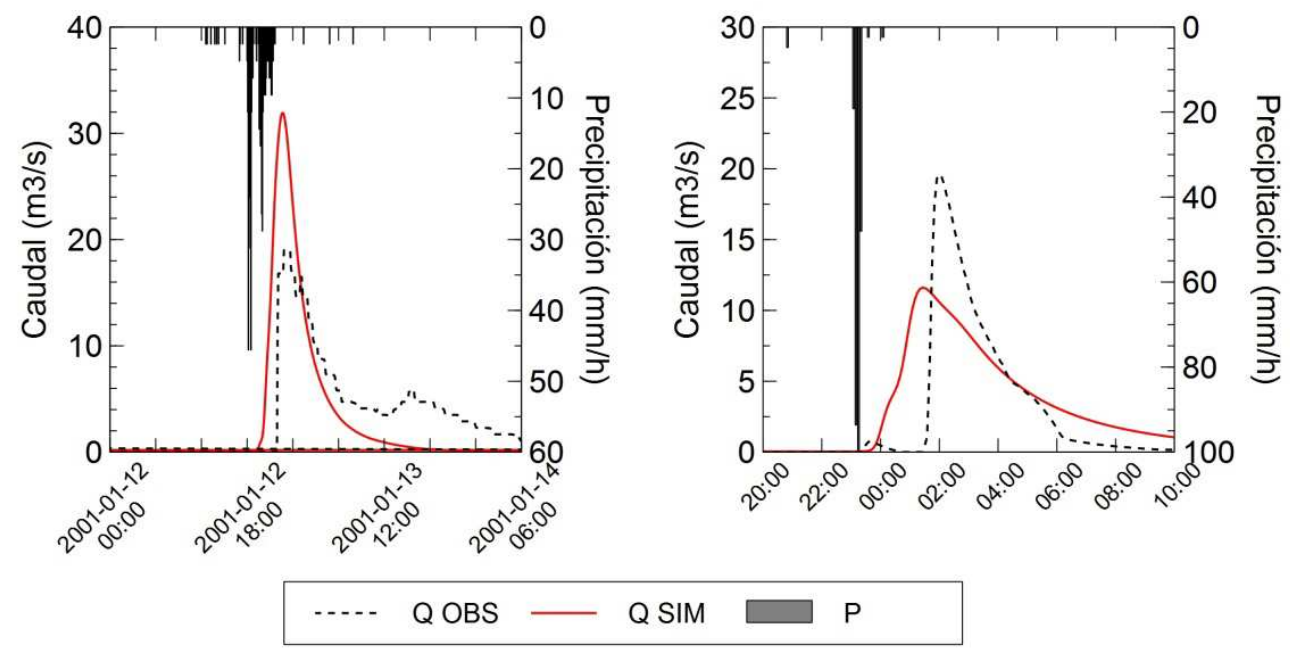

Figure 5.43 - Temporal validation (left, 2001 event; right, 2004 event) at the 5-minutal time scale at the Rambla del Poyo stream gauge station.

\subsubsection{Calibration and spatial validation of the sedimentological sub-model}

The following step of this chapter is the calibration and spatial validation of the sedimentological sub-model.

The TETIS sedimentological sub-model was calibrated using the total sediment volume accumulated behind the check dam. The variability in time of the reservoir TE was taken into account by coupling the TETIS and the STEP models. The reservoir was divided into 10 
finite volumes, and the reservoir routing time step was 1 second; incoming water and sediment discharges were calculated by means of the TETIS model. The input SY was divided into three textural classes (sand, silt and clay), and a settling velocity was assigned to each particle size.

The calibration was carried out by manually adjusting the values of $\alpha$ and $\beta$ coefficients within a range of feasible values, following the modellers' expertise. The objective function used in this calibration processes was the total VE expressed in percentage. The best value of the objective function (i.e. $0 \%$ ) was provided by the parameter set $\alpha=350$ and $\beta=0.05$.

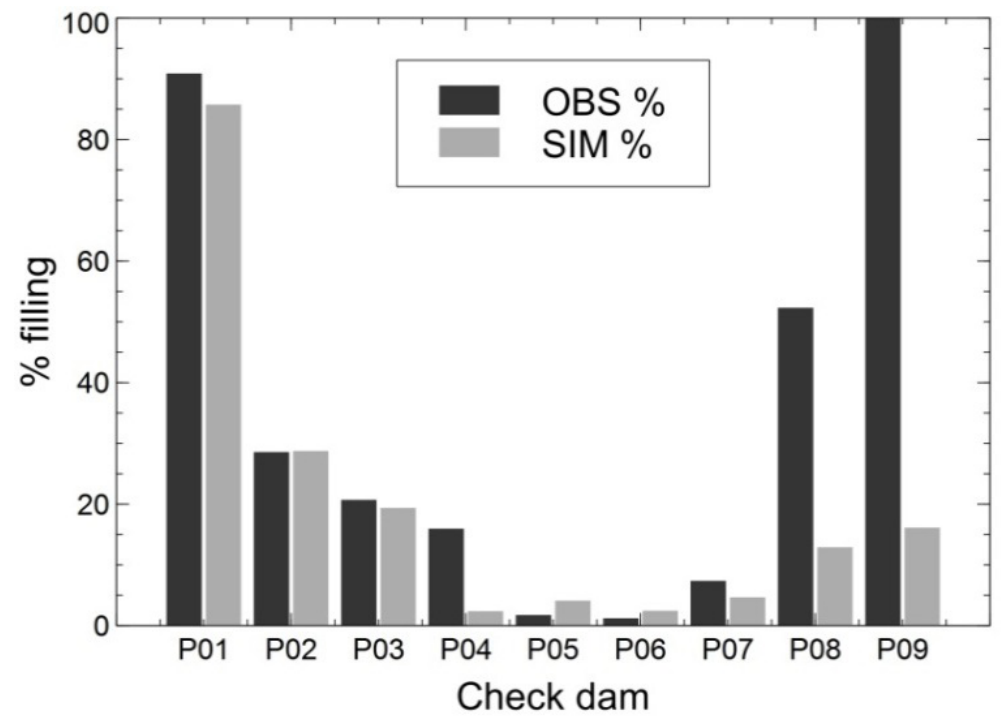

Figure 5.44 - Spatial validation of the sedimentological sub-model at the check dam 2.

As can be seen in Figure 5.44, the results are satisfactory for check dam 1 and 3 (small VE). For check dams 4 to 7, the model reproduces well the low sediment retention (or low sediment transport). For check dam 4 the error is greater than the other check dams. This is due to the presence of local sediment and gravel incomes such as rock outcrops which provided the stream network of a new source of sediments which was not taken into account. As an evidence of this phenomenon, the check dam 4 is the only one of the whole catchment which has high gravel content in its deposit.

For dams 8 and 9, the error is greater. The model tends to overestimate the observed volumes. For the check dam 9, this can be due to the dam characteristics. The check dam 9 is a very small dam ( $2 \mathrm{~m}$ high), located in a very steep slope. A possibility is that the STEP model does not apply in this situation, given that it was developed for larger reservoirs and gentle slopes. Check dam 8 error is probably due to some error in the parameter estimation or in the observed volume estimation.

The model results for check dam 2 are shown in Table 5.17. The simulated texture is very similar to the observed one (sediment mainly sandy with some amount of silt and almost no clay). This good matching is due to a satisfactory behaviour of the STEP model. 


\begin{tabular}{|c|c|c|c|c|c|}
\hline № & Date & $\begin{array}{c}\text { Sediment } \\
\text { volume }\left(\mathrm{m}^{3}\right)\end{array}$ & $\%$ sand & $\%$ silt & $\%$ clay \\
\hline 1 & 08/09/1990 & 0.01 & $100 \%$ & $0 \%$ & $0 \%$ \\
\hline 2 & 09/10/1990 & 1.6 & $76 \%$ & $22 \%$ & $2 \%$ \\
\hline 3 & 11/12/1991 & 23.1 & $94 \%$ & $5 \%$ & $0 \%$ \\
\hline 4 & 07/06/1992 & 8.7 & $91 \%$ & $9 \%$ & $0 \%$ \\
\hline 5 & 24/12/1992 & 9.2 & $88 \%$ & $11 \%$ & $0 \%$ \\
\hline 6 & 19/04/1994 & 25.2 & $92 \%$ & $8 \%$ & $0 \%$ \\
\hline 7 & $10 / 12 / 1995$ & 224.7 & $98 \%$ & $2 \%$ & $0 \%$ \\
\hline 8 & $30 / 01 / 1996$ & 2.8 & $78 \%$ & $22 \%$ & $0 \%$ \\
\hline 9 & 23/01/1997 & 0.3 & $49 \%$ & $49 \%$ & $2 \%$ \\
\hline 10 & 28/01/1998 & 38.6 & $95 \%$ & $5 \%$ & $0 \%$ \\
\hline 11 & $25 / 05 / 1998$ & 0.01 & $100 \%$ & $0 \%$ & $0 \%$ \\
\hline 12 & $31 / 07 / 1999$ & 60.3 & $98 \%$ & $2 \%$ & $0 \%$ \\
\hline 13 & 04/09/1999 & 0.6 & $57 \%$ & $40 \%$ & $3 \%$ \\
\hline 14 & $21 / 10 / 2000$ & 449.3 & $98 \%$ & $2 \%$ & $0 \%$ \\
\hline 15 & $22 / 12 / 2000$ & 4.4 & $93 \%$ & $7 \%$ & $0 \%$ \\
\hline 16 & $11 / 01 / 2001$ & 11.2 & $96 \%$ & $4 \%$ & $0 \%$ \\
\hline 17 & $30 / 04 / 2001$ & 62.0 & $98 \%$ & $2 \%$ & $0 \%$ \\
\hline 18 & $19 / 09 / 2001$ & 0.01 & $41 \%$ & $40 \%$ & $19 \%$ \\
\hline 19 & $06 / 05 / 2002$ & 22.1 & $95 \%$ & $5 \%$ & $0 \%$ \\
\hline 20 & $30 / 06 / 2002$ & 18.3 & $96 \%$ & $4 \%$ & $0 \%$ \\
\hline 21 & $05 / 05 / 2003$ & 7.7 & $93 \%$ & $7 \%$ & $0 \%$ \\
\hline 22 & 03/09/2003 & 57.3 & $99 \%$ & $1 \%$ & $0 \%$ \\
\hline 23 & $26 / 03 / 2004$ & 2.5 & $84 \%$ & $15 \%$ & $0 \%$ \\
\hline 24 & $15 / 04 / 2004$ & 1.4 & $91 \%$ & $9 \%$ & $0 \%$ \\
\hline 25 & $02 / 05 / 2004$ & 1.0 & $79 \%$ & $21 \%$ & $0 \%$ \\
\hline 26 & $10 / 05 / 2004$ & 7.0 & $96 \%$ & $4 \%$ & $0 \%$ \\
\hline 27 & $02 / 09 / 2004$ & 0.7 & $76 \%$ & $24 \%$ & $0 \%$ \\
\hline 28 & $07 / 02 / 2005$ & 2.5 & $86 \%$ & $14 \%$ & $0 \%$ \\
\hline 29 & $28 / 07 / 2005$ & 0.01 & $38 \%$ & $41 \%$ & $21 \%$ \\
\hline 30 & $10 / 11 / 2005$ & 12.9 & $93 \%$ & $7 \%$ & $0 \%$ \\
\hline 31 & 09/01/2006 & 4.5 & $92 \%$ & $8 \%$ & $0 \%$ \\
\hline 32 & $07 / 11 / 2006$ & 46.8 & $97 \%$ & $3 \%$ & $0 \%$ \\
\hline 33 & 05/04/2007 & 54.3 & $98 \%$ & $2 \%$ & $0 \%$ \\
\hline 34 & $11 / 10 / 2007$ & 82.2 & $98 \%$ & $2 \%$ & $0 \%$ \\
\hline 35 & 08/06/2008 & 4.6 & $92 \%$ & $8 \%$ & $0 \%$ \\
\hline 36 & 09/10/2008 & 72.0 & $98 \%$ & $2 \%$ & $0 \%$ \\
\hline 37 & $19 / 10 / 2008$ & 0.4 & $78 \%$ & $22 \%$ & $0 \%$ \\
\hline 38 & $27 / 09 / 2009$ & 112.8 & $98 \%$ & $2 \%$ & $0 \%$ \\
\hline
\end{tabular}

Table 5.17-Sedimentological sub-model results in terms of sediment volume and texture at the check dam 2.

\subsubsection{Alluvial infill volume estimation of check dam 2}

The geometry of the dam 2 alluvial infill can be described as a sedimentary wedge with a triangular plan view (Figure 5.45). The active channel is bordering the right margin of the reservoir area, partially undercutting the slope deposits. In the upper-mid reach of the reservoir the most relevant morphosedimentary feature is a lateral gravel bar $(43 \mathrm{~m}$ in length) attached to the left valley side, with a prominent 1-m high frontal scarp, indicating a progradation over the fine deposits located closer to the dam. This alluvial bar is composed by poorly sorted gravels and boulders in a matrix of sand and silt, with a lack of structure, suggesting a deposition by flash flow(s) associated with detrital heavy load and loss of energy due slope reduction caused by the previous dam infill. Closer to the dam wall, the 
alluvial infill comprises a 2.5 m-thick deposit composed by multiple layers of well sorted sands and silts with ripples, planar and cross-bedded lamination and parallel lamination. The geometry of the layers is horizontal, close to the reservoir centre, but increases its elevation and decreases its thickness towards the valley side.

Two trenches were dug across the check dam sedimentation infill. The first trench (BG-1, Figure 5.45) is about $10 \mathrm{~m}$ in length, covering from the left valley side to the main channel at the right margin, by $2.5 \mathrm{~m}$ in depth exposing sequences of multiple fine-grained flood deposits linked to the development of an eddy flow behind of the over-elevated left part of the dam wall. The stratigraphic sequences found in BG-1 (Figure 5.45) provides evidence of at least 15 individual floods units post-dating the dam as the dam infill fine sediments overlay old slope and stream channel gravels (Figure 5.45). The lower seven flood units suggest a period of relatively small floods, on the basis of the very fine and fine sand grain size and thin stratigraphic layers. The upper part of the sequence is represented by eight flood layers of medium to coarse sand within units of 20 to $60 \mathrm{~cm}$ in thickness with parallel and planar cross-stratification indicating a higher energy and sediment load than the lower flood units. The flood units 3 to 10 contain a large amount of charcoal debris concentrated on distinct 1-2 cm-thick laminae which are probably deposited after severe wildfires that occurred in 1994 and 2000.

The second trench (BG-2, Figure 5.45) is about $8.5 \mathrm{~m}$ long by $2 \mathrm{~m}$ deep, and it was excavated across the reservoir infill $12.5 \mathrm{~m}$ upstream of BG-1. In the lower 1-m section, at least eight flood units were distinguished and correlated with the lower ten flood units in BG-1, with exception of units 5 and 8 that pinched out at some point between both trenches. The upper one meter of BG-2 is composed by gravels with cross-bedding at the base and massive non-structured gravels at the top, the latter being the frontal lee face of the lateral gravel bar described previously. The relationship of these gravels with the fine-grain deposits of BG-1 is not obvious and either the gravels are the proximal facies of the floods that deposited units 11 to 15 in BG-1, or they correspond to a later large magnitude flood whose coarse sediments are prograding over the upper five units in BG-1.

However, the lack of stratigraphic breaks in the gravel unit prevents a detail correlation with the last five events described in BG1, and for practical purposes the gravel volume was considered as a sum of the last five events described in BG1. A complete textural analysis was carried out for each flood unit in BG-1, showing that sediments are mainly composed by sand, whose percentage varies between 77 and $99 \%$. The dBD of the infill deposits was estimated in $1.195 \mathrm{t} \mathrm{m}^{-3}$ using the approach suggested by Lane and Koelzer based on textural data and coefficients for dry reservoirs. 


\begin{tabular}{|c|c|c|c|c|c|c|c|c|}
\hline LAYER & $\begin{array}{c}\text { Calculated } \\
\text { volume - } 1 \\
\left(\mathrm{~m}^{3}\right)\end{array}$ & $\begin{array}{c}\text { Calculated } \\
\text { volume - } 2 \\
\left(\mathrm{~m}^{3}\right)\end{array}$ & \%sand & $\%$ silt & \%clay & $\begin{array}{c}\% \text { on the } \\
\text { total }\end{array}$ & $\begin{array}{l}\text { Presence } \\
\text { of } \\
\text { charcoal? }\end{array}$ & $\begin{array}{c}\text { The layer } \\
\text { is present } \\
\text { in trench } \\
2 ?\end{array}$ \\
\hline BG1-1 & 34 & 38 & $80.0 \%$ & $14.1 \%$ & $5.9 \%$ & $2.4 \%$ & NO & YES \\
\hline BG1-2 & 8 & 28 & -- & -- & -- & $0.5 \%$ & NO & YES \\
\hline BG1-3 & 172 & 78 & $94.4 \%$ & $3.9 \%$ & $1.7 \%$ & $12.0 \%$ & YES & YES \\
\hline BG1-4 & 10 & 27 & -- & -- & -- & $0.7 \%$ & YES & YES \\
\hline BG1-5 & 14 & 18 & $80.5 \%$ & $12.7 \%$ & $6.8 \%$ & $0.9 \%$ & YES & NO \\
\hline BG1-6 & 55 & 18 & $95.9 \%$ & $2.4 \%$ & $1.7 \%$ & $3.9 \%$ & YES & YES \\
\hline BG1-7 & 22 & 11 & $77.2 \%$ & $15.1 \%$ & $7.6 \%$ & $1.5 \%$ & YES & NO \\
\hline BG1-8 & 20 & 41 & $98.7 \%$ & $0.6 \%$ & $0.6 \%$ & $1.4 \%$ & YES & YES \\
\hline BG1-9 & 195 & 96 & $95.0 \%$ & $2.5 \%$ & $2.5 \%$ & $13.6 \%$ & YES & YES \\
\hline BG1-10 & 153 & 233 & $97.5 \%$ & $2.0 \%$ & $0.5 \%$ & $10.7 \%$ & YES & YES \\
\hline BG1-11 & 75 & 110 & $95.9 \%$ & $2.5 \%$ & $1.6 \%$ & $5.2 \%$ & NO & NO \\
\hline BG1-12 & 8 & 11 & $88.7 \%$ & $7.4 \%$ & $3.9 \%$ & $0.6 \%$ & NO & NO \\
\hline BG1-13 & 37 & 46 & $79.9 \%$ & $11.5 \%$ & $8.7 \%$ & $2.6 \%$ & NO & NO \\
\hline BG1-14 & 30 & 23 & $91.7 \%$ & $4.3 \%$ & $4.0 \%$ & $2.1 \%$ & NO & NO \\
\hline BG1-15 & 18 & 22 & $88.5 \%$ & $6.2 \%$ & $5.3 \%$ & $1.3 \%$ & NO & NO \\
\hline $\begin{array}{c}\text { Surface } \\
\text { gravel } \\
\text { volume }\end{array}$ & 528 & 448 & -- & -- & -- & $40.6 \%$ & NO & NO \\
\hline
\end{tabular}

Table 5.18 - Stratigraphical analysis results for check dam 2. 


\section{PROFILE BG-2}

PROFILE BG-1
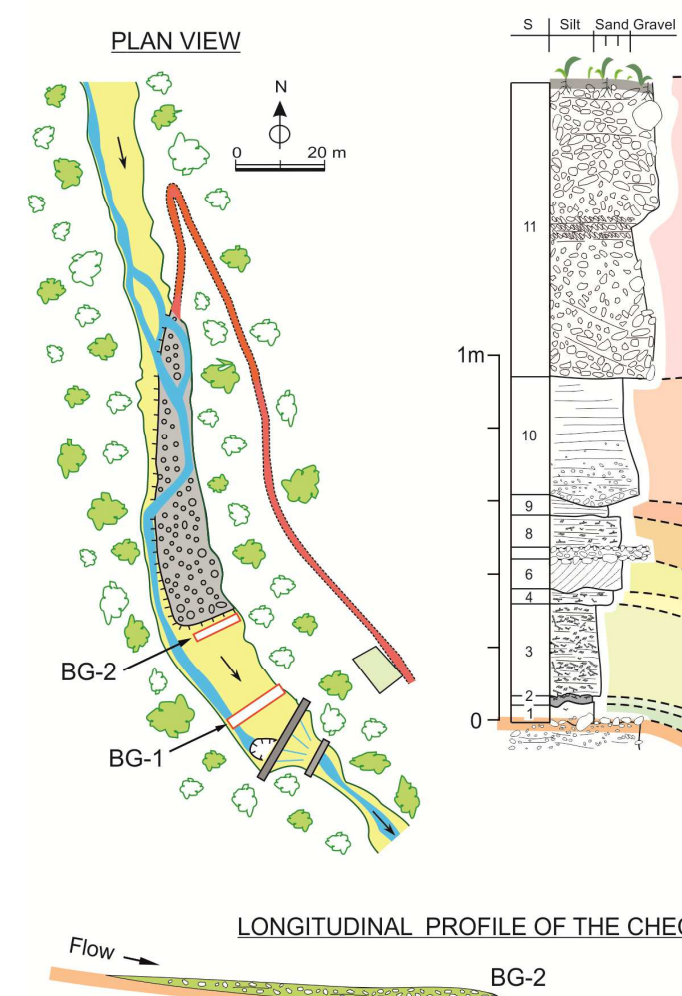

$\mathrm{S}=$ Number of sequence (each represents one flood only)

$s \mid$ Silt Sand Gravel
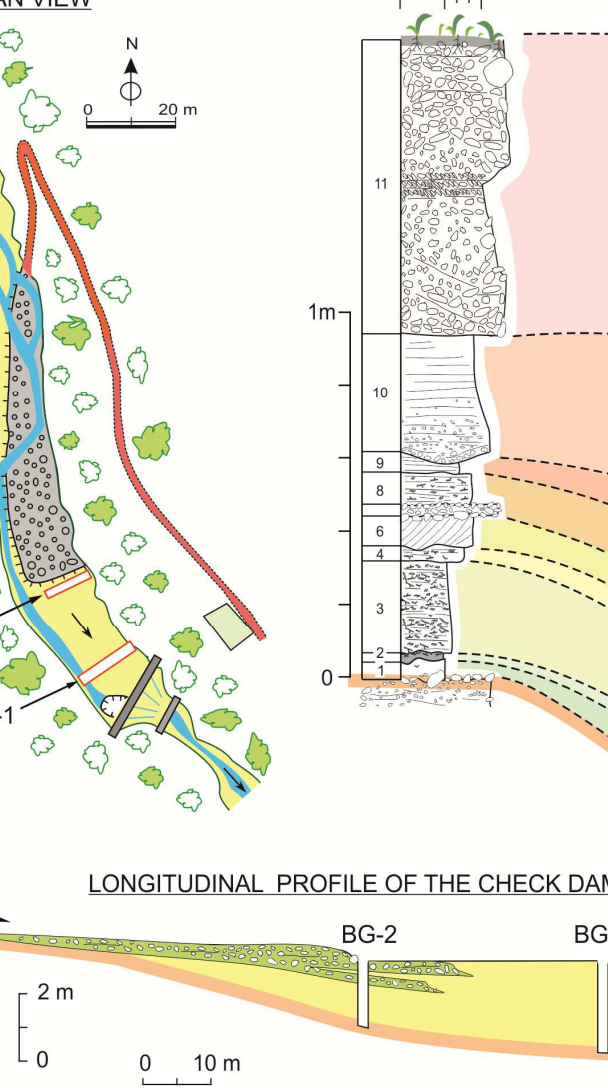

LEGEND

\begin{tabular}{|c|c|c|c|c|c|}
\hline 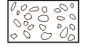 & Gravel & $\infty$ & Clay level & $\Leftarrow$ & Cross bedding \\
\hline & Sand & 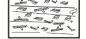 & Vegetables debris, charcoal & 96 & Gastropod, bivalves \\
\hline & Silt & & Parallel lamination & 功 & Roots \\
\hline
\end{tabular}

Figure 5.45 - Reconstruction of the stratigraphical profile of reservoir 2.

\subsubsection{Temporal validation of the sedimentological sub- model}

The simulated SY and deposited sediment series were analysed. As shown in Figure 5.46, the simulated depositional sequence shows the predominance of seven flood events, which account for the $86 \%$ of the total simulated deposits of the check dam reservoir of the time period $1990-2009$. 


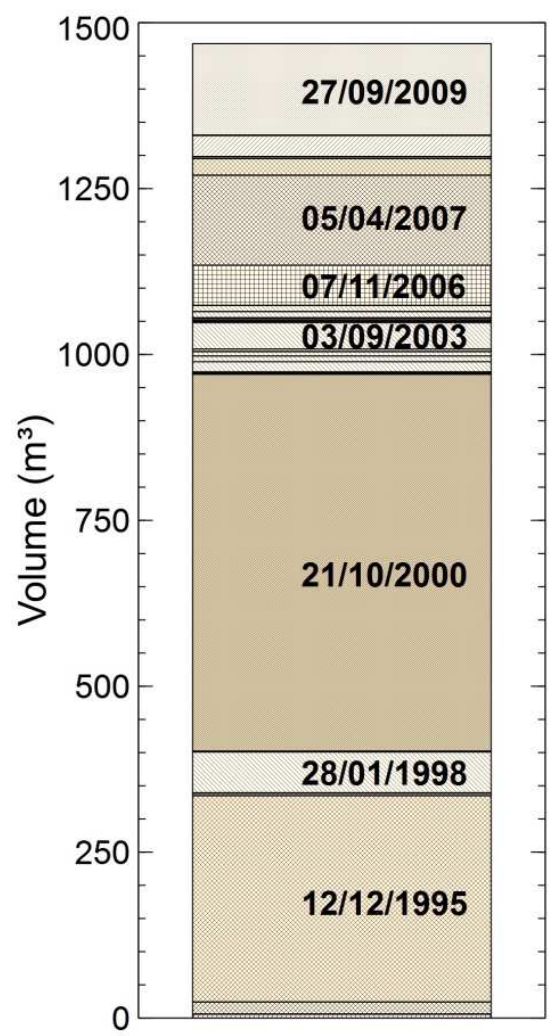

Figure 5.46 - Simulated deposits in check dam 2 (the most important events are labelled).

An age was assigned to the flood units described in the stratigraphy, in order to reconstruct the hydrological and sediment regime, considering (1) the relative stratigraphic order of layers since dam construction in 1990, (2) largest rainy events were able to produce the largest SYs, and moreover (3) sedimentary units containing 1-2 cm charcoal debris lamina were deposited during rainfalls following wildfire events. Two major wildfires occurred in the check dam 2 sub-catchment, since early '90s, dating summer 1994 and 2000, and the first floods following the fires took place in December 1995 and October 2000. Lamina with high content of charcoal debris was detected in layer 3 and 9, with decreasing concentration on the overlying beds. Hence, the flood unit 3 was related to the December 1995 flood event and the flood units 1 and 2 to the previous two floods (December 1992 and April 1994). As a partial confirmation of this statement, the flood unit 3 is one of the thickest layers, and following the hydrological model results, the December 1995 flood event had the second highest peak discharge of the simulated series $(1990-2009)$. Flood units 4 to 7 were assigned to four consecutive minor flood events (January 1996, January 1997, January 1998 and July 1999).

Flood units 8, 9 and 10 were all related to the October 2000 flood event; in fact, this flood event presented three peaks (Figure 5.41 - left), and for this reason, deposited three flood units. Flood units 11 to 15 were related to the following 5 flood events (April 2001, May 2002, September 2003, November 2006 and April 2007). The upper layer of undistinguished 
sediments was assumed to be produced by the last three flood events of the time series (October 2007, October 2008 and September 2009).

Following the previous chronological assumptions on the dam's alluvial stratigraphy (Figure 5.47), sediment volume estimated for flood units (i.e. the observed volume of each layer) and the simulated volume provided by the model were compared (Figure 5.47).

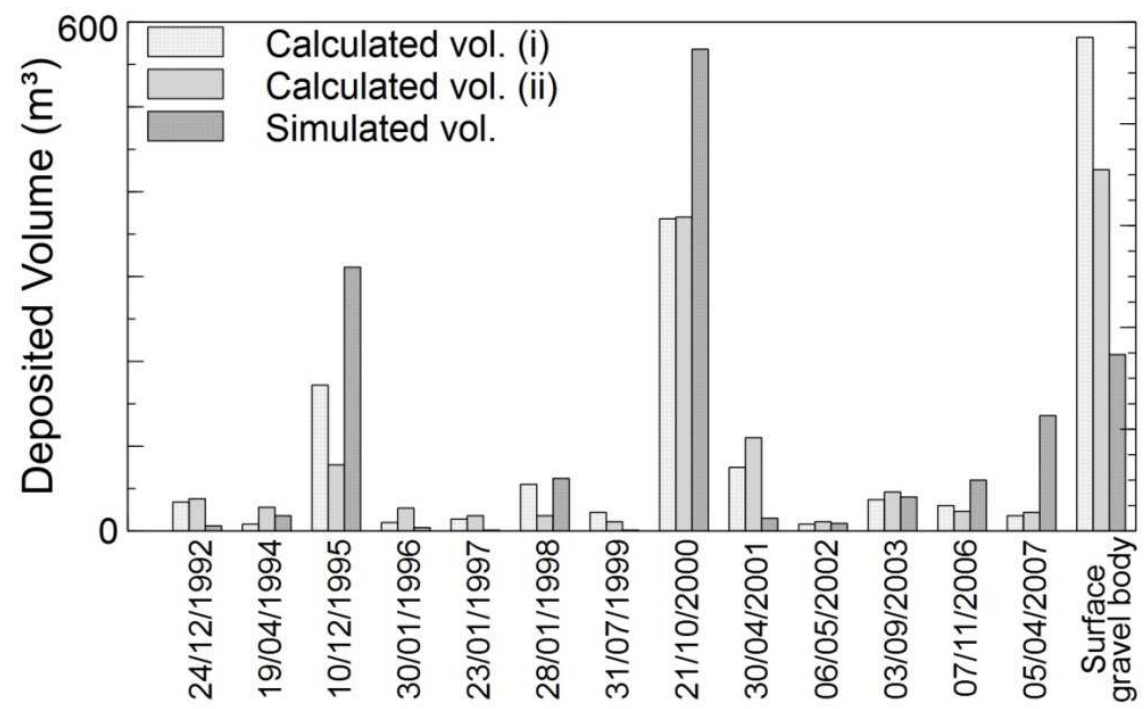

Flood event

Figure 5.47 - Sediment temporal validation (1/2): 13 events (out of 38 modelled flood events) were associated with the 15 detected flood units. The surface gravel body corresponds to the last three modelled events. The model was calibrated using the total sedimentation volume.

As the temporal validation (Figure 5.47) shows, the results are reasonably acceptable giving the high uncertainty of the process, showing a VE between $-80 \%$ and $80 \%$ for the most relevant events. Nevertheless, it is clear that the model tends to overestimate the observed values, especially for the high magnitude events. Since the model was calibrated using the total volume deposited in the reservoir, the overestimation is compensated by the underestimation of the remaining sedimentation volume, i.e. the gravel and sand massive deposit on BG-2, with an error of $-66 \%$. This error is probably due to an incorrect reproduction of the sediment reservoir dynamics when the sedimentation overcomes a threshold. When the reservoir filling overcomes a certain level, the conditions for fine alluvial deposition are not fulfilled anymore, and erosion and mixing processes take place. The STEP model does not take into account these phenomena, since it only considers sediment deposition.

In order to overcome this problem, the model was calibrated using the period 1992 - 2007; in this way, the simulated period does not cover the last years, when the STEP model is supposedly not reproducing correctly the reservoir dynamics. The results show a better agreement between the estimated and the simulated volumes, as shown in Figure 5.48. The resulting parameter set is $\alpha=268$ and $\beta=0.05$. 


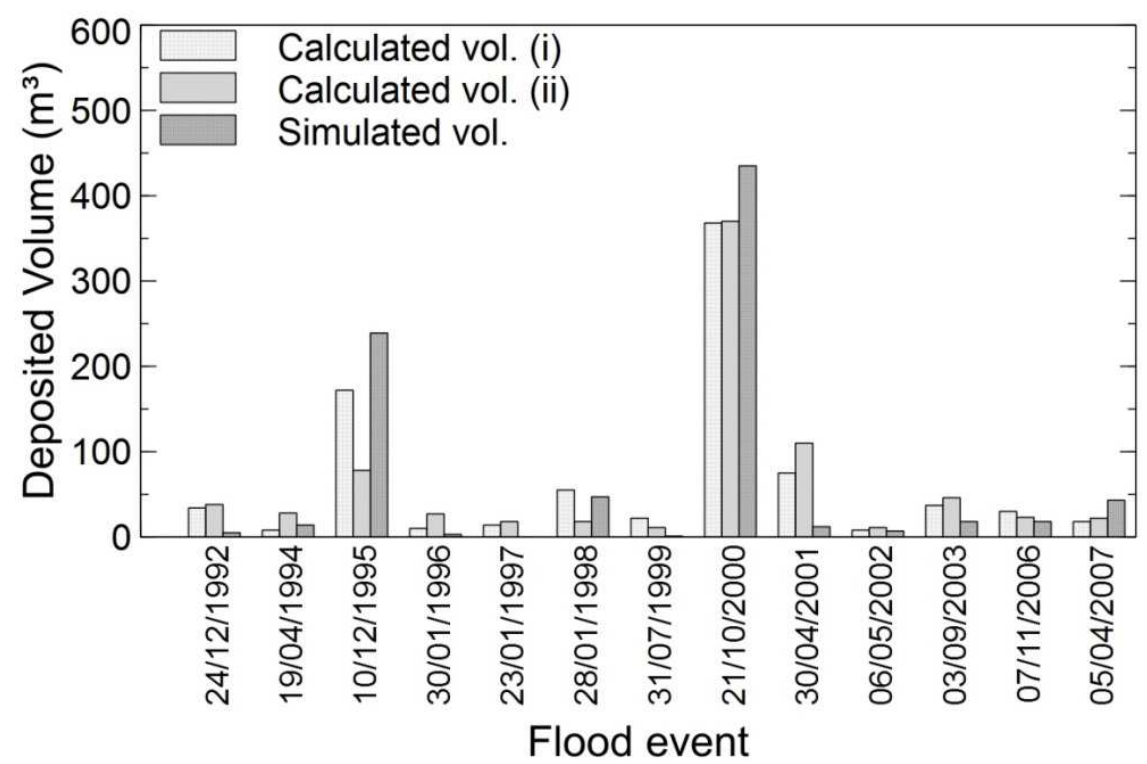

Figure 5.48 - Sediment temporal validation (2/2): 13 events (out of 38 modelled flood events) were associated to the 15 detected flood units. The surface gravel body was not considered. Notice that model was calibrated using the sum of sedimentation volumes from 1 to 15.

The model performance can be described as satisfactory, since the VE for the deepest flood unit is included between -50 and $50 \%$, which, considering the high uncertainty involved in the modelling process can be considered a positive result. This statement confirms that small check dams can be a very important source of information for modelling calibration and validation, and shows that palaeoflood techniques can help improving model performance and calculating SY both for long and short term.

Table 5.19 shows the results concerning each flood event.

The model provided an average sediment TE of 51\%, ranging from $29 \%$ to $100 \%$ depending on the peak discharge magnitude. The TE varies depending on the flood magnitude and the reservoir capacity, which changes in time, along with the reservoir filling. Giving the annual average simulated flow $\left(2.05 \mathrm{Hm}^{3}\right)$ and the reservoir storage capacity $\left(3,000 \mathrm{~m}^{3}\right)$, the Brune curves provide a TE value ranging between $44 \%$ and $68 \%$, with a median of $57 \%$, which is reasonably close to the value provided by the model. Nevertheless, the Brown equation, used in Bellin et al. [2011] and in Boix-Fayos et al. [2008], provides a lower value, equal to $33 \%$. The STEP model was able to reproduce the event-to-event trap efficiency variability, providing a time-variable value which could not be computed with simpler sediment trap efficiency equations such as the Brown or Brune approaches. 


\begin{tabular}{|c|c|c|c|c|c|}
\hline Event & $\begin{array}{c}\text { Deposit } \\
\left(\mathrm{m}^{3}\right)\end{array}$ & $\begin{array}{c}\% \text { of the total } \\
\text { volume }\end{array}$ & $\begin{array}{l}\text { Sediment } \\
\text { yield }\left(\mathrm{m}^{3}\right)\end{array}$ & $\begin{array}{c}\text { Specific SY } \\
\text { (Mg/ha) }\end{array}$ & TE \\
\hline 1 & - & - & 1 & 0.000 & - \\
\hline 2 & - & - & 20 & 0.015 & - \\
\hline 3 & - & - & 57 & 0.044 & - \\
\hline 4 & - & - & 47 & 0.036 & - \\
\hline 5 & 4.4 & $0 \%$ & 16 & 0.012 & $36 \%$ \\
\hline 6 & 12.9 & $1 \%$ & 52 & 0.040 & $32 \%$ \\
\hline 7 & 219.3 & $22 \%$ & 819 & 0.635 & $35 \%$ \\
\hline 8 & 2.5 & $0 \%$ & 10 & 0.008 & $33 \%$ \\
\hline 9 & 0.4 & $0 \%$ & 2 & 0.001 & $37 \%$ \\
\hline 10 & 43.4 & $4 \%$ & 165 & 0.128 & $34 \%$ \\
\hline 11 & 0.0 & $0 \%$ & 0 & 0.000 & $100 \%$ \\
\hline 12 & 0.9 & $0 \%$ & 3 & 0.003 & $34 \%$ \\
\hline 13 & 0.3 & $0 \%$ & 1 & 0.001 & $38 \%$ \\
\hline 14 & 400.1 & $40 \%$ & 1503 & 1.165 & $35 \%$ \\
\hline 15 & 1.2 & $0 \%$ & 4 & 0.003 & $43 \%$ \\
\hline 16 & 1.3 & $0 \%$ & 5 & 0.004 & $34 \%$ \\
\hline 17 & 10.9 & $1 \%$ & 40 & 0.031 & $36 \%$ \\
\hline 18 & 0.0 & $0 \%$ & 0 & 0.000 & $100 \%$ \\
\hline 19 & 6.0 & $1 \%$ & 23 & 0.018 & $34 \%$ \\
\hline 20 & 4.7 & $0 \%$ & 17 & 0.013 & $37 \%$ \\
\hline 21 & 2.7 & $0 \%$ & 9 & 0.007 & $37 \%$ \\
\hline 22 & 16.7 & $2 \%$ & 66 & 0.051 & $33 \%$ \\
\hline 23 & 0.4 & $0 \%$ & 1 & 0.001 & $41 \%$ \\
\hline 24 & 0.0 & $0 \%$ & 0 & 0.000 & $48 \%$ \\
\hline 25 & 0.1 & $0 \%$ & 0 & 0.000 & $45 \%$ \\
\hline 26 & 0.5 & $0 \%$ & 2 & 0.002 & $33 \%$ \\
\hline 27 & 0.1 & $0 \%$ & 0 & 0.000 & $26 \%$ \\
\hline 28 & 0.0 & $0 \%$ & 0 & 0.000 & $34 \%$ \\
\hline 29 & 0.0 & $0 \%$ & 0 & 0.000 & $100 \%$ \\
\hline 30 & 1.5 & $0 \%$ & 5 & 0.004 & $38 \%$ \\
\hline 31 & 1.7 & $0 \%$ & 6 & 0.004 & $39 \%$ \\
\hline 32 & 16.2 & $2 \%$ & 63 & 0.048 & $34 \%$ \\
\hline 33 & 39.4 & $4 \%$ & 160 & 0.124 & $32 \%$ \\
\hline 34 & 23.2 & $2 \%$ & 43 & 0.034 & $70 \%$ \\
\hline 35 & 2.6 & $0 \%$ & 4 & 0.003 & $76 \%$ \\
\hline 36 & 29.4 & $3 \%$ & 65 & 0.050 & $59 \%$ \\
\hline 37 & 0.3 & $0 \%$ & 1 & 0.000 & $73 \%$ \\
\hline 38 & 126.8 & $13 \%$ & 305 & 0.237 & $54 \%$ \\
\hline
\end{tabular}

Table 5.19 - Sedimentological sub-model results in terms of TE and SY for each event.

The resulting average specific SY (SSY) at the catchment is $0.136 \mathrm{t} \mathrm{ha}^{-1}$ year ${ }^{-1}$. Given an interannual average value of TE, equation (2.2) for calculating area-specific SY can be used ( $\mathrm{t}$ ha ${ }^{-1}$ $\left.\operatorname{year}^{-1}\right)$ :

Using the sediment TE value provided by the model and the density calculated above, the SSY provided by equation (2.2) is $0.137 \mathrm{t} \mathrm{ha}^{-1}$ year $^{-1}$, which is very similar to the value obtained by the model. Therefore, a simple lumped approach has obtained the same result 
in terms of specific sediment yield at the check dam 2. However, SSY computed in this simple way provides limited information, especially in a Mediterranean catchment, due to the high interannual and interevent variability of runoff and sediment yield. In fact, the model results suggest that annual sediment yield varies between $0.0032 \mathrm{t} \mathrm{ha}^{-1}$ for the year 2004 and $1.168 \mathrm{t} \mathrm{ha}^{-1}$ for the year 2000, as shown in Figure 5.49.

The above-estimated mean SSY can be considered a low erosion rate for Mediterranean catchments [Boix-Fayos et al., 2005; González-Hidalgo et al., 2007; Romero-Díaz et al., 2007; Bellin et al., 2011; Sougnez et al., 2011]. In particular, Boix-Fayos et al. [2005] found that 1 $\mathrm{t} \mathrm{ha}^{-1} \mathrm{y}^{-1}$ was one of the lowest erosion rates recorded in the SE of Spain at catchment scale. Nevertheless, these studies were carried out in more erosion-prone catchments. In fact, low erosion rates in shrubland catchments with limestone geology, like Rambla del Poyo, were also observed by other authors (e.g., Kosmas et al. [1997]). The main reasons for this significant difference with other Spanish areas are the land cover and the lithological origin of the soil. No degraded areas such as marl gullies or badlands are present in the Rambla del Poyo catchment, mainly because the dominant rock is the limestone with relevant outcrop areas, and the vegetation cover is rather homogeneous and denser than other Mediterranean catchment studied in the previously cited papers (mostly located in more arid areas such as the SE of Spain). As stated by Cerdà [1997], soils originated from limestone have high infiltration rates especially during the dry season, reducing the direct flow on the hillslopes and thus decreasing soil erosion. The homogeneous shrubland cover has also a positive effect on land degradation [Cerdà, 1998a], although it increases the risk of fire. This dynamic is typical of many Mediterranean catchments, which suffered strong land abandonment during the 1960s, inducing accelerated land degradation and the development of a shrub cover, as is the case of the Rambla del Poyo catchment. This behaviour was mentioned in various studies, such as Cerdà [1998], Rey Benayas et al. [2007] and Baeza et al. [2007].

The greatest flood event, in terms of peak flow and SY, was the October 2000 flood, which accounted for the $40 \%$ of the total deposited volume and the $43 \%$ of the total SY of the check dam sub-catchment. The SSY for this event was $1.16 \mathrm{t} \mathrm{ha}^{-1}$, a high SY value for shrubland catchments. The TE was $35 \%$. The most important four events accounted for the $80 \%$ of the total SY, while the most relevant eight for the $90 \%$. This phenomenon, which has been noticed in many ephemeral streams [Gallart et al., 2005], is due to the rainfall regime, which is characterized by long dry periods and heavy and short bursts, and to the highly non-linear relationship between water discharge and SY. 


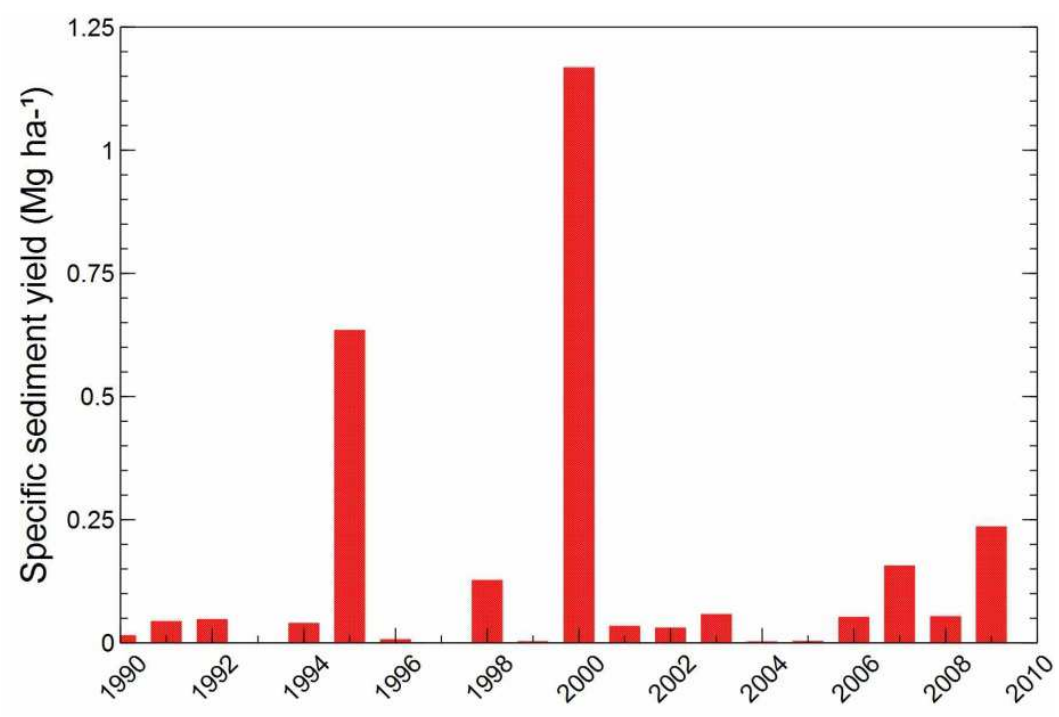

Figure 5.49 - Specific SY (model simulation).

The simulated texture of deposited sediments is sandy (between $87 \%$ and $100 \%$ of sand), agreeing with the field measurements, as shown in Figure 5.50. The mean texture of the "main check dam" catchment (20-60-20\% of sand-silt-clay) does not correspond with the reservoir deposit texture, much sandier, because only the coarser material is trapped into the "main check dam". Nevertheless, the simulated deposit texture of the deposit is very similar to the observed one. This observation suggests that the sediment trap efficiency submodel STEP is working properly.

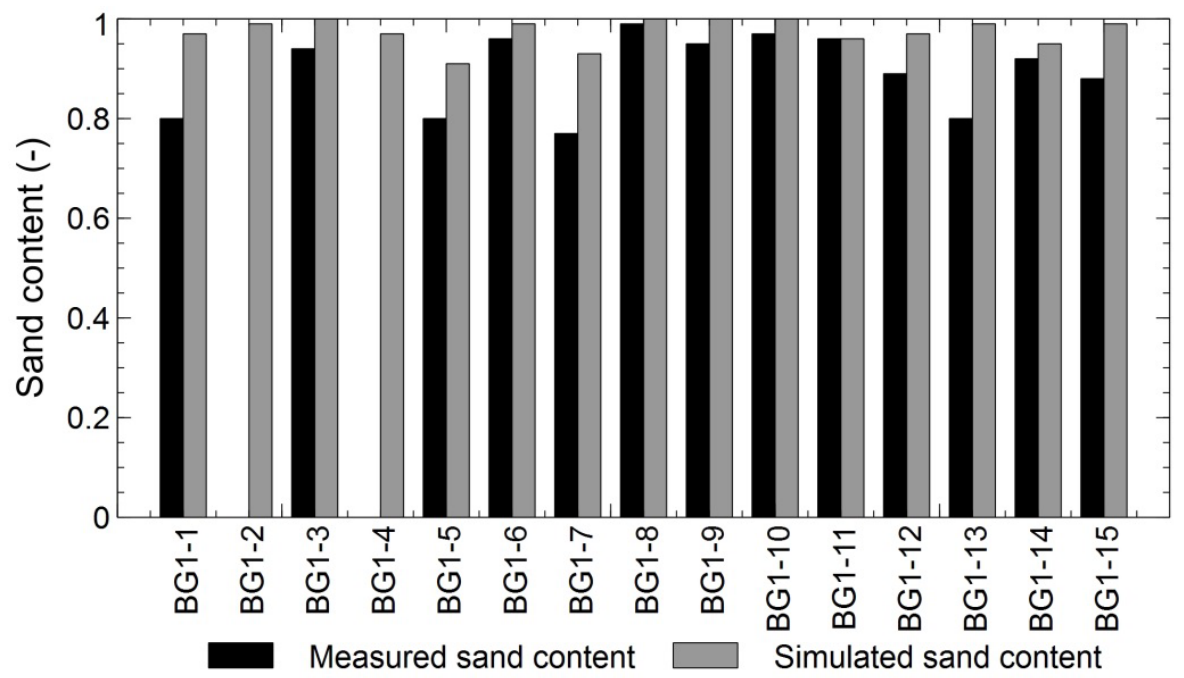

Figure 5.50-. Observed vs simulated sediment texture of all layers found inside the analysed deposit. 


\subsection{Conclusions}

Deposits stored in check dams record direct evidence of sediment produced at the upstream catchment, for both short- (event scale) and long-term (since dam construction). Mean annual SY can be calculated from the total volume of sediment retained behind the check dams, as done by Bellin et al. [2011] and Sougnez et al. [2011].

This chapter showed that a distributed sediment model can be implemented using check dam deposits for calibration and validation. The model calibration considered not only the total volume retained in the check dam but also volumes associated with individual flood layers. Detailed alluvial stratigraphy was analysed in two parallel trenches (12.5 m apart) across the dam infill. At least 15 flood layers associated to single flood or flood pulses were identify based on evidences of aerial exposure of sediment contacts (e.g. mudcracks, rootmarks). These palaeoflood sedimentary units were traced along the trenches and correlations between the layers found at the two trenches were established on the basis of key beds containing charcoal debris or dark mud. A detail differential GPS survey together with the thickness and geometry of individual flood layers provided a total estimated accumulation volume ranging between 1250 and $1435 \mathrm{~m}^{3}$, depending on the calculation approach, that were deposited over the time period $1990-2009$.

A SY model (TETIS) was calibrated using the total sediment volume accumulated in the check dam infill. The variability in time of the reservoir TE was taken into account by coupling the TETIS and the STEP models. The simulated results show good agreement with the estimated sediment volumes retained behind the check dam, both at short- and longterm.

The model provides a specific SY of $0.136 \mathrm{t} \mathrm{h}^{-1}$ a year ${ }^{-1}$ for a $12.9 \mathrm{~km}^{2}$ sub-catchment of Rambla del Poyo, which is lower than other SY rates recorded or estimated in the east of Spain, probably due to extensive limestone bedrock outcrops, thin soils and vegetation cover (shrublands with a little portion of pine forest). The model confirms the ephemeral behaviour of the stream, and the Mediterranean character of the SY mainly associated to flow pulses during a limited number of storm events. Almost $90 \%$ of total deposited volume behind the check dam is due to only 8 events in 20 years, and the $80 \%$ of total volume to 4 flood events. The greatest flood event (October 2000) account for the $40 \%$ of the total deposited volume and the $43 \%$ of the total SY, following model results.

The TE, calculated by the Sediment Trap Efficiency for Small Ponds model [Verstraeten and Poesen, 2001a], varies depending on the magnitude of the flood event, from around $30 \%$ for the first rainfalls of the simulated series to $55-60 \%$ for the most recent flood events. The estimated long-term TE is $51 \%$, which is reasonably close to the value estimated by using the Brune curves, i.e. $57 \%$.

The main contributions of this chapter are:

- The TETIS model was applied to a sediment ungauged basin, and the sedimentological sub-model was calibrated with proxy data, obtaining positive and satisfactory results. 
- $\quad$ An application of the TETIS model coupled with the STEP model for small reservoir TE computation was presented, and showed good results.

- The usefulness of reservoir bottom deposits for calibration and validation of the sedimentological sub-model was proven.

- An application of the TETIS model coupled with palaeohydrological techniques was presented, and its results exploited for the temporal validation. 



\section{Rambla del Poyo: transfer of information}




\subsection{Introduction and goals}

In the previous chapter, the usefulness of small reservoir bottom deposits for calibration and validation of a sediment model was proven and checked. The preceding chapter demonstrated that, in case of no sediment data availability, sediment deposits accumulated behind a check dam can replace in some way the direct measurements of sediment transport.

Nowadays, many Mediterranean rivers are not instrumented even for water discharge measurement, i.e. many Mediterranean catchments are ungauged both for sediment and water fluxes. In these cases, the use of conceptual or physically based models is strongly limited, or even impossible, given that model predictions cannot be significant without comparing them with observed data. The hydrological prediction in this kind of catchments has been a principal concern for the scientific community during the last years [Sivapalan et al., 2003]. The International Association for Hydrological Sciences (IAHS) started in 2003 a research decade on Prediction in Ungauged Basins (PUB). The aim was to make a coordinate effort for deepening the knowledge and overcoming common limitations on prediction in ungauged catchments [Sivapalan et al., 2003].

One of the possibilities to be exploited for overcoming lack of water discharge data for hydrological modelling is the use of indirect information. This information can be used to constrain the feasibility range of model calibration parameter or to enclose model output [Seibert and McDonnell, 2002; Winsemius et al., 2009]. This kind of information is called "proxy data" [Blöschl, 2001] if it is someway quantifiable, or "soft information" [Seibert and McDonnell, 2002] if it regards knowledge about hydrological processes which cannot be quantified.

In this chapter, proxy data are used for calibration and validation of a daily scale TETIS model in the Rambla del Poyo catchment, while the measured water discharge series is only employed for verifying the model behaviour. The proxy data to be used is represented by the stratigraphical analysis and volume quantification carried out at the previous chapter within the check dam 2 reservoir deposit. The model is simplified by making some assumption about the hydrological behaviour of the catchment, corroborated by field observation. Then the model is calibrated to reproduce the total volume of sediment accumulated behind the check dam 2 and validated against the results of the stratigraphical analysis. Finally, the model functioning is verified by comparing water discharge predictions at the Rambla del Poyo catchment outlet with gauged data.

The aim of this chapter is to take advantage of the proxy data in order to calibrate and validate hydrological and sediment model in ungauged catchment. The new methodology to be developed is easily transferable to similar catchments, and must take into account the soft information, or knowledge, about catchment hydrology. Sediment proxy data and soft information help constraining model calibration, analogously to what stated by Medici et al. [2012], who demonstrated the utility of water quality data for restricting the calibration of an hydrological model. 


\subsection{Results}

In this chapter, the TETIS hydrological and sedimentological sub-models is calibrated and validated using sediment volumes estimated by means of a stratigraphical analysis of a check dam sediment deposit detailed in the previous chapter. In order to complete this task, the model must be simplified. The number of parameters needs to be reduced, due to the fact that calibrating on an accumulate volume can lead to several equifinal parameter sets. The model simplification is required for avoiding or limiting the equifinality problem.

The hydrological behaviour of the catchment was analysed starting from literature and field observations, without taking into account the information provided by the water discharge series, which is only used form model checking. It was noticed that no base flow takes places: channel flow is only visible during the next days following a severe rainfall event. Channels usually show as in Figure 6.1, often covered with vegetation (mainly bushes and shrubs) due to the flow intermittency. Many months, in some cases even years, can pass without having flow along the stream network.
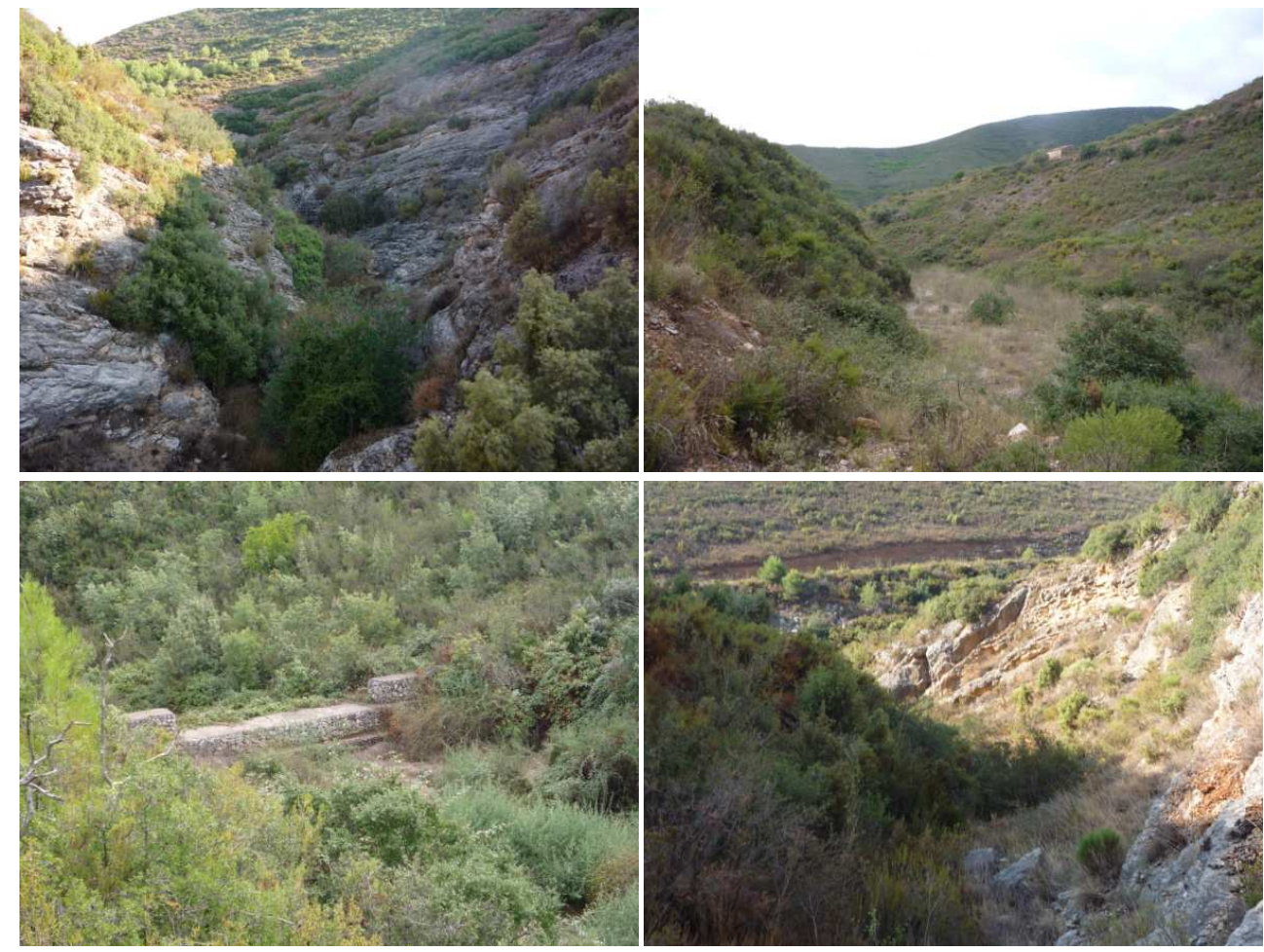

Figure 6.1 - The Rambla del Poyo catchment.

Another consideration backing this statement is that the Rambla del Poyo catchment is dominated by shallow soils over a limestone bedrock, especially the headwaters [Camarasa and Segura Beltrán, 2001]. The limestone is a low permeability rock which makes difficult the occurrence of a low velocity hydrological response as the base flow is. The Rambla del 
Poyo limestone is also highly fractured [Camarasa and Segura Beltrán, 2001]. This phenomenon facilitates percolation towards karstic aquifers, which are not connected with the stream network.

For this reason, the correction factor 8 (base flow velocity) was set at 0 , while the percolation capacity and the loss coefficient (correction factor 5 and 7 respectively) is set at the same high value, in order to classify as losses the portion of rainfall which percolates.

The field work also suggested that the importance of interflow in the Rambla del Poyo catchment hydrological response is limited. This is because the hydrological response to an extreme rainfall is very fast and short. The hydrograph duration never overcomes 2 or 3 days. It is logical to consider that the interflow is almost negligible, and the infiltration is also reduced. These considerations, along with the knowledge of zone climate, characterised by short and high intensity rainfalls concentrated in the fall season, induce to state that the dominant infiltration mechanism is hortonian [Horton, 1941], i.e. the runoff is generated when the high precipitation intensity overcomes soil infiltration capacity.

These considerations can be traduced into a model simplification by using a low infiltration capacity (low correction factor 3). Moreover, as was found by Nadal-Romero et al. [2008], the hortonian mechanism predominance allows to better correlate sediment transport and precipitation, eventually facilitating model calibration.

In conclusion, the model calibration is carried out by adjusting the following correction factors:

- $\quad$ CF1 - maximum static storage;

- $\quad$ CF3 - infiltration capacity;

- $\quad$ CF6 - interflow velocity;

- $\quad$ CF9 - channel flow velocity;

- $\quad \alpha$-maximum transport capacity coefficient for hillslopes.

Additionally, the calibration of other correction factors was discarded because they were considered as not influent, and their values were set at 1 :

- $\quad$ CF2 - evapotranspiration. This correction factor has a low variability, between 0.8 and 1.2 .

- $\quad$ CF4 - flow velocity on hillslopes. This correction factor is not very influent for daily scale models, especially when the threshold area defining hillslopes is set to one cell, as this case.

- $\quad$ B1 and b2 - maximum transport capacity coefficient for channels and gullies. These correction factors affect the Engelund-Hansen equation which is a physically based equation, and are usually not very different than 1.

Moreover, the correction factor 8 (base flow) was set to 0 , and the correction factors 5 and 7 (percolation and losses) were set to high values, as stated above.

Available precipitation data are the same of the previous chapter, and span from 1990 up to 2013. A daily scale model was implemented, due to the historical series length and the high 
computational times which a low time step simulation requires. A variable time step model as the previous chapter could not be implemented because it is not possible to know when a flood event occurred a priori without knowing discharge data.

The model was calibrated adjusting the five correction factors mentioned above in order to equal the total deposited volume simulated by the TETIS model coupled with the STEP model and the observed deposited volume. The observed volume is 1435 or $1248 \mathrm{~m}^{3}$, depending on the estimation methodology. The model calibration is therefore carried out to $1341 \mathrm{~m}^{3}$, which is the average between the two values.

The resulting correction factors are shown in Table 6.1.

\begin{tabular}{cc}
\hline CF & value \\
\hline CF1 & 1.5 \\
CF3 & 1.3 \\
CF6 & 100 \\
CF9 & 0.5 \\
$\alpha$ & 0.01 \\
\hline
\end{tabular}

Table 6.1 - Correction factors resulting from the Rambla del Poyo model calibration - calibration with the total accumulated volume.

The model results confirm the direct runoff (or superficial runoff) predominancy and the total absence of base flow, fulfilling the hypothesis made above.

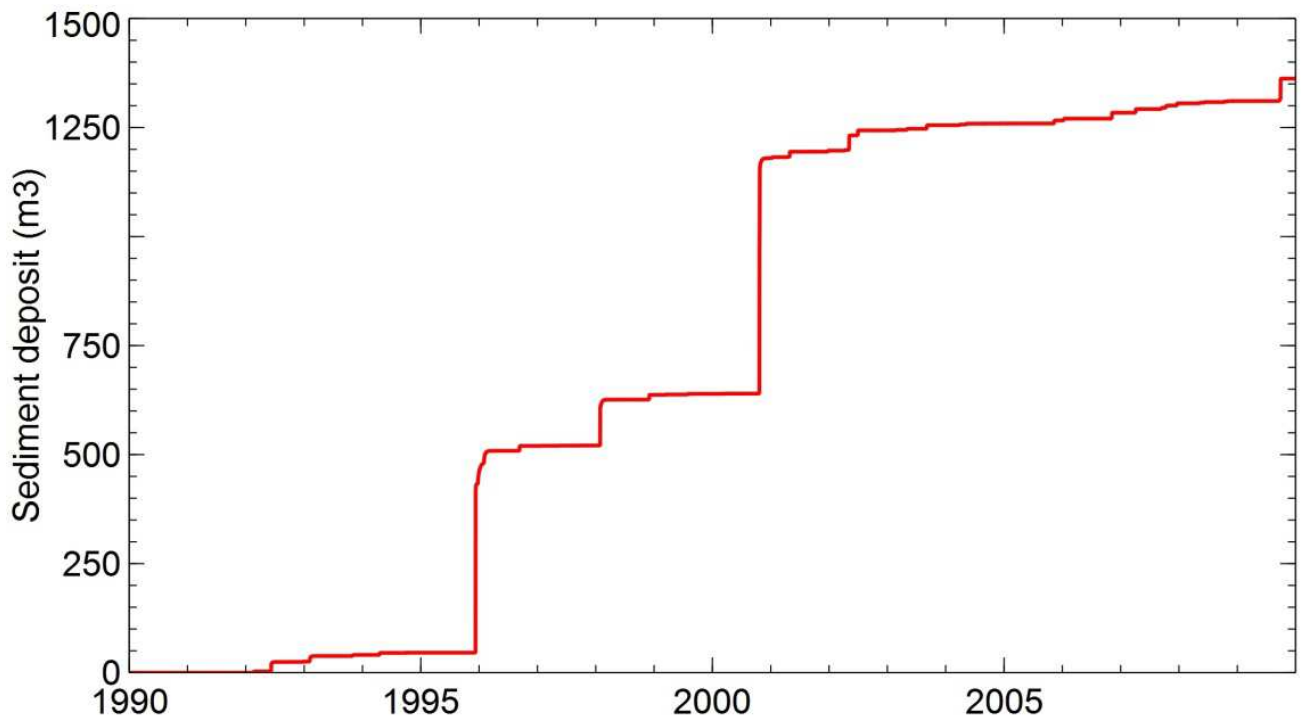

Figure 6.2 - Simulated temporal evolution of the check dam 2 deposit volume.

The model was validated comparing the observed and simulated temporal evolution of the deposit accumulation (Figure 6.2). For a better understanding of this phase, the flood events resulting from model simulation are named with letters, and the layers identified during the 
stratigraphical analysis are named with the same numbers used in the previous case study (Rambla del Poyo: proxy data).

In order to carry out this task, it is necessary to assign each flood event a date. This means to associate every deposited sediment layer observed in the stratigraphical analysis with a flood event, identified by the model results. The model provided the flood events shown in Table 6.3, which are compared to the stratigraphical description from Table 6.2.

Due to charcoal traces found in layers form 3 to 10 , the event $E(11-12 / 12 / 1995)$ corresponds to layer 3, and, consequently, events F, G and H (11/09/1996, 29-30/01/1998 and 03/12/1998) correspond to layers 4, 5 and 6. The event I (22-23-24-25/10/2000), the greatest of all simulated events, is composed by more than one peak, and corresponds to layers 9 and 10, which are the deepest ones and the last which contain charcoal. Layers 7 and 8 are probably due to minor events which were not properly simulated by the model, and for this reason they are assigned to a date comprised between 1998 and 2000.

\begin{tabular}{ccc}
\hline LAYER & $\begin{array}{c}\text { Estimated } \\
\text { volume - } \mathbf{1} \\
\left(\mathbf{m}^{\mathbf{3}}\right)\end{array}$ & $\begin{array}{c}\text { Estimated } \\
\text { volume - } \\
\mathbf{2}\left(\mathbf{m}^{\mathbf{3}}\right)\end{array}$ \\
\hline 1 & 34 & 38 \\
2 & 8 & 28 \\
3 & 172 & 78 \\
4 & 10 & 27 \\
5 & 14 & 18 \\
6 & 55 & 18 \\
7 & 22 & 11 \\
8 & 20 & 41 \\
9 & 195 & 96 \\
10 & 153 & 233 \\
11 & 75 & 110 \\
12 & 8 & 11 \\
13 & 37 & 46 \\
14 & 30 & 23 \\
15 & 18 & 22 \\
surface & 528 & 448 \\
\hline
\end{tabular}

Table 6.2 - Stratigraphical profile results.

The following five layers $(11,12,13,14$ and 15 were assigned to the events $J, K, L, M$ and $P$, which are the most important events following the 2000 flood, and all the following events to the surface layer.

Given this reconstruction, a visual validation can be carried out by comparing observed and simulated temporal evolution of the total deposit volume, as shown in Figure 6.3.

Looking at Figure 6.3, it is clear that there is some error in the model results. Although the global trend and the shape of the curve are correct, the model cannot reproduce the "jump" corresponding to the surface layer. For this reason, calibrating with the total volume brings to a general overestimation of all deposit volumes. 


\begin{tabular}{|c|c|c|}
\hline Event & Date & $\begin{array}{c}\text { Deposit } \\
\left(\mathrm{m}^{3}\right)\end{array}$ \\
\hline$A$ & 09/06/1992 & 13 \\
\hline B & 24/12/1992 & 1 \\
\hline C & 04/11/1993 & 2 \\
\hline $\mathrm{D}$ & 19/04/1994 & 6 \\
\hline \multirow{2}{*}{$E$} & $11 / 12 / 1995$ & 250 \\
\hline & $12 / 12 / 1995$ & 7 \\
\hline $\mathrm{F}$ & $11 / 09 / 1996$ & 3 \\
\hline \multirow{2}{*}{ G } & 29/01/1998 & 62 \\
\hline & $30 / 01 / 1998$ & 1 \\
\hline $\mathrm{H}$ & 03/12/1998 & 2 \\
\hline \multirow{4}{*}{ I } & $22 / 10 / 2000$ & 472 \\
\hline & $23 / 10 / 2000$ & 37 \\
\hline & $24 / 10 / 2000$ & 115 \\
\hline & $25 / 10 / 2000$ & 3 \\
\hline $\mathrm{J}$ & $01 / 05 / 2001$ & 4 \\
\hline \multirow{2}{*}{ K } & $07 / 05 / 2002$ & 5 \\
\hline & $08 / 05 / 2002$ & 9 \\
\hline $\mathrm{L}$ & $01 / 07 / 2002$ & 4 \\
\hline $\mathrm{M}$ & 06/09/2003 & 3 \\
\hline $\mathrm{N}$ & $11 / 11 / 2005$ & 2 \\
\hline 0 & $10 / 01 / 2006$ & 1 \\
\hline \multirow{2}{*}{$\mathrm{P}$} & $07 / 11 / 2006$ & 3 \\
\hline & $08 / 11 / 2006$ & 2 \\
\hline Q & $06 / 04 / 2007$ & 2 \\
\hline $\mathrm{R}$ & $21 / 12 / 2007$ & 1 \\
\hline$S$ & 23/09/2009 & 1 \\
\hline$T$ & 29/09/2009 & 26 \\
\hline
\end{tabular}

Table 6.3 - Daily sediment volume (for days with more than $1 \mathrm{~m}^{3}$, following model results).

In order to undertake this inconvenient, the surface layer is excluded from the model calibration and validation. The model is calibrated reproducing the accumulated volume between the beginning of the simulation and 2007, which is the date of the last flood event before the formation of the superficial layer. The observed deposit is 800 or $852 \mathrm{~m}^{3}$, depending on the methodology. The mean objective value is $826 \mathrm{~m}^{3}$.

Results are shown in Figure 6.4. 


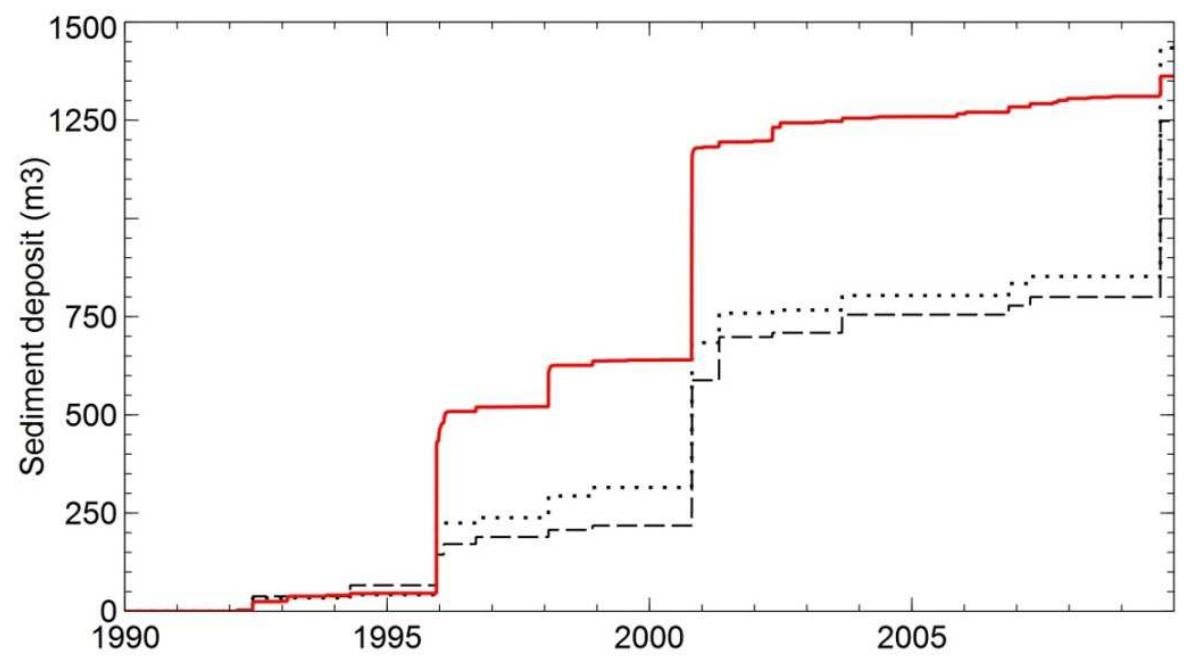

Figure 6.3-Observed and simulated temporal evolution of the check dam 2 bottom deposit -calibration with the total accumulated volume.

The resulting correction factors are shown in Table 6.4.

\begin{tabular}{cc}
\hline CF & value \\
\hline CF1 & 1.5 \\
CF3 & 1.5 \\
CF6 & 100 \\
CF9 & 0.6 \\
$\alpha$ & 0.01 \\
\hline
\end{tabular}

Table 6.4 - Correction factors resulting from the Rambla del Poyo model calibration - calibration with the accumulated volume up to 2007.

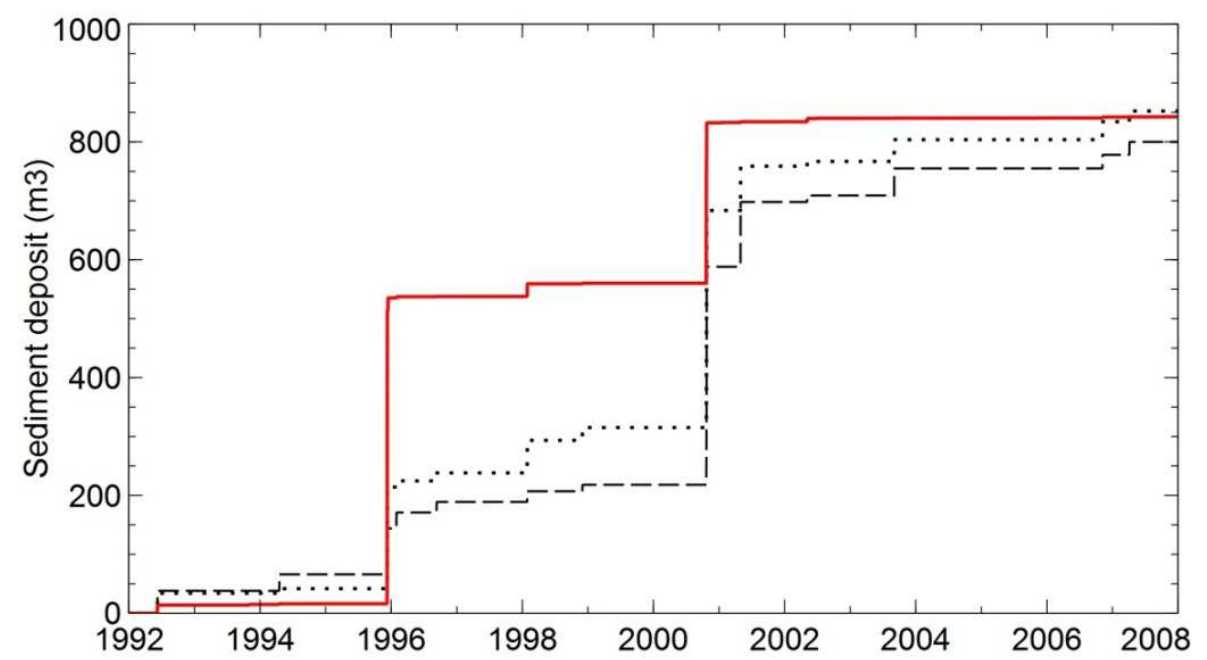

Figure 6.4-Observed and simulated temporal evolution of the check dam 2 bottom deposit - calibration with the accumulated volume up to 2007. 
As it can be seen, the results improved compared to the previous calibration. The model behaviour is consistent up to 2007. However, after 2007 some unidentified phenomena take place. Some hypothesis can be done about this issue:

- $\quad$ The surface layer is perhaps composed by material provided by local contributions from landslides or rock detachment, which are not taken into account by the TETIS model.

- The sedimentation sub-model, STEP, is not adequate when reaching a given level of reservoir filling, due to velocity and turbulence conditions modification.

In order to check the model behaviour, the model was run for the whole catchment up to the outlet station, covering the period 1995-2010. Simulated and observed discharges are compared in Figure 6.5 and in Figure 6.6 (accumulated water volume of the daily events of more than $0.2 \mathrm{Hm}^{3}$ ).

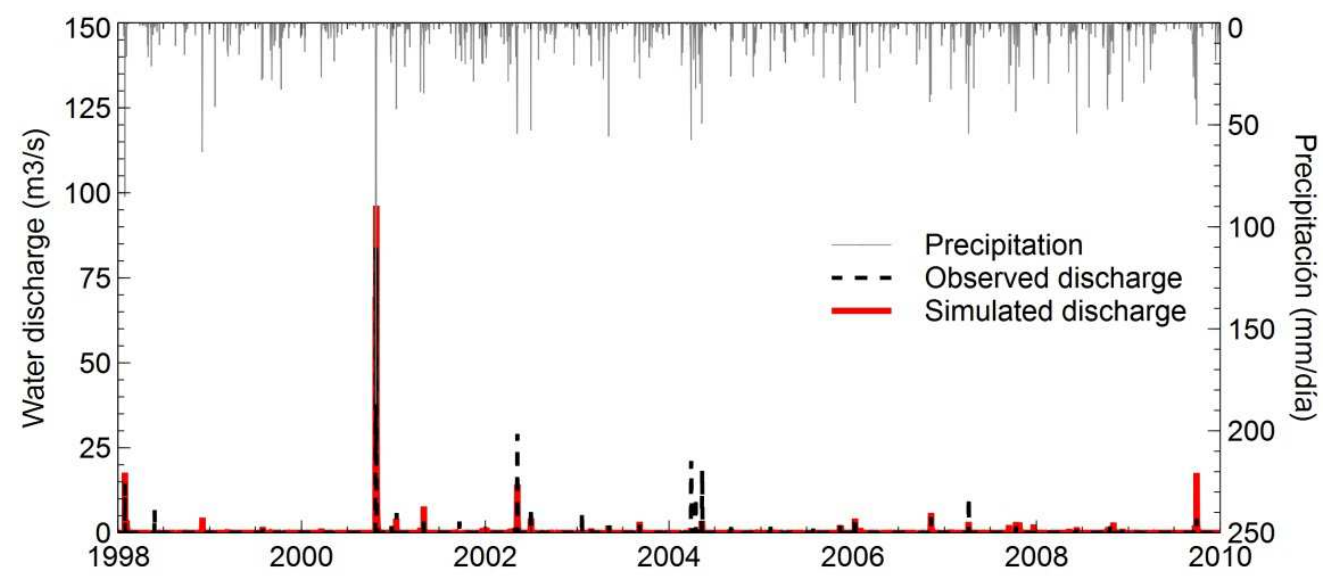

Figure 6.5-Observed and simulated water discharge at the catchment outlet.

The results are very satisfactory, and the model can reproduce with an excellent performance the observed discharge. The NSE is 0.80 for the whole series and 0.77 for days with a discharge greater than $2 \mathrm{~m}^{3} / \mathrm{s}$.

The model provide a ration between direct runoff and interflow equal to 5:3, although during flood days, responsible of the majority of the sediment transport, the direct runoff is almost $100 \%$ of total flow. 


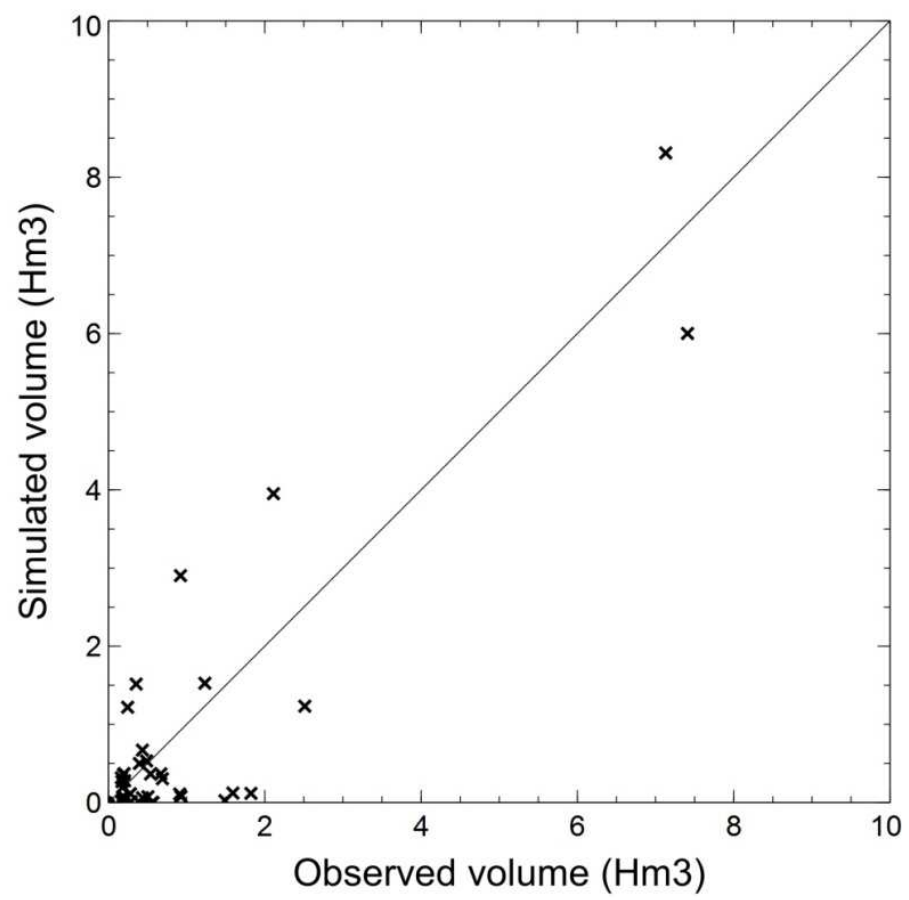

Figure 6.6-Observed and simulated water volume of the most significatn flood events at the Rambla del Poyo gauging station.

Even though the results of this exercise are positive, the methodology can be criticised for its subjectivity, given that the correction factors were chosen by the modeller. Many equifinal calibration sets can certainly be selected in order to obtain similar calibration results, but their performance at the stream gauge may not be as positive as for the previously shown calibration set.

For this reason, a Monte Carlo analysis was conducted on the check dam catchment model. 50,000 simulations of the catchment drained by the check dam were carried out, varying four correction factors (CF1, CF3, CF9 and a) within a feasible range, shown in Table 6.5.

\begin{tabular}{ccc}
\hline CF & Min & Max \\
\hline CF1 & 1.0 & 2.0 \\
CF3 & 0.8 & 1.8 \\
CF9 & 0.3 & 1.0 \\
$\alpha$ & 0.001 & 0.1 \\
\hline
\end{tabular}

Table 6.5 - Correction factors range.

The 100 best calibration sets in terms of check dam reservoir filling reproduction were selected and used for running 100 simulations of the stream gauge station catchment. Their performance was analysed: the simulated discharge of each one of those simulations was 
compared with the observed one for the 21 highest discharge days. The results are shown in Figure 6.7.

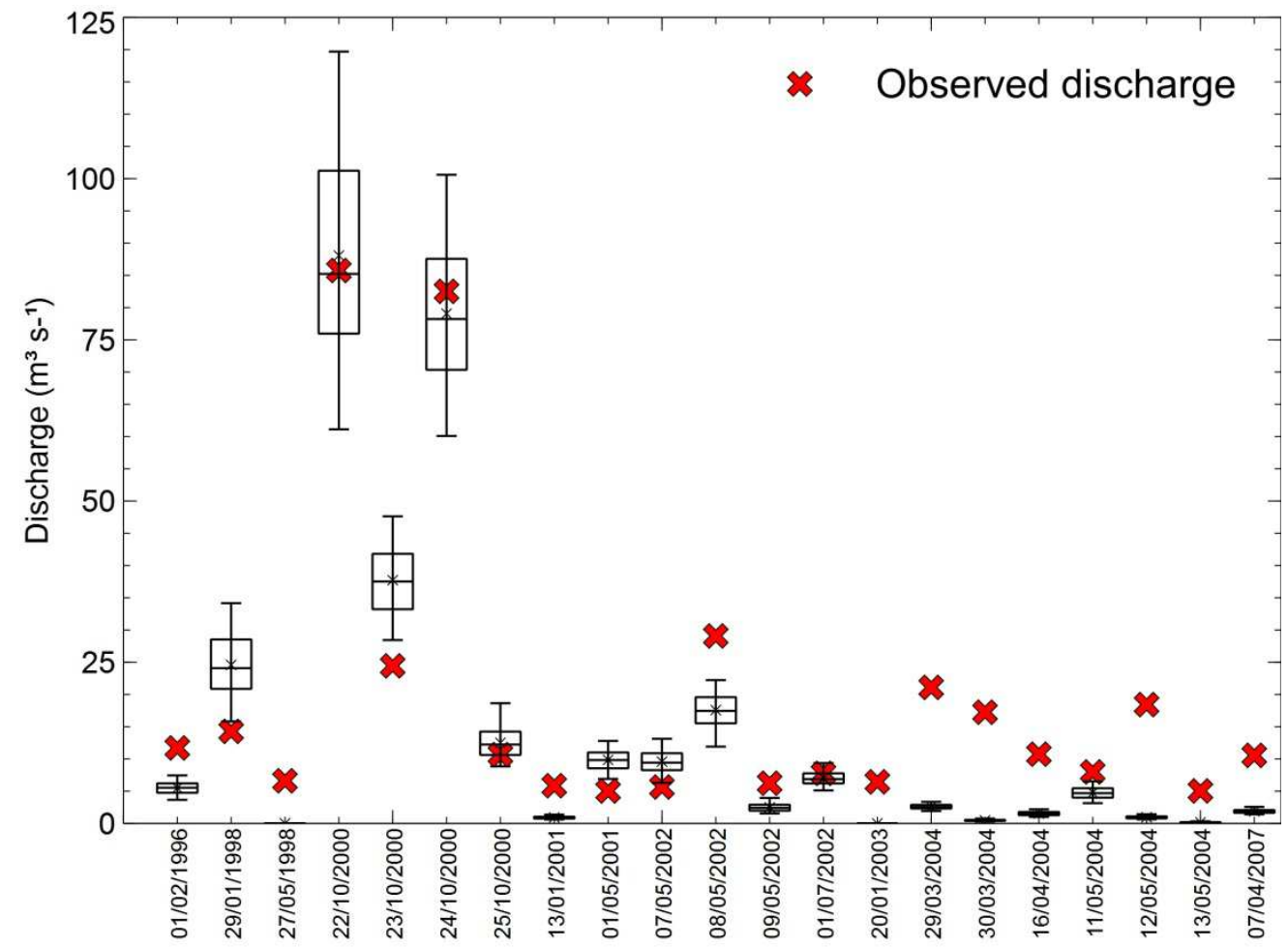

Figure 6.7-Results of the 100 best calibration sets.

As can be seen, the median value obtained by the 100 best calibration sets is reasonably close to the observed value, although a trend to the underestimation of the smallest event can be noticed. The range of variation can also be considered reasonably close to the observed value for all the 21 events. In general, the results can be considered satisfactory, proving that all the 100 equifinal calibration sets can reproduce the hydrological regime of the Rambla del Poyo catchment within a reasonable range of variation.

\subsection{Conclusions}

In this chapter, a further application of the TETIS model has been presented. The model was applied to an ungauged catchment, the Rambla del Poyo catchment (no water and sediment discharge records). The TETIS model was calibrated using the accumulated volume trapped behind a small check dam. Palaeohydrological techniques were used in order to carry out a stratigraphical analysis of all layers identified within the reservoir deposit. The model was also simplified based on field observation, the modeller's expertise and the literature, in order to reduce the number of parameters to be calibrated and the problem complexity. 
The scientific interest of this chapter is the presentation and the application of a new methodology form model calibration and validation in a Mediterranean semi-arid ungauged catchment. This methodology takes advantage of the interactions between the water cycle and the sediment cycle. The aim is to transfer information from a sub-model to the other and constrain the model calibration.

The results show a very good model performance, given that the NSE on the observed discharge at the basin outlet is 0.8 .

The main contributions of this chapter are the following:

- It has been demonstrated that it is possible to take advantage of the information transfer between erosion and transport processes and rainfall-runoff processes in order to constrain the hydrological sub-model calibration, and, consequently, to reduce the model uncertainty.

- A new and innovative methodology has been implemented for ungauged catchment model calibration, which uses different techniques coming from several field of the Earth science, such as palaeohydrology, hydrological modelling, reservoir sedimentation, erosion modelling, et.

- The proposed methodology is potentially applicable to every small to median size Mediterranean catchment, because it only needs precipitation and temperature data, usually available in this kind of catchment, and soil and vegetation spatial coverage, which can be obtained or measured easily. The only special requirement is the presence of partially filled check dams, which can be found in almost all Mediterranean catchment headwaters, given the high grade of erodibility of these zones.

This chapter represents a first step towards a complete sensitivity analysis and uncertainty assessment, although a more detailed analysis must be carried out. 


\section{7. Ésera River: proxy and gauged data}




\subsection{Introduction and goals}

One of the most important concerns in calibration and validation of a sediment cycle model is the data availability [Cerdà et al., 2013]. Continuous sediment yield measurements are very scarce, and almost exclusively available for small catchments or experimental plots. In order to apply a model in a generic catchment and to properly and scientifically validate it, new sediment data set are required, and, given the scarcity of monitored catchments, new sediment data sources are needed. An alternative is to develop new modelling techniques in order to exploit proxy and soft data [Blöschl, 2001; Seibert and McDonnell, 2002] for gaining information with the intention of constraining model calibration.

Many authors have already explored this technique, especially focusing on the sediment volume accumulated in lakes and reservoirs as an indirect validation method for modelling sediment yield at the regional scale [Van Rompaey et al., 2003; Grauso et al., 2008; Alatorre et al., 2010]. As streams enter reservoirs, their flow velocity reduces, decreasing the stream sediment transport capacity and causing sedimentation [Julien, 1995, 2010]. Due to this phenomenon, part of the sediments transported by the stream may be retained behind the dam, forming a deposit. It is estimated that the annual loss in storage capacity of the world's reservoirs due to sediment deposition is around $0.5-1 \%$ [Verstraeten et al., 2003]. For many reservoirs, however, annual storage reduction rates are much higher and can reach $4 \%$ or $5 \%$, such that they lose the majority of their capacity after only $25-30$ years [Verstraeten et al., 2003].

In the past 15 years, lake and reservoir sediment deposits were also used for distributed model validation, as showed in Srinivasan et al. [1998], de Vente et al. [2005], de Vente et al. [2008], Alatorre et al. [2010] and Haregeweyn et al. [2013]. Srinivasan et al. [1998] calibrated the SWAT sedimentological sub-model at the monthly scale with the sedimentation surveys of the Richland-Chambers Lake. In de Vente et al. [2005], the FSM model [Verstraeten et al., 2003] and the PSIAC model [Pacific South West Inter-Agency Committee, 1968], both semi-quantitative models for mean annual sediment yield estimation, are compared, and their results contrasted versus reservoir sedimentation rates. In de Vente et al. [2008], the reservoir sedimentation rates were used to compare the results of three distributed approaches for soil erosion rates and long-term sediment yield rates estimation: the WATEM/SEDEM model [Van Rompaey et al., 2001], the PESERA model [Kirkby et al., 2008] and the SPADS model [de Vente et al., 2008]. In Alatorre et al [2010], the WATEM/SEDEM model is calibrated using the depositional story of the Barasona reservoir (Spain) and then used for Ésera river sediment yield modelling, providing mean annual erosion and sediment yield. All these studies calculated interannual soil erosion rates, or sediment yields, averaged over several years. With the above-mentioned models it is not possible to determine the temporal dynamics of the soil erosion and sediment transport at a smaller temporal scale, such as, for example the daily scale. Some attempt to calibrate and validate daily models with reservoir sedimentation volumes was also carried out in the last years. For example, Raclot and Albergel [2006] applied the WEPP model to a catchment in Tunisia, and calibrated it by using siltation volumes of a small reservoir. Nevertheless, their results were disappointing concerning reproduction of the sediment transport. 
In this chapter, another application of the TETIS model is shown. In this case, the model is applied to the Barasona reservoir (also known as "Joaquín Costa" reservoir) catchment. Its main watercourse is the Ésera River, and it is located in the north of the Aragón region, in Southern Central Pyrenees.

This watershed shows relevant signs of erosion. Many sediment production zones were identified in past studies, especially located in the central part of the catchment, where a marl strip caused the formation of numerous badlands. The Barasona reservoir also shows a high siltation rate due to the high sediment transport of the Ésera River and its tributaries. For these reasons, the catchment has been studied by many research groups, from different point of view. For instance, the "Instituto Pirenáico de Ecología" (Pyrenees Institute of Ecology of the National Research Council) and the Zaragoza University (Spain) implemented a sediment cycle model [Alatorre, 2010]. In the same research centre, many reservoir lake sedimentation and coring studies were carried out during the last years [Valero-Garcés et al., 1999]. The University of Potsdam (Germany) also studied the catchment [Mamede, 2008; Müller et al., 2010] within the framework of the SESAM Project. They developed a new sedimentation model called WASA-SED. The Fluvial Dynamics Research Group of the Lleida University also worked on the Ésera catchment, monitoring the suspended sediment transport of the Ésera main tributary, the Isábena River [López-Tarazón, 2011].

The catchment is monitored by the SAIH of the River Ebro Basin Authority (rainfall, discharge and reservoir hydrological variables at 15 minutes time step) and by AEMET (rainfall and temperature at the daily scale). As mentioned before, the University of Lleida continuously monitored the suspended sediment transport of the Isábena River during the last 7 years with a 15 minutes time step. The Barasona reservoir also disposes of many bathymetries, which are useful for quantifying the sediment transport to the catchment outlet.

The scientific interest of this case study is that the soil erosion and degradation problems and the consequent formation of badlands are very relevant and evident, and must be studied in detail. Its consequences are affecting the human activities downstream: as an example, the very high silting rates of the Barasona reservoir, which could cause a complete loss of storage capacity in a few decades if the reservoir is not dredged. The origin of this high erodibilidy is due to the soil composition and geology. The Ésera soils mainly generated from highly erodible marls.

Moreover, this study was developed in the framework of the SCARCE - Consolider project named "Assessing and predicting effects on water quantity and quality in Iberian rivers caused by global change". The aim of this study within the SCARCE project is to develop a reliable water and sediment cycle model in order to analyse the effects of climate change on hydrological and sedimentological variables. In this chapter, the implementation and analysis of the TETIS model is presented. The climate change application is left for future studies.

In this chapter, an application of the TETIS model to the Ésera River catchment is presented. 
In order to improve the knowledge concerning hydrological and sediment modelling using proxy data, in this study the TETIS distributed hydrological and sediment model [Vélez et al., 2005; Francés et al., 2007] is applied to a highly erodible catchment drained by a large reservoir with relevant siltation problems and with availability of suspended sediment records. The aims of this study are to apply the TETIS model at the daily scale at a sediment ungauged catchment (the model application is carried out as if no measured sediment transport series were available) and to calibrate and validate the model using the sedimentation volumes of the Barasona reservoir, a $92.2 \mathrm{Hm}^{3}$ reservoir located in the north of the Aragón region, in Southern Central Pyrenees (Spain). The Barasona catchment (or Ésera River catchment) is a highly erodible area, which has been recently studied due to its high sediment production and the extreme suspended sediment concentrations carried by its river courses [López-Tarazón et al., 2009, 2010, 2012; Müller et al., 2010; Alatorre et al., 2012]. The TETIS model is calibrated and validated using reservoir sedimentation volumes, and successively checked by comparing its results with the suspended sediment series gauged by López-Tarazón et al. [2012] at the Capella station, on the Isábena River (main tributary of the Ésera River).

The aims of this chapter are:

- To apply the TETIS model at an ungauged catchment (the model application is carried out as if no measured sediment transport series were available).

- To apply the TETIS model to a case study with high erosion rates and elevate sediment transport.

- To calibrate and validate the model using the sedimentation volumes of a large reservoir such as the Barasona reservoir.

- To check whether the calibration and validation with reservoir sedimentation data works properly with gauged sediment data at the Isábena River.

- To implement a reliable model for its application within the SCARCE project (climate change impact assessment on water and sediment).

\subsection{The case study: Ésera River}

\subsubsection{Catchment characteristics}

The Ésera River catchment is located in the Southern Central Pyrenees, and covers $1532 \mathrm{~km}^{2}$ (Figure 7.1). The Ésera River springs are located between the "Forao de Aigualluts" karst formation and the "Hospital de Benasque" mountain refuge, from the union of many little creeks proceeding from the Pyrenees peaks. The "Forao de Aigualluts" karst formation is an interesting geological singularity. From a topographical point of view, the superficial catchment drained by the "Forao" $\left(10 \mathrm{~km}^{2}\right)$ belongs to the Ésera River catchment. Nevertheless, the water drained by it infiltrates into an extended and complex karst formation and ends at the French side of the Pyrenees, contributing to the Garonne River Catchment.

Many high reliefs above $3000 \mathrm{~m}$ a.s.l. are included within the Ésera River catchment, such as the northern side of the Maladeta, Posets, Eriste and Perdiguero massifs [Ramírez-Solano, 
2012]. Steep slopes and high altitudes are the main characteristics of the Ésera River headwaters. At Villanova $\left(323 \mathrm{~km}^{2}\right)$, the portion of catchment above $2500 \mathrm{~m}$ a.sl. is $26.4 \%$ and the portion of catchment above $2000 \mathrm{~m}$ a.sl. is $65.6 \%$. At Graus ( $889.5 \mathrm{~km}^{2}$ catchment), they are respectively $9.5 \%$ and $27.6 \%$.

The main tributary of the Ésera River is the Capella River. It represents almost the $30 \%$ $\left(425.9 \mathrm{~km}^{2}\right)$ of the whole Ésera catchment $\left(1532 \mathrm{~km}^{2}\right.$ at its confluence with the Cinca River). It reaches the Ésera River by the left side, a few kilometres upstream the Barasona reservoir. The river mouth is located a few kilometres downstream the Barasona reservoir.

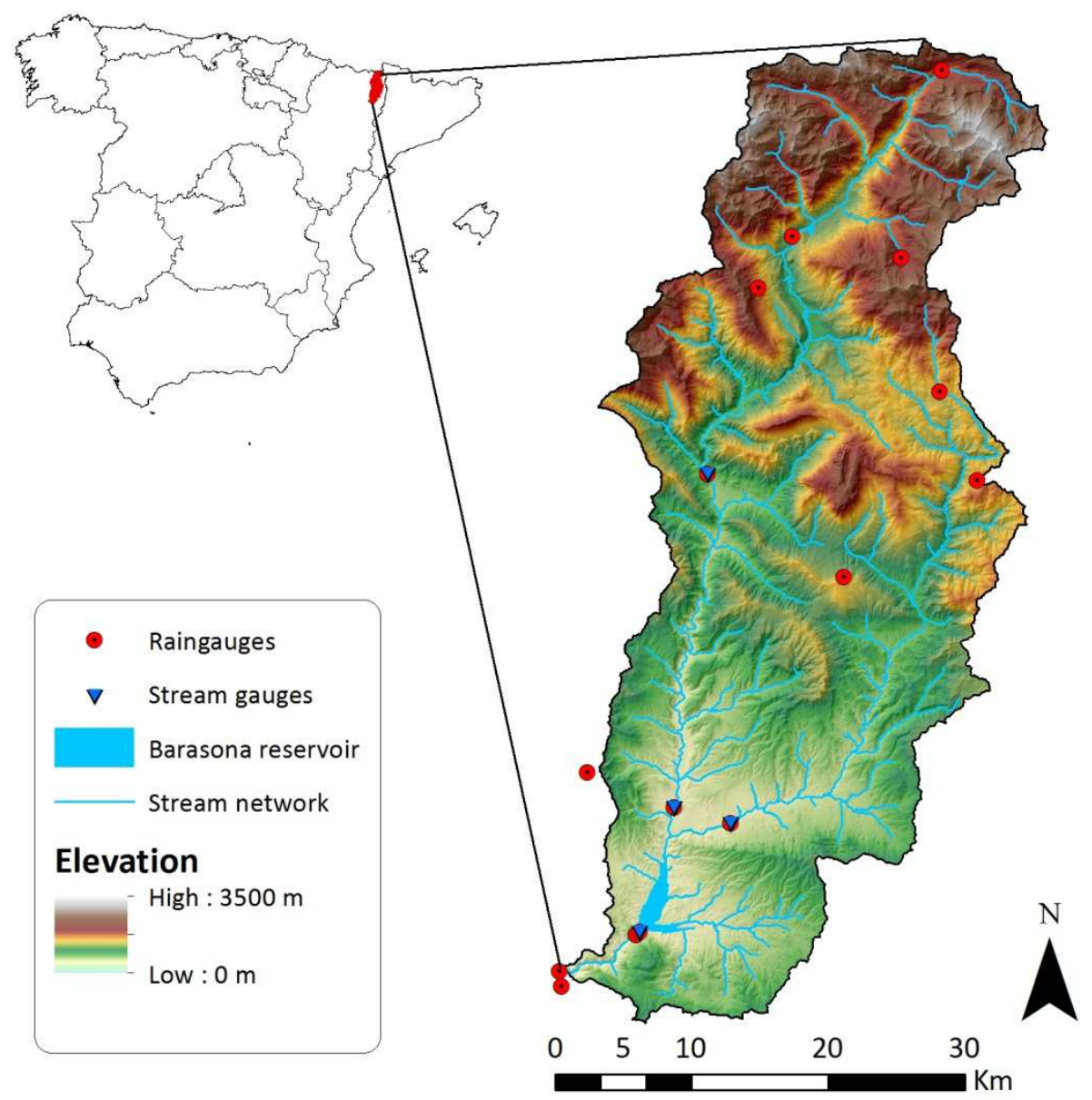

Figure 7.1 - Ésera River catchment location.

The Ésera River catchment is located in a climatic zone characterized by two main influences: the oceanic climate and the Mediterranean domain. The oceanic climate dominates on the Western Pyrenees, and the Mediterranean on the Central Pyrenees. The Ésera River catchment climate mainly belongs to the Mediterranean type, with a high 
thermal contrast: dry winters with high insolation and stormy summer with torrential precipitations.

From a climatic point of view, the zone can be divided in two parts. The first one lies at south of the Turbón massif and it is warmer and dryer, typically Mediterranean. The other one is Sub-Alpine and it is typical of the headwaters (above $1600 \mathrm{~m}$ a.s.l.).

The land use of the Ésera River catchment is dominated by forest (34\% of all catchment), with some shrublands (27\%), grassland and pastures (12\%) and arable dryland (10\%). The rest is mainly an alternation urban land and arable land. In the headwaters, many rock outcrops and screes can be found, among which many typical Pyrenean lakes are presents ("ibones"), between pine forests and shrublands. Grasslands and pastures are located along the river course, especially in the intermediate part of the catchment. The arable land is located within the low part of the catchment. This area suffered a strong land abandonment during the first half of the twentieth century, which caused a reduction in the arable land and a gradual reforestation and had a relevant impact on soil erosion [Cerdà and Lasanta, 2005; Navas et al., 2007; López-Vicente et al., 2008, 2013].

The geology of the area is complex and organized in structures going from WNW to ESE [Alatorre et al., 2010]. The main types of lithology are limestone and shale for the headwaters, limestone and sandstone for the intermediate part, an important marl strip crossing the whole catchment from west to east close in the middle part (close to the Campo stream gauge) and conglomerate and sandstone for the low part of the catchment.

\subsubsection{Hydrometeorological data}

The available hydrometeorological data is detailed as following:

- Daily rainfall and temperature gauged in 12 AEMET stations covering different periods between 1950 and 2012;

- Rainfall data at 15 minutes time step in 6 SAlH stations from 1997 up to now and other 6 raingauges from 2009 up to now;

- Barasona reservoir daily level, volume and effluent discharge from 1944 to 2008, provided by CEDEX (and measured by the Ebro River Water Board);

- Daily discharge in the Eriste, Capella, Campo and Graus stations, measured by CEDEX;

- 15 minutes time step discharge from 1997 up to now in the same stations, measured by SAIH.

Since the aim of this study is to simulate the depositional history of the Barasona reservoir since its construction (1932) or, at least, its re-growing (1972), the AEMET rainfall data must be used. Nevertheless, the AEMET data is very intermittent and its quality is low. Moreover, the orographic effect is very important in this catchment, and almost all raingauges are located in the low part of the catchment.

Ramírez-Solano [2012], who implemented two TETES model on three Spanish Mediterranean catchments (including the Ésera River catchment) using as input rainfall the AEMET point data and the Spain02 gridded rainfall and temperature data set respectively, 
found that the results of the second model were equivalent to the first one, and in some case, they were better than the point data model results, especially for mountainous catchments as the Ésera one. For this reason, in this study, the Spain02 gridded rainfall data set is used as model input.

The Spain02 gridded rainfall and temperature data set is a research project developed by the Meteorology Research Group of the University of Santander (Spain) ${ }^{7}$, the Institute of Physics of Cantabria (Spain) and the AEMET. It is a database of daily rainfall and daily minimum and maximum temperature above a regular mesh $(0.2 \circ \times 0.2 \circ$, around $20 \times 20 \mathrm{~km})$, which covers the whole Spanish peninsular territory. This database was obtained by interpolating AEMET point data after a strict pre-processing and control phase. This database is completely free and available online8. The grids were validated versus observations and were used for global and regional atmospheric models validation.

The observed data from which Spain02 was created are the AEMET point data. The first records of this monitoring network are the 1st of September 1859 at the $3195 Z$ raingauge, Madrid. The gridded data set covers from 1950 to 2008.

Following the Spain02 database, the mean annual rainfall for the Ésera River catchment varies between $990 \mathrm{~mm} /$ year (Northern zone) and $570 \mathrm{~mm} /$ year (southern zone).

\subsubsection{Sediment data}

The sediment cycle of the Ésera River catchment has been studied in many occasions, as explained above. In this chapter, two kinds of sediment information are exploited, coming from the literature:

- Barasona reservoir bathymetries and volume quantifications [Mamede, 2008; Müller et al., 2010].

- Suspended sediment discharge series measured at Capella station (Isábena River) [López-Tarazón et al., 2009, 2010, 2011, 2012; López-Tarazón, 2011].

\subsubsection{Sediment deposited in the Barasona reservoir}

Sediment deposits accumulated in reservoirs can provide a precise estimate of the mean catchment SY. In this case of study, the Barasona reservoir, many studies are available which provide a reservoir storage value or a sediment deposit volume [Mamede, 2008].

The reservoir was built in 1932, with a capacity of $71 \mathrm{Hm}^{3}$, and later re-growth up to 92.2 $\mathrm{Hm}^{3}$ [Valero-Garcés et al., 1999; Mamede, 2008]. The historical reconstruction of Barasona storage variations is a complex task, because of the high uncertainty on bathymetry values and because many of the flushing (bottom outlet opening for sediment loosing) and dredging (direct extraction of the deposited sediment after emptying the reservoir) operations carried out during the reservoir life are unknown or no extracted volume is available. This task will be carried out in the result section. Amongst others, Mamede [2008]

\footnotetext{
${ }^{7}$ http://www.meteo.unican.es/en/main

${ }^{8}$ http://www.meteo.unican.es/es/datasets/spain02
} 
also carried out a storage variation reconstruction, doing an exhaustive literature search (Figure 7.2).

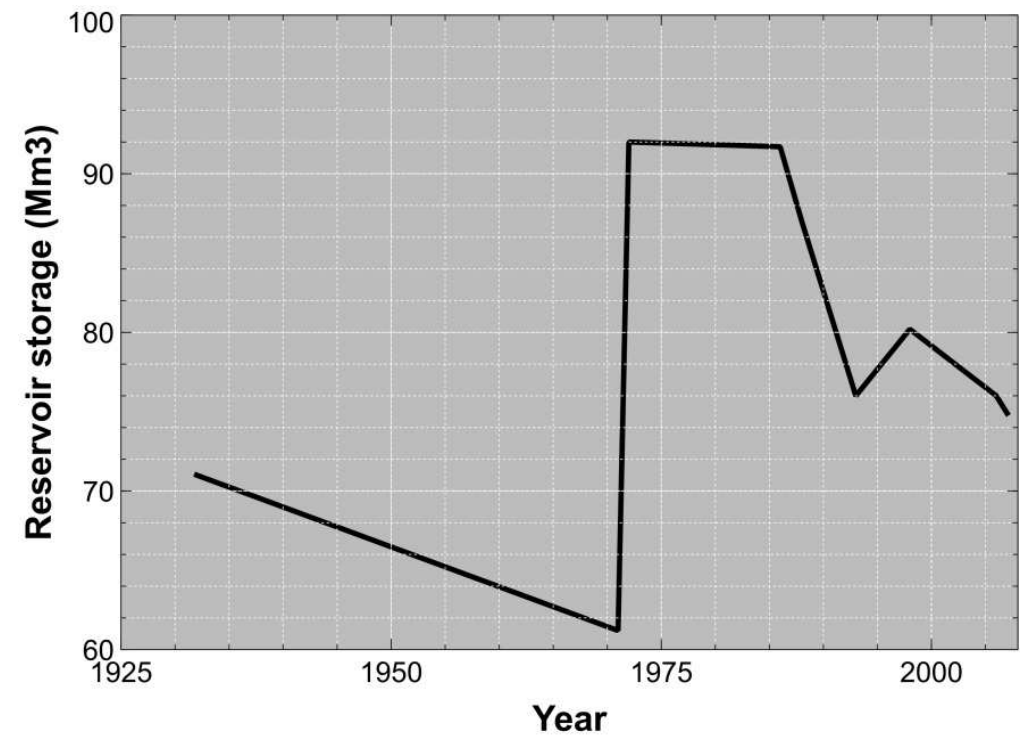

Figure 7.2 - Temporal evolution of the Barasona reservoir storage capacity, modified from Mamede [2008].

\subsubsection{Suspended sediment transport series at Capella station}

Suspended sediment transport data at the Capella station were measured within the framework of José Andrés López-Tarazón's PhD thesis [López-Tarazón, 2011], from the RIUS $^{9}$ research group, University of Lleida (Spain). The aim of López-Tarazón's PhD thesis was to measure, monitor and model the suspended sediment transport of the Isábena River. This river often transport very high load of suspended sediment. Sediment concentrations up to $300 \mathrm{~g} / \mathrm{l}$ were recorded during last 5 years.

López-Tarazón's PhD thesis had four main objectives:

1) To calculate the suspended SY of the Isábena River Catchment by means of a "black box" approach based on continuously gauged data with 15 minutes time step.

2) To study the relationships between rainfall, runoff and sediment transport.

3) To study the sediment storage within the river bed.

4) To determine the catchment sediment balance by coupling field work and statistical tools.

In this dissertation, the point 1 ) is used, i.e. the suspended sediment concentration series measured at the Capella station from 1/10/2005 to 30/9/2010 (Figure 7.3 and Figure 7.4).

\footnotetext{
${ }^{9}$ www.fluvialdynamics.com
} 


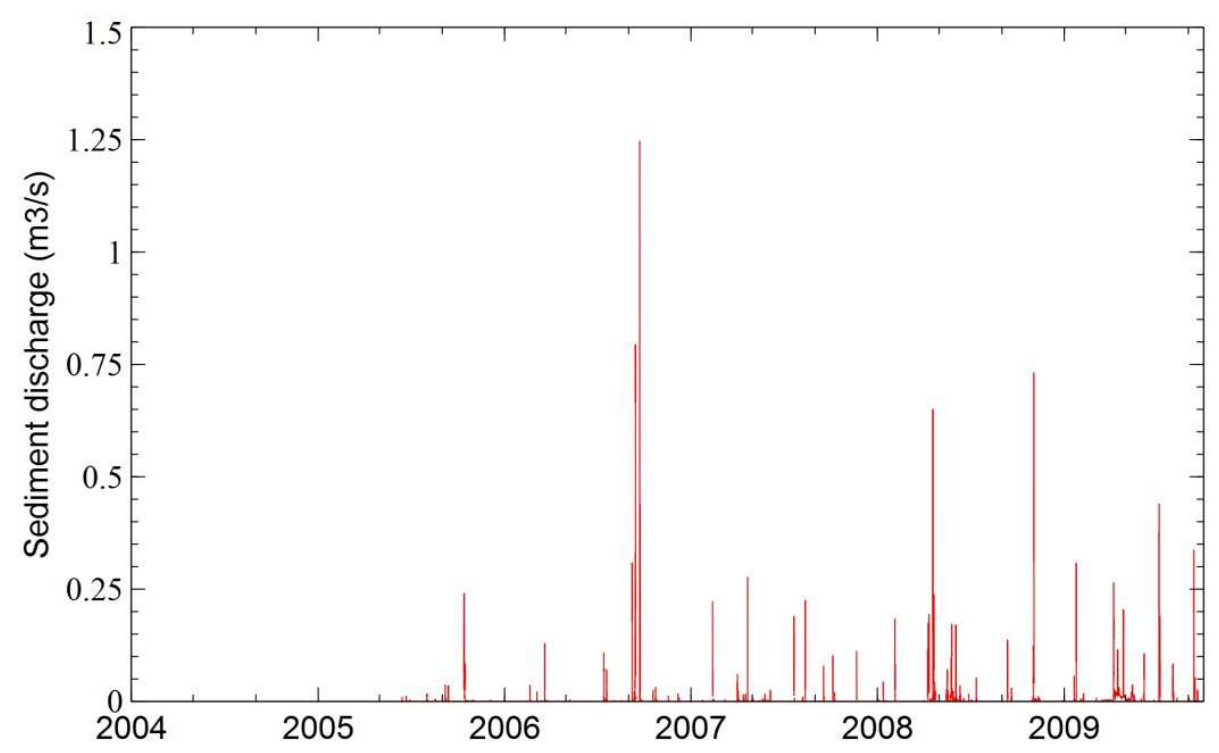

Figure 7.3 - Suspended sediment discharge, from López-Tarazón [2011] .

This suspended sediment series reveals that the mean suspended SY for the 2005-2010 period was $6.00 \mathrm{t} \mathrm{ha}^{-1}$ year $\mathrm{r}^{-1}$. This number does not take into account the bed load. Given that TETIS uses a total load equation to compute stream sediment transport capacity, it is impossible to carry out a proper validation because observed and simulated data are not comparable. Nevertheless, and taking into account that around the $90 \%$ of the total sediment transport at the earth scale is due to suspended load [Webb et al., 1995], it is know that the Isábena sediment texture is rather fine, with a total absence of coarse material such as sand [López-Tarazón, personal communication]. This statement is confirmed by the Barasona 1986 bathymetry: the authors found only a $5 \%$ of sand [Avendaño Salas and Cobo Rayán, 1998]. Given that the coarse material is more easily trapped into reservoir, the conclusion is that sandy sediments are not frequent in the Ésera River catchment, and for this reason, the suspended sediment transport should represent a great portion of the total load, probably between 90 and $100 \%$. As stated by Walling and Fang [2003], suspended sediment measurements are reliable if they account for around the $90 \%$ of the total load [González-Hidalgo et al., 2013], as is the case of the Ésera and Isábena Rivers. 


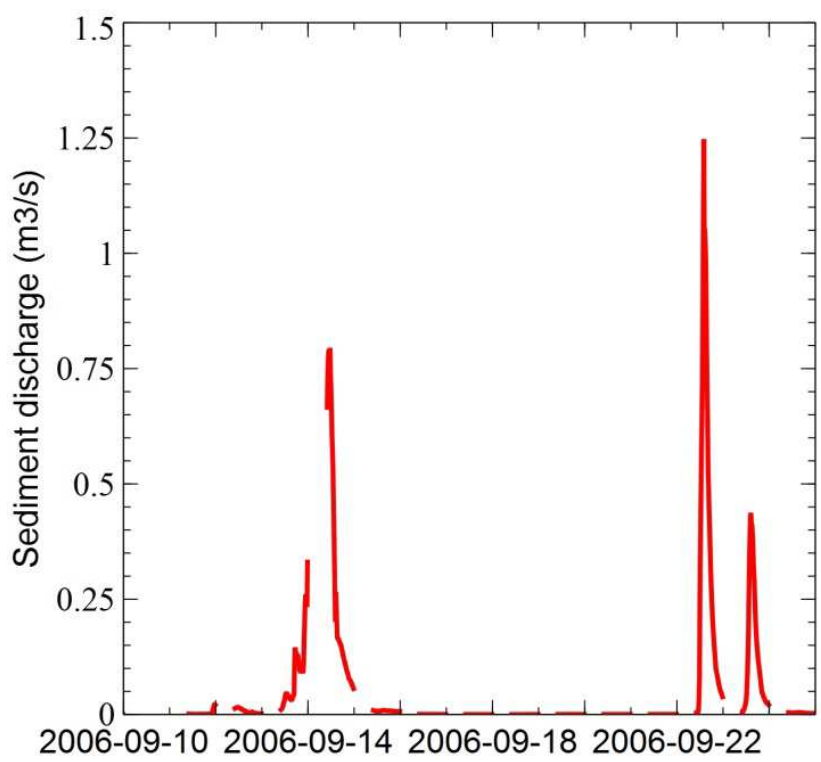

Figure 7.4 - Some of the highest suspended sediment peaks of the series (September 2006).

\subsubsection{Model parameters}

The model parameter section was taken and modified from Ramírez-Solano [2012], who estimated the model parameter for the Ésera River Catchment and implemented the TETEIS hydrological sub-model.

DEM and all derived parameters were obtained from the PNOA (Plan Nacional de Ortofotografía Aérea, National Plan of Aerophotogrammetry) 25x25 DEM and resampled to $100 \times 100 \mathrm{~m}$.

Soil parameters were estimated starting from the European Soil Database (ESDB v2.010). The ESDB is the resulting product of a collaborative project involving all the European Union and neighbouring countries. It is a simplified representation of the diversity and spatial variability of the soil coverage. The methodology used to differentiate and name the main soil types is based on the terminology of the F.A.O. legend for the Soil Map of the World at scale 1:5,000,000. This terminology was refined and adapted to take account of the specificities of the landscapes in Europe. The ESDB contains 73 attributes which describe each a soil property, grouped into 14 categories.

The land use and the vegetation cover were obtained from the CORINE 2006 and the $C$ and $\mathrm{K}$ USLE factors from previous studies.

\footnotetext{
${ }^{10}$ http://eusoils.jrc.ec.europa.eu/ESDB_Archive/ESDB/index.htm
} 


\subsubsection{Hydrological parameters}

The vegetation cover map was obtained by reclassifying 2006 CORINE Land Cover (Figure 7.6). In Figure 7.5 the vegetation classes employed in this study can be seen.

For each land use class, 12 vegetation coefficients were established, one each month, in order to estimate the reference evapotranspiration day by day. For each vegetation class, a maximum interception was also set, taken from Ramírez-Solano [2012].

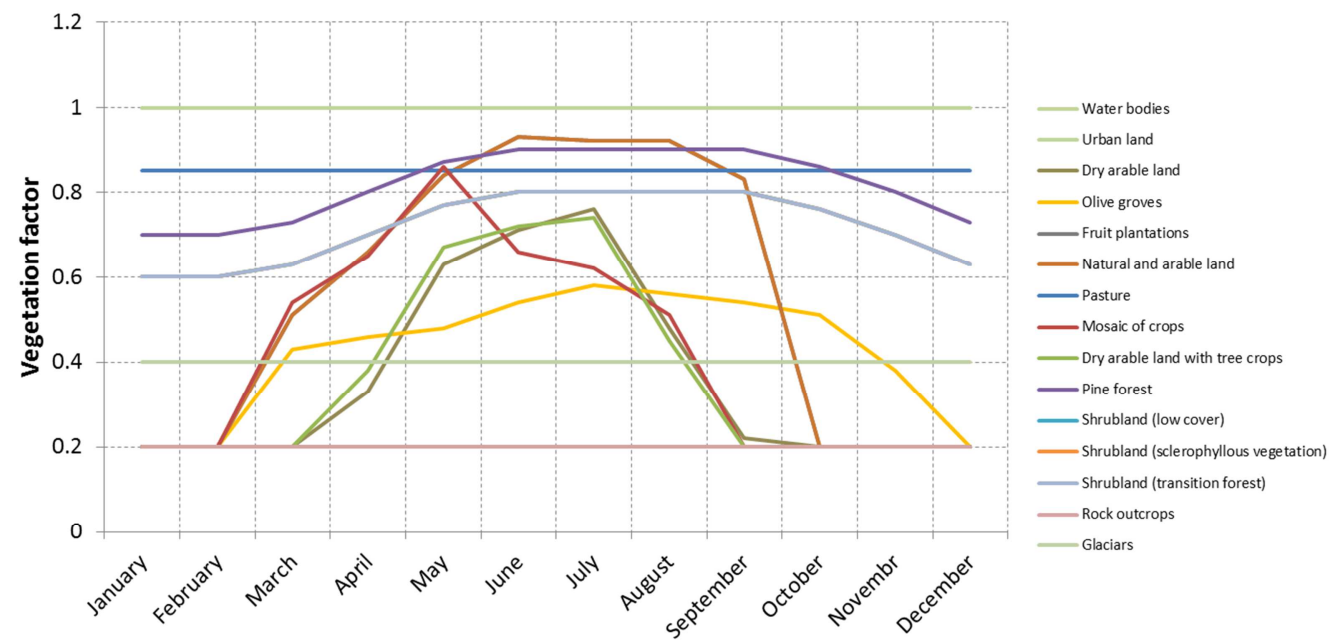

Figure 7.5 - Vegetation factors of the Ésera River catchment.

From the ESDB database, the attributes AWC_TOP (topsoil available water content), ROO (obstacle to roots development depth) and TXT-SRF-DOM (topsoil texture) were used. The first two maps were reclassified from the qualitative categories of the original map as follows.

\begin{tabular}{cc}
\hline AWC_TOP $(\mathrm{mm} / \mathrm{m})$ & Reclassification $(\mathrm{mm} / \mathrm{m})$ \\
\hline Low $(<100 \mathrm{~mm} / \mathrm{m})$ & 80 \\
Medium $(100-140 \mathrm{~mm} / \mathrm{m})$ & 120 \\
High $(140-190 \mathrm{~mm} / \mathrm{m})$ & 165 \\
Very high $(>190 \mathrm{~mm} / \mathrm{m})$ & 200 \\
\hline
\end{tabular}

Table 7.1 - Reclassification of the ESDB parameter AWC_TOP for describing the soil capillary storage.

\begin{tabular}{cc}
\hline ROO (cm) & Reclassification $(\mathbf{c m})$ \\
\hline$>80$ & 100 \\
$60-80$ & 70 \\
$40-60$ & 50 \\
$20-40$ & 30 \\
\hline
\end{tabular}

Table 7.2 - Reclassification of the ESDB parameter ROO for describing the root depth.

\begin{tabular}{cc}
\hline TXT-SRF (\%) & Description \\
\hline Peat soils & -
\end{tabular}


Clay $<18 \%$; Sand $>65 \%$.

Clay between $18-35 \%$ and sand $>=15 \%$, or clay $<18 \%$ and sand between $15-65 \%$.

Sand $<15 \%$; Clay $<35 \%$

\section{Coarse}

Medium

Medium - fine

Table 7.3 - Reclassification of the soil texture following the ESDB.

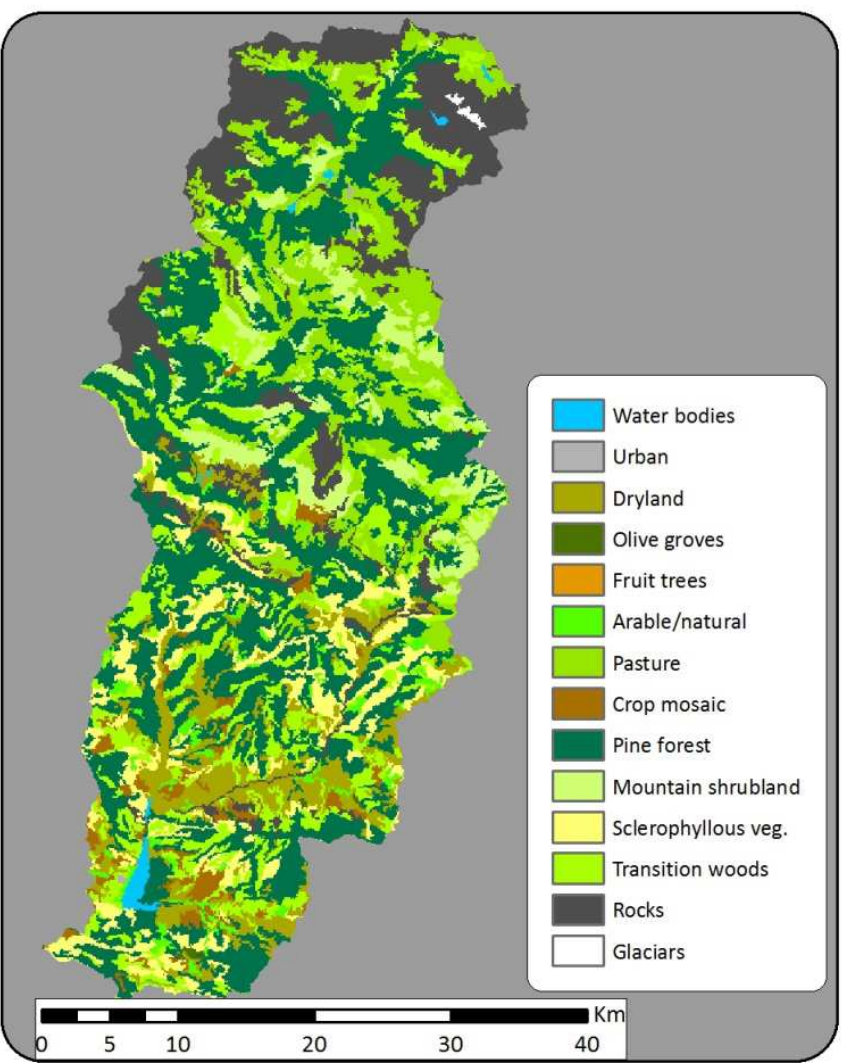

Figure 7.6 - Land use of the Ésera River catchment.

Given this information, the following parameters were estimated:

- Soil static storage;

- Infiltration capacity;

- Percolation capacity;

The interflow conductivity is estimated as equal to the infiltration capacity and the aquifer conductivity is estimated as equal to the percolation capacity. The loss coefficient is estimated as 0.1 times the aquifer conductivity.

The static storage was estimated as the sum of the surface storage and the available water content in $\mathrm{mm}$. The available water content was obtained by multiplying the AWC_TOP ESDB map and the root depth, which is an estimator of the soil depth. The root depth was 
calculated as the minimum value for each cell between the ROO map and the root depth based on land use.

The infiltration capacity map was estimated using the TXT-SRF ESDB map. The Mualem-Van Genuchten pedotransfer functions [Mualem, 1976] were used to calculate a hydraulic conductivity value for each textural class; the hydraulic conductivity corresponds to the infiltration capacity.

The resulting maps can be seen in Figure 7.7.

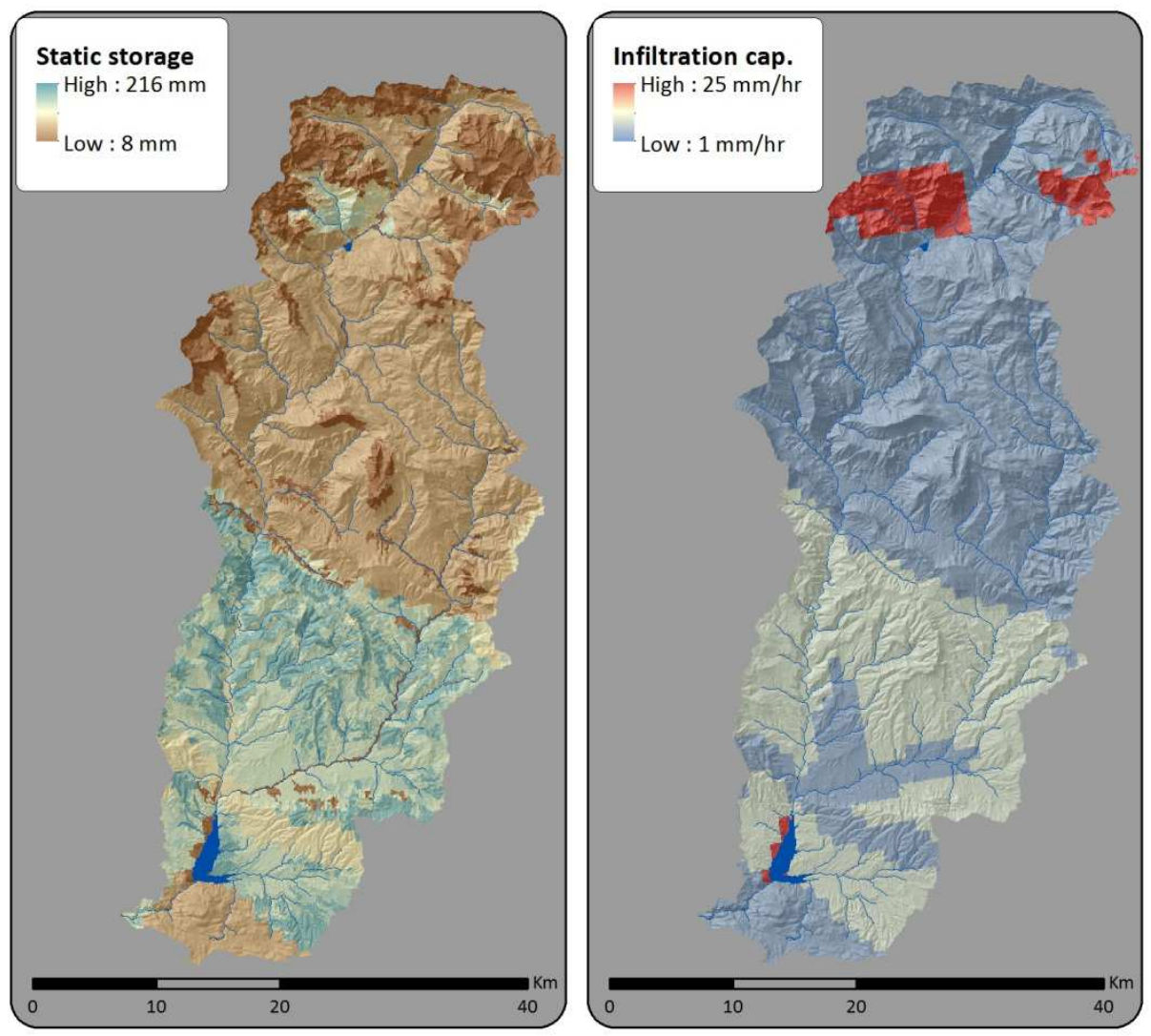

Figure 7.7-Maximum static storage and infiltration capacity of the Ésera River catchment.

In order to characterise the geological parameters of TETIS, a lithological map of Spain 1:200,000 was used. The lithological units there defined are:

(C) Carbonate rock

(D) Detrital rock

(Q) Quaternary

(V) Volcanic 
(M) Metadetrital rock

(I) Igneous rock

(E) Evaporite

This map also classifies the aquifer permeability in a qualitative way: $(\mathrm{VH})$ Very high, $(\mathrm{H})$ High, (M) Medium, (L) Low, (VL) Very low. In order to estimate the percolation capacity, the lithological map was used, crossing lithology and qualitative permeability. A percolation capacity value was assigned to each category following literature and previous studies. The results can be seen in Table 7.4.

\begin{tabular}{|c|c|}
\hline Cathegory & Value \\
\hline$C-M B$ & 0.000416667 \\
\hline$C-B$ & 0.074094975 \\
\hline$C-M$ & 13.17615692 \\
\hline$C-A$ & 2343.088855 \\
\hline$C-M A$ & 416666.6667 \\
\hline$E-M B$ & 0.041666667 \\
\hline$E-B$ & 0.740949754 \\
\hline$E-M$ & 13.17615692 \\
\hline$D-M B$ & 4.16667E-06 \\
\hline$D-B$ & 0.000416667 \\
\hline$D-M$ & 0.041666667 \\
\hline$D-A$ & 4.166666667 \\
\hline$D-M A$ & 416.6666667 \\
\hline$M-M B$ & 4.16667E-07 \\
\hline$M-B$ & 2.34309E-05 \\
\hline$M-M$ & 0.001317616 \\
\hline$Q-B$ & 0.007409498 \\
\hline$Q-M$ & 1.317615692 \\
\hline$Q-A$ & 234.3088855 \\
\hline$Q-M A$ & 41666.66667 \\
\hline$V-M B$ & 0.36 \\
\hline$V-B$ & 1.138419958 \\
\hline$I-M B$ & 0.00000036 \\
\hline$I-B$ & 0.000036 \\
\hline
\end{tabular}

Table 7.4 - Values for the percolation capacity depending on the geology.

\subsubsection{Geomorphological parameters}

The nine Geomorphological Kinematic Wave parameters used by TETIS were taken from previous geomorphological studies on similar basins [Vélez, 2001]. In particular, the River Tagus values were used in this project [DIHMA, 2001].

\subsubsection{Sediment parameters}

$\mathrm{K}$ and $\mathrm{C}$ maps of USLE were obtained from a previous study, carried out by Alatorre et al. [2010]. The soil erodibility factor, K, was computed by the authors starting from a fiwield 
campaign of soil profile analysis, determining texture, organic matter and other characteristics. The results can be seen in Figure 7.8.

The crop factor, C, was estimated by the same authors starting from the CORINE land use map and the reclassification proposed by Almorox et al. [1994]. In particular, the value 0 was assigned to water bodies and urban zones, 0.01-0.3 to forest zones, $0.08-0.2$ to shrubland zones, $0.045-0.15$ to pastures, $0.1-0.4$ to crop fields and $0.166-0.8$ to bare soil. The results can be seen in Figure 7.8 .

\begin{tabular}{cc}
\hline Parameter & Value \\
\hline$\kappa$ & 1.2968 \\
$\varphi$ & 0.7571 \\
$a_{1}$ & 3.1301 \\
$\alpha_{1}$ & 0.5088 \\
$\alpha_{2}$ & 0.3253 \\
$c_{d}$ & 6.5156 \\
$\theta$ & 0.6548 \\
$c_{n}$ & 0.0470 \\
$\xi$ & 0.1667 \\
\hline
\end{tabular}

Table 7.5 - Values for the hydraulic geometry coefficients and exponents. 

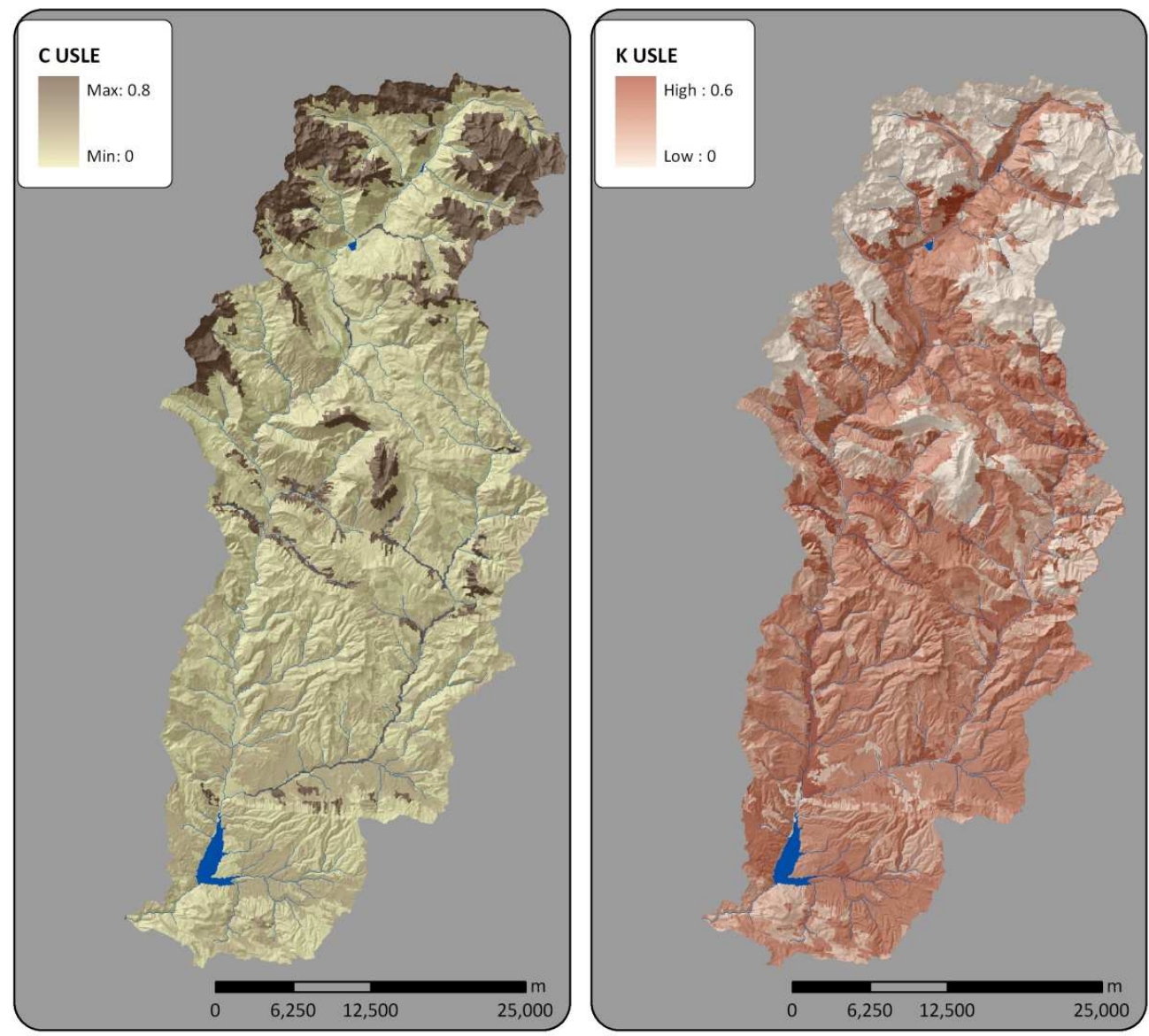

Figure 7.8 - C and $K$ USLE factores of the Ésera River catchment.

The texture data used to elaborate the $\mathrm{K}$ map were not made available. Given that the TETIS sediment sub-model requires this data, the geological map and the USLE K factor map were used. The $\mathrm{K}$ factor of USLE depends on soil texture, soil structure and soil organic matter content. The soil organic matter content is known, by using the OCTOP map form the European soil database [Jones et al., 2004, 2005]. Given that it is not possible to build a relationship between the $K$ single value and three values of texture (percentage of sand, silt and clay), the clay content was estimated from the geological map, supposing a clay percentage depending on the lithological origin of the soil. For example, limestone will generate a soil with less content of clay than marls. Results were validated with soil profile analysis available in other regions of the Iberian Peninsula. Results can be seen in Figure 7.9. The texture maps shows that the Ésera catchment soils are mainly fine (clay and silt), with a small content of coarse material (sand). 

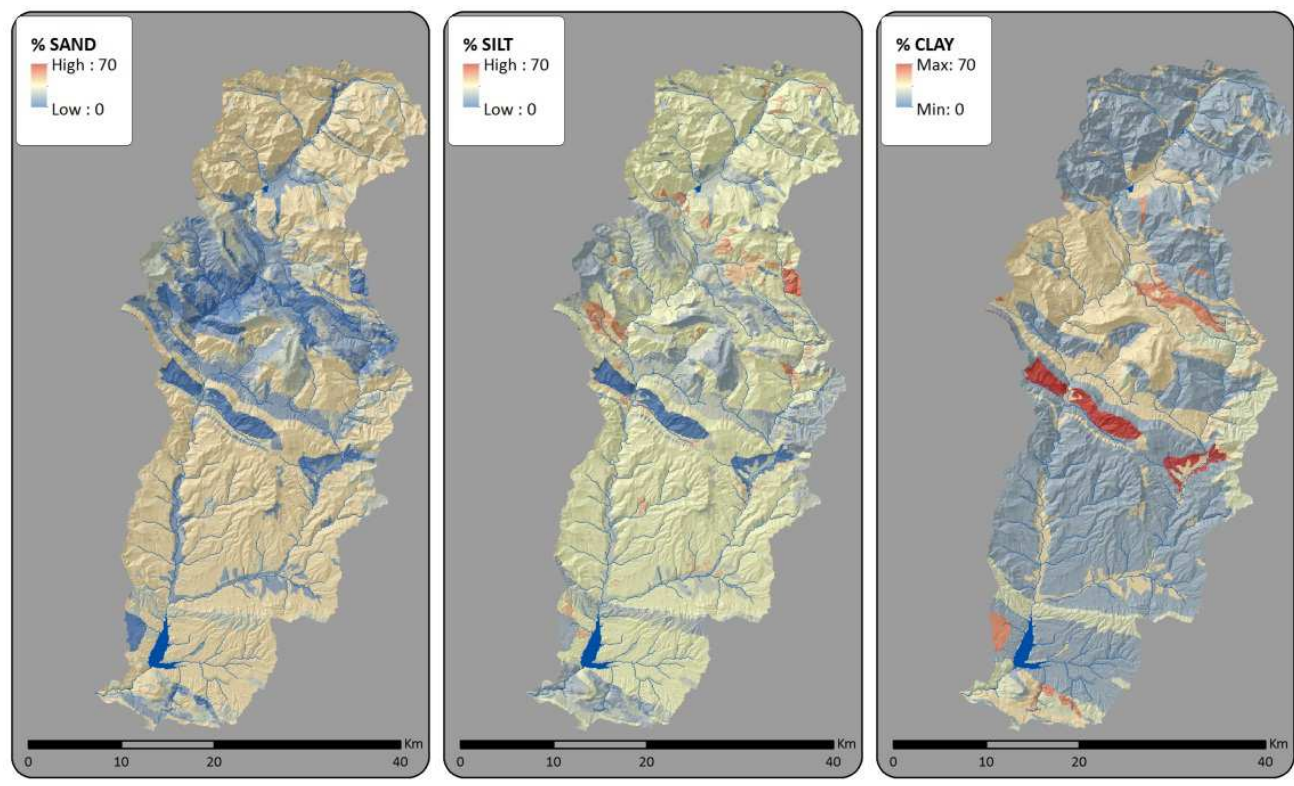

Figure 7.9 - Topsoil texture of the Ésera River catchment.

\subsection{Results}

\subsubsection{Hydrological sub-model calibration and validation}

The Ésera River catchment model was calibrated at the Capella stream gauge with a daily time step. This station was selected as calibration point because the sediment series was measured at this stream gauge, and it is important to reduce the hydrological sub-model error at this point in order to evaluate properly the sedimentological sub-model.

The selected calibration period was from $1 / 10 / 2005$ to $1 / 10 / 2008$, and the validation period from $1 / 10 / 1997$ to $1 / 10 / 2005$. The model was also spatially validated at the Graus and Campo stream gauges and against the observed discharge entering the Barasona reservoir. The calibration results can be seen in Figure 7.10, the spatial validation at the Barasona reservoir in Figure 7.11, the temporal validation at Capella in Figure 7.12 and the spatiotemporal validation at Barasona reservoir in Figure 7.13. Table 7.6 and Table 7.7 show the results in terms of NSE and VE.

\begin{tabular}{ccc}
\hline Station & NSE & VE\% \\
\hline Capella & 0.720 & $-6 \%$ \\
Graus & 0.581 & $-28 \%$ \\
Campo & 0.294 & $-44 \%$ \\
Barasona & 0.708 & $-10 \%$
\end{tabular}

Table 7.6 - Calibration and spatial validation of the Ésera River hydrological sub-model. 


\begin{tabular}{ccc}
\hline Station & NSE & VE\% \\
\hline Capella & 0.686 & $-39 \%$ \\
Graus & 0.704 & $-61 \%$ \\
Campo & 0.455 & $-35 \%$ \\
Barasona & 0.529 & $-22 \%$
\end{tabular}

Table 7.7 - Temporal validation of the Ésera River hydrological sub-model.

In Table 7.8 the calibrated correction factors are shown.

\begin{tabular}{cc}
\hline Correction factor & Value \\
\hline CF1 & 1.8362 \\
CF2 & 0.9000 \\
CF3 & 0.2819 \\
CF4 & 3.0000 \\
CF5 & 0.7524 \\
CF6 & 1408.2396 \\
CF7 & 0.0000 \\
CF8 & 938.2601 \\
CF9 & 0.7249 \\
\hline
\end{tabular}

Table 7.8 - Hydrological sub-model correction factors for the Ésera daily model.

It can be seen that, in general, the model performances are between good and very good, both in calibration and in validation. It is important to underline that the peak flow reproduction is satisfactory, while the base flow simulation it is not, especially at the Campo gauging station. This is probably due to a bad reproduction of the aquifer dynamics by the TETIS model, or to a bad reproduction of the snow melting process. However, given that the aim of this work is the sediment cycle simulation, the low flows are much less important than peak flow. The peak flows are responsible of the great majority of the sediment transport (this can be observed in Figure 7.3). For these reasons, the Ésera River catchment hydrological sub-model can be considered satisfactorily calibrated. The hydrological submodel results evidence the existence of a fluctuating but constant base flow, which increases during the periods of snow melting, alternated by high peaks mainly composed by direct runoff, especially concentrated in autumn and spring. 


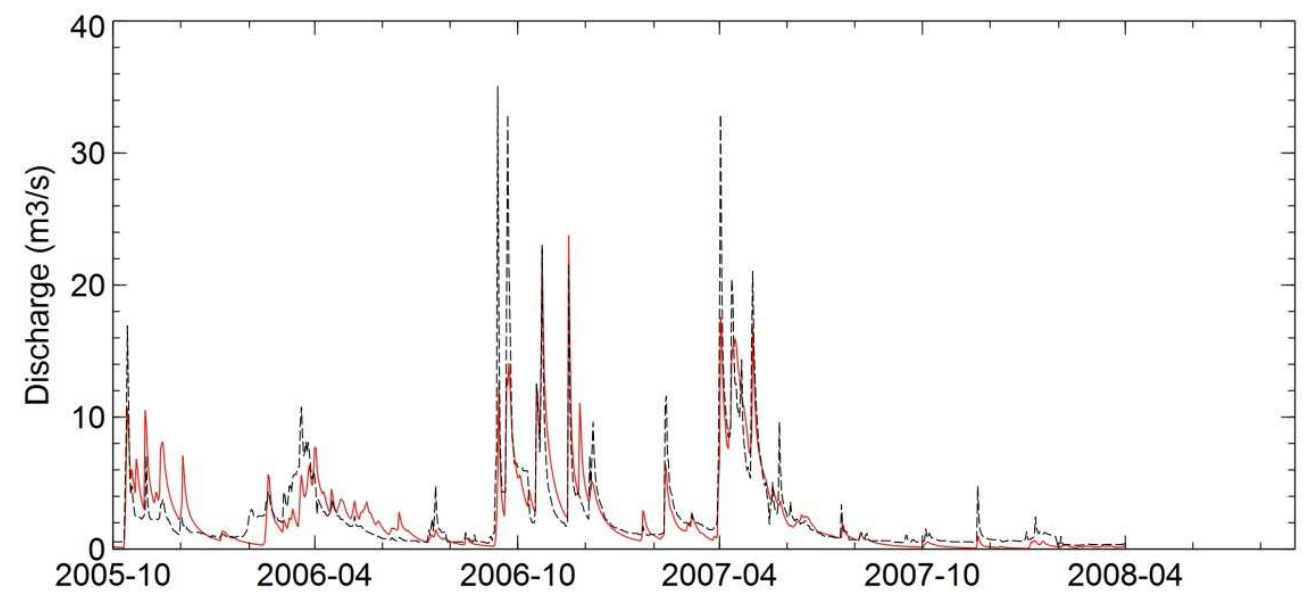

Figure 7.10-Hydrological sub-model calibration of the Ésera River model at Capella station.

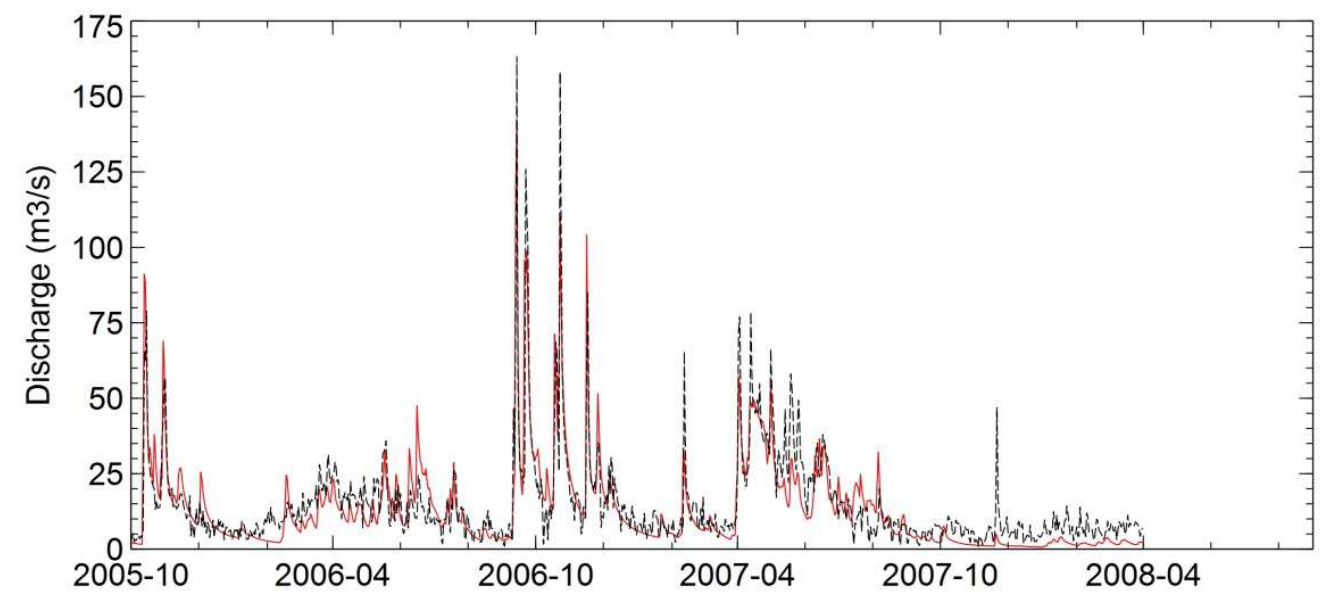

Figure 7.11 - Hydrological sub-model spatial validation of the Ésera River model at Barasona reservoir. 


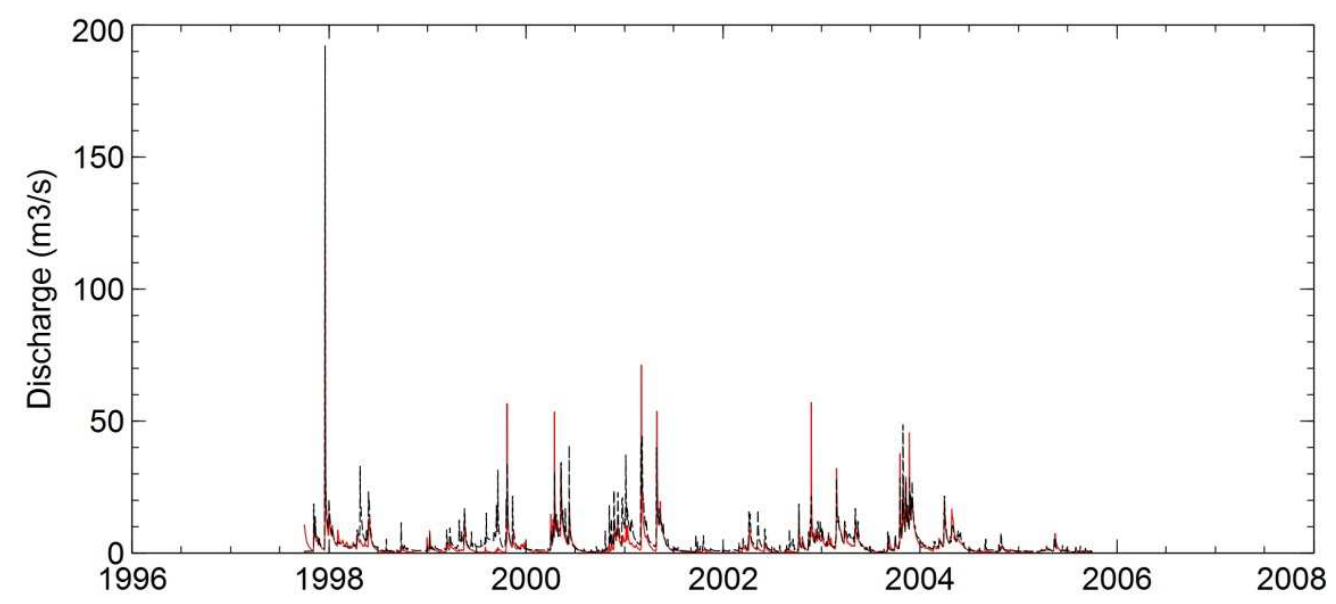

Figure 7.12 - Hydrological sub-model temporal validation of the Ésera River model at Capella station.

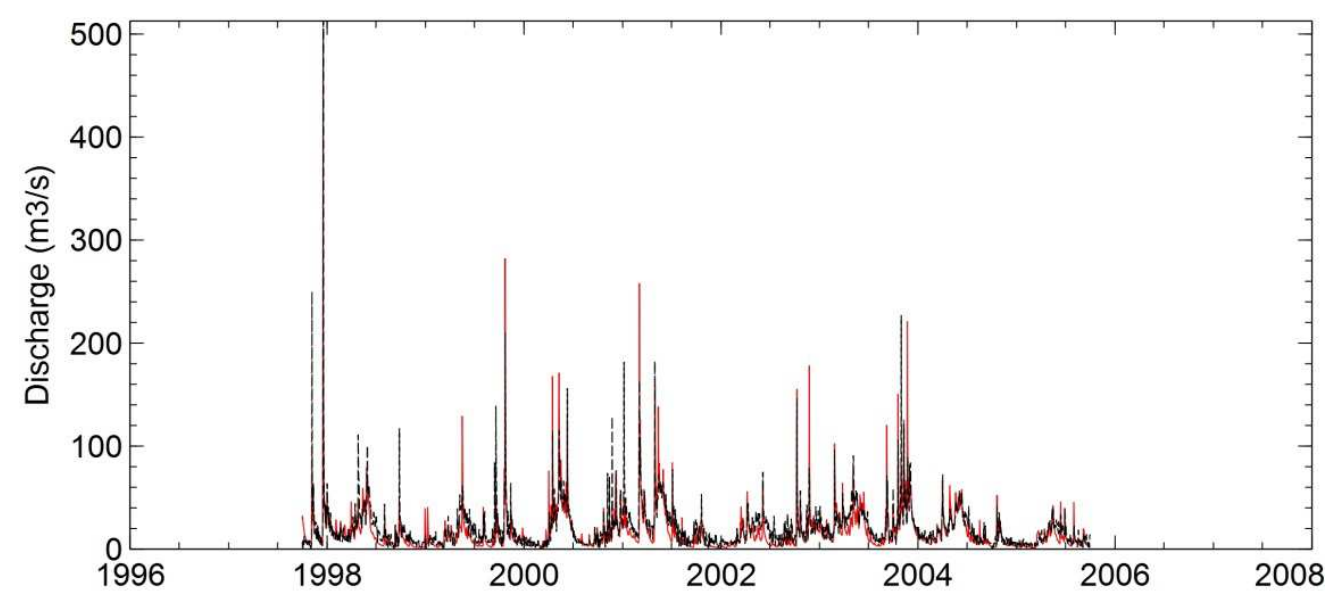

Figure 7.13 - Hydrological sub-model spatio-temporal validation of the Ésera River model at Barasona reservoir.

\subsubsection{Sedimentological sub-model calibration and validation}

In order to implement the sedimentological sub-model, some preliminary steps are necessary. These steps are detailed as following.

First of all, a reservoir needs to be introduced into the model. It is the Linsole reservoirs, located in the Eriste municipality (Figure 7.14 and Figure 7.15). 


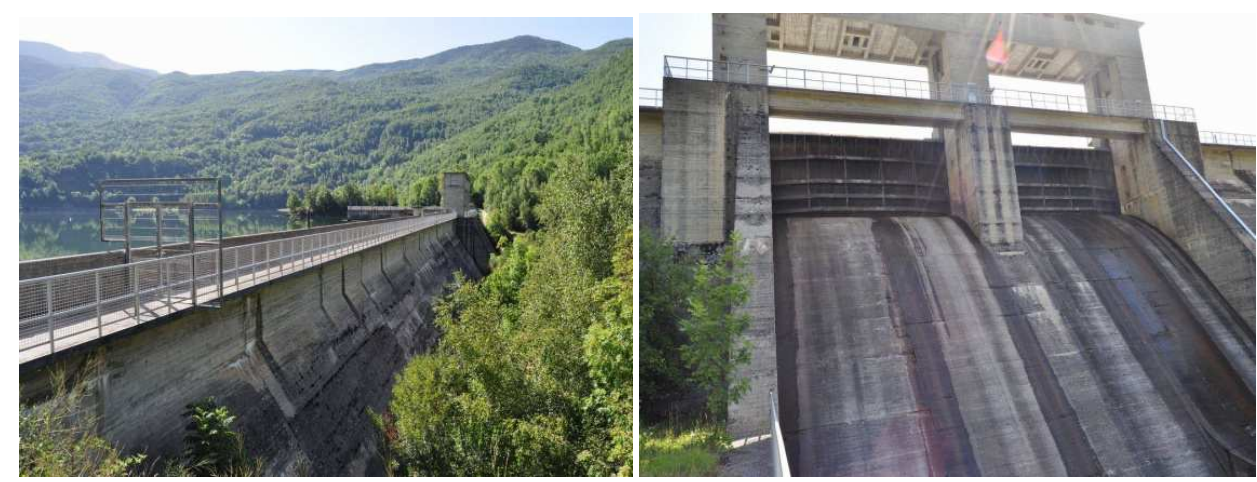

Figure 7.14 - Linsoles (or Eriste) reservoir (potos taken from embalses.net).

It is a rather small reservoir ( $36 \mathrm{~m}$ tall and $2.5 \mathrm{Hm}^{3}$ capacity). The drainage catchment has an extension of $400 \mathrm{~km}^{2}$. This reservoir represents a great obstacle for the sediment transit, and is modelled by using the STEP model coupled to the TETIS model.

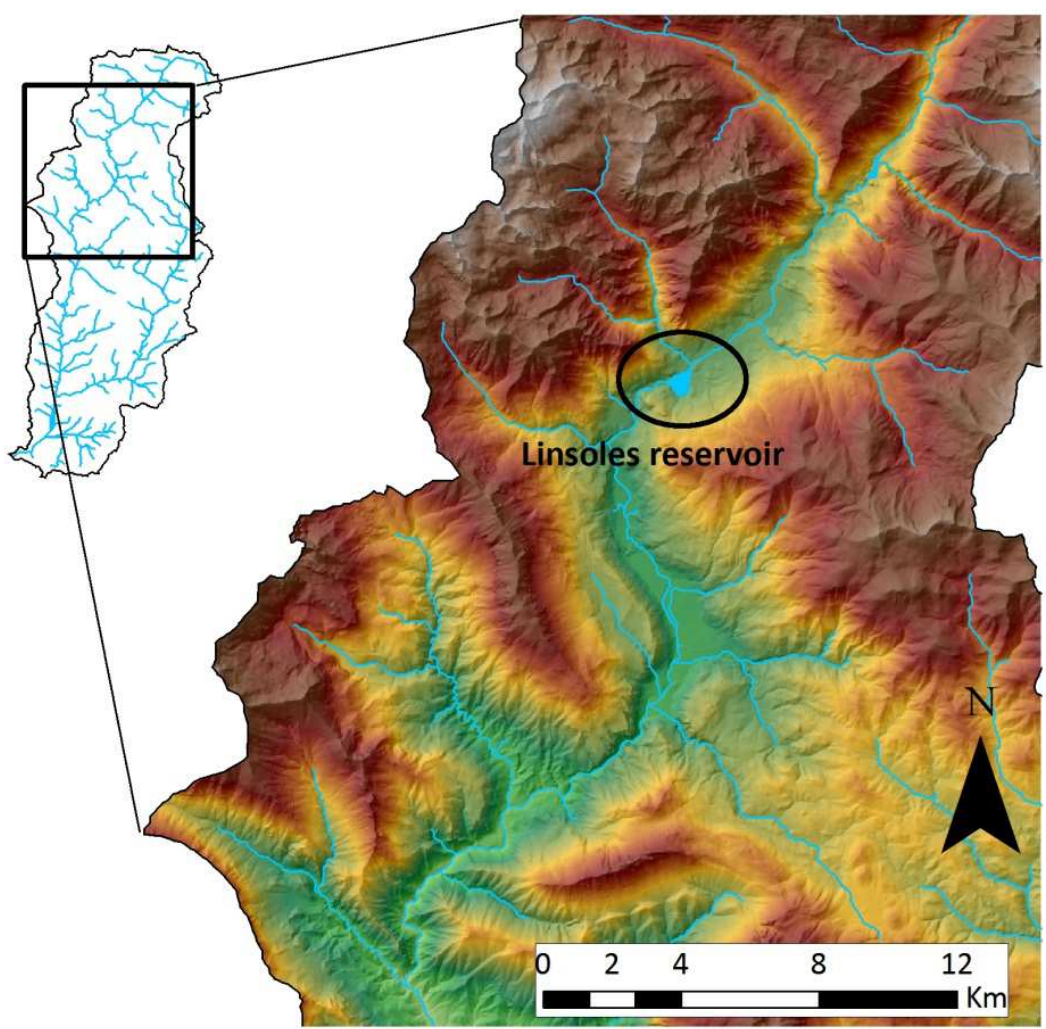

Figure 7.15 - Linsoles (or Eriste) reservoir location.

Secondly, the dBD of the Barasona reservoir must be determined, in order to be able to estimate the reservoir capacity. The Miller [1953] formula, with the Lane and Koelzer [1943] 
coefficients for almost always submerged sediments, are used to compute the sediment $\mathrm{dBD}$. The TETIS simulated texture is used as an input for the formula.

Following the bathymetry carried out in 1998, the mean sediment texture in the Barasona reservoir is clayey silt ( $65.87 \%$ silt, $26.56 \%$ clay and $5.57 \%$ sand). Close to the dam body, the clay content increases up to $39.24 \%$, being the silt percentage $60.48 \%$ and the sand percentage $0.28 \%$.

The mean sediment density is $1.112 \mathrm{t} \mathrm{m}^{-3}$, measured by Avendaño Salas and Cobo Rayán [1998]. This last data is contrasting the one provided by Mamede [2008], who stated that the mean dBD of the Barasona deposit is $1.52 \mathrm{t} \mathrm{m}^{-3}$. This last measurement was taken also from not submerged deposits and may not be representative of the whole reservoir bottom deposit. The first value is taken as reference and simulated $\mathrm{dBD}$ is compared to the measured value of $1.112 \mathrm{t} \mathrm{m}^{-3}$.

In order to take into account the temporal variability of $\mathrm{dBD}$, the evolution of this along the simulation time is computed. This is done by assigning an initial value of unconsolidated deposit to the sediment layer deposited during a given hydrological year (using the Miller formula), and increasing this value year by year (also using Miller formula). The resulting mean $\mathrm{dBD}$ is the weighted mean of all deposited layer. It is expected that older layers have a higher $\mathrm{dBD}$ due to consolidation processes.

In third place, the sediment TE is estimated by using the Brune [1953] curves. Given that the reservoir storage capacity varies (between 70 and $92 \mathrm{Hm}^{3}$, following the available literature), as well as the mean annual inflow, consequently the sediment TE also varies along the simulation period. The annual average inflow also varies. Three hydrological epochs were detected, between which there is an apparent change of mean annual inflow. This can be seen in Figure 7.16. These three values were used to take into account the variation of the mean annual inflow for TE estimation.

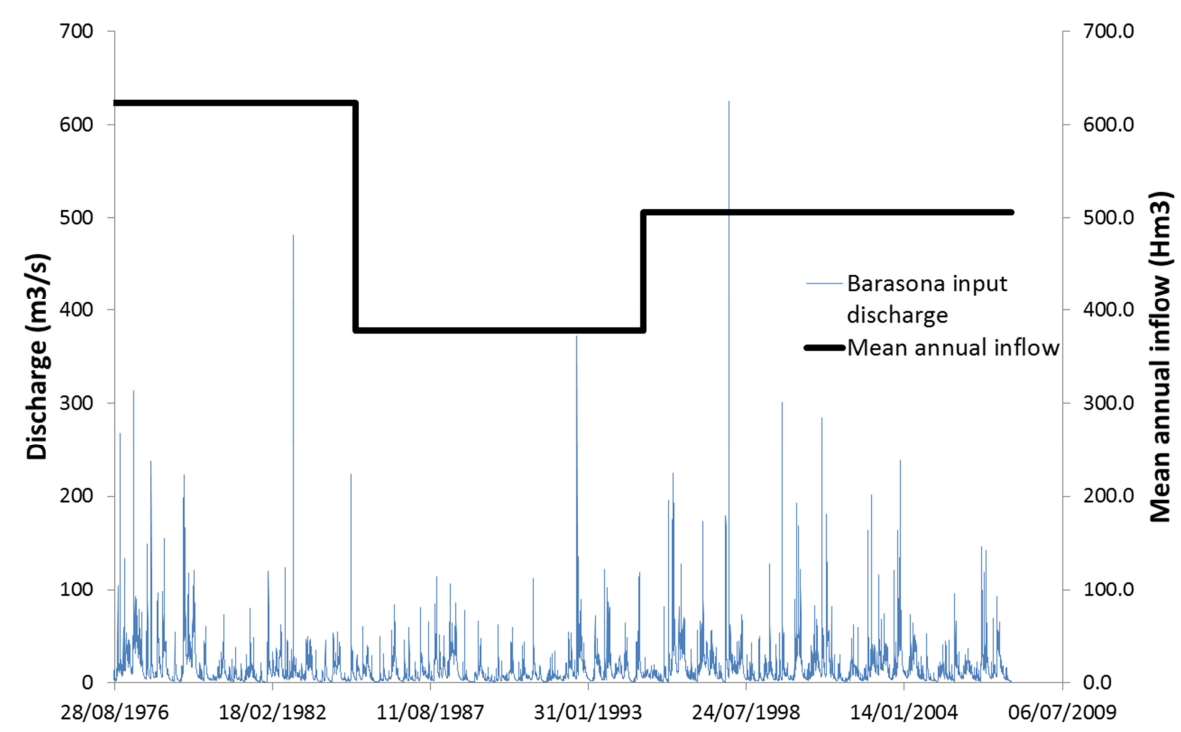


Figure 7.16 - Daily discharge and mean annual inflow at the Barasona reservoir.

For these reasons, the TE is estimated dynamically. Following Brune curves, the TE is between $80 \%$ and $90 \%$. This value confirms the Avendaño Salas et al. [1995] and Alatorre et al. [2010] conclusions; these authors calculated the TE as $86 \%$ and $90 \%$ respectively. Using this value, they calculated a mean annual SY of $3.50 \mathrm{t} \mathrm{ha}^{-1}$ year $^{-1}$ and $3.70 \mathrm{t} \mathrm{ha}^{-1}$ year respectively.

Given these premises, prior to the sedimentological sub-model calibration and validation, the sedimentological and depositional history of the Barasona reservoir need to be reconstructed, starting from literature data and bathymetries.

As stated before, various sources agree that the Barasona reservoir was built in 1932 with a capacity of $71 \mathrm{Hm}^{3}$, and was regrowth in 1971 up to a capacity of $92.2 \mathrm{Hm}^{3}$ (although it is not known if this capacity was measured by a bathymetry or simply computed by using the original depth-volume reservoir curve). From 1973 to 1978, the licensed enterprise (HidroNitro) carried out various flushing operation aiming to eliminate part of the accumulated sediments [Armengol, 1998], although the removed volume is unknown.

A bathymetry was carried out in February 1986 [CEH, 1987]. The storage value was 91.761 $\mathrm{Hm}^{3}$. During this bathymetry, the $\mathrm{dBD}$ of the bottom deposits was measured, resulting in $1.112 \mathrm{t} \mathrm{m}^{-3}$. In 1988, following Armengol [1998], the deposit was thought to occupy $5 \mathrm{Hm}^{3}$, and, therefore, the estimated capacity was $87.2 \mathrm{Hm}^{3}$, although no bathymetry was carried out.

The next bathymetry was carried out in December 1993 [CEH, 1994], and provided a storage capacity of $75.940 \mathrm{Hm}^{3}$ [Avendaño Salas and Cobo Rayán, 1998]. This value, which appears in many papers and official documents, can be considered as very reliable.

In 1995 a seismic study of the Barasona reservoir was conducted, and the bottom deposit was estimated at around 16-18 $\mathrm{Hm}^{3}$ [Sanz Montero et al., 1996; Alatorre et al., 2010]. This conclusion provides a water storage capacity of $75 \mathrm{Hm}$. Nevertheless, this value cannot be considered very precise and reliable, given that the estimation methodology is unknown and the tolerance interval is very broad $\left(-/+1 \mathrm{Hm}^{3}\right)$.

In the years 1995, 1996 and 1997, three flushing operations were carried out, respectively [Avendaño Salas and Cobo Rayán, 1998]. These operations are very well documented by an ecological point of view, such as the riverine ecosystem impact [Armengol, 1998; Avendaño Salas and Cobo Rayán, 1998; Palau Ybars, 1998], but the sediment volume extracted it is not well quantified. In some studies, the value of $9 \mathrm{Hm}^{3}$ extracted can be found [LópezTarazón et al., 2012], although this data cannot be considered reliable.

In 1998, the CEDEX carried out a third bathymetry, in which the capacity was estimated at $84.798 \mathrm{Hm}^{3}$ [Avendaño Salas and Cobo Rayán, 1998]. This value can be considered reliable.

Within the framework of the SESAM project (Sediment Export from Semi-Arid Catchments ${ }^{11}$ ), an European Reserch Project, funded by the European Union and

${ }^{11}$ http://brandenburg.geoecology.uni-potsdam.de/projekte/sesam/index.php 
participated by the Potsdam University, the Geoscience German Research Centre (GFZ), the University of Lleida and the University of Ceara (Brasil), two bathymetries were carried out in 2006 and 2007. These results are contained into the project final report [Mueller and Francke, 2008] and in the G. Mamede PhD thesis, cited several times within this dissertation. The measured storage capacity was $75.78 \mathrm{Hm}^{3}$ in June 2006 and $75.18 \mathrm{Hm}^{3}$ in May 2007.

Using the storage values mentioned up to now, four periods were chosen between bathymetries, which is used for calibration and validation of the sedimentological submodel. The data can be seen in Table 7.9. The first two periods must be considered highly unreliable because of the uncertainty on the extracted volume, and is not used for model calibration and validation.

The sedimentological sub-model was calibrated adjusting the sedimentological sub-model correction factors for reproducing the 1998-2006 sediment accumulation, and it was validated against the other period. This period was selected because it is considered the most representative of the total series, and because the hydrological sub-model calibration was also carried out in a part of that period (2005-2007). The period 2006-2007 was considered too short to be representative of the Ésera River sediment cycle. The model results are shown in Table 7.10.

\begin{tabular}{ccc}
\hline Period & $\begin{array}{c}\text { Accumulated } \\
\text { sediments } \mathrm{Hm}^{3}\end{array}$ & Specific SY t ha ${ }^{-1}$ year $^{-1}$ \\
\hline $1972-1986$ & 32.53 & 16.90 \\
$1988-1993$ & 11.26 & 16.30 \\
$1998-2006$ & 9.02 & 8.20 \\
$2006-2007$ & 0.60 & 4.35 \\
\hline
\end{tabular}

Table 7.9 -Sediment deposited into the Barasona reservoir.

\begin{tabular}{cccc}
\hline Period & $\begin{array}{c}\text { Observed volume } \\
\mathbf{H m}^{3}\end{array}$ & $\begin{array}{c}\text { Simulated volume } \\
\mathbf{H m}^{3}\end{array}$ & VE \% \\
\hline $1998-2006$ & 9.02 & 9.02 & $0 \%$ \\
$2006-2007$ & 0.60 & 0.76 & $23 \%$ \\
\hline
\end{tabular}

Table 7.10-Calibration and validation results of the TETIS sedimentological sub-model at the Barasona reservoir.

The model results can be considered satisfactory, taking into account the high uncertainty lying behind the calibration data. Once the model was calibrated and validated, the depositional history of the Barasona reservoir was reconstructed, from 1998 to 2008. The results are shown in Figure 7.17. The period 1972 - 1998 was also simulated; nevertheless, given that the extracted volumes are unknown and the land use change, which was relevant in this area during that period [Navas et al., 2007], was not taken into account, no comparison can be made between model results and observations. As can be seen in Figure 7.17., the most relevant reservoir storage losses correspond to the highest water discharge peaks, although the relationship is not directly proportional, due mainly to the rainfall 
spatial variability and to the antecedent conditions of deposited sediment in the stream network.

\begin{tabular}{cc}
\hline Correction factor & Value \\
\hline$\alpha$ & 4.2 \\
$\beta_{1}$ & 3.0 \\
$\beta_{2}$ & 3.0 \\
\hline
\end{tabular}

Table 7.11 - Sedimentological sub-model correction factors for the Ésera River daily model.

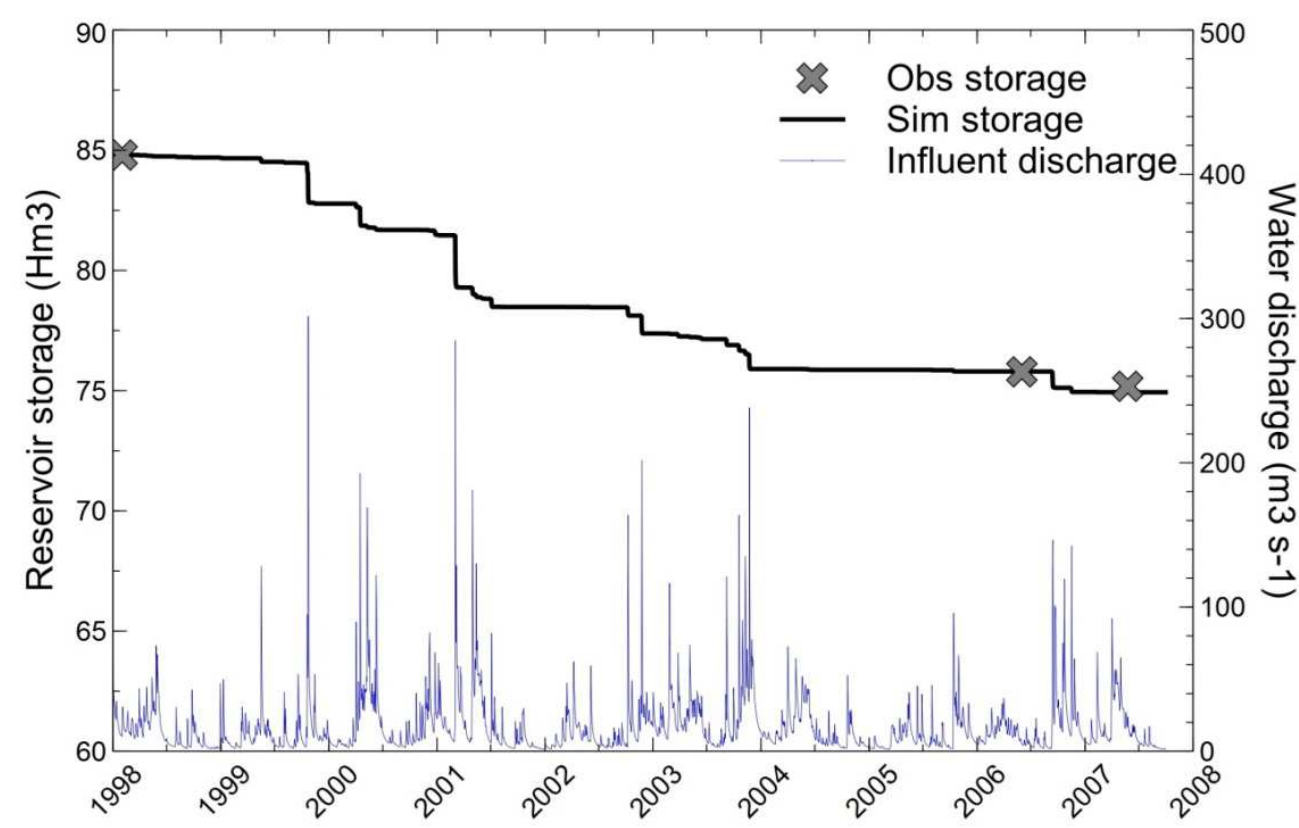

Figure 7.17-Observed and simulated storage capacity variation of the Barasona reservoir.

The simulated sediment texture is $5 \%$ of sand, $50 \%$ of silt and $45 \%$ of clay. Comparing this result with the measured texture of the deposited sediment inside the reservoir (1986 bathymetry), it can be observed that the model obtain a very good approximation, although the simulated sediment is slightly more clayey. This is because the TE was not computed for each textural class, given that the TE calculated by Brune curves does not depend on the sediment texture. The coarser sediment is trapped more easily into the reservoir than the finer material, and, for this reason, the simulated texture is slightly finer than the observed one.

In Figure 7.18 the temporal variation of the $\mathrm{dBD}$ and the TE is shown.

Concerning the $\mathrm{dBD}$, the Figure 7.18 shows that, although the mean deposit density value does not change a lot during time (the range of variation is $1.03-1.04 \mathrm{t} \mathrm{m}^{-3}$ ), the general trend is to the consolidation of the deposit with an increase of the bulk density, only contrasted by the highest sediment loads brought by the most extreme events, which makes the dBD decrease. 
The mean value is not far from the measured value of $1.112 \mathrm{t} \mathrm{m}^{-3}$. . Given the high uncertainty of the consolidation process, the error can be considered very small. The difference can be due to consolidation processes that took place during the drawdown periods and the Miller formula does not take into account.

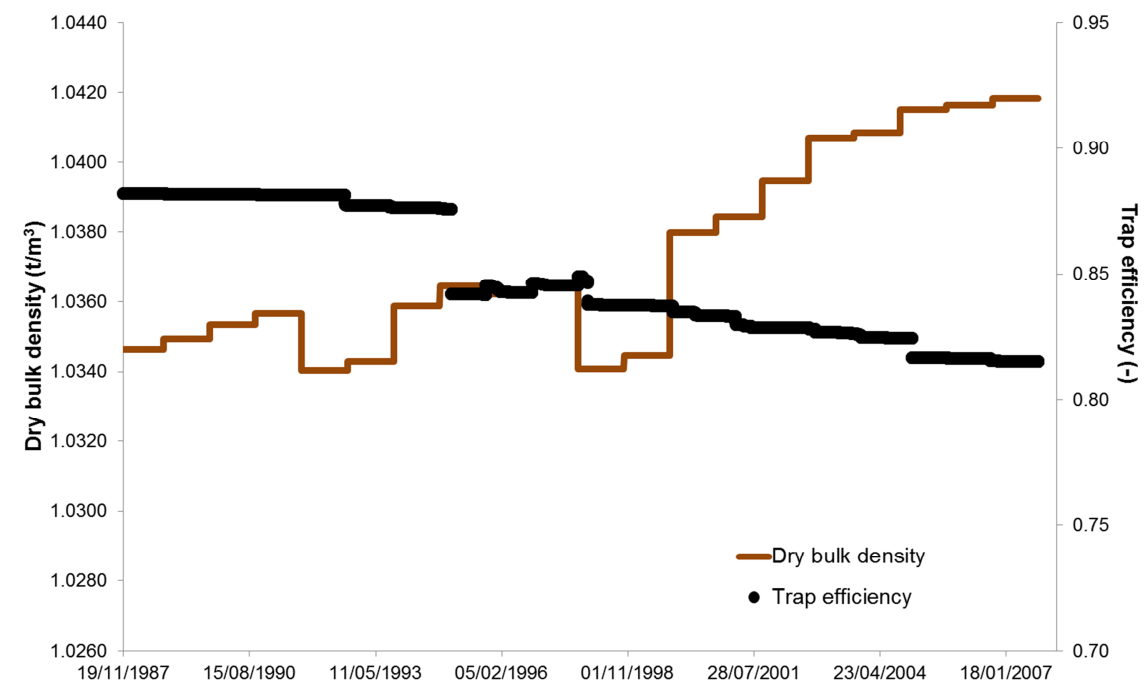

Figure 7.18 - Simulated $d B D$ and TE of the Barasona reservoir.

The calculated TE variations follow the reservoir capacity variations. The Brune curves do not estimate the event-scale TE, but rather the long-term TE, and for this reason, the TE values cannot be considered as corresponding to each flood event. The variations are small, and the range of values spans from 0.82 to 0.84 .

In order to properly validate the Ésera River catchment model, the suspended sediment data gauged at the Capella station (Isábena River) were used. This series only quantifies the suspended sediment discharge, while the TETIS model uses a total load equation (Engelund and Hansen equation) and provides this variable; therefore the two quantities are not comparable. However, the comparison between the series can provide interesting conclusions, such as the magnitude order of the transport processes. Moreover, as stated before, the suspended sediment of the Isábena River represents a high percentage of the total transport.

Results can be seen in Figure 7.19. It can be noticed that the TETIS model overestimates the observed sediment discharge, coherently with what stated above. In order to carry out a more detailed analysis, the Capella series was separated into three relevant periods, as shown in Figure 7.20. 


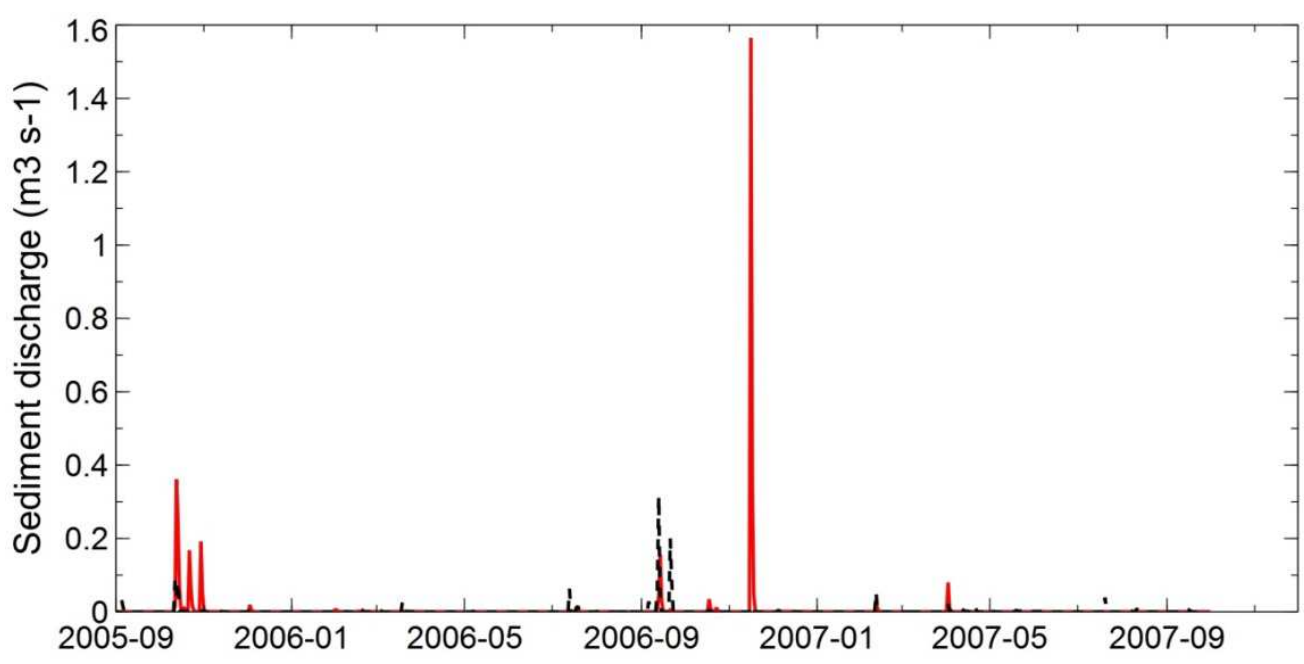

Figure 7.19 - TETIS sedimentological sub-model validation vs gauged suspended sediment at the Capella station.

A first period with medium intensity events can be seen (maximum simulated discharge $=$ $0.4 \mathrm{~m}^{3} \mathrm{~s}^{-1}$ ), a second high intensity period (maximum simulated discharge $=1 \mathrm{~m}^{3} \mathrm{~s}^{-1}$ ) and a third low intensity period (maximum simulated discharge $=0.08 \mathrm{~m}^{3} \mathrm{~s}^{-1}$ ).

Analysing these graphs (Figure 7.20), it can be concluded that the model is forecasting in the majority of the cases the sediment mobilisation, i.e. whether sediment transport takes place or not. The model reproduces adequately the low intensity events but overestimates the high intensity ones. The observed but not simulated peaks in Figure 7.20 (centre and left) correspond to rainfall events not properly simulated by the hydrological sub-model. In fact, the simulated water discharge of those events underestimates the observed discharge, mainly due to the observed rainfall, which probably underestimates the actual rainfall. For example, for the non-simulated event depicted in Figure 7.20 (centre) (19 September 2006), the observed discharge was $33 \mathrm{~m}^{3} \mathrm{~s}^{-1}$, while the simulated discharge was $14 \mathrm{~m}^{3} \mathrm{~s}^{-1}$. Concerning the overestimated peaks of Figure 7.20 (left), the problem is the opposite: the hydrological sub-model overestimates the peaks of 22/10/2005 and 30/10/2005 (second and third peak in Figure 7.20-left), also due to rainfall overestimation.

The sediment transport non-linearity enhances the errors of the hydrological sub-model and enlarges the difference between observed and simulated sediment transport. Nonetheless, both the hydrological and the sedimentological sub-model behaviours can be considered satisfactory, given the spatial and temporal validation results and taking into account the errors in the input data (precipitation, water discharge and sediment discharge) and in the model parameter estimation.

Concerning the 16/11/2006 event (the huge peak in Figure 7.20-centre), given that the hydrological sub-model behaves correctly in this case, the sediement error is not due to hydrological model errors. A first explanation may be that the most severe events, such as the $09 / 2006$ and the $08 / 2005$, mobilise a great bed load, which was not measured, but it is not sufficient to explain it entirely, given that the sediment transported by the Isábena River 
is especially fine. Nevertheless, the model simulates a sand content of around $4 \%$, in accordance with reality.
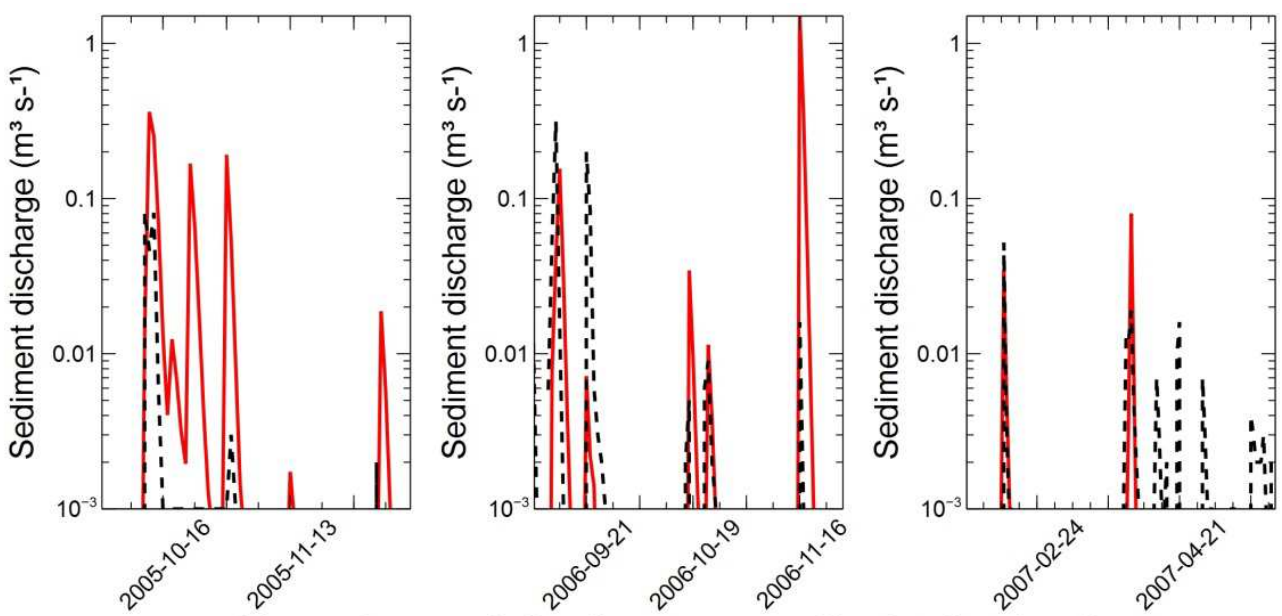

-... Observed suspended sediment

Simulated total sediment

Figure 7.20 - TETIS sedimentological sub-model validation against gauged suspended sediment at the Capella station (semi-log plot). Details of three time periods.

Another possibility regards the gauging methodology. The Capella data series was measured with a turbidimeter previously calibrated with manual samples. The turbidimeter measurements always carry a high uncertainty when the fluid concentration is elevated, due to particle size effect on water turbidity. This effect was firstly noticed during 80s [Olive and Rieger, 1988]. Nowadays, some authors are also critical with turbidimeter measurements in marly zones with badlands [Regüés and Nadal-Romero, 2012; Soler et al., 2012]. In particular, these authors, after studying the suspended sediment transport of a catchment similar to the Ésera catchment from a climatic and geomorphologic point of view, stated that a great underestimation of the sediment transport can occur when the transported material is mainly composed by silt and clay, and when the concentration overcomes a threshold (e.g. $100 \mathrm{~g} / \mathrm{l}$ ). The correction factor for adjusting the measure can be up to 5 or 6 , due to the fact that the hyper-concentrated flow has a higher transport capacity than still water. The Isábena River fulfils the conditions described by these authors, and, therefore, this is likely to be the main cause of the observed-simulated value difference for high intensity events, although it cannot be the only one, given that the difference between observed and simulated values is greater than what stated above. It is probably caused by a sum of errors (measure error, model error, bed load, etc.).

A very high variability can be seen in the annual sediment load. The annual specific SY varies between 0.06 and $68.72 \mathrm{t} \mathrm{ha}^{-1}$ (1976 and 1982 respectively), as the Figure 7.21 shows. Due to the high inter-annual variability of sediment load, three years of the whole series (1974, 1982 and 1997) account for the $44 \%$ of the total load. On the other hand, during the period 1986 - 1991 the sediment discharge to the Barasona reservoir was especially small (between 0.44 and $1.63 \mathrm{t} \mathrm{ha}^{-1}$ ). 


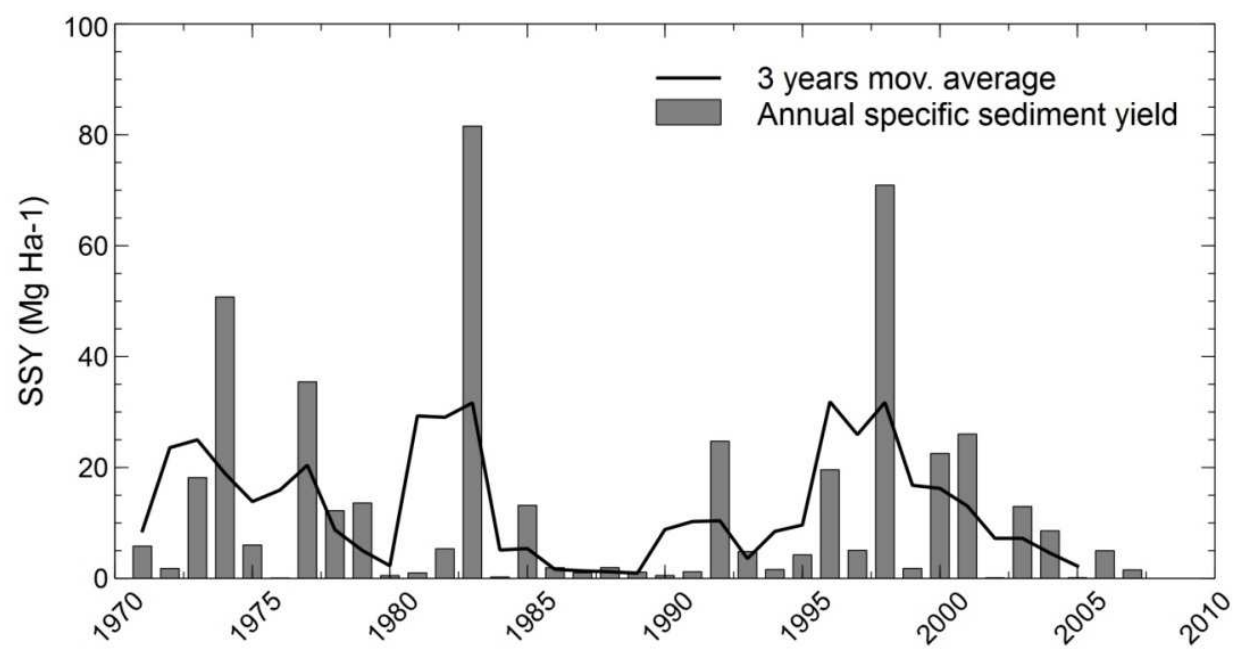

Figure 7.21 - Simulated annual specific SY at the Barasona reservoir.

The average inter-annual SY following model results is $12.50 \mathrm{t} \mathrm{ha}^{-1} \mathrm{y}^{-1}$. This value is higher than the one provided by Avendaño Salas et al. [1995], which was $3.50 \mathrm{t} \mathrm{ha}^{-1} \mathrm{y}^{-1}$ [Batalla and Vericat, 2011]. This difference is due to two factors. The first one is that the analysis by Avendaño Salas et al. [1995] covered from 1932 to 1995; given the extreme inter-annual variability of the Ésera River sediment transport, during this large period of time the mean annual SY may have been very different, although this is in contrast with the conclusions of Valero-Garcés et al. [1999], who analysed the sedimentation rate of the Barasona reservoir by means of several cores, and found smaller sedimentation rates for the 1970-1990 period than for the preceding periods. The second possible reason is that Avendaño Salas et al. [1995] probably did not considered the dredging and flushing operations carried out along the Barasona reservoir history, which could bring the authors to a substantial underestimation.

The value of specific SY calculated in this study $\left(12.50 \mathrm{tha}^{-1} \mathrm{y}^{-1}\right)$ is also higher than the value provided by Alatorre et al. [2010] (3.70 t ha $\mathrm{y}^{-1}$ ), although the authors stated that their model was calibrated only on three years of gauged sediment transport, and might not be representative of the sediment dynamics of the Barasona catchment. Alatorre et al. [2010] calibrated the WATEM/SEDEM model from May 2005 to May 2008, obtaining a specific SY of $4.40 \mathrm{t} \mathrm{ha}^{-1} \mathrm{y}^{-1}$ for the Isábena sub-catchment at the Capella station. The difference between the results of Alatorre et al. [2010] and this study may be due to the choice of the calibration period. In this study, a larger calibration period was chosen, including large rainfall events.

Concerning the hillslope erosion, the Figure 7.22 shows the TETIS model output map of parental material erosion. The most eroded zones correspond to the zones with highest slopes (headwater) and to the central marl strip which originated badland formations. This observation is confirmed by López-Tarazón et al. [2012], who studied the Isábena River dynamics. These authors identified the most erodible zones within the headwaters, 
especially corresponding with the badland areas. Valero-Garcés et al. [1999] also found that the Pyrenean Internal Ranges (to which the central marl strip belongs) constitute the area with the highest erosion hazard, based on comparative mineralogical studies of the Ésera river channels and the Barasona reservoir sediment.

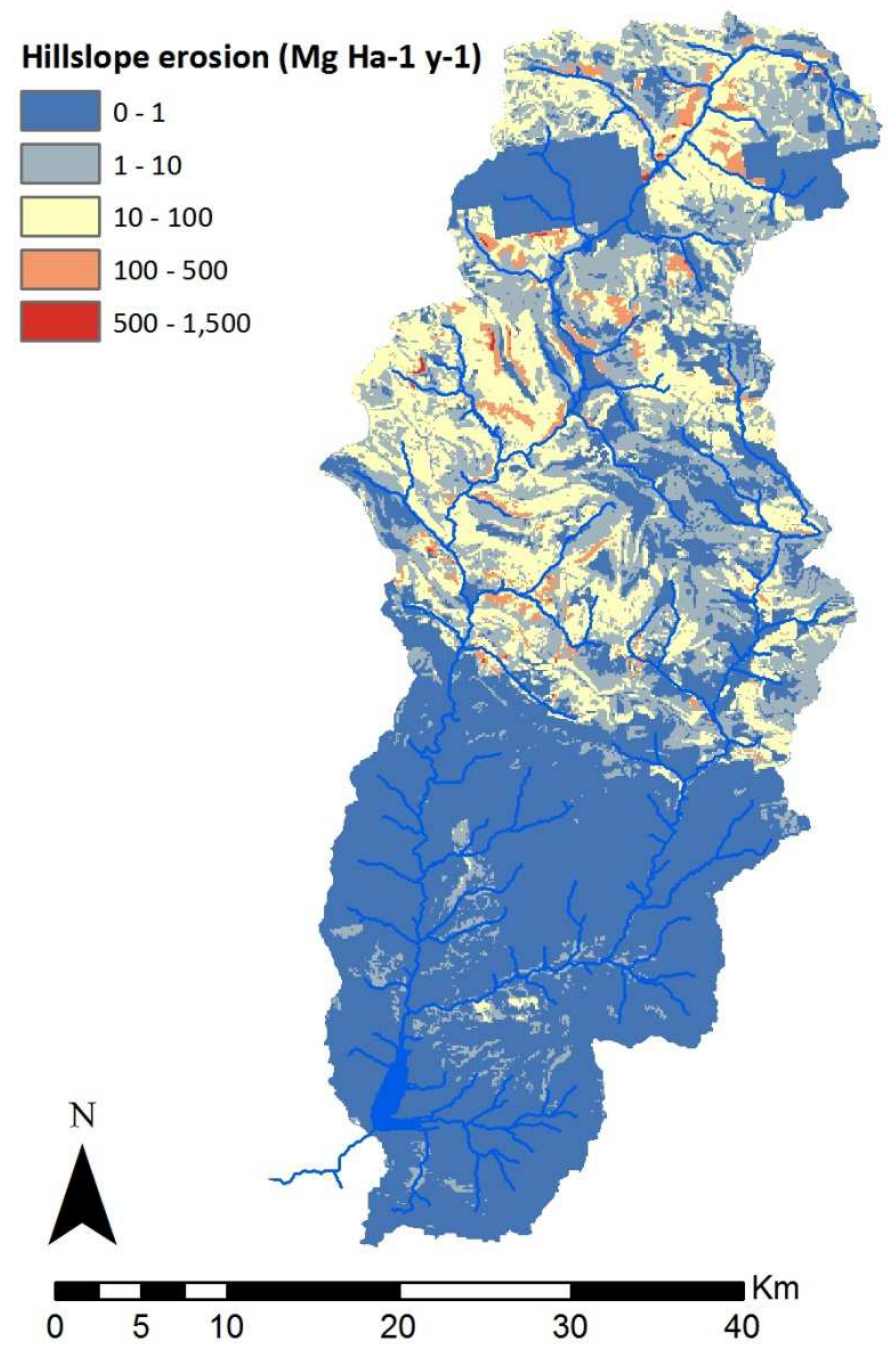

Figure 7.22 - Erosion sources within the Ésera Catchment.

This last result can also be compared with the conclusions of Alatorre et al. [2010], which stated that the principal sources of erosion are the badlands area on the marl strip in the middle part of the catchment and in those areas of the headwater with high elevation and sparse land cover, although they suggest that the marl area has a better connectivity with the drainage network than other zones of the catchments. These statements substantially 
agree with the conclusions of this study. The soil erosion values on the hillslope of the badlands areas vary between 1 and $100 \mathrm{t} \mathrm{ha}^{-1} \mathrm{y}^{-1}$. These values agrees with the soil erosion values measured by other authors in similar areas of the Spanish Pyrenees, such as GarcíaRuiz et al. [2008] and Gallart et al. [2005].

The hillslope erosion computed by the model can also be contrasted with the study of Cerdà and Lasanta [2005], who measured the soil erosion of some plots located in the Central Pyrenees, with slope ranging from 30 to $60 \%$ and shrubland cover. For similar plots, the model provided an erosion rate ranging between 0.02 and $0.6 \mathrm{t} \mathrm{ha}^{-1} \mathrm{y}^{-1}$. Cerdà and Lasanta [2005] measured, for natural plots, a soil erosion rate around $0.1 \mathrm{tha}^{-1} \mathrm{y}^{-1}$, which is comparable to the results obtained by the model.

One of the main advantages of using a model such as TETIS, which can be employed both at the continuous simulation and the event scale, compared to other models which only provide the mean annual specific SY, is that its model results allow carrying out an analysis at the daily scale. In the Figure 7.23, the model results at the Barasona inlet are presented, in terms of daily sediment volume, from 1970 to 2008.

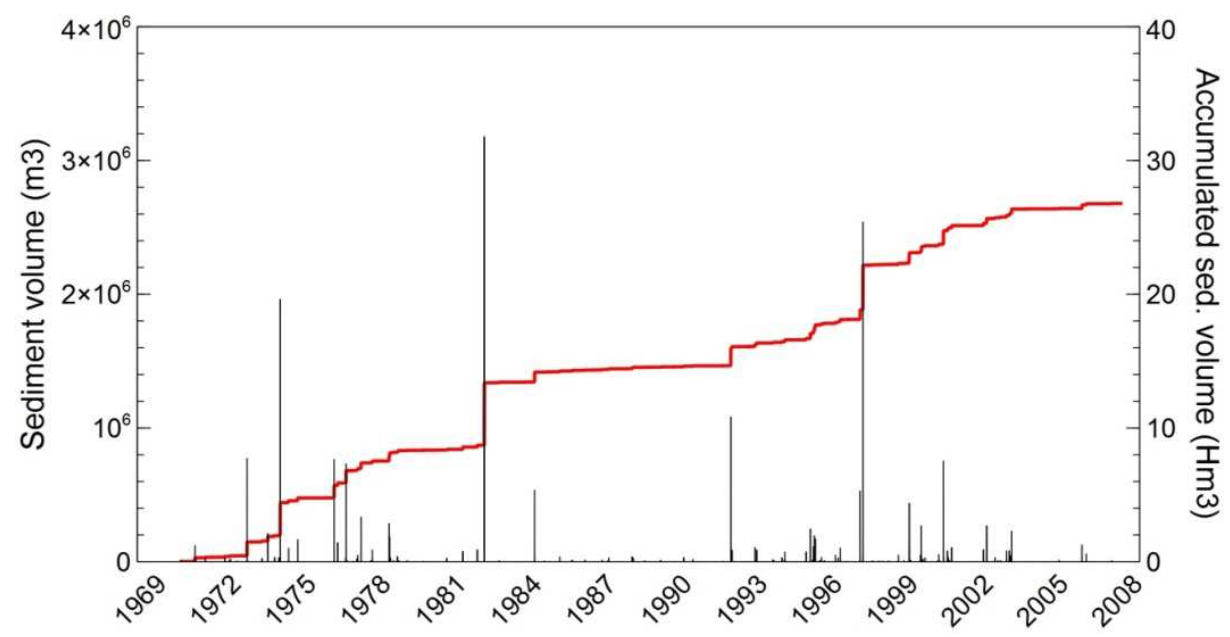

Figure 7.23 - Simulated daily sediment volume series (actual in black and accumulated in red) at the Barasona reservoir inlet.

In Figure 7.23, the high intermittency of the sediment transport can be seen. Sediments are only mobilised corresponding to flood peaks, while base flow carries a negligible volume of sediments. Three major events can be identified: November 1982 (sediment volume: 3.2 $\mathrm{Hm}^{3}$ ), December $1997\left(2.5 \mathrm{Hm}^{3}\right)$ and September $1974\left(2.0 \mathrm{Hm}^{3}\right)$. These three events account for the $30 \%$ of the total sediment transport of the whole series (from 197 to 2008). This phenomenon, called time compression, was observed in several catchment, e.g. Gallart et al. [2005] or Gonzalez-Hidalgo et al. [2012] and shows the highly non-linear relationship between water and sediment discharge. Event-based analysis is fundamental for timecompressed phenomena such as soil erosion and sediment transport, which only occur during short time windows [González-Hidalgo et al., 2013]. In case that no gauged data are 
available for this kind of analysis, distributed models can be used. The 5 largest events account for the $37 \%$ of the total volume between 1970 and 2008, while the largest 25 events accounts for the $68 \%$. These results agree with the conclusions of Gonzalez-Hidalgo et al. [2013], who found similar results for catchments of the same size located in North America.

Regarding the Ésera River catchment, although the water flow is divided into $4 \%$ of direct flow, $26 \%$ interflow and $70 \%$ base flow following the results of the hydrological model, the great majority of the sediment mobilisation occurs with direct runoff. This is because direct runoff is one of the main causes of the soil erosion, but it also demonstrates that the sediment dynamics of the Ésera River catchment is dominated by headwater hillslope erosion, while gully and channel transport plays a secondary role. This statement was also stressed by López-Tarazón et al. [2009], who analysed a group of 73 floods of the Isábena River and found that the majority of them (57\%) showed a counterclockwise hysteresis loop in a water discharge - sediment concentration plot, which means that sediment is mainly generated in headwater areas.

\subsection{Conclusions}

In this study another application of the TETIS model was presented. In this case, the TETIS model was applied to the Ésera River catchment, located in the Central Southern Pyrenees (Spain). The catchment is drained by the Barasona reservoir. Rainfall, temperature and water discharge are monitored at various points within the catchment. Suspended sediment discharge is continuously monitored since 2005 at one section.

In this chapter, the TETIS sedimentological sub-model was calibrated and validated through the sediment accumulated volumes at the bottom of the Barasona reservoir. This is possible thanks to various bathymetries carried out along the reservoir life. In order to check the correct functioning of the TETIS sedimentological sub-model, it was verified against the gauged suspended sediment data series, measured at the Capella station (Isábena River, the main Ésera River tributary).

The scientific interest of this study is the implementation of a conceptual distributed sediment model without any sediment discharge data for calibration (the gauged sediment series was only used to verify the model performances). Large reservoirs are usually monitored, and their capacity through the years is normally known, so that the methodology employed in this chapter can be used for all catchments drained by a large reservoir.

Furthermore, the Ésera River catchment is highly erodible due to the geological origin of some of its soils, with generated many badlands. It is, therefore, of interest to apply the TETIS model to such a catchment and check its performances.

The procedure followed in this study is simple. First of all, the sedimentological history of the Barasona reservoir, i.e. the evolution of reservoir storage capacity in time, was reconstructed through a literature analysis. Then, the reservoir storage capacity evolution 
was used to calibrate and validate the TETIS sedimentological sub-model, taking into account the sediment TE of the reservoir and the $\mathrm{dBD}$ of the deposit. Lastly, the model results were verified and analysed by comparing them to the measured sediment discharge at Capella station. The results show a good behaviour of the TETIS model, taking into account the really high uncertainty affecting all parts of this methodology, such as for example the deposited sediment estimation.

The model behaviour is generally satisfactory concerning the material detachment and mobilisation. The model reproduces in an acceptable way the small and medium magnitude events, although the error made in the high magnitude event simulation is greater. This error can also be done to the measurement technique (turbidimeter).

The main contributions of this chapter are:

- $\quad$ The TETIS model was successfully applied to a catchment without any sediment records, using the accumulated volumes of sediment trapped by a large reservoir as an estimate of the SY.

- $\quad$ The TETIS model could reproduce the sediment cycle dynamics of a highly erodible Pyrenean catchment with land degradation problems and high sediment transport rates.

- The data employed in this modelling study is available on the whole Spanish territory. The methodology used in this study is transferable to every catchment drained by a large reservoir whose depositional history is known.

- The model implemented in this chapter can be used in the framework of the SCARCE project, in order to analyse the effect of the climate change on water resources and SY. 



\section{Conclusions}


In the last decades, mathematical modelling of environmental processes has become a widespread technique used by environmental professionals, engineers and public environmental agencies. Nevertheless, in many of the fields of environmental sciences the state of the art is far from having provided complete, reliable and transferable tools to modellers. Sediment cycle modelling is one of these fields. Given the high uncertainty affecting the sediment transport measurement, the scarcity of those measurements and the little understanding of the erosion and sediment transport processes at a larger scale than the plot, the hillslope or a small catchment, an error of the same magnitude of the modelled variable is often considered acceptable. For these reasons, it is essential to continue the research activity on sediment cycle modelling and model applicability.

This dissertation, as stated in the first chapter, has the principal aim of investigating the applicability of the TETIS water and sediment cycle mathematical model in different data availability scenarios. The great scientific and technical usefulness of this research effort is that, from a practical point of view, is often impossible to calibrate and/or validate sediment models due to the lack of data.

For this reason, this dissertation outlined the problem of model implementation, including satisfactory calibration and validation, in sediment ungauged catchment. In order to carry out this task, first of all, the TETIS model was implemented in a fully monitored experimental catchment. The goal was to check the correct functioning of the model and analyse its behaviour. Furthermore, the influence of sediment initial conditions on model calibration and validation was investigated. Three initial deposit estimation techniques were compared, and their performances were analysed and discussed, both in terms of sedigraph and hysteresis loop reproduction.

Then, the model was applied to other two catchments located in Spain, the Rambla del Poyo and the Ésera River catchments. These two catchments do not dispose of sediment transport continuous monitoring structures. The source of data for calibration and validation was represented by the accumulated volumes at the bottom of different reservoirs. These deposits, existing in some way behind every dam in the world, both in large and small reservoir, may provide valuable information about the catchment scale sediment cycle. They can provide qualitative information, which can be obtained through a stratigraphical analysis of sample cores extracted from the deposit, or quantitative information, such as the total mean annual SY, which can be provided by reservoir bottom deposits.

Reservoir deposits have been used in many occasions to determine the mean annual SY at the catchment scale, dividing the accumulated volume by the number of years and the catchment extension, and taking into account the deposit density and the reservoir sediment TE. Nevertheless, mean annual SY does not describe the catchment sedimentological behaviour neither provides information regarding the hydrosedimentological response of the catchment to heavy rainfall events.

As stated in the introduction, this dissertation was carried out in order to demonstrate the great potential offered by sediment proxy data such as reservoir bottom deposits for model calibration and validation. This dissertation also offered different techniques for proxy data 
exploitation depending on the situation and the reservoir. With the aim of taking the maximum advantage of the indirect information provided by reservoir deposits, this dissertation proposed the use of them for model calibration, employing the TETIS hydrological and sediment model. A hydrological and sediment model describes the rainfall - runoff transformation processes and the consequent soil erosion caused by water, the particle transport from hillslope to stream network and the deposition of these particles. The implementation of a sediment cycle model can provide further information about the sediment dynamics than the calculation of the mean annual SY using simple empirical formulae or accumulated volumes into reservoirs. The usefulness of a sediment model comes from its potential use for reproducing event scale SY, for erosion and deposition areas identification, for estimating SY in several points of the catchment, etc.

The dissertation was structured as follows.

- Following a short introduction and the explanation of some basic concept regarding soil erosion, transport and deposition processes, some of the most used sediment models have been briefly described, as well as some of their calibrationvalidation studies.

- Later, the last advances in SY estimation from proxy data have been showed, together with the procedures to follow for a correct exploitation of indirect data. In this part, the scientific need for this research activity was clarified, showing the utility of this kind of techniques and its lack in the field of sediment modelling.

- A short introduction on palaeohydrological techniques has been also presented, in order to state some basic concepts and to investigate the possible integration of palaeohydrological techniques into the proxy data exploitation process.

- The last advances of the TETIS model have been also presented. In this dissertation, some conceptual and practical improvements have been developed, such as the automatic calibration tool for the sediment correction factors and the reservoir sediment retention tool.

- The first case study presented in this dissertation is the Goodwin Creek experimental catchment. This application to a highly monitored catchment has allowed checking the positive model performances, demonstrating the importance of initial stream network sediment deposits and comparing different techniques for estimating them. The continuous simulation of a warm up period has proven to be the most reliable technique.

- The second case study has been the Rambla del Poyo catchment. In this case of study, a Mediterranean medium sized catchment has been modelled. This catchment, as the majority of semi-arid Mediterranean catchments, does not dispose of sediment transport records or measurements. This chapter has demonstrated that sediment deposits trapped behind check dams are a very useful source of sediment proxy data and allow to properly calibrate and validate a sediment model, given their frequent presence in Mediterranean catchments. This chapter has also demonstrated that, using palaeohydrological techniques for carrying out a stratigraphical analysis of the sediment reservoir deposits can improve strongly the amount of information for model calibration and validation, especially because it provide event-by-event information. 
- The third case study has also been implemented in the Rambla del Poyo catchment. In this case, the catchment has been considered as ungauged, i.e. without any sediment and water discharge record. In this chapter, the TETIS hydrological sub-model has been calibrated by only exploiting the stratigraphical description carried out in the previous chapter. This chapter shows that there is a strong transfer of information between the strongly inter-related water and sediment processes. This transfer of information allows constraining the model calibration.

- In the fourth case study, the TETIS model has been applied to a high erodible Pyrenean catchment, the Ésera River catchment (Central Southern Pyrenees, Spain). This catchment is drained by a large reservoir (named Barasona reservoir). The aim of this chapter was to calibrate and validate the TETIS sedimentological sub-model with volumetric estimations of accumulated sediment starting from bathymetries. The model has also been verified against measured suspended sediment data, showing satisfactory results. The model has been implemented using spatial and hydro-meteorological data freely available for all the Spanish territory, making this methodology totally transferable to other Spanish catchments.

\subsection{Main contributions}

The main contributions of this PhD dissertation have been separated into "contributions to the model structure", both from the conceptual and practical point of view, and "contributions to the model implementation".

The main contributions to the model structure are:

- A new automatic calibration tool for the sedimentological sub-model was developed, similar to the automatic calibration tool of the hydrological sub-model, already existing in TETIS. The tool is based on the SCE-UA algorithm.

- Three new correction factors were introduced in the sediment transport capacity equations in order to calibrate the model without altering the spatial pattern of the parameter maps.

- A new pre-processor for sediment initial conditions setting was integrated to the TETIS software, in order to manually define the deposited sediments in hillslope, gully and channel cells.

- A new sediment TE module was integrated in the TETIS model, based on the STEP (Sediment Trap Efficiency for small Ponds) model, with the goal of reproducing the sedimentation dynamics inside a small reservoir such as a check dam reservoir.

And the main contributions to the model implementation are:

- A new calibration technique was implemented in case of large data availability, based on two calibration steps (a first calibration of the hillslope and gully correction factors in a headwater sub-catchment and a second calibration of the river channel correction factor at the catchment outlet). 
- The relevance of the initial condition of deposited sediment at the beginning of a rainfall event was proven, providing and comparing various methods of stream network deposited sediment estimation. The continuous simulation of a warm period resulted to be the most satisfactory methodology.

- Three initial deposit estimation strategies were tested and evaluated, and their applicability was defined.

- The great potential of reservoir sedimentation proxy data for sediment model calibration and validation was proven, demonstrating its applicability in different catchments, with different reservoirs, from large dams to small check dams and different data availability scenarios.

- The stratigraphical analysis of the reservoir sedimentation profile was integrated into the process of proxy data exploitation, providing a relevant improvement to the results.

- A transferable methodology was set up for hydrological and sediment model calibration and validation with no water and sediment discharge data availability. This methodology is applicable to several semi-arid catchments.

- A methodology for implementing a sediment sub-model in a catchment drained by a large reservoir was set up, taking into account dry bulk density and trap efficiency variations.

\subsection{Limitations and future research lines}

The research activity contained in this $\mathrm{PhD}$ dissertation has some limitations which could be overcome by conducting future research on the topics listed as follows.

Probably the most relevant limitation of this dissertation is that predictive uncertainty of model results was not assessed, despite its high relevance. Model results must not only match observations, but also hold as less uncertainty as possible (often represented as narrow uncertainty bounds). This problem has been deeply analysed for hydrological models [e.g. Beven and Binley, 1992; Krzysztofowicz, 1999; Todini, 2007], and it is still being an important research interest at the present time. Some attempts were also made for sediment models [Quinton, 1997; Brazier et al., 2000]. A demonstration of the importance of model uncertainty is provided in section 4.3.2. In the Goodwin Creek case study, the TETIS model obtains very good results in terms of sedigraph reproduction, but, in spite of that, hysteresis loop analysis shows that the model is not reproducing satisfactorily the sediment transport and the sediment dynamics within the catchment. An uncertainty analysis would probably have enhanced this problem too. For this reason, sediment model predictive uncertainty assessment should be a future research line.

For calibration and validation of the TETIS sedimentological sub-model at the Goodwin Creek catchment (chapter 4), only fine sediments (particle diameter $<0.062 \mathrm{~mm}$ ) were used, because these data were the only available on the Ars-USDA webpage. Given that the aim of the work was to check model behaviour and to carry out some considerations about initial deposits, this choice was justified. However, it will be of interest to repeat the application using the total sediment discharge series [Kuhnle et al., 1989] for calibration and 
validation, in order to analyse the differences on the correction factors and on the hysteresis loops.

In the Rambla del Poyo application (chapter 5), some field work limitation affected the study. For example, the reservoir volumes were calculated making the hypothesis that the reservoir shape is half-pyramidal. This hypothesis can be unfulfilled in some cases. Other methodologies for accumulated sediment volume estimation need to be developed, for instance based on topographical surveys or geophysical techniques. Another possibility is to repeat the experiment in a reservoir whose topography was known before the reservoir filling.

In the same study, the date assignment of flood units was carried out by the reconstruction of the hydrological regime. This procedure holds a relevant uncertainty. Alternative techniques may be used, such as isotopes tracing $\left({ }^{14} \mathrm{C}\right.$ or $\left.{ }^{137} \mathrm{Cs}\right)$.

Concerning the chapter 6 (transfer of information from sediment proxy data to the hydrological sub-model in the Rambla del Poyo catchment), the transferability of the methodology should be checked by applying it to other catchments with a different size, different geological origin and different hydrological response. This would be necessary because the Rambla del Poyo catchment has a quite simple hydrological behaviour (the hydrological response is almost entirely direct runoff), and soils are mainly sandy and originating from limestone. In other catchments with different characteristics, the application of this methodology will surely raise new research questions.

The Ésera River catchment application (chapter 7) was developed starting from bathymetry data. This procedure always holds high uncertainty concerning reservoir storage estimation, $\mathrm{dBD}$ estimation and TE estimation. In order to reduce this uncertainty, it is advisable to measure directly the $\mathrm{dBD}$, to validate the model with future events and to try alternative methods for TE estimation.

Apart of these considerations about the limitations of this dissertation, some further research lines can be identified.

Firstly, the simulation time step used in this study was different depending on the problem to be solved. Nevertheless, the scale effect on the sediment cycle reproduction has not been investigated yet, as well as its effects on the correction factors of the model effective parameters and on the model results.

Secondly, a mathematical model result of a research activity has to be meant as a constantly developing tool. For this reason, it is important to continue with the model development, incorporating processes which, nowadays, are not taken into account, such as gravel transport, landslides and other local contribution to the total load, or the effect of forest roads on the sediment production. Moreover, as it has been illustrated in this dissertation, the parameterisation of the effect of wildfires has not been defined clearly, and could be studied more in deep.

An additional element to be further investigated is the gully initiation phenomenon. In TETIS, this is modelled using the threshold area concept. Nevertheless, it has been widely 
shown that gully initiation depends on both contributing area and hillslope gradient (e.g., see Desmet et al. [1999]). This aspect should be included into TETIS in order to better define the location of hillslope/gully threshold.

Furthermore, the TETIS model could be the base for developing a landscape evolution model, or a more comprehensive environmental model, integrating processes at different time and spatial scales. The TETIS model, as seen for many model in literature, can also be the basis for a contaminant transport model, given that many contaminants are carried by sediment particles.

From an operational point of view, it seems that an exhaustive sensitivity analysis should be carried out in order to asses model parameter influence on model results and to possibly reduce model complexity. This analysis should include the effect of data quality on model results, given that uncertainties affecting sediment data are sometimes of the same order of magnitude of uncertainties affecting model parameters and model conceptualization. Furthermore, the effect of introducing other input data on model predictions accuracy should also be considered.

Lastly, coupling palaeohydrological techniques and stratigraphical reconstructions to distributed environmental modelling may provide interesting perspectives for the future development and application of hydrological and sediment models, and must be investigated further. 



\section{References}


Ackermann, W. C., and R. L. Corinth (1962), An empirical equation for reservoir sedimentation, in Symposium of Bari (Italy), International Association of Hydrological Sciences Publication 59, pp. 359-366, Bari (Italy).

Aksoy, H., and M. L. Kavvas (2005), A review of hillslope and watershed scale erosion and sediment transport models, Catena, 64(2-3), 247-271, doi:10.1016/j.catena.2005.08.008.

Alatorre, L. C. (2010), Erosión del suelo y fuentes de sedimento en la cuenca del río Ésera (Pirineo Central). Analisis espacial y dinámica temporal mediante técnicas de simulación y teledetección. PhD Thesis, 256 pp., Universidad de Zaragoza.

Alatorre, L. C., S. Beguería, and J. M. García-Ruiz (2010), Regional scale modeling of hillslope sediment delivery: A case study in the Barasona Reservoir watershed (Spain) using WATEM/SEDEM, J. Hydrol., 391, 109-123, doi:10.1016/j.jhydrol.2010.07.010.

Alatorre, L. C., S. Beguería, N. Lana-Renault, A. Navas, and J. M. García-Ruiz (2012), Soil erosion and sediment delivery in a mountain catchment under scenarios of land use change using a spatially distributed numerical model, Hydrol. Earth Syst. Sci., 16, 1321-1334, doi:10.5194/hess-16-13212012.

Allen, R. G., L. S. Pereira, and D. Raes (1998), Crop evapotranspiration - Guidelines for computing crop water requirements., in FAO Irrigation and drainage paper 56.

Almorox, J., R. de Antonio, A. Saa, M. Cruz Díaz, and J. M. Gascó (1994), Metodos de estimación de la erosión hídrica, Editorial Agrícola Española S.A.

Alonso, C. V. (1996), Hydrologic research on the USDA Goodwin Creek experimental watershed, northern Mississippi, pp. 25-36.

Anderson, J. D. (1995), Computational Fluid Dynamics; the Basics with Applications, McGraw-Hill, New York.

Andrés-Doménech, I., J. C. Múnera, F. Francés, and J. B. Marco (2010), Coupling urban event-based and catchment continuous modelling for combined sewer overflow river impact assessment, Hydrol. Earth Syst. Sci., 14, 2057-2072, doi:10.5194/hess-14-2057-2010.

Andreu, V., A. C. Imeson, and J. L. Rubio (2001), Temporal changes in soil aggregates and water erosion after a wildfire in a Mediterranean pine forest, Catena, 44, 69-84, doi:10.1016/S03418162(00)00177-6.

Antolín Tomás, C. (1998), El suelo como recurso natural en la Comunidad Valenciana, Consellería de Obras Públicas, Urbanismo y Transportes, Generalitat Valenciana, Valencia.

Armengol, J. (1998), Efectos ecológicos del dragado y vaciado del embalse de Barasona, Limnética, 14, 17-33.

Arnold, J. G., R. Srinivasan, R. S. Muttiah, and J. R. Williams (1998), Large area hydrologic modeling and assessment. I. Model development., JAWRA J. Am. Water Resour. Assoc., 34 (1), doi:10.1111/j.1752-1688.1998.tb05961.x.

Avendaño Salas, C., and R. Cobo Rayán (1997), Metodología para estimar la erosión de cuencas fluviales a partir de la batimetría de embalses, in El paisaje mediterráneo a través del espacio y del tiempo. Implicaciones en la desertificación, edited by J. J. Ibáñez, B. L. Valero Garcés, and C. Machado, pp. 239-258, Geoforma Ediciones, Logroño.

Avendaño Salas, C., and R. Cobo Rayán (1998), Seguimiento de los sólidos en suspensión durante el vaciado del embalse de Joaquín Costa, Limnética, 14, 113-120.

Avendaño Salas, C., R. Cobo Rayán, J. L. Gómez Montaña, and M. E. Sanz Montero (1995), Procedimiento para evaluar la degradación específica (erosión) de cuencas de embalses a partir de los sedimientos acumulados en los mismos. Aplicación al estudio de embalses españoles, Ing. Civ., 99, 51-58. 
Avendaño Salas, C., M. E. Sanz Montero, R. Cobo Rayán, and J. L. Gómez Montaña (1997), Sediment yield at Spanish reservoirs and its relationship with the drainage basin area., in Proceedings of the 19th Symposium of Large Dams, Florence. ICOLD (International Committee on Large Dams), pp. 863-874, Florence.

Baade, J., S. Franz, and A. Reichel (2012), Reservoir siltation and sediment yield in the Kruger National Park, South Africa: a first assessment, L. Degrad. Dev., 23(6), 586-600, doi:10.1002/ldr.2173. [online] Available from: http://doi.wiley.com/10.1002/ldr.2173 (Accessed 19 November 2013)

Baeza, M. J., A. Valdecantos, J. A. Alloza, and V. R. Vallejo (2007), Human disturbance and environmental factors as drivers of long-term post-fire regeneration patterns in Mediterranean forests, J. Veg. Sci., 18(2), 243-252, doi:10.1111/j.1654-1103.2007.tb02535.x.

Baker, V. R. (1983), Paleo flood hydrologic techniques for the extension of stream flow records., Transp. Res. Rec., 922, 18-23.

Baker, V. R. (1987), Paleoflood hydrology and extraordinary flood events, J. Hydrol., 96, 79-99, doi:10.1016/0022-1694(87)90145-4.

Baker, V. R. (2008), Paleoflood hydrology: Origin, progress, prospects, Geomorphology, 101, 1-13, doi:10.1016/j.geomorph.2008.05.016.

Batalla, R. J., and D. Vericat (2011), An appraisal of the contemporary sediment yield in the Ebro Basin, J. Soils Sediments, 11, 1070-1081, doi:10.1007/s11368-011-0378-8.

Beasley, D. B., L. F. Huggins, and E. J. Monke (1980), ANSWERS: A model for watershed planning, Trans. ASAE, 23(4).

Bellin, N., V. Vanacker, B. Van Wesemael, A. Solé-Benet, and M. M. Bakker (2011), Natural and anthropogenic controls on soil erosion in the Internal Betic Cordillera (southeast Spain), Catena, 87, 190-200, doi:10.1016/j.catena.2011.05.022.

Benet, J. M. (1983), La Albufera de Valencia. Datos para una política de soluciones, Rev. Obras Públicas, 167-180.

Benito, G., Y. Sánchez-Moya, and A. Sopeña (2003), Sedimentology of high-stage flood deposits of the Tagus River, Central Spain, Sediment. Geol., 157, 107-132, doi:10.1016/S0037-0738(02)001963.

Benito, G., V. R. Thorndycraft, M. Rico, Y. Sánchez-Moya, and A. Sopeña (2008), Palaeoflood and floodplain records from Spain: Evidence for long-term climate variability and environmental changes, Geomorphology, 101(1-2), 68-77, doi:10.1016/j.geomorph.2008.05.020.

Benito, G., M. Rico, Y. Sánchez-Moya, A. Sopeña, V. R. Thorndycraft, and M. Barriendos (2010), The impact of late Holocene climatic variability and land use change on the flood hydrology of the Guadalentín River, southeast Spain, Glob. Planet. Change, 70(1-4), 53-63, doi:10.1016/j.gloplacha.2009.11.007.

Bennett, J. P. (1974), Concepts of mathematical modeling of sediment yield, Water Resour. Res., 10(3), 485-492.

Bennett, N. D. et al. (2013), Characterising performance of environmental models, Environ. Model. Softw., 40, 1-20, doi:10.1016/j.envsoft.2012.09.011.

Beven, K. (1989), Changing ideas in hydrology: the case of physically-based models, J. Hydrol., 105(12), doi:10.1016/0022-1694(89)90101-7.

Beven, K. (2001), Rainfall-runoff modeling. The primer, Wiely, Chichester.

Beven, K., and A. Binley (1992), The future of distributed models: Model calibration and uncertainty prediction, Hydrol. Process., 6(3), 279-298, doi:10.1002/hyp.3360060305.

Beven, K., and M. J. Kirkby (1979), A physically based, variable contributing area model of basin hydrology, Hydrol. Sci. Bull., 24(1), 43-69, doi:10.1080/02626667909491834. 
Bhuyan, S. J., P. K. Kalita, K. A. Janssen, and P. L. Barnes (2002), Soil loss predictions with three erosion simulation models, Environ. Model. Softw., 17(2), 135-144, doi:10.1016/S1364-8152(01)000469.

Blackmarr, W. A. (1995), Documentation of hydrologic, geomorphic, and sediment transport measurements on the Goodwin Creek Experimental Watershed, northern Mississippi, for the period 1982-1993, preliminary release, US Dep. Agric. Natl. Sediment. Lab. Oxford, MS.

Blöschl, G. (2001), Scaling in hydrology, Hydrol. Process., 15(4), 709-711, doi:10.1002/hyp.432.

Boardman, J. (2006), Soil erosion science: reflections on the limitations of current approaches, Catena, 68(2-3), 73-86, doi:10.1016/j.catena.2006.03.007.

Boiten, W. (2003), Hydrometry, Taylor \& Francis.

Boix-Fayos, C., M. Martínez-Mena, A. Calvo-Cases, V. Castillo, and J. Albaladejo (2005), Concise review of interrill erosion studies in SE Spain (Alicante and Murcia): erosion rates and progress of knowledge from the 1980s, L. Degrad. Dev., 16(6), 517-528, doi:10.1002/ldr.706.

Boix-Fayos, C., J. de Vente, M. Martínez-Mena, G. G. Barberá, and V. Castillo (2008), The impact of land use change and check-dams on catchment sediment yield, Hydrol. Process., 22(25), 49224935, doi:10.1002/hyp.7115.

Bouraoui, F., and T. A. Dillaha (1996), ANSWERS-2000: Runoff and sediment transport model, J. Environ. Eng., 122(6), 493-502, doi:10.1061/(ASCE)0733-9372(1996)122:6(493).

Brath, A., A. Montanari, and E. Toth (2004), Analysis of the effects of different scenarios of historical data availability on the calibration of a spatially-distributed hydrological model, J. Hydrol., 291(3-4), 232-253, doi:10.1016/j.jhydrol.2003.12.044.

Brazier, R., K. Beven, J. Freer, and J. S. Rowan (2000), Equifinality and uncertainty in physically based soil erosion models: application of the GLUE methodology to WEPP-the Water Erosion Prediction Project-for sites in the UK and USA, Earth Surf. Process. Landforms, 25(8), 825-845, doi:10.1002/1096-9837(200008)25:8<825::AID-ESP101>3.0.CO;2-3.

Brown, C. (1943), Discussion of sedimentation in reservoir, in Proceedings of the American Society of Civil Engineers 69, edited by J. Witzig, pp. 1493-1500.

Brune, G. M. (1953), Trap efficiency of reservoirs, Trans. AGU, 34(3), 407-418.

Butcher, D. P., J. C. Labadz, W. R. Potter, and P. White (1993), Reservoir sedimentation rates in the Southern Pennine Region, in Geomorphology and sedimentology of lakes and Reservoirs, edited by J. McManus and R. Duck, pp. 73-92, Wiley, Chichester.

Callander, R. A., and J. N. Duder (1979), Reservoir sedimentation in the Rangitaiki River, New Zeal. Eng., 34(9), 208-215.

Camarasa Belmonte, A. M., and F. Segura Beltrán (2001), Flood events in Mediterranean ephemeral streams (ramblas) in Valencia region, Spain, Catena, 45(3), 229-249, doi:10.1016/S03418162(01)00146-1.

Campo, J., V. Andreu, E. Gimeno-Garcia, O. González, and J. L. Rubio (2006), Occurrence of soil erosion after repeated experimental fires in a Mediterranean environment, Geomorphology, 82(3-4), 376-387, doi:10.1016/j.geomorph.2006.05.014.

Castillo, V., W. M. Mosch, C. Conesa García, G. G. Barberá, J. A. Navarro Cano, and F. López-Bermúdez (2007), Effectiveness and geomorphological impacts of check dams for soil erosion control in a semiarid Mediterranean catchment: El Cárcavo (Murcia, Spain), Catena, 70(3), 416-427, doi:10.1016/j.catena.2006.11.009.

CEH (1987), Reconocimiento batimétrico del embalse de Barasona en Febrero de 1986.

CEH (1994), Reconocimientos batimétricos de embalses. Embalse de Barasona en Diciembre de 1993.

Cerdà, A. (1997), Seasonal changes of the infiltration rates in a Mediterranean scrubland on limestone, J. Hydrol., 198(1-4), 209-225, doi:10.1016/S0022-1694(96)03295-7. 
Cerdà, A. (1998a), Changes in overland flow and infiltration after a rangeland fire in a Mediterranean scrubland, Hydrol. Process., 12(7), 1031-1042, doi:10.1002/(SICI)10991085(19980615)12:7<1031::AID-HYP636>3.0.CO;2-V.

Cerdà, A. (1998b), Post-fire dynamics of erosional processes under Mediterranean climatic conditions, Zeitschrift für Geomorphol., 42(3), 373-398.

Cerdà, A. (1998c), Soil aggregate stability under different Mediterranean vegetation types, Catena, 32(2), 73-86, doi:10.1016/S0341-8162(98)00041-1.

Cerdà, A., and S. H. Doerr (2008), The effect of ash and needle cover on surface runoff and erosion in the immediate post-fire period, Catena, 74(3), 256-263, doi:10.1016/j.catena.2008.03.010.

Cerdà, A., and T. Lasanta (2005), Long-term erosional responses after fire in the Central Spanish Pyrenees, Catena, 60(1), 59-80, doi:10.1016/j.catena.2004.09.006.

Cerdà, A., R. Brazier, M. Nearing, and J. de Vente (2013), Scales and erosion, Catena, 102, 1-2, doi:10.1016/j.catena.2011.09.006.

Chen, C. (1975), Design of sediment retention basins, in Proceedings, National Symposium on Urban Hydrology and Sediment Control, pp. 285-298, University of Kentucky, Lexington, KY.

Churchill, M. A. (1948), Discussion of Analyses and use of reservoir sedimentation data, in Proceedings of the federal inter-agency sedimentation conference, pp. 139-140, US Geological Survey, Denver, Colorado.

Coulthard, T. J., M. J. Kirkby, and M. G. Macklin (1998), Non-linearity and spatial resolution in a cellular automaton model of a small upland basin, Hydrol. Earth Syst. Sci., 2(2-3), 257-264.

Cowpertwait, P., D. Ocio, G. Collazos, O. de Cos, and C. Stocker (2013), Regionalised spatiotemporal rainfall and temperature models for flood studies in the Basque Country, Spain, Hydrol. Earth Syst. Sci., 17, 479-494, doi:10.5194/hess-17-479-2013.

Dickinson, W. T., R. P. Rudra, and G. J. Wall (1986), Identification of soil erosion and fluvial sediment problems, Hydrol. Process., 1(1), 111-124, doi:10.1002/hyp.3360010110.

DIHMA (2001), Un Modelo de Predicción de Crecidas para el SAIH de la Confederación Hidrográfica del Tajo. Informe Final para UTE SAIH Tajo., Valencia.

Dissmeyer, G. E., and G. R. Foster (1984), A guide for predicting sheet and rill erosion on forest land, USDA, Forest Service, Southern Region, Atlanta, Ga. (USA).

Doe, W. W., and R. S. Harmon (2001), Introduction to soil erosion and landscape evolution modeling, in Landscape Erosion and Evolution Modelling.

Duan, Q., S. Sorooshian, and V. Gupta (1992), Effective and efficient global optimization for conceptual rainfall-runoff models, Water Resour. Res., 28(4), 1015-1031, doi:10.1029/91WR02985.

Duan, Q., V. Gupta, and S. Sorooshian (1993), Shuffled complex evolution approach for effective and efficient global minimization, J. Optim. Theory Appl., 76(3), 501-521, doi:10.1007/BF00939380.

Duan, Q., S. Sorooshian, and V. Gupta (1994), Optimal use of the SCE-UA global optimization method for calibrating watershed models, J. Hydrol., 158(3-4), 265-284, doi:10.1016/00221694(94)90057-4.

Duck, R., and J. McManus (1987), Sediment yields in lowland Scotland derived from reservoir surveys, Trans. R. Soc. Edinburgh, Earth Sci., 78, 369-377.

Duck, R., and J. McManus (1993), Sedimentation in natural and artificial Impoundments: an indicator of evolving climate, land use and dynamic conditions, in Geomorphology and sedimentology of lakes and Reservoirs, edited by J. McManus and R. Duck, Wiley.

Eder, A., P. Strauss, T. Krueger, and J. N. Quinton (2010), Comparative Calculation of Suspended Sediment Loads with Respect to Hysteresis Effects (in the Petzenkichen Catchment, Austria), J. Hydrol., 389(1-2), 168-176, doi:10.1016/j.jhydrol.2010.05.043. 
Einstein, H. A. (1951), The bed-load function for sediment transportation in open channel flows, Water Resour. Build., 43.

Einstein, H. A. (1964), Sedimentation, Part II: River sedimentation, in Handbook of Applied Hydrology, edited by V. T. Chow, McGraw-Hill, New York.

Engelund, F., and E. Hansen (1967), A monograph on sediment transport in alluvial streams, Monogr, Denmark Tech Univ, Hydraul Lab.

Farnham, C. W., C. E. Beer, and H. . Heinemann (1966), Evaluation of factors affecting reservoir sediment deposition, in Symposium of Garda (Italy): Hydrology of Lakes and Reservoirs, International Association of Hydrological Sciences Publication, pp. 747-758, Garda (Italy).

Favis-Mortlock, D., J. Boardman, and V. J. MacMillan (2001), The limits of erosion modelling: why we should proceed with care, in Landscape Erosion and Evolution Modelling, edited by R. S. Harmon and W. W. Doe, pp. 477-516, Kluwer Academic Publishers, New York.

Ferro, V., and M. Minacapilli (1995), Sediment delivery processes at basin scale, Hydrol. Sci. Journal/Journal des Sci. Hydrol., 40(6), 703-718, doi:10.1080/02626669509491460.

Ferro, V., and P. Porto (2000), Sediment delivery distributed (SEDD) model, J. Hydrol. Eng., 5(4), 411422, doi:10.1061/(ASCE)1084-0699(2000)5:4(411).

Folly, A., J. N. Quinton, and R. E. Smith (1999), Evaluation of the EUROSEM model using data from the Catsop watershed, The Netherlands, Catena, 37(3-4), 507-519, doi:10.1016/S03418162(99)00036-3.

Foster, G. R., and L. D. Meyer (1972), Transport of soil particles by shallow flow, Trans. ASAE, 15(1), 99-102.

Foster, I. D. L. (2006), Lakes and Reservoirs in the Sediment Delivery System: Reconstructing Sediment Yields, in Soil erosion and sediment redistribution in river catchments. Measurement, Modelling and Management., edited by P. Owens and A. Collins, p. 328, Biddles Ltd, King's Lynn.

Foster, I. D. L., and D. E. Walling (1994), Using reservoir deposits to reconstruct changing sediment yields and sources in the catchment of the Old Mill Reservoir, South Devon, UK, over the past 50 years, Hydrol. Sci. Journal/Journal des Sci. Hydrol., 39(4), 347-368, doi:10.1080/02626669409492755.

Francés, F., J. J. Vélez, J. I. Vélez, and M. Puricelli (2002), Distributed modelling of large basins for a real time flood forecasting system in Spain, in Proceedings Second Federal Interagency Hydrologic Modelling Conference, pp. 3513-3524, Gan, TY and Biftu, Las Vegas.

Francés, F., J. I. Vélez, and J. J. Vélez (2007), Split-parameter structure for the automatic calibration of distributed hydrological models, J. Hydrol., 332(1-2), 226-240, doi:10.1016/j.jhydrol.2006.06.032.

Francés, F., R. García-Bartual, E. Ortiz, S. Salazar, J. L. Miralles, G. Blöschl, J. Komma, C. Habereder, A. Bronstert, and T. Blume (2008), Efficiency of non-structural flood mitigation measures: "room for the river" and "retaining water in the landscape."

Freedman, V. L., V. L. Lopes, and M. Hernandez (1998), Parameter identifiability for catchment-scale erosion modelling: a comparison of optimization algorithms, J. Hydrol., 207(1-2), 83-97, doi:10.1016/S0022-1694(98)00131-0.

Gabriele, S., R. Gaudio, and D. Caloiero (1999), Sediment yield estimation using GIS and remote sensing. An application to an experimental watershed, in River sedimentation. Theory and application. Proc. seventh international symposium on river sedimentation, pp. 591-596, Hong Kong.

Gallart, F., J. C. Balasch, D. Regüés, M. Soler, and X. Castelltort (2005), Catchment dynamics in a Mediterranean mountain environment: the Vallcebre research basins (South Eastern Pyrenees). II Erosion and sediment dynamics, Catchment Dyn. river Process. latest Res. with examples from Mediterr. Clim. Reg. Elsevier, 17-29. 
Garcia-Bartual, R. (1991), Efecto de las variaciones temporales de la intensidad de precipitación en el hidrograma de la crecida generada, Rev. Obras Públicas, 13-21.

García-Ruiz, J. M., D. Regüés, B. Alvera, N. Lana-Renault, P. Serrano-Muela, E. Nadal-Romero, A. Navas, J. Latron, C. Martí-Bono, and J. Arnáez (2008), Flood generation and sediment transport in experimental catchments affected by land use changes in the central Pyrenees, J. Hydrol., 356(1-2), 245-260, doi:10.1016/j.jhydrol.2008.04.013.

Geiger, A. F. (1957), Sediment yields from small watersheds in the United States, in 11th General Assembly of the International Union of Geodesy and Geophysics, vol. 1, pp. 269-276, Toronto (Canada).

Gonzalez-Hidalgo, J. C., R. J. Batalla, A. Cerdà, and M. de Luis (2012), A regional analysis of the effects of largest events on soil erosion, Catena, 95, 85-90, doi:10.1016/j.catena.2012.03.006.

González-Hidalgo, J. C., J. L. Peña-Monné, and M. de Luis (2007), A review of daily soil erosion in Western Mediterranean areas, Catena, 71(2), 193-199, doi:10.1016/j.catena.2007.03.005.

González-Hidalgo, J. C., R. J. Batalla, and A. Cerdà (2013), Catchment size and contribution of the largest daily events to suspended sediment load on a continental scale, Catena, 102, 40-45, doi:10.1016/j.catena.2010.10.011.

Grauso, S., G. Fattoruso, C. Crocetti, and A. Montanari (2008), Estimating the suspended sediment yield in a river network by means of geomorphic parameters and regression relationships, Hydrol. Earth Syst. Sci., 12, 177-191, doi:10.5194/hess-13-1937-2009.

Grayson, R., and G. Blöschl (2001), Spatial modelling of catchment dynamics, in Spatial Patterns in Catchment Hydrology: Observations and Modelling, edited by R. Grayson and G. Blöschl, pp. 5181, Cambridge University Press.

Grunwald, S., and L. D. Norton (2000), Calibration and validation of a non-point source pollution model, Agric. Water Manag., 45(1), 17-39, doi:10.1016/S0378-3774(99)00074-8.

Guichard-Romero, D., R. García-Bartual, F. Francés, and R. Domínguez-Mora (2009), Análisis de la densidad de estaciones en zonas de lluvias convectivas. Caso del Mediterráneo español., Ing. Hidráulica México, 24(3), 35-49.

Haregeweyn, N., and F. Yohannes (2003), Testing and evaluation of the agricultural non-point source pollution model (AGNPS) on Augucho catchment, western Hararghe, Ethiopia, Agric. Ecosyst. Environ., 99(1-3), 201-212, doi:10.1016/S0167-8809(02)00120-2.

Haregeweyn, N., J. Poesen, G. Verstraeten, G. Govers, J. de Vente, J. Nyssen, J. Deckers, and J. Moeyersons (2013), Assessing the performance of a spatially distributed soil erosion and sediment delivery model (WATEM/SEDEM) in northern Ethiopia, L. Degrad. Dev., 24(2), 188204, doi:10.1002/ldr.1121.

Hargreaves, G. H., and Z. A. Samani (1985), Reference crop evapotranspiration from ambient air temperature., Am. Soc. Agric. Eng., Monograph.

Harmon, R. S., and W. W. Doe (2001), Landscape erosion and evolution modeling, Plenum Pub Corp.

Heinemann, H. G. (1984), Reservoir trap efficiency, in Erosion and sediment yield: Some Methods of Measurement and Modelling, edited by R. F. Hadley and D. E. Walling, pp. 201-218, Geo Books, Norwich.

Hessel, R., V. Jetten, B. Liu, Y. Zhang, and J. Stolte (2003), Calibration of the LISEM model for a small Loess Plateau catchment, Catena, 54(1-2), 235-254, doi:10.1016/S0341-8162(03)00067-5.

Horton, R. E. (1941), An Approach Toward a Physical Interpretation of Infiltration-Capacity1, Soil Sci. Soc. Am. J., 5(C), 399, doi:10.2136/sssaj1941.036159950005000C0075x.

ICOLD (1989), Sedimentation Control of Reservoirs. Guidelines., ICOLD.

IGME (1978), Mapa geológico de España a escala 1:50000 y memoria explicativa., IGME. 
Jetten, V., A. de Roo, and D. Favis-Mortlock (1999), Evaluation of field-scale and catchment-scale soil erosion models, Catena, 37(3-4), 521-541, doi:10.1016/S0341-8162(99)00037-5.

Johnson, B., P. Julien, D. K. Molnar, and C. C. Watson (2000), The two-dimensional upland erosion model CASC2D-SED, JAWRA J. Am. Water Resour. Assoc., 36(1), 31-42, doi:10.1111/j.17521688.2000.tb04246.x.

Jolly, J. P. (1982), A proposed method for accurately calculating sediment yields from reservoir deposition volumes, in Proceedings of the Exeter Symposium, IAHS Publ. No 37.

Jones, R. J. A., R. Hiederer, E. Rusco, P. Loveland, and L. Montanarella (2004), The map of organic carbon in topsoils in Europe, Version 1.2, September 2003: Explanation of Special Publication Ispra 2004 No.72 (S.P.I.04.72). European Soil Bureau Research Report No.17, EUR 21209 EN, 26pp. and 1 map in ISO B1 format., Luxembourg.

Jones, R. J. A., R. Hiederer, E. Rusco, P. Loveland, and L. Montanarella (2005), Estimating organic carbon in the soils of Europe for policy support, Eur. J. Soil Sci., 56(5), 655-671, doi:10.1111/j.1365-2389.2005.00728.x.

Julien, P. (1995), Erosion and sedimentation, Cambridge University Press.

Julien, P. (2010), Erosion and sedimentation, Second edi., Cambridge University Press.

Julien, P., and D. B. Simons (1985), Sediment transport capacity of overland flow, Trans. ASAE.

Karydas, C. G., P. Panagos, and I. Z. Gitas (2012), A classification of water erosion models according to their geospatial characteristics, Int. J. Digit. Earth, 1-22, doi:10.1080/17538947.2012.671380.

Kilinc, M., and E. V. Richardson (1973), Mechanics of soil erosion from overland flow generated by simulated rainfall, Color. State Univ. Hydrol. Pap.

Kirkby, M. J. (1998), Modelling across scales: the MEDALUS family of models, NATO ASI Ser. I Glob. Environ. Chang., 55, 161-174.

Kirkby, M. J., B. J. Irvine, R. J. A. Jones, and G. Govers (2008), The PESERA coarse scale erosion model for Europe. I.-Model rationale and implementation, Eur. J. Soil Sci., 59(6), 1293-1306, doi:10.1111/j.1365-2389.2008.01072.x.

Klemeš, V. (1986), Operational testing of hydrological simulation models, Hydrol. Sci. J., 31(1), 13-24, doi:10.1080/02626668609491024.

Kliment, Z., J. Kadlec, and J. Langhammer (2008), Evaluation of suspended load changes using AnnAGNPS and SWAT semi-empirical erosion models, Catena, 73(3), 286-299, doi:10.1016/j.catena.2007.11.005.

Knisel, W. . (1980), CREAMS: a field scale model for Chemicals, Runoff, and Erosion from Agricultural Management Systems [USA], United States. Dept. Agric. Conserv. Res. Rep.

Kochel, R. C., and V. R. Baker (1982), Paleoflood Hydrology, Science (80-. )., 215(4531), 353-361, doi:10.1126/science.215.4531.353.

Koelzer, V. A., and J. M. Lara (1958), Densities and compaction rates of deposited sediment, J. Hydraul. Div., 84(2), 1-15.

Komura, S. (1963), Discussion of "Sediment transportation mechanics: introduction and properties of sediment," J. Hydraul. Div., 89, 263-266.

Kosmas, C. et al. (1997), The effect of land use on runoff and soil erosion rates under Mediterranean conditions, Catena, 29(1), 45-59, doi:10.1016/S0341-8162(96)00062-8.

Krzysztofowicz, R. (1999), Bayesian theory of probabilistic forecasting via deterministic hydrologic model, Water Resour. Res., 35(9), 2739-2750, doi:10.1029/1999WR900099.

Kuhnle, R. A., J. C. Willis, and A. J. Bowie (1989), Total sediment load calculations for Goodwin Creek, in Sediment Transport Modeling. Proceedings of the international Symposium, edited by S. S. Y. Wang, pp. 700-705, New Orleans, Louisiana. 
Kuhnle, R. A., R. L. Bingner, G. R. Foster, and E. H. Grissinger (1996), Effect of land use changes on sediment transport in Goodwin Creek, Water Resour. Res., 32(10), 3189-3196, doi:10.1029/96WR02104.

Kuhnle, R. A., R. L. Bingner, E. J. Langendoen, A. Simon, C. G. Wilson, F. D. Shields Jr, and A. USDA (2005), Goodwin Creek Experimental Watershed-Assessment of Conservation and Environmental Effects, in 2005 ASAE Annual International Meeting, p. 052130, Tampa, Florida, USA.

Laflen, J. M., L. J. Lane, G. R. Foster, and A. USDA (1991a), WEPP: a new generation of erosion prediction technology, J. soil water Conserv., 46(1), 34-38.

Laflen, J. M., W. J. Elliot, J. R. Simanton, C. S. Holzhey, K. D. Kohl, and A. USDA (1991b), WEPP: soil erodibility experiments for rangeland and cropland soils, J. soil water Conserv., 46(1), 39-44.

Lane, E. W., and V. A. Koelzer (1943), Density of sediments deposited in reservoirs, Rep. No. 9 a Study Methods Used Meas. Anal. Sediment Loads Streams.

Lara, J. M., and E. L. Pemberton (1963), Initial unit weight of deposited sediments, Proc. Fed. InterAgency Sedimenta-tion Conf. USDA, (Paper No. 82).

Lawler, D. M., G. E. Petts, I. D. L. Foster, and S. Harper (2006), Turbidity dynamics during spring storm events in an urban headwater river system: the Upper Tame, West Midlands, UK., Sci. Total Environ., 360(1-3), 109-26, doi:10.1016/j.scitotenv.2005.08.032.

Leopold, L. B., and T. Maddock (1953), The hydraulic geometry of stream channels and some physiographic implications, United States Government Printing Office.

Leopold, L. B., and J. P. Miller (1954), A postglacial chronology for some alluvial valleys in Wyoming. Geological survey water-supply paper 1261, US government printing office, Washington.

Lindley, M. R., B. J. Barfield, J. C. Ascough, B. N. Wilson, and E. W. Stevens (1988), The surface impoundment element for WEPP, Trans. ASAE, 41(3), 555-564.

Lopes, V. L. (1987), Numerical Model of Watershed Erosion and Sediment Yield, Univ. Microfilm. Int. 300 N. Zeeb Road, Ann Arbor, MI 48106, Order, (8711635).

López-Tarazón, J. A. (2011), The sediment budget of a highly erodible catchment. The river Isábena (Ebro basin, central Pyrenees). PhD Thesis, 320 pp., Universidad de Zaragoza.

López-Tarazón, J. A., R. J. Batalla, D. Vericat, and T. Francke (2009), Suspended sediment transport in a highly erodible catchment: The River Isábena (Southern Pyrenees), Geomorphology, 109, 210221, doi:10.1016/j.geomorph.2009.03.003.

López-Tarazón, J. A., R. J. Batalla, D. Vericat, and J. C. Balasch (2010), Rainfall, runoff and sediment transport relations in a mesoscale mountainous catchment: The River Isábena (Ebro basin), Catena, 82, 23-34, doi:10.1016/j.catena.2010.04.005.

López-Tarazón, J. A., R. J. Batalla, and D. Vericat (2011), In-channel sediment storage in a highly erodible catchment: the River Isábena (Ebro Basin, Southern Pyrenees), Zeitschrift für Geomorphol., 55, 365-382, doi:10.1127/0372-8854/2011/0045.

López-Tarazón, J. A., R. J. Batalla, D. Vericat, and T. Francke (2012), The sediment budget of a highly dynamic mesoscale catchment: The River Isábena, Geomorphology, 138, 15-28, doi:10.1016/j.geomorph.2011.08.020.

López-Vicente, M., A. Navas, and J. Machín (2008), Modelling soil detachment rates in rainfed agrosystems in the south-central Pyrenees, Agric. Water Manag., 95(9), 1079-1089, doi:10.1016/j.agwat.2008.04.004.

López-Vicente, M., J. Poesen, A. Navas, and L. Gaspar (2013), Predicting runoff and sediment connectivity and soil erosion by water for different land use scenarios in the Spanish PrePyrenees, Catena, 102, 62-73, doi:10.1016/j.catena.2011.01.001. 
Machado, M. J., G. Benito, M. Barriendos, and F. S. Rodrigo (2011), 500 years of rainfall variability and extreme hydrological events in southeastern Spain drylands, J. Arid Environ., 75, 1244-1253, doi:10.1016/j.jaridenv.2011.02.002.

Maidment, D. R. (1993), Handbook of hydrology, McGraw-Hill.

Mamede, G. (2008), Reservoir Sedimentation in Dryland Catchments: Modelling and Management. PhD Thesis, 98 pp., University of Potsdam.

Martínez-Lloris, M., A. Romero-Díaz, and F. Alonso-Sarriá (2001), Respuesta erosiva de cuencas, corregidas mediante diques de retenciónd e sedimentos, ante lluvias de alta intensidad. Cuenca del Río Quípar, sureste de España, Papeles de goeografía, 34, 191-203.

Martín-Rosales, W., A. Pulido-Bosch, J. Gisbert, and A. Vallejos (2003), Sediment yield estimation and check dams in a semiarid area (Sierra de Gádor, southern Spain), in Erosion prediction in ungauged basins: integrating methods and techniques, edited by D. de Boer, pp. 51-58, IAHS Publ. No 279, Sapporo (Japan).

McManus, J., and R. Duck (1985), Sediment yield estimated from reservoir siltation in the Ochil Hills, Scotland, Earth Surf. Process. Landforms, 10(2), 193-200, doi:10.1002/esp.3290100211.

Medici, C., A. J. Wade, and F. Francés (2012), Does increased hydrochemical model complexity decrease robustness?, J. Hydrol., 440-441, 1-13, doi:10.1016/j.jhydrol.2012.02.047.

Merritt, W. S., R. A. Letcher, and A. J. Jakeman (2003), A review of erosion and sediment transport models, Environ. Model. Softw., 18(8), 761-799, doi:10.1016/S1364-8152(03)00078-1.

Miller, C. R. (1953), Determination of the unit weight of sediment for use in sediment volume computations. Memorandum., Denver, CO.

Ministerio de Medio Ambiente (2004), Estudio de batimetrías históricas, in Estudio para el desarrollo sostenible de L'Albufera de Valencia., Ministerio de Medio Ambiente.

Mintegui, J. A. (1986), Análisis metodológico de la sedimentación en la Albufera de Valencia., in European Forestry Commission. Working Party on the Management of Mountain Watersheds., p. 39, Innsbruck (Austria).

Misra, R. K., and C. W. Rose (1996), Application and sensitivity analysis of process-based erosion model GUEST, Eur. J. Soil Sci., 47(4), 593-604, doi:10.1111/j.1365-2389.1996.tb01858.x.

Molnár, P., and J. A. Ramírez (1998), An analysis of energy expenditure in Goodwin Creek, Water Resour. Res., 34(7), 1819-1829, doi:10.1029/98WR00982.

Montoya, J. J. (2008), Desarrollo de un modelo conceptual de producción, transporte y depósito de sedimentos. PhD Thesis, 267 pp., Universitat Politècnica de València (Spain).

Morales de la Cruz, M., and F. Francés (2008), Hydrological modelling of the "Sierra de las Minas" in Guatemala, by using a conceptual distributed model and considering the lack of data, in GeoEnvironment and Landscape Evolution III, edited by U. Mander, C. A. Brebbia, and J. F. MartínDuque, pp. 97-108, WITpress.

Morgan, R. P. C., J. N. Quinton, R. E. Smith, G. Govers, J. Poesen, K. Auerswald, G. Chisci, D. Torri, and M. E. Styczen (1998), The European Soil Erosion Model (EUROSEM): a dynamic approach for predicting sediment transport from fields and small catchments, Earth Surf. Process. Landforms, 23(6), 527-544, doi:10.1002/(SICI)1096-9837(199806)23:6\%3C527::AID-ESP868\%3E3.0.CO;2-5.

Moriasi, D. N., J. G. Arnold, M. W. Van Liew, R. L. Bingner, R. D. Harme, and T. L. Veith (2007), Model evaluation guidelines for systematic quantification of accuracy in watershed simulations, Trans. ASAE, 50(3), 885-900.

Mualem, Y. (1976), A new model for predicting the hydraulic conductivity of unsaturated porous media, Water Resour. Res., 12(3), 513-522, doi:10.1029/WR012i003p00513.

Müller, E. N., and T. Francke (2008), SESAM DATA. SESAM: Sediment Export from Semi-Arid Catchments - Measurement and Modelling (2005-2008), Potsdam, Germany. 
Müller, E. N., A. Güntner, T. Francke, and G. Mamede (2010), Modelling sediment export, retention and reservoir sedimentation in drylands with the WASA-SED model, Geosci. Model Dev., 3, 275291, doi:10.5194/gmd-3-275-2010.

Múnera, J. C., and F. Francés (2009), Integración del modelo TETIS en el sistema de alarma temprana DELFT FEWS para predicción de avenidas en tiempo real en algunas cuencas de la C.H. del Júcar, in I Jornadas de la Ingeniería del Agua, Madrid.

Nadal-Romero, E., J. Latron, C. Martí-Bono, and D. Regüés (2008), Temporal distribution of suspended sediment transport in a humid Mediterranean badland area: The Araguás catchment, Central Pyrenees, Geomorphology, 97(3-4), 601-616, doi:10.1016/j.geomorph.2007.09.009.

Nash, J. E., and J. V. Sutcliffe (1970), River flow forecastin through conceptual models - Part 1 - A discussion of principles, J. Hydrol., 10(3), 282-290, doi:10.1016/0022-1694(70)90255-6.

Navas, A., J. Machín, S. Beguería, M. López-Vicente, and L. Gaspar (2007), Soil properties and physiographic factors controlling the natural vegetation re-growth in a disturbed catchment of the Central Spanish Pyrenees, Agrofor. Syst., 72(3), 173-185, doi:10.1007/s10457-007-9085-2.

Nearing, M. A., L. Deer-Ascough, J. M. Laflen, and A. USDA (1990), Sensitivity analysis of the WEPP hillslope profile erosion model, Trans. ASAE, 33(3), 839-849.

Nehyba, S., D. Nývlt, U. Schkade, G. Kirchner, and E. Francu (2011), Depositional rates and dating techniques of modern deposits in the Brno reservoir (Czech Republic) during the last 70 years, $J$. Paleolimnol., 45, 41-55, doi:10.1007/s10933-010-9478-5.

Neil, D. T., and R. K. Mazari (1993), Sediment yield mapping using small dam sedimentation surveys, Southern Tablelands, New South Wales, Catena, 20(1-2), 13-25, doi:10.1016/03418162(93)90026-L.

Nistor, C. J., and M. Church (2005), Suspended sediment transport regime in a debris-flow gully on Vancouver Island, Hydrol. Process., 19(4), 861-885, doi:10.1002/hyp.5549.

Ogden, F. L., and A. Heilig (2001), Two-dimensional watershed-scale erosion modeling with CASC2D, in Landscape Erosion and Evolution Modelling.

Olive, L. J., and W. A. Rieger (1988), An examination of the role of sampling strategies in the study of suspended sediment transport, in Sediment Budgets, pp. 259-267, IAHS Publ. No 174, Washington, DC.

Van Oost, K., G. Govers, O. Cerdan, D. Thauré, A. Van Rompaey, A. Steegen, J. Nachtergaele, I. Takken, and J. Poesen (2005), Spatially distributed data for erosion model calibration and validation: The Ganspoel and Kinderveld datasets, Catena, 61(2-3), 105-121, doi:10.1016/j.catena.2005.03.001.

Oreskes, N., K. Shrader-Frechette, and K. Belitz (1994), Verification, validation, and confirmation of numerical models in the Earth sciences., Science, 263(5147), 641-646, doi:10.1126/science.263.5147.641.

Osterkamp, W. R., and T. J. Toy (1997), Geomorphic considerations for erosion prediction, Environ. Geol., 29(3-4), 152-157, doi:10.1007/s002540050113.

Owens, P. N., and A. J. Collins (2006), Soil erosion and sediment redistribution in river catchments: measurement, modelling and management, $\mathrm{CABI}$.

Pacific South West Inter-Agency Committee (1968), the water management subcommittee on factors affecting sediment yield in the Pacific Southwest area and selection and evaluation of measures for reduction, Sedimentation Task Force, PSIAC.

Palau Ybars, A. (1998), Estudio limnológico del ecosistema fluvial afectado por los vaciados del embalse de Barasona, Limnética, 14, 1-15.

Parks, S. W., J. K. Mitchell, and J. N. Scarborough (1982), Soil erosion simulation on small watersheds: a modified ANSWERS model, Trans. ASAE, 25(6). 
Pascual Aguilar, J. A. (2002), Cambios de usos del suelo y régimen hídrico en la rambla de Poyo y el barranc de Carraixet. PhD Thesis, 421 pp., Universitat de València.

Pascual Aguilar, J. A., F. Francés, and J. Mateu (2003), Dinámica de usos del suelo y régimen hídrico de pequeñas cuencas mediterráneas: la rambla de Poyo y el barranc de Carraixet (Valencia), Ing. Civ., 131, 41-46.

Phillips, C. J., and C. S. Nelson (1981), Sedimentation in an artificial lake - Lake Matahina, Bay of Plenty, New Zeal. J. Mar. Freshw. Res., 15(4), 459-473, doi:10.1080/00288330.1981.9515938.

Piest, R. F., J. M. Bradford, and G. M. Wyatt (1975), Soil erosion and sediment transport from gullies, J. Hydraul. Div., 101(1), 65-80.

Pilotti, M., and B. Bacchi (1997), Distributed evaluation of the contribution of soil erosion to the sediment yield from a watershed, Earth Surf. Process. Landforms, 22(13), 1239-1251, doi:10.1002/(SICI)1096-9837(199724)22:13<1239::AID-ESP839>3.0.CO;2-K.

Polyakov, V., A. Fares, D. Kubo, J. Jacobi, and C. Smith (2007), Evaluation of a non-point source pollution model, AnnAGNPS, in a tropical watershed, Environ. Model. Softw., 22(11), 16171627, doi:10.1016/j.envsoft.2006.12.001.

Prosser, I. P., and L. Williams (1998), The effect of wildfire on runoff and erosion in native Eucalyptus forest, Hydrol. Process., 12(2), 251-265, doi:10.1002/(SICI)1099-1085(199802)12:2<251::AIDHYP574>3.0.CO;2-4.

Puricelli, M. (2003), Estimación y distribución de parámetros del suelo para la mdoelación hidrológica. PhD Thesis, 434 pp., Universitat Politècnica de València.

Quevedo, D. I., and F. Francés (2008), A conceptual dynamic vegetation-soil model for arid and semiarid zones, Hydrol. Earth Syst. Sci., 12, 1175-1187.

Quinton, J. N. (1997), Reducing predictive uncertainty in model simulations: a comparison of two methods using the European Soil Erosion Model (EUROSEM), Catena, 30(2-3), 101-117, doi:10.1016/S0341-8162(97)00022-2.

Raclot, D., and J. Albergel (2006), Runoff and water erosion modelling using WEPP on a Mediterranean cultivated catchment, Phys. Chem. Earth, Parts A/B/C, 31(17), 1038-1047, doi:10.1016/j.pce.2006.07.002.

Ramírez-Solano, L. M. (2012), Análisis de la implementación de un modelo hidrológico distribuido con información estándar en España. MSc Thesis., 255 pp., Universitat Politècnica de València.

Rausch, D. L., and H. G. Heinemann (1984), Measurement of reservoir sedimentation, in Erosion and sediment yield: Some Methods of Measurement and Modelling, edited by R. F. Hadley and D. E. Walling, pp. 179-200, Geo Books, Norwich.

Regüés, D., and E. Nadal-Romero (2012), Uncertainty in the evaluation of sediment yield from badland areas: Suspended sediment transport estimated in the Araguás catchment (central Spanish Pyrenees), Catena, in press, doi:10.1016/j.catena.2012.05.006.

Regüés, D., J. C. Balasch, X. Castelltort, M. Soler, and F. Gallart (2000), Relación entre las tendencias temporales de producción y transporte de sedimentos y las condiciones climáticas en una pequeña cuenca de montaña mediterránea (Vallcebre, Pirineos Orientales), Cuad. Investig. geográfica, 26, 41-65.

Renard, K. G., G. R. Foster, G. A. Weesies, and J. P. Porter (1991), RUSLE: Revised universal soil loss equation, J. soil water Conserv., 46(1), 30-33.

Rey Benayas, J. M., A. Martins, J. M. Nicolau, and J. Schulz (2007), Abandonment of agricultural land: an overview of drivers and consequences., CAB Rev. Perspect. Agric. Vet. Sci. Nutr. Nat. Resour., 2(057), doi:10.1079/PAVSNNR20072057. 
Roering, J. J., J. W. Kirchner, and W. E. Dietrich (1999), Evidence for nonlinear, diffusive sediment transport on hillslopes and implications for landscape morphology, Water Resour. Res., 35(3), 853-870, doi:10.1029/1998WR900090.

Rohel, J. W. (1962), Sediment source areas, delivery ratios, and influencing morphological factors, in Symposium of Bari (Italy), International Association of Hydrological Sciences Publication 59, pp. 202-213, Bari (Italy).

Rojas, R. (2002), GIS-based upland erosion modeling, geovisualization and grid size effects on erosion simulations with CASC2D-SED. PhD Thesis, Colorado State University.

Romero-Díaz, A. (2008), Los diques de corrección hidrológica como instrumento de cuantificación de la erosión, Cuad. Investig. geográfica, 34, 83-99.

Romero-Díaz, A., F. Alonso-Sarriá, and M. Martínez-Lloris (2007), Erosion rates obtained from checkdam sedimentation (SE Spain). A multi-method comparison, Catena, 71(1), 172-178, doi:10.1016/j.catena.2006.05.011.

Romero-Díaz, A., J. D. Ruiz Sinoga, and F. Belmonte Serrano (2011), Tasas de erosión hídrica en la región de Murcia, Boletín la Asoc. Geógrafos Españoles, 56, 129-153.

Van Rompaey, A., G. Verstraeten, K. Van Oost, G. Govers, and J. Poesen (2001), Modelling mean annual sediment yield using a distributed approach, Earth Surf. Process. Landforms, 26(11), 1221-1236, doi:10.1002/esp.275.

Van Rompaey, A., V. Vieillefont, R. J. A. Jones, L. Montanarella, G. Verstraeten, P. Bazzoffi, T. Dostal, J. Krasa, J. de Vente, and J. Poesen (2003), Validation of soil erosion estimates at European scale. European Soil Bureau Research Report No.13, EUR 20827 EN., Office for Official Publications of the European Communities, Luxembourg.

Van Rompaey, A., P. Bazzoffi, R. J. A. Jones, and L. Montanarella (2005), Modeling sediment yields in Italian catchments, Geomorphology, 65(1-2), 157-169, doi:10.1016/j.geomorph.2004.08.006.

De Roo, A., and V. Jetten (1999), Calibrating and validating the LISEM model for two data sets from the Netherlands and South Africa, Catena, 37(3-4), 477-493, doi:10.1016/S0341-8162(99)00034-X.

De Roo, A., C. G. Wesseling, and C. J. Ritsema (1996a), LISEM: a single-event physically based hydrological and soil erosion model for drainage basins. I: Theory, input and output, Hydrol. Process., 10(8), 1107-1117, doi:10.1002/(SICI)1099-1085(199608)10:8<1107::AIDHYP415>3.0.CO;2-4.

De Roo, A., R. Offermans, and N. Cremers (1996b), LISEM: a single-event, physically based hydrological and soil erosion model for drainage basins. II: sensitivity analysis, validation and application, Hydrol. Process., 10(8), 1119-1126, doi:10.1002/(SICI)1099-1085(199608)10:8<1119::AIDHYP416>3.0.CO;2-V.

Le Roux, J. S., and Z. N. Roos (1982), The rate of soil erosion in the Wuras Dam catchment calculated from sediments trapped in the dam, Zeitschrift für Geomorphol., Suppl. 26, 315-329.

Rubio, J. L., J. Sánchez, and J. Forteza (1995), Proyecto LUCDEME. Mapa de suelos de la Comunidad Valenciana.

Rulli, M. C., M. Spada, S. Bozzi, D. Bocchiola, and R. Rosso (2005), Modelling sediment yield in burned areas, in Sediment budgets: proceedings of the International Symposium on Sediment Budgets: held during the Seventh Scientific Assembly of the International Association of Hydrological Sciences (IAHS), edited by A. Horowitz and D. Walling, pp. 162-170, IAHS Publ. No 292, Foz do Iguaço (Brazil).

Salazar, S., F. Francés, J. Komma, G. Blöschl, T. Blume, T. Francke, and A. Bronstert (2008), Efficiency of non-structural flood mitigation measures "room for the river" and "retaining water in the landscape," in Flood Risk Management: Research and Practice, edited by W. Allsop, P. Samuels, J. Harrop, and S. Huntington, CRC Press. 
Salazar, S., F. Francés, R. García-Bartual, E. Ortíz, J. C. Múnera, and J. J. Vélez (2009), Flood risk assessment in a Spanish Mediterranean catchment, in EGU General Assembly, Vienna (Austria).

Salazar, S., F. Francés, J. Komma, T. Blume, T. Francke, A. Bronstert, and G. Blöschl (2013), A comparative analysis of the effectiveness of flood management measures based on the concept of "retaining water in the landscape" in different European hydro-climatic regions, Nat. Hazards Earth Syst. Sci., 12(11), 3287-3306, doi:10.5194/nhess-12-3287-2012.

Sanjaume, E., F. Segura Beltrán, M. J. López-García, and J. Pardo (1992), Tasas de sedimentación en L'Albufera de València, Cuad. Geogr., 51, 63-81.

Santos, C., L. Pinto, P. De Macedo Machado Freire, and S. Mishra (2010), Application of a particle swarm optimization to a physically-based erosion model, Ann. Warsaw Univ. Life Sci. - SGGW. L. Reclam., 42(1), doi:10.2478/v10060-008-0063-9.

Santos, C. A. G., V. S. Srinivasan, K. Suzuki, and M. Watanabe (2003), Application of an optimization technique to a physically based erosion model, Hydrol. Process., 17(5), 989-1003, doi:10.1002/hyp.1176.

Sanz Montero, M. E., R. Cobo Rayán, C. Avendaño Salas, and J. L. Gómez Montaña (1996), Influence of the drainage basin area on the sediment yield to Spanish reservoirs, in Proceedings of the First European Conference and Trace Exposition on Control Erosion.

Saxton, K. E., and W. J. Rawls (2006), Soil Water Characteristic Estimates by Texture and Organic Matter for Hydrologic Solutions, Soil Sci. Soc. Am. J., 70, 1569-1578, doi:10.2136/sssaj2005.0117.

Schumm, S. A., and R. W. Lichty (1965), Time, space and causality in geomorphology, Am. J. Sci., 263, 110-119.

Seeger, M., M. P. Errea, S. Beguería, J. Arnáez, C. Martí, and J. M. García-Ruiz (2004), Catchment soil moisture and rainfall characteristics as determinant factors for discharge/suspended sediment hysteretic loops in a small headwater catchment in the Spanish Pyrenees, J. Hydrol., 288(3-4), 299-311, doi:10.1016/j.jhydrol.2003.10.012.

Seibert, J., and J. J. McDonnell (2002), On the dialog between experimentalist and modeler in catchment hydrology: Use of soft data for multicriteria model calibration, Water Resour. Res., 38(11), 23-1-23-14, doi:10.1029/2001WR000978.

Senarath, S. U. S., F. L. Ogden, C. W. Downer, and H. O. Sharif (2000), On the calibration and verification of two-dimensional, distributed, Hortonian, continuous watershed models, Water Resour. Res., 36(6), 1495-1510, doi:10.1029/2000WR900039.

Shakesby, R. A. (2011), Post-wildfire soil erosion in the Mediterranean: Review and future research directions, Earth-Science Rev., 105(3-4), 71-100, doi:10.1016/j.earscirev.2011.01.001.

Sivapalan, M. et al. (2003), IAHS Decade on Predictions in Ungauged Basins (PUB), 2003-2012: Shaping an exciting future for the hydrological sciences, Hydrol. Sci. Journal/Journal des Sci. Hydrol., 48(6), 857-880, doi:10.1623/hysj.48.6.857.51421.

Smith, H. G., and D. Dragovich (2009), Interpreting sediment delivery processes using suspended sediment-discharge hysteresis patterns from nested upland catchments, south-eastern Australia, Hydrol. Process., 23(17), 2415-2426, doi:10.1002/hyp.7357.

Smith, R. E. (1981), A kinematic model for surface mine sediment yield, Trans. ASAE, 24, 1508-1514.

Smith, R. E., D. C. Goodrich, C. L. Unkrich, and A. USDA (1999), Simulation of selected events on the Catsop catchment by KINEROS2: a report for the GCTE conference on catchment scale erosion models., Trans. ASAE.

Soler, M., G. Nord, G. Catari, and F. Gallart (2012), Assessment of suspended sediment concentration measurement error in relation to particle size, using continuous sensors in a small mountain stream (Vallcebre catchments, Eastern Pyrenees), Zeitschrift für Geomorphol. Suppl. Issues, 56(3), 99-113, doi:10.1127/0372-8854/2012/S-00106. 
Sorooshian, S., Q. Duan, and V. Gupta (1993), Calibration of Rainfall-Runoff Models: Application of Global Optimization to the Sacramento Soil Moisture Accounting Model, Water Resour. Res., 29(4), 1185-1194, doi:10.1029/92WR02617.

Sougnez, N., B. Van Wesemael, and V. Vanacker (2011), Low erosion rates measured for steep, sparsely vegetated catchments in southeast Spain, Catena, 84(1-2), 1-11, doi:10.1016/j.catena.2010.08.010.

Srinivasan, R., T. S. Ramanarayanan, J. G. Arnold, and S. T. Bednarz (1998), Large area hydrologic modeling and assessment part II: model application, JAWRA J. Am. Water Resour. Assoc., 34(1), 91-101, doi:10.1111/j.1752-1688.1998.tb05962.x.

Storm, B., G. H. Jorgensen, and M. E. Styczen (1987), Simulation of water flow and soil erosion processes with a distributed physically-based modelling system, For. Hydrol. Watershed Manag. Int. Assoc. Hydrol. Sci. Press. Inst. Hydrol. Wallingford, Oxfordsh. UK. IAHS Publ., (167).

Takken, I., G. Govers, V. Jetten, J. Nachtergaele, A. Steegen, and J. Poesen (2005), The influence of both process descriptions and runoff patterns on predictions from a spatially distributed soil erosion model, Earth Surf. Process. Landforms, 30(2), 213-229, doi:10.1002/esp.1176.

Thorndycraft, V. R., and G. Benito (2006), Late Holocene fluvial chronology of Spain: The role of climatic variability and human impact, Catena, 66(1-2), 34-41, doi:10.1016/j.catena.2005.07.007.

Thorndycraft, V. R., G. Benito, D. E. Walling, A. Sopeña, Y. Sánchez-Moya, M. Rico, and A. Casas (2005), Caesium-137 dating applied to slackwater flood depoists of the Llobregat River, NE Spain, Catena, 59(3), 305-318, doi:10.1016/j.catena.2004.09.002.

Thornes, J. B. (1980), Erosional processes of running water and their spatial and temporal controls: a theoretical viewpoint., Soil Eriosion, Ed. by J. B. Kirkby R. P. C., 129-182.

Todini, E. (2007), Hydrological catchment modelling: past, present and future, Hydrol. Earth Syst. Sci., 11(1), 468-482, doi:10.5194/hess-11-468-2007.

U. S. Weather Bureau (1961), Rainfall frequency atlas of the United States, Tech. Pap., 40.

Valero-Garcés, B. L., A. Navas, J. Machín, and D. Walling (1999), Sediment sources and siltation in mountain reservoirs: a case study from the Central Spanish Pyrenees, Geomorphology, 28(1-2), 23-41, doi:10.1016/S0169-555X(98)00096-8.

Vanmaercke, M., W. Maetens, J. Poesen, B. Jankauskas, G. Jankauskiene, G. Verstraeten, and J. de Vente (2012), A comparison of measured catchment sediment yields with measured and predicted hillslope erosion rates in Europe, J. Soils Sediments, 1-17, doi:10.1007/s11368-0120479-z.

Vanoni, V. A. (1975), Sedimentation Engineering, ASCE, Reston.

Veihe, A., and J. N. Quinton (2000), Sensitivity analysis of EUROSEM using Monte Carlo simulation I: hydrological, soil and vegetation parameters, Hydrol. Process., 14(5), 915-926, doi:10.1002/(SICI)1099-1085(20000415)14:5<915::AID-HYP978>3.0.CO;2-4.

Veihe, A., J. N. Quinton, and J. Poesen (2000), Sensitivity analysis of EUROSEM using Monte Carlo simulation II: the effect of rills and rock fragments, Hydrol. Process., 14(5), 927-939.

Vélez, J. I. (2001), Desarrollo de un modelo hidrológico conceptual y distribuido orientado a la simulación de crecidas. PhD Thesis, Universitat Politècnica de València.

Vélez, J. I., F. Francés, J. Lavabre, and M. Puricelli (1999), Adaptación del Modelo GR3 a un Modelo Distribuido por Isocronas para Simulación de Crecidas. Aplicación a la Cuenca del Réal Collobrier., Av. en Recur. Hidráulicos, 6, 23-36.

Vélez, J. I., J. J. Vélez, and F. Francés (2002a), Modelo distribuido para la simulación hidrológica de crecidas en grandes cuencas, in XX Congreso Latinoamericano de Hidráulica, La Habana. 
Vélez, J. J. (2003), Desarrollo de un modelo distribuido de predicción en tiempo real para eventos de crecidas. PhD. Thesis, Universitat Politècnica de València.

Vélez, J. J., and F. Francés (2005), Automatic calibration of initial state variables for flood forecasting using a distributed model, Int. Conf. Innov. Adv. Implement. flood Forecast. Technol. 17 to 19 Oct. 2005, Troms $\varnothing$, Norw.

Vélez, J. J., J. I. Vélez, and F. Francés (2002b), Simulación hidrológica de crecidas en grandes cuencas mediante el uso de la modelación distribuida, Proc. $3^{a}$ Asam. Hisp. Geod. y Geofísica. Ed. UPV. Val. España. Febrero, 7-8.

Vélez, J. J., F. Francés, and J. I. Vélez (2005), TETIS: A Catchment Hydrological Distributed Conceptual Model, Gen. Assem. Eur. Geosci. Union.

Vélez, J. J., M. Puricelli, F. López Unzu, and F. Francés (2009), Parameter extrapolation to ungauged basins with a hydrological distributed model in a regional framework, Hydrol. Earth Syst. Sci., 13(2), 229-246, doi:10.5194/hess-13-229-2009.

De Vente, J., J. Poesen, and G. Verstraeten (2005), The application of semi-quantitative methods and reservoir sedimentation rates for the prediction of basin sediment yield in Spain, J. Hydrol., 305(1-4), 63-86, doi:10.1016/j.jhydrol.2004.08.030.

De Vente, J., J. Poesen, M. Arabkhedri, and G. Verstraeten (2007), The sediment delivery problem revisited, Prog. Phys. Geogr., 31(2), 155-178, doi:10.1177/0309133307076485.

De Vente, J., J. Poesen, G. Verstraeten, A. Van Rompaey, and G. Govers (2008), Spatially distributed modelling of soil erosion and sediment yield at regional scales in Spain, Glob. Planet. Change, 60(3-4), 393-415, doi:10.1016/j.gloplacha.2007.05.002.

Verstraeten, G. (2006), Regional scale modelling of hillslope sediment delivery with SRTM elevation data, Geomorphology, 81(1-2), 128-140, doi:10.1016/j.geomorph.2006.04.005.

Verstraeten, G., and J. Poesen (2000), Estimating trap efficiency of small reservoirs and ponds: methods and implications for the assessment of sediment yield, Prog. Phys. Geogr., 24(2), 219251, doi:10.1177/030913330002400204.

Verstraeten, G., and J. Poesen (2001a), Modelling the long-term sediment trap efficiency of small ponds, Hydrol. Process., 15(14), 2797-2819, doi:10.1002/hyp.269.

Verstraeten, G., and J. Poesen (2001b), Variability of dry sediment bulk density between and within retention ponds and its impact on the calculation of sediment yields, Earth Surf. Process. Landforms, 26(4), 375-394.

Verstraeten, G., J. Poesen, J. de Vente, and X. Koninckx (2003), Sediment yield variability in Spain: a quantitative and semiqualitative analysis using reservoir sedimentation rates, Geomorphology, 50(4), 327-348, doi:10.1016/S0169-555X(02)00220-9.

Viney, N. R., and M. Sivapalan (1999), A conceptual model of sediment transport: application to the Avon River Basin in Western Australia, Hydrol. Process., 13(5), 727-743, doi:10.1002/(SICI)10991085(19990415)13:5<727::AID-HYP776>3.0.CO;2-D.

Viney, N. R., M. Sivapalan, and D. Deeley (2000), A conceptual model of nutrient mobilisation and transport applicable at large catchment scales, J. Hydrol., 240(1-2), 23-44, doi:10.1016/500221694(00)00320-6.

Van den Wall Blake, G. W. (1986), Siltation and soil erosion survey in Zimbabwe, in Drainage basin sediment delivery (proceedings of the Albuquerque symposium, August 1986). IAHS Publication 159., edited by R. Hadley, pp. 69-80.

Walling, D. E., and D. Fang (2003), Recent trends in the suspended sediment loads of the world's rivers, Glob. Planet. Change, 39(1-2), 111-126, doi:10.1016/S0921-8181(03)00020-1. 
Ward, A. D., C. T. Haan, and B. J. Barfield (1977), The performance of sediment detention structures., in Proceedings of the international symposium on urban hydrology, hydraulics and sediment control, pp. 58-68, University of Kenctucky, Lexington, KY.

Webb, B. W., I. D. L. Foster, and A. Gurnell (1995), Hydrology, water quality and sediment behavior., in Sediment and water quality in river catchments, edited by I. D. L. Foster, A. Gurnell, and B. W. Webb, pp. 1-30, Wiley, Chichester.

White, P., J. C. Labadz, and D. P. Butcher (1996), Sediment yield estimates from reservoir studies: an appraisal of variability in the southern Pennines of the UK, in Erosion and sediment yield: global and regional perspectives (proceedings of the Exeter symposium, July 1996). IAHS Publication 236, edited by D. Walling and B. Webb, pp. 163-74, Wallingford: IAHS Press.

Wicks, J. M., and J. C. Bathurst (1996), SHESED: a physically based, distributed erosion and sediment yield component for the SHE hydrological modelling system, J. Hydrol., 175(1-4), 213-238, doi:10.1016/S0022-1694(96)80012-6.

Williams, G. P. (1989), Sediment concentration versus water discharge during single hydrologic events in rivers, J. Hydrol., 111(1-4), 89-106, doi:10.1016/0022-1694(89)90254-0.

Williams, J. R. (1980), SPNM, a model for predicting sediment, phosphorous and nitrogen yields from agricultural basins, JAWRA J. Am. Water Resour. Assoc., 16(5), 843-848, doi:10.1111/j.17521688.1980.tb02497.x.

Willis, J. C., R. W. Darden, and A. J. Bowie (1986), Sediment transport in Goodwin Creek, in Proceedings of the 4th Federal Interagency Sedimentation Conference, pp. 4.30-4.39, Las Vegas.

Wilson, B. N., and B. J. Barfield (1984), A sediment detention pond model using CSTRS mixing theory, Trans. ASAE, 27, 1339-1344.

Wilson, B. N., and B. J. Barfield (1985), Modeling Sediment Detention Ponds Using Reactor Theory and Advection-Diffusion Concepts, Water Resour. Res., 21(4), 523-532, doi:10.1029/WR021i004p00523.

Winsemius, H. C., B. Schaefli, A. Montanari, and H. H. G. Savenije (2009), On the calibration of hydrological models in ungauged basins: A framework for integrating hard and soft hydrological information, Water Resour. Res., 45(12), doi:10.1029/2009WR007706.

Wischmeier, W. H., and J. V. Mannering (1969), Relation of Soil Properties to its Erodibility, Soil Sci. Soc. Am. J., 33(1), 131-137.

Wischmeier, W. H., and D. D. Smith (1961), A universal soil-loss equation to guide conservation farm planning, Trans. ASAE, 418.

Wischmeier, W. H., and D. D. Smith (1978), Predicting rainfall erosion losses-a guide to conservation planning, United States Dep. Agric. (USDA). Washington, DC, USA. 1978. 58 p., 58.

Wu, W., and S. S. Y. Wang (2006), Formulas for Sediment Porosity and Settling Velocity, J. Hydraul. Eng., 132(8), 858-862, doi:10.1061/(ASCE)0733-9429(2006)132:8(858).

Young, R. A., C. A. Onstad, D. D. Bosch, and W. P. Anderson (1989), AGNPS: A nonpoint-source pollution model for evaluating agricultural watersheds, J. soil water Conserv., 44(2), 168-173.

Zeleke, G. (2001), Application and Adaptation of WEPP to the Traditional Farming Systems of the Ethiopian Highlands, in Sustaining the Global Farm. Selected papers from the 10th International Soil Conservation Organization Meeting, May 24-29, 1999, West Lafayette, IN, edited by D. E. Stott, R. H. Mohtar, and G. C. Steinhard, pp. 903-912, International Soil Conservation Organization.

Zhang, X. C. (2004), Calibration, refinement, and application of the WEPP model for simulating climatic impact on wheat production., Trans. ASAE. 


\section{List of figures}

Figure 2.1 - Hillslope erosion (modified from Doe and Harmon [2001]) .8

Figure 2.2 - Sediment sources within a catchment (modified from Doe and Harmon [2001]) 9

Figure 2.3 - Localization and results of the study by Avendaño Salas et al. [1995]. ..............23

Figure 2.4 - dBD vs particles median diameter (taken from $\mathrm{Wu}$ and Wang). .......................26

Figure 2.5 - Simplified distribution of the reservoir bottom sediments (modified from

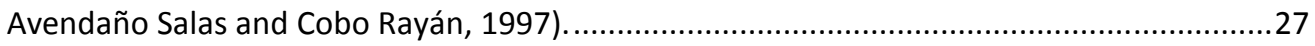

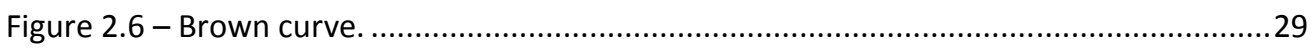

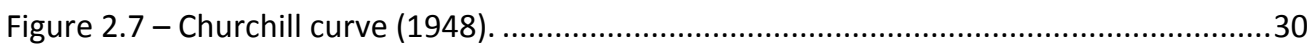

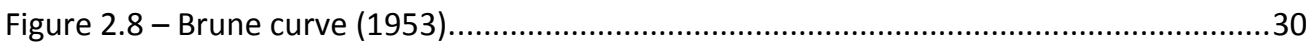

Figure 2.9 - Laminated deposit behind a small check dam. ..............................................33

Figure 3.1 - Conceptual scheme of the TETIS hydrological sub-model at one cell.................37

Figure 3.2 - Horizontal water movement in TETIS (2-dimensional simplification)................41

Figure 3.3 - Conceptual representation of the effective parameter (after Grayson and

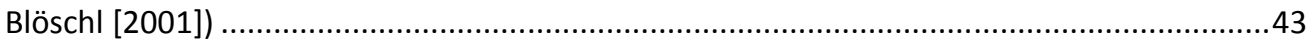

Figure 3.4 - Sediment availability and transport capacity curve (modified from Julien

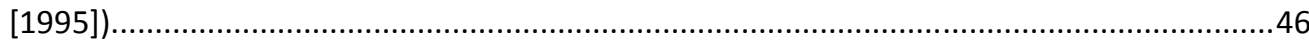

Figure 3.5 - Hillslope processes TETIS conceptualization..................................................48

Figure 3.6 - Gully and channel processes TETIS conceptualization...................................49

Figure 3.7 - Clockwise hysteresis loop in the relationship water - sediment discharge. Given a water discharge value $(\mathrm{Qw})$, two sediment discharge values correspond to it. A greater value (Qs2) corresponds to Qw during the rising limb of the hydrograph, and a lower value (Qs1) during the falling lim. Modified from Nistor and Church [2005].

Figure 3.8 - Longitudinal section of a small pond reservoir divided into sectors (modified from Verstraeten and Poesen [2001a]).

Figure 3.9 - Water level correction when one or more sectors are empty (modified from Verstraeten and Poesen [2001a]).

Figure 3.10 - Sediment routing modification from a finite volume to another (modified from Verstraeten and Poesen [2001a]).

Figure 4.1 - Goodwin Creek location

Figure 4.2 - Goodwin Creek catchment - the raingauges and stream gauges used in this study are shown.

Figure 4.3 - Land use change in Goodwin Creek [Kuhnle et al., 2005].............................65

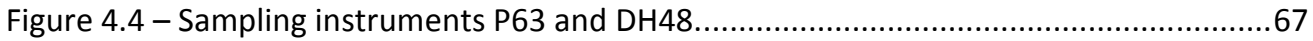

Figure 4.5 - Maximum static storage map $(\mathrm{mm})$..............................................................69

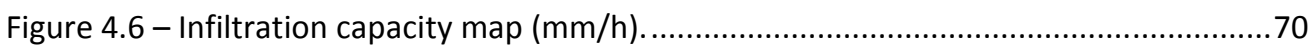

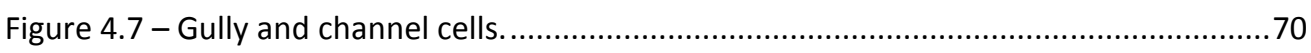


Figure $4.8-\mathrm{K}$ (left) and C (right) factors for the Goodwin Creek catchment. ......................71

Figure 4.9 - Texture of the Goodwin Creek catchment soils.

Figure 4.10 - Calibration and spatial validation on the August 1982 event in Q01 (left) and Q06 (right).

Figure 4.11 - Spatio-temporal validation on the May 1983 event in Q01 (left) and Q06 (right).

Figure 4.12 - Spatio-temporal validation on the April 1984 event in Q01 (left) and Q06 (right).

Figure 4.13 - Observed vs simulated fine sediment volume for 5 event and 5 stream gauge stations, for all strategies

Figure 4.14 - Observed and simulated sedigraphs (left) and hysteresis loops (right) for station Q01.

Figure 4.15 - Observed and simulated sedigraphs (left) and hysteresis loops (right) for station Q04.

Figure 4.16 - Observed and simulated sedigraphs (left) and hysteresis loops (right) for station Q06.

Figure 4.17 - Observed and simulated sedigraphs (left) and hysteresis loops (right) for station Q07.

Figure 4.18 - Observed and simulated sedigraphs (left) and hysteresis loops (right) for station Q08.

Figure 4.19 - Hysteresis loop types (modified form Nistor and Church, 2005). Qs indicates sediment discharge and Qw indicates water discharge. .85

Figure 4.20 - Observed vs simulated Hysteresis Index for all strategies. .............................88

Figure 4.21 - Goodwin Creek continuous simulation results - overall comparison. .90

Figure 4.22 - Comparison between the TETIS results and the results of other models in Goodwin Creek.

Figure 5.1 - Rambla del Poyo catchment location. .96

Figure 5.2 - Rambla del Poyo catchment elevation .97

Figure 5.3 - Sub-catchments drained by the nine check dams. .99

Figure 5.4 - Dam 1. 100

Figure 5.5 - Dam 2. 101

Figure 5.6 - Dam 2 - sketch. 101

Figure 5.7 - Dam 3. .102

Figure 5.8 - Dam 3 - sketch .102

Figure 5.9 - Dam 4. 103

Figure 5.10 - Dam 4 - sketch. .103

Figure 5.11 - Dam 5. 104

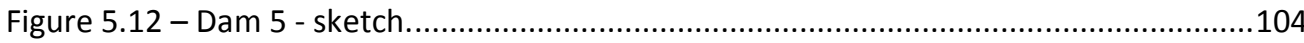

Figure 5.13 - Dam 6. .105 


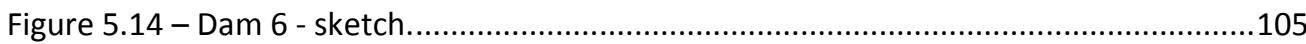

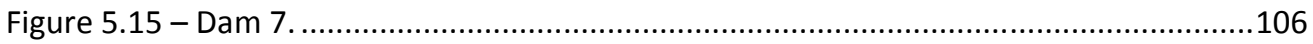

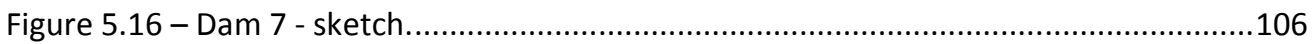

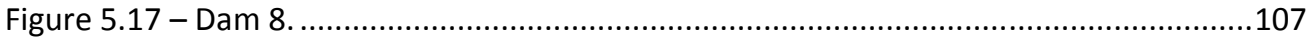

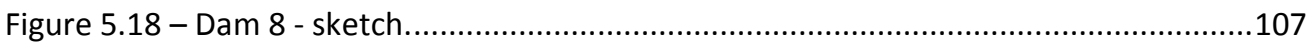

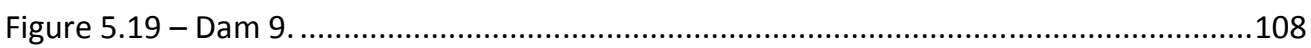

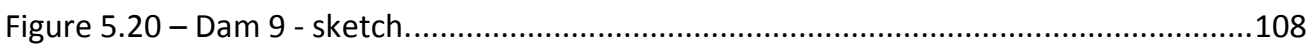

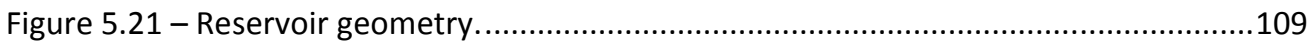

Figure 5.22 - Reservoir storage curves of the Rambla del Poyo check dams.....................110

Figure 5.23 - Reservoir 2 seen from above. ..............................................................112

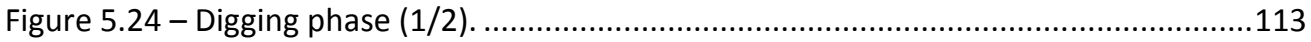

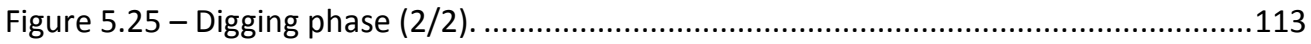

Figure 5.26 - Stratigraphical analysis phase............................................................114

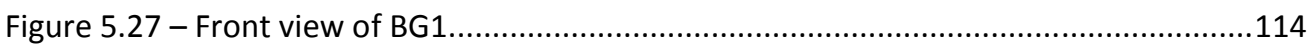

Figure 5.28 - Stratigrahphical profile (front view) .........................................................115

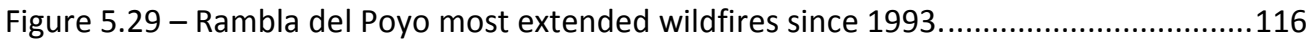

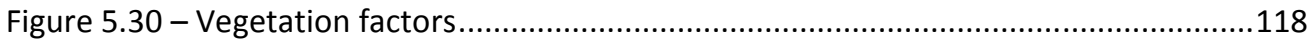

Figure 5.31 - Land use map of the Rambla del Poyo catchment......................................119

Figure 5.32 - Maximum static storage of the Rambla del Poyo catchment. .......................119

Figure 5.33 - Infiltration capacity of the Rambla del Poyo catchment...............................120

Figure 5.34 - Percolation capacity of the Rambla del Poyo catchment. ..............................120

Figure 5.35 - Topsoil clay percentage of the Rambla del Poyo catchment. ........................123

Figure 5.36 - Topsoil silt percentage of the Rambla del Poyo catchment..........................123

Figure 5.37 - Topsoil sand percentage of the Rambla del Poyo catchment.......................124

Figure 5.38 - USLE C factor of the Rambla del Poyo catchment.......................................124

Figure 5.39 - USLE K factor of the Rambla del Poyo catchment.........................................125

Figure 5.40 - Calibration and temporal validation of the hydrological sub-model at the daily scale at the Rambla del Poyo stream gauge station.

Figure 5.41 - Calibration (right) and temporal validation (left, 1998 event) at the 5-minutal time scale at the Rambla del Poyo stream gauge station.

Figure 5.42 - Temporal validation (left, 2006 event; right, 2002 event) at the 5-minutal time scale at the Rambla del Poyo stream gauge station.

Figure 5.43 - Temporal validation (left, 2001 event; right, 2004 event) at the 5-minutal time scale at the Rambla del Poyo stream gauge station.

Figure 5.44 - Spatial validation of the sedimentological sub-model at the check dam 2. ...129

Figure 5.45 - Reconstruction of the stratigraphical profile of reservoir 2 .

Figure 5.46 - Simulated deposits in check dam 2 (the most important events are labelled). 
Figure 5.47 - Sediment temporal validation (1/2): 13 events (out of 38 modelled flood events) were associated with the 15 detected flood units. The surface gravel body corresponds to the last three modelled events. The model was calibrated using the total sedimentation volume.

Figure 5.48 - Sediment temporal validation (2/2): 13 events (out of 38 modelled flood events) were associated to the 15 detected flood units. The surface gravel body was not considered. Notice that model was calibrated using the sum of sedimentation volumes from 1 to 15. 136

Figure 5.49 - Specific SY (model simulation). 139

Figure 5.50 -. Observed vs simulated sediment texture of all layers found inside the analysed deposit. 139

Figure 6.1 - The Rambla del Poyo catchment. .145

Figure 6.2 - Simulated temporal evolution of the check dam 2 deposit volume.

Figure 6.3 - Observed and simulated temporal evolution of the check dam 2 bottom deposit - calibration with the total accumulated volume. .150

Figure 6.4 - Observed and simulated temporal evolution of the check dam 2 bottom deposit - calibration with the accumulated volume up to 2007. .150

Figure 6.5 - Observed and simulated water discharge at the catchment outlet. 151

Figure 6.6 - Observed and simulated water volume of the most significatn flood events at the Rambla del Poyo gauging station. 152

Figure 6.7 - Results of the 100 best calibration sets. .153

Figure 7.1 - Ésera River catchment location. .159

Figure 7.2 - Temporal evolution of the Barasona reservoir storage capacity, modified from Mamede [2008]. 162

Figure 7.3 - Suspended sediment discharge, from López-Tarazón [2011] .163

Figure 7.4 - Some of the highest suspended sediment peaks of the series (September 2006).

Figure 7.5 - Vegetation factors of the Ésera River catchment. .164

Figure 7.6 - Land use of the Ésera River catchment. .165

Figure 7.7 - Maximum static storage and infiltration capacity of the Ésera River catchment.

Figure 7.8 - C and K USLE factores of the Ésera River catchment.

Figure 7.9 - Topsoil texture of the Ésera River catchment.

Figure 7.10 - Hydrological sub-model calibration of the Ésera River model at Capella station.

Figure 7.11 - Hydrological sub-model spatial validation of the Ésera River model at Barasona reservoir.

Figure 7.12 - Hydrological sub-model temporal validation of the Ésera River model at Capella station. .174 
Figure 7.13 - Hydrological sub-model spatio-temporal validation of the Ésera River model at Barasona reservoir. 174

Figure 7.14 - Linsoles (or Eriste) reservoir (potos taken from embalses.net)....................175

Figure 7.15 - Linsoles (or Eriste) reservoir location...........................................................175

Figure 7.16 - Daily discharge and mean annual inflow at the Barasona reservoir..............177

Figure 7.17 - Observed and simulated storage capacity variation of the Barasona reservoir. 179

Figure 7.18 - Simulated $\mathrm{dBD}$ and TE of the Barasona reservoir. 180

Figure 7.19 - TETIS sedimentological sub-model validation vs gauged suspended sediment at the Capella station.

Figure 7.20 - TETIS sedimentological sub-model validation against gauged suspended sediment at the Capella station (semi-log plot). Details of three time periods....................182

Figure 7.21 - Simulated annual specific SY at the Barasona reservoir. ...............................183

Figure 7.22 - Erosion sources within the Ésera Catchment..............................................184

Figure 7.23 - Simulated daily sediment volume series (actual in black and accumulated in red) at the Barasona reservoir inlet. .185 


\section{List of tables}

Table 2.1 - Sediment model scales [Doe and Harmon, 2001].

Table 2.2 - Literature reference of the main sediment cycle models (in bold the models described below).

Table 2.3 - $\mathrm{dBD}_{1}$ and $\mathrm{K}$ values following Lane and Koelzer (1943).

Table $2.4-\mathrm{dBD}_{1}$ and $\mathrm{K}$ values following Lara and Pemberton (1963). .28

Table 3.1 - Outflow from T2, depending on the origin and receiving cells. .41

Table 3.2 - Outflow from T3, depending on the origin and receiving cells. .41

Table 3.3 - Outflow from T4, depending on the origin and receiving cells. .41

Table 3.4 - Range of variation of the Leopold and Maddock coefficients and exponents (after F. Francés et al, 2007). .43

Table 3.5 - Correction factors and corresponding parameters. .45

Table 3.6 - Mean grain size and mean settling velocity used in TETIS. .47

Table 3.7 - Sediment correction factors and corresponding parameters.

Table 3.8 - Hysteresis loop types for one-peak hydrographs. Modified from Nistor and Church [2005]. Qs is the sediment discharge and Qw is the water discharge. .53

Table 4.1 - Land use in Goodwin Creek and proportion of badland. .64

Table 4.2 - Maximum expected rainfall values $(\mathrm{mm})$ .65

Table 4.3 - Raingauges (UTM coordinates). .66

Table 4.4 - Stream gauges (UTM coordinates) ..............................................................66

Table 4.5 - Main characteristics of the chosen flood events. ...............................................68

Table 4.6 - Values for the hydraulic geometry coefficients and exponents..........................71

Table 4.7 - Hydrological calibration and validation results of the Goodwin Creek catchment

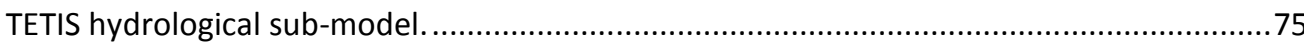

Table 4.8 - Correction factor for the Goodwin Creek model. ................................................76

Table 4.9 - Goodwin Creek calibrated correction factors ....................................................76

Table 4.10 - Amount $\left(\mathrm{m}^{3} \mathrm{~m}^{-1}\right)$ and texture of the calibrated sediment initial condition for strategy 1 .

Table 4.11 - Sedimentological sub-model calibration and validation results in terms of NSE for all strategies (in grey the calibration event - August 1982 - and the calibration stations Q01 and Q06). .78

Table 4.12 - Hysteresis loop shape analysis................................................................... 86

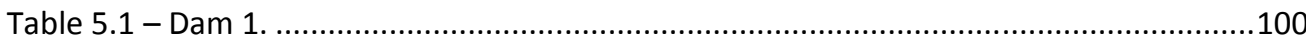

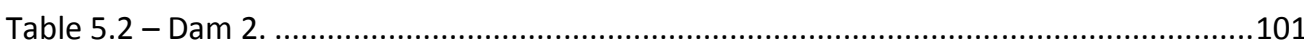

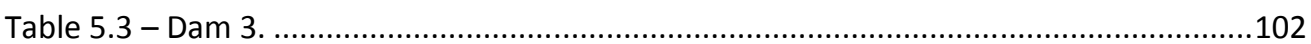

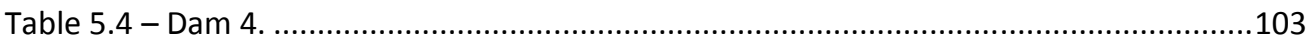


Table 5.5 - Dam 5. 104

Table 5.6 - Dam 6. .105

Table 5.7 - Dam 7. .106

Table 5.8 - Dam 8. 107

Table 5.9 - Dam 9. .108

Table 5.10 - Check dam characteristics from field survey (linear dimensions in $\mathrm{m}$ ). 109

Table 5.11 - dBD of the Rambla del Poyo deposits. .110

Table 5.12 - TE following Brune.

Table 5.13 - Percolation capacity values depending on the lithology. 121

Table 5.14 - Geomorphological parameters for the Rambla del Poyo catchment.

Table $5.15-\mathrm{K}$ [t ha h ha $\mathrm{MJ}^{-1} \mathrm{~mm}^{-1}$ ] and $\mathrm{C}$ [-] factor statistics of the Rambla del Poyo catchment.

Table 5.16 - Correction factors for the Rambla del Poyo daily model.

Table 5.17 - Sedimentological sub-model results in terms of sediment volume and texture at the check dam 2 .

Table 5.18 - Stratigraphical analysis results for check dam 2.

Table 5.19 - Sedimentological sub-model results in terms of TE and SY for each event. ....137 Table 6.1 - Correction factors resulting from the Rambla del Poyo model calibration calibration with the total accumulated volume.

Table 6.2 - Stratigraphical profile results.

Table 6.3 - Daily sediment volume (for days with more than $1 \mathrm{~m}^{3}$, following model results).

Table 6.4 - Correction factors resulting from the Rambla del Poyo model calibration calibration with the accumulated volume up to 2007

Table 6.5 - Correction factors range.

Table 7.1 - Reclassification of the ESDB parameter AWC_TOP for describing the soil capillary storage.

Table 7.2 - Reclassification of the ESDB parameter ROO for describing the root depth. ....165

Table 7.3 - Reclassification of the soil texture following the ESDB. .166

Table 7.4 - Values for the percolation capacity depending on the geology. 168

Table 7.5 - Values for the hydraulic geometry coefficients and exponents.

Table 7.6 - Calibration and spatial validation of the Ésera River hydrological sub-model...171

Table 7.7 - Temporal validation of the Ésera River hydrological sub-model. .172

Table 7.8 - Hydrological sub-model correction factors for the Ésera daily model. .172

Table 7.9 -Sediment deposited into the Barasona reservoir.

Table 7.10 - Calibration and validation results of the TETIS sedimentological sub-model at the Barasona reservoir. 
Table 7.11 - Sedimentological sub-model correction factors for the Ésera River daily model. .179 


\section{Acronyms}

In this PhD dissertation, many acronyms are used frequently. For each one, an explanation is provided at their first use in the document. In order to help the reader finding every acronym meaning easily, a further explanation is reported below.

AEMET = Agencia Estatal de Meteorología (Spanish Meteorological Agency)

ARS-USDA = Agriculture Research Service of the United States Departement of Agriculture

CORINE = Coordination of Information on the Environment

$\mathrm{dBD}=$ dry bulk density

DIHMA = Departamento de Hidráulica y Medio Ambiente (Hydraulics and Environment Department, Technical University of Valencia, Spain)

GIS = Geographical Information System

NSE = Nash and Sutcliffe Efficiency

LUCDEME = Proyecto de Lucha contra la Desertificación en el Mediterráneo (Project for fighting against desertification in the Mediterranean)

$\mathrm{SAIH}=$ Sistema Automático de Información Hidrológica (hyrological monitoring automatic system)

STEP = Sediment Trap Efficiency for small Ponds

SY = Sediment yield

TE $=$ Trap efficiency

USDA = United States Departement of Agriculture

USLE = Universal Soil Loss Equation

VE $=$ Volume error 